WBS: $1.2 .1 / 1.2 .2 / 1.2 .4$

Civilian Radioactive Waste Management System Management \& Operating Contractor

Initial Summary Report for Repository/Waste Package Advanced Conceptual Design

\begin{abstract}
August 29, 1994
Document No. B00000000-01717-5705-00015 Rev. 00

Prepared for:

U.S. Department of Energy

Yucca Mountain Site Characterization Project

101 Convention Center Drive

Las Vegas, Nevada 89109
\end{abstract}

Prepared by:

o

TRW Environmental Safety Systems Inc.

101 Convention Center Drive

Las Vegas, Nevada 89109

\title{
Volume II
}

Under Contract Number

DE-AC01-91RW00134 


\section{SURFACE REPOSITORY DESIGN DESCRIPTION}

\subsection{WASTE HANDLING BUILDING (WHB)}

\subsubsection{Reference Conceptual WHB Design}

The reference concept of the WHB is the one produced and baselined in the 1987 SCP-CDR. The sections below describe the salient features of the reference concept and compare the features to the present conceptual thinking on the WHB.

\subsubsection{Waste Forms}

\section{Reference Concept}

The WHB is designed to handle specific waste forms. The waste forms that the reference WHB is designed to handle are: 1) Bare spent fuel assemblies (SFAs); and 2) Defense high level waste canisters (HLWC).

\section{Current Concept}

The waste forms currently expected to be handled in the WHB are: 1) Bare SFAs; 2) HLWC; and 3) Multi-purpose canisters (MPCs). The MPCs are sealed metal canisters each carrying SFAs. Two models of the MPCs are expected at the MGDS: $75 \mathrm{~T}$ and $125 \mathrm{~T}$.

Whereas in the reference concept 100 percent of the fuel assemblies come bare, the current scenario brings only 11 percent of the SFAs bare while 89 percent of the SFAs come in MPCs. This change makes waste handling more efficient: for example, twenty bare SFAs require twenty maneuvers of the overhead crane in the cell to transfer while twenty SFAs packaged in an MPC require only one crane maneuver to transfer. The resulting efficiency tends to reduce the utilization of the waste handling lines in the WHB, thus reducing the number of waste handling lines required.

\subsubsection{Shipment Scenario}

\section{Reference Concept}

The rate at which waste arrives and flows through the WHB determines the size of the WHB. For the reference case in the SCP-CDR, the shipment schedule, in terms of rail and truck casks, is shown in the table below. 
Table 7-1. Rail and Truck Cask Shipment Schedule

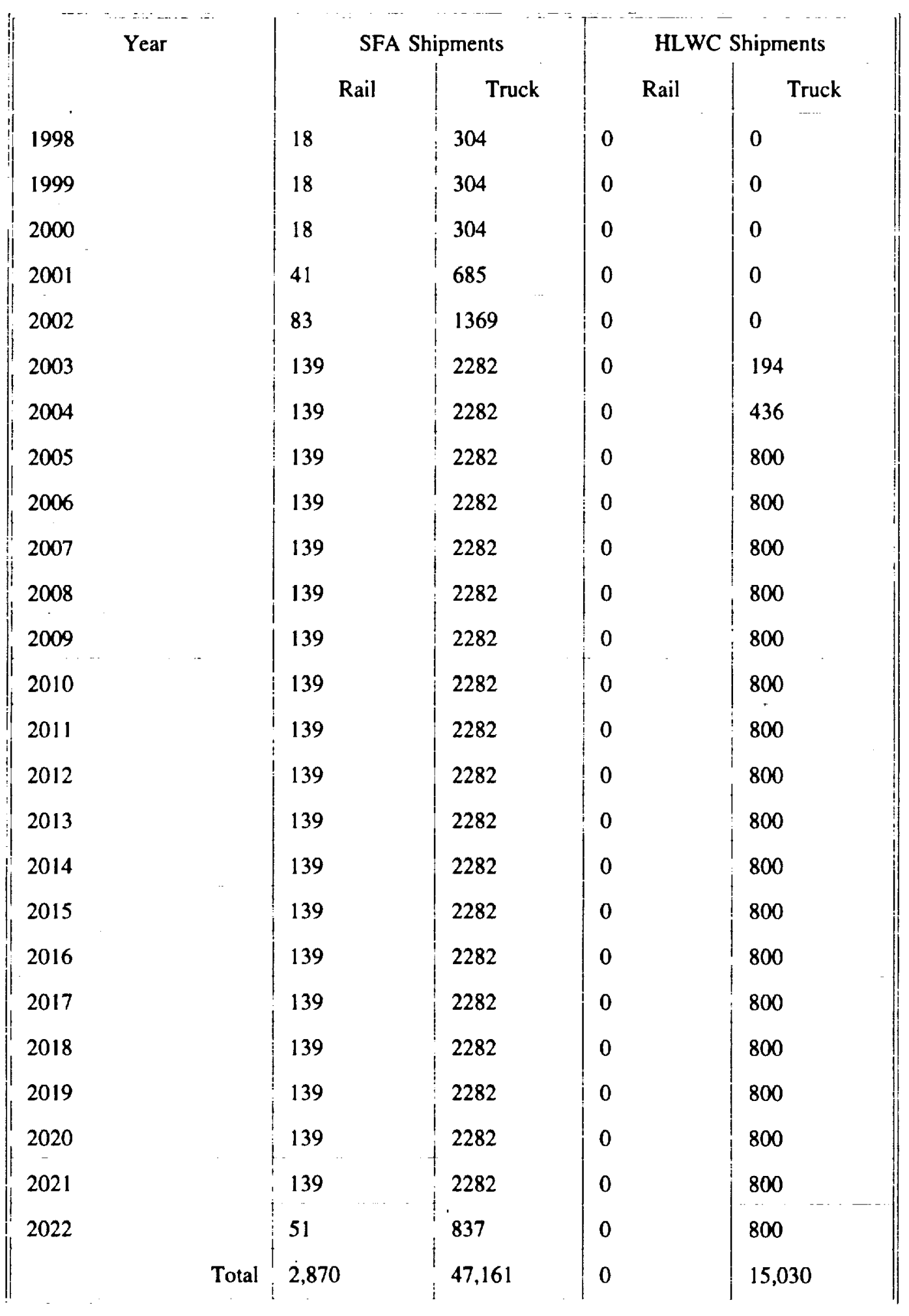




\section{Current Concept}

Table 7-2. Current Shipment Scenario

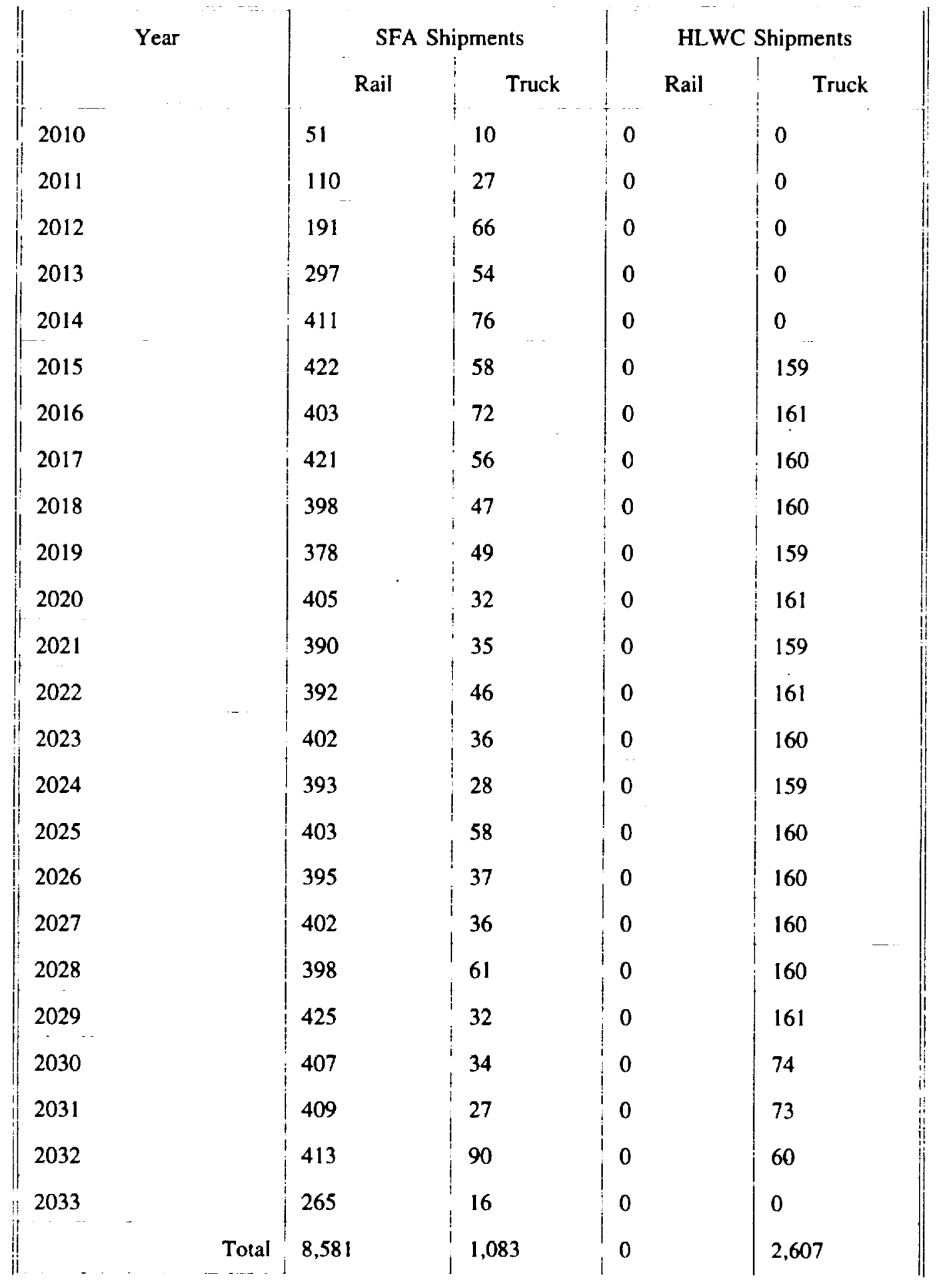


While the reference shipment scenario is a predominantly truck scenario, the current scenario is a predominantly rail scenario: in the reference scenario, only 4 percent of the waste comes by rail; in the current scenario, 91 percent of the waste comes by rail. Rail shipments bring large amounts of waste at once per shipment, which makes rail waste handling a more efficient operation than truck waste handling. Again, the efficiency tends to reduce the utilization of the waste handling lines in the WHB, thus reducing the number of waste handling lines required.

\subsubsection{Number of WHBs}

\section{Reference Concept}

In order to start receiving waste by 1998 , the date stipulated by the Nuclear Waste Policy Act, the DOE elected to construct and operate the repository in two stages: construct one WHB, called WHB 1, first to start receiving SFAs by 1998, and then construct WHB 2. When WHB 2 comes on line, WHB 1 is relegated to handling HLWC only. Figures 7.1-1 and 7.1-2 show WHB 1 and WHB 2 respectively.

\section{Current Concept}

Due to programmatic changes in the direction of the CRWMS, the two WHBs of the reference concept have been merged into one WHB. Figures 7.1-3 to 7.1-10 show the current concept of the WHB. The sections below describe how the current WHB compares with WHB 2, the main WHB of the reference concept.

\subsubsection{WHB Cask Receipt Concept and Operations}

\section{Reference Concept}

The shipments of the reference concept are predominantly truck shipments. Trucks bring smaller quantities of waste at a time than do rail shipments. This means truck shipments require more cask handling, for which reason the SCP-CDR WHBs have four truck receipt areas and no rail receipt areas in WHB 1 and eight truck areas and only four rail areas in WHB 2. Each receipt area has its own air lock, which renders WHB 2 with eight airlocks.

An overview of cask receipt operations for the reference concept is shown in Figure 7.1-11. Note that once a cask enters a slot in the WHB receiving area, the slot is held until the cask is unloaded and exits the WHB.

\section{Current Concept}

The current shipment scenario is a predominantly rail scenario. Rail shipments bring large amounts of waste at a time, which helps in reducing the size of the WHB. In the current WHB concept, the WHB has a single receiving area for both rail and truck. Entry to the receiving area is through a single air lock. Rail shipments enter and exit through the same air lock while truck shipments enter from one end of the receiving area and exit through the other end. 


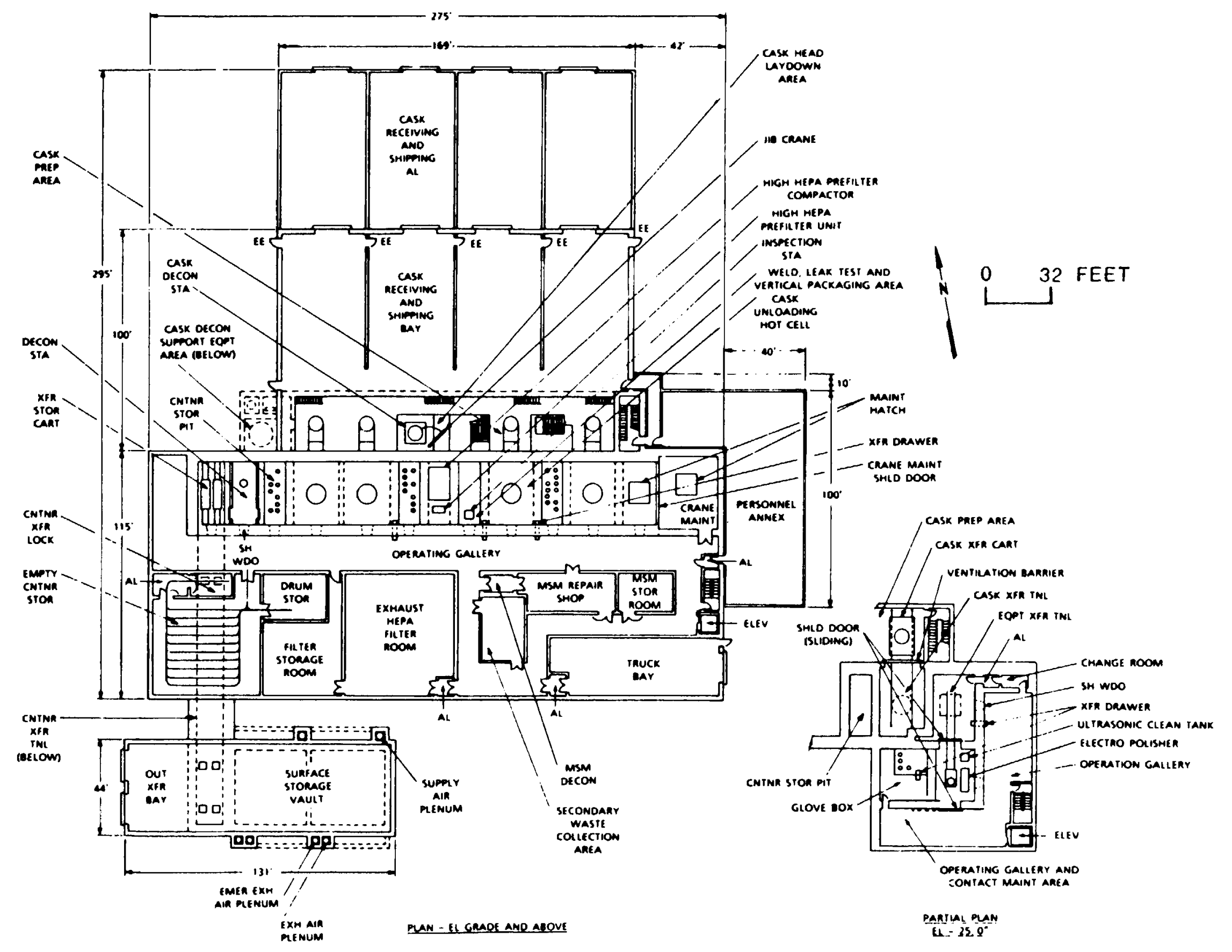



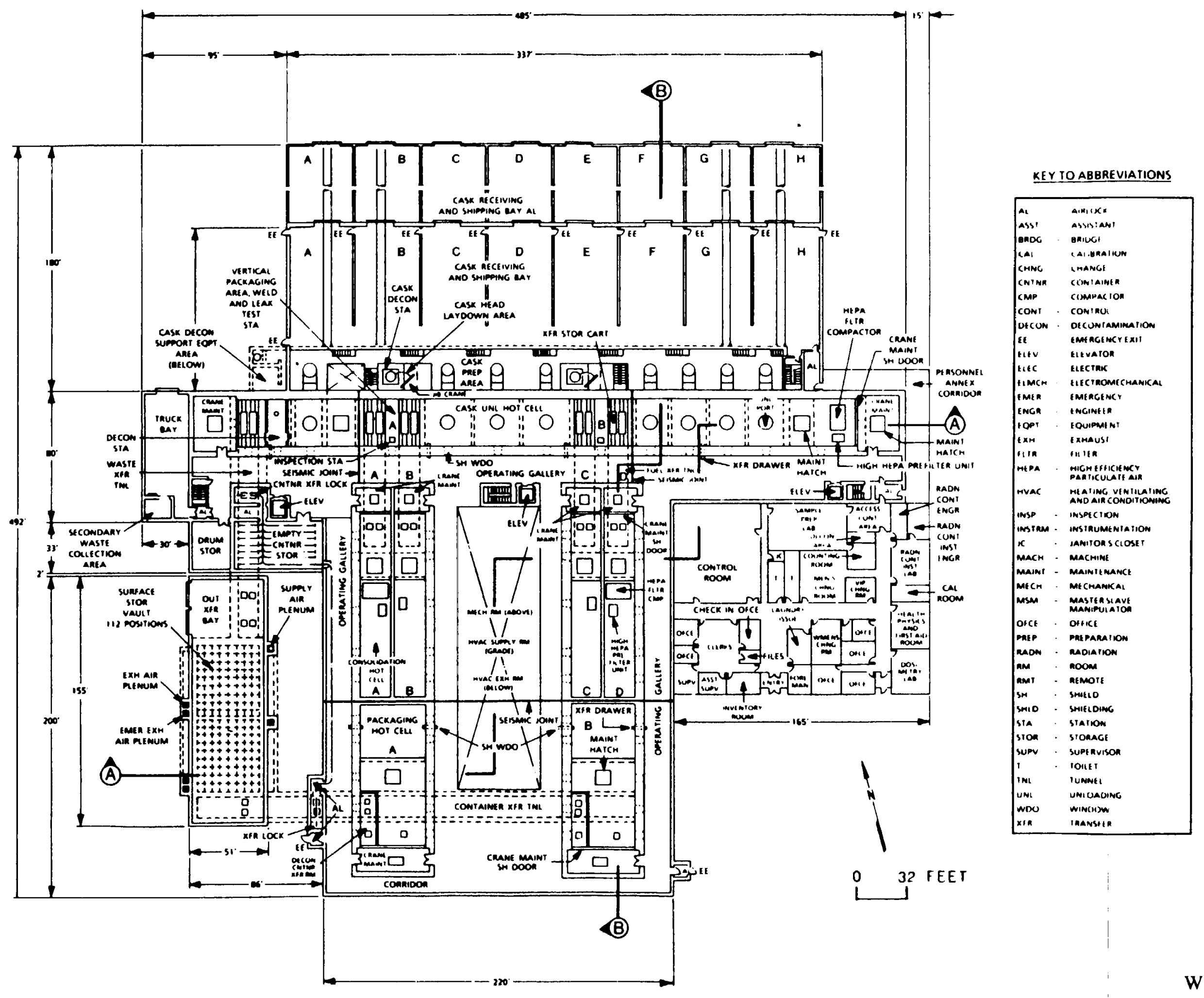

Figure 7.1-2

Waste Handling Building 2 Preliminary General Arrangement 


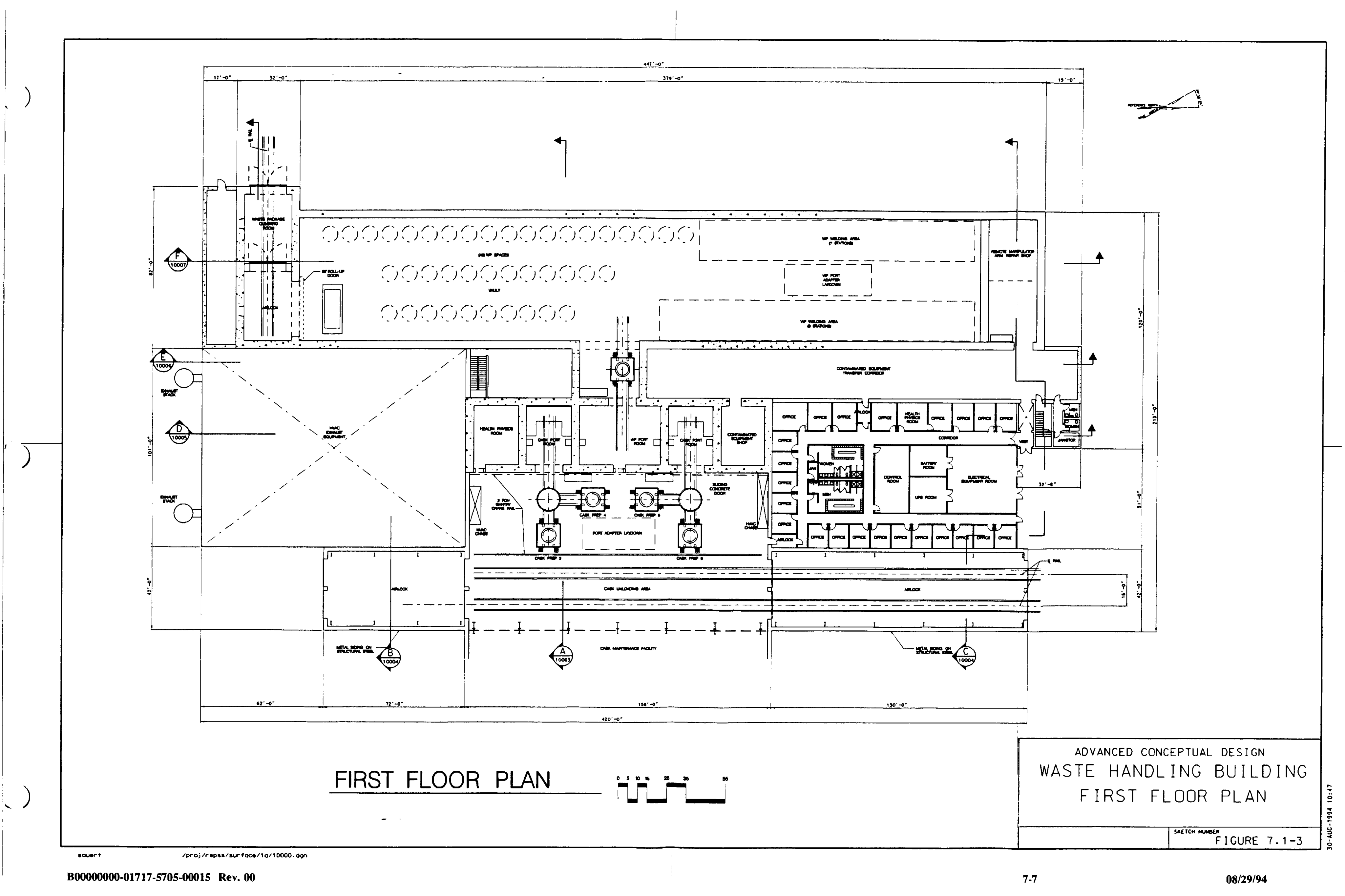




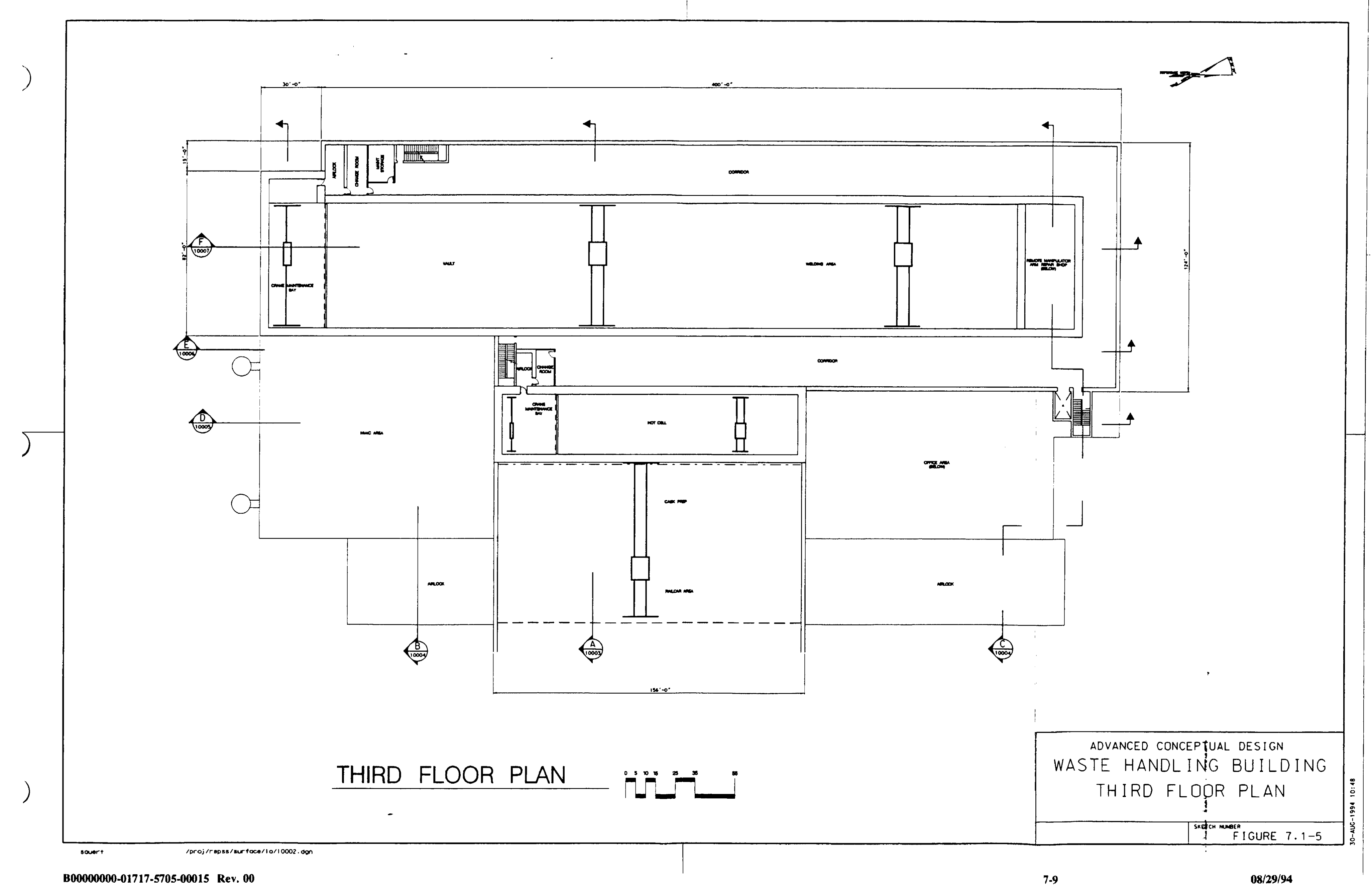




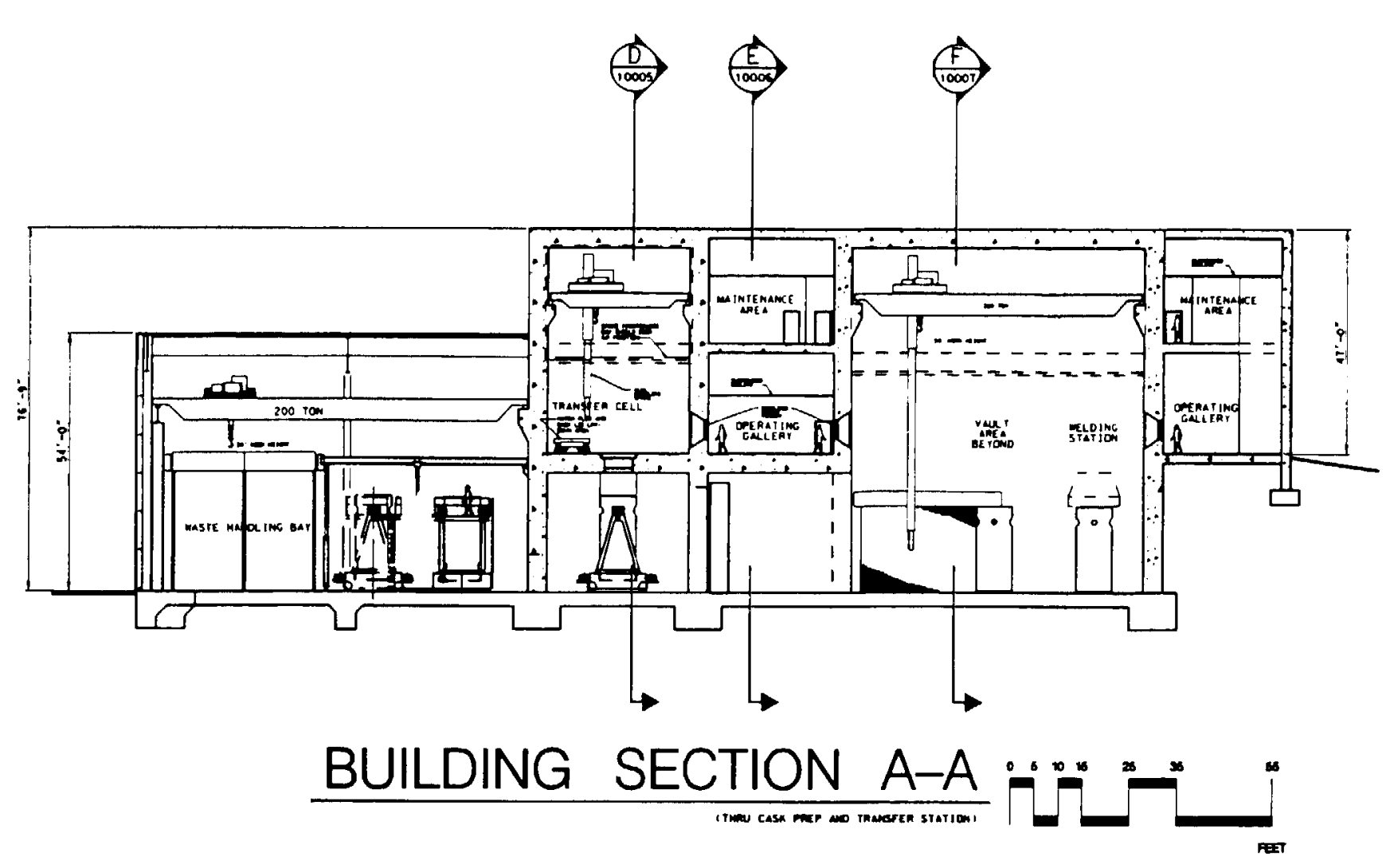

ADVANCED CONCEPTUAL DESIGN WASTE HANDL ING BUILDING BUILDING SECTION Ske ICH Mesect I GURE $7.1-6$ 

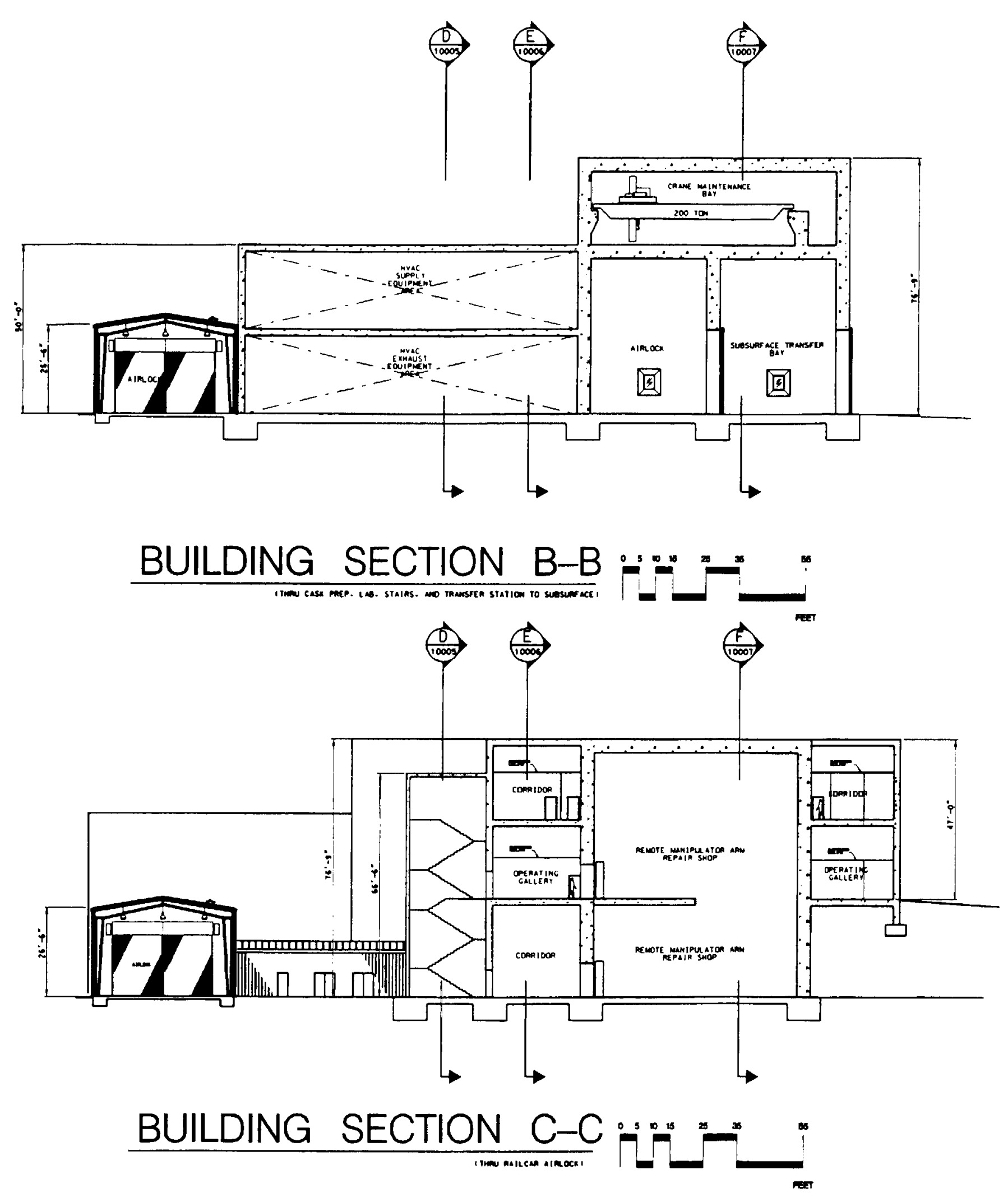

ADVANCED CONCEPTUAL DESIGN WASTE HANDL ING BUILDING BUILDING SECTIONS

SKE TCH MUDeER I GURE $7.1-7$ 


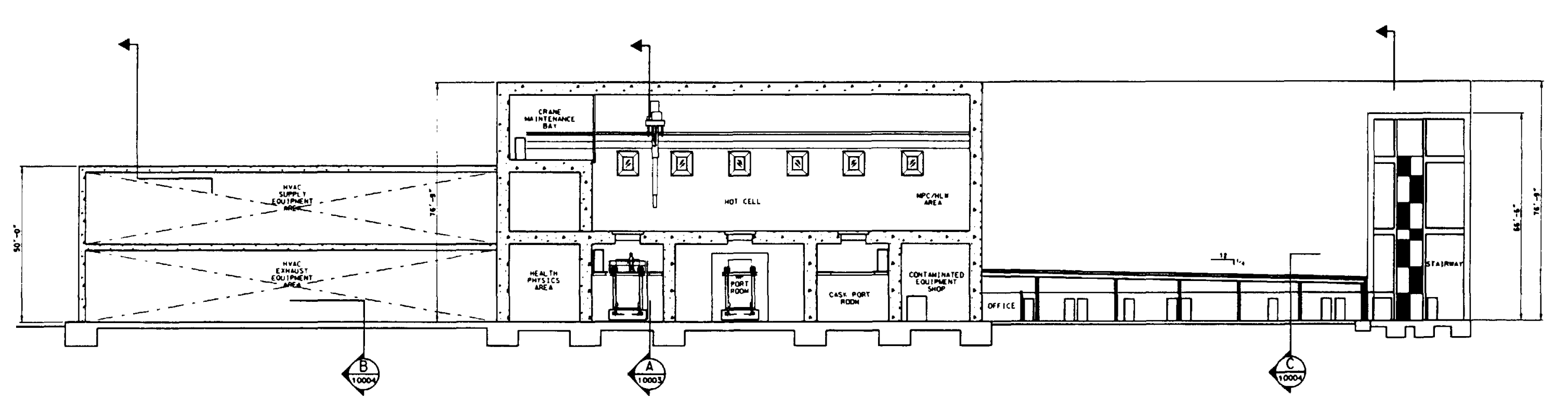

BUILDING SECTION D-D D

ADVANCED CONCEPTUAL DESIGN WASTE HANDLING BUILDING BUILDING SECTION

SEETCH MuterR I GURE 7.1-8 


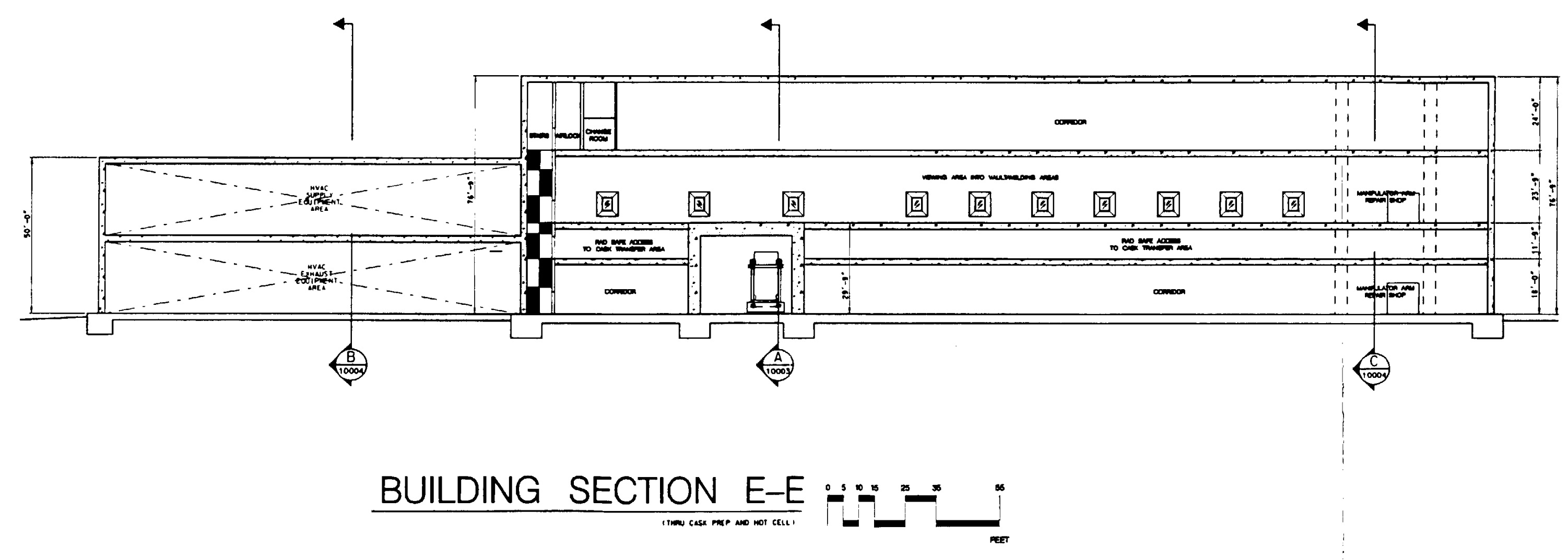

ADVANCED CONCEPTUAL DESIGN WASTE HANDL ING BUILDING BUILDING SECTION SKE ECH MUDERR F I UURE 7.1-9 


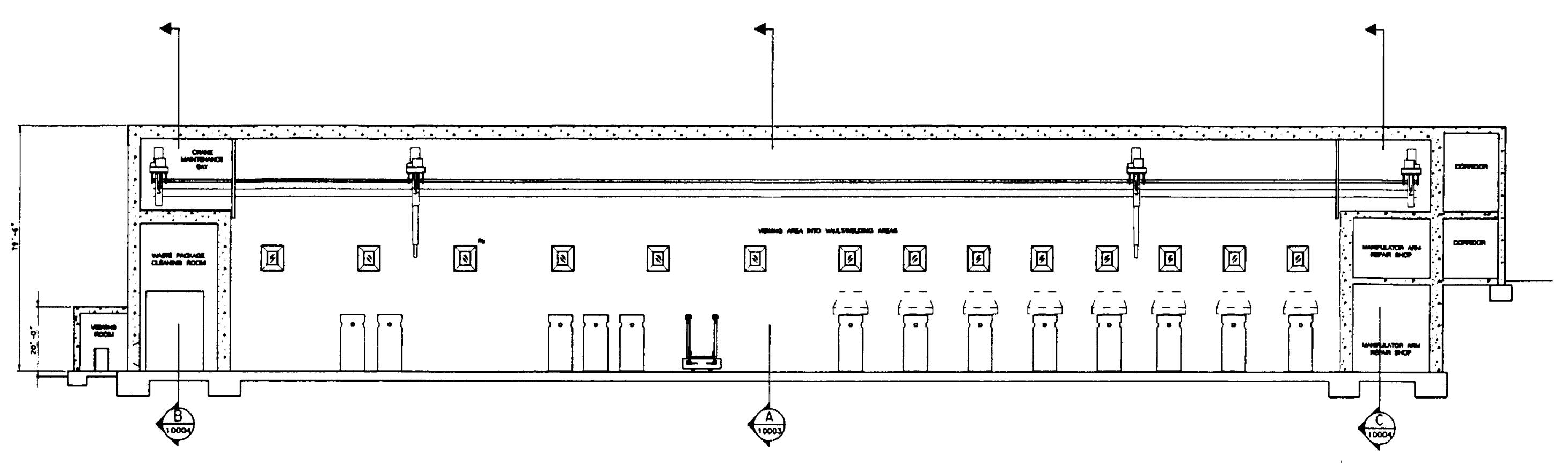

BUILDING SECTION F-F

ADVANCED CONCEPTUAL DESIGN WASTE HANDL ING BUILDING BUILDING SECTION

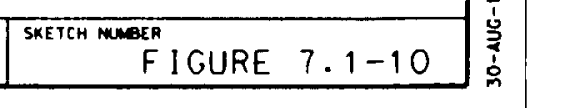




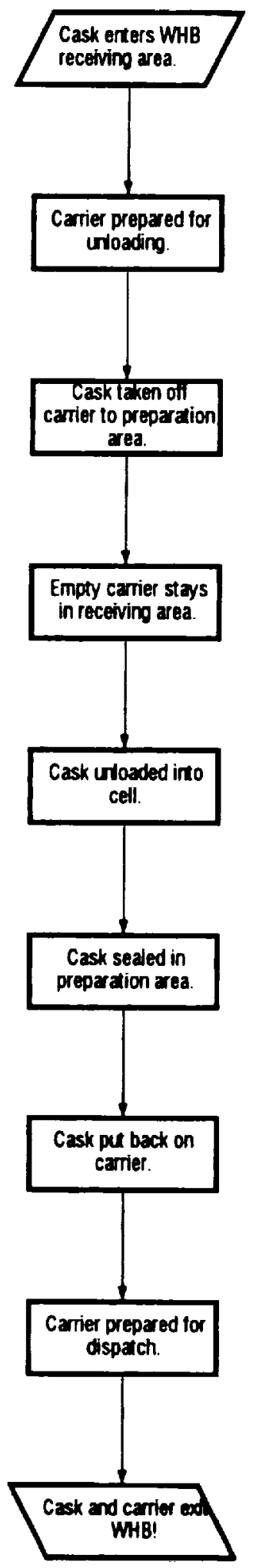

Figure 7.1-11. Reference Concept: Receipt Operation 
An overview of the current cask receipt operations is shown in Figure 7.1-12. In this concept, the carrier is prepared for unloading in a shed outside the WHB. This helps in reducing the number of receiving slots required inside the WHB. Even when the carrier does bring the cask into the WHB, the carrier does not stay in the WHB. The cask is taken off the carrier, and then the empty carrier is taken outside the WHB, where it waits until the cask has been unloaded and is ready to leave the WHB. Then the carrier is brought back into the WHB on the unloaded cask lane. The cask is loaded on the carrier, and the carrier is moved out of the WHB. The carrier is prepared for dispatch outside the WHB. Preparing carriers for receipt and dispatch are time consuming operations. Moving these operations out of the WHB helps in reducing the size of and simplifying the receiving area.

\subsubsection{WHB Cask Preparation Area Concept and Operations}

In the cask preparation area, a loaded cask is prepared for unloading and an unloaded cask is sealed and prepared for dispatch.

\section{Reference Concept}

The preparation area in the reference concept is a trench that runs the length of the WHB. In the preparation area, a cart accepts the cask. After the cask is prepared for unloading, the cart moves the cask into the port room, where the cask mates with the cell port. The port room is separated from the preparation area by a roll-up door. A shadow shield drops down to prevent neutron streaming into the preparation area.

The WHB 2 preparation area has eight preparation stations, one for each slot in the receiving bay, and also one for each port in the transfer cell. Each preparation station accommodates only one cask at a time. Thus in the reference concept, operations for preparation, unloading, and preparation for dispatch are done in series on one cask at a time.

\section{Current Concept}

The preparation area in the current concept of the WHB is at the same level as the bay. Shield doors, instead of shadow shields, protect the preparation area from neutron streaming out of the port rooms. The preparation area has four preparation stations, one for each port of the transfer cell. Each station accommodates two casks. While one cask is being unloaded at the cell, another cask is being prepared either for unloading or for dispatch. Thus in the current concept, the operations for preparation, unloading, and preparation for dispatch can be done in parallel between two casks, which helps in reducing the number of ports required in the cell and hence in reducing the overall size of the WHB.

\subsubsection{WHB Transfer Cell Concept and Operations}

The transfer cell is where waste forms are transferred from transport casks to waste packages. This is also where the waste packages are closed and temporarily stored until transfer to the underground transporter. 


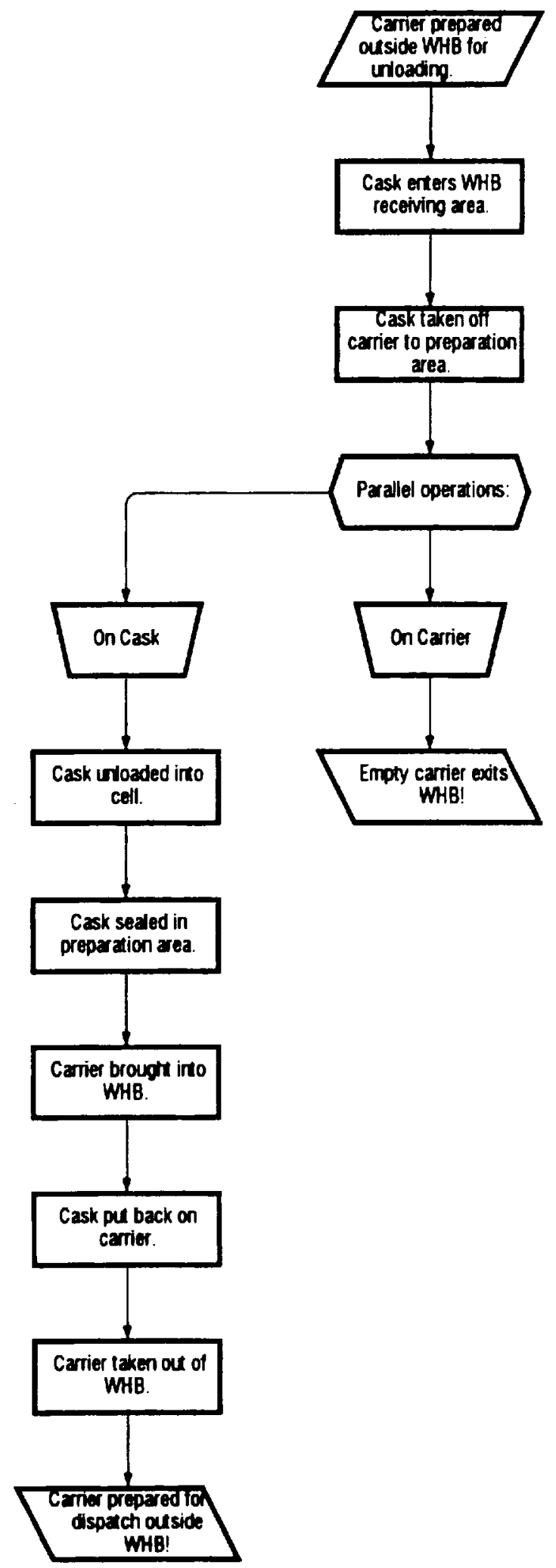

Figure 7.1-12. Current Concept: Receipt Operations 


\section{Reference Concept}

The transfer cell of the reference concept has eight cask ports. The cell has no lag storage. Instead, the cell has ten carts, each capable of carrying six SFAs, two of the carts reserved for SFAs found damaged and overpacked into canisters. The carts double as lag storage, providing a buffer between the transfer cell and the downstream areas.

The downstream areas are the consolidation cells, packaging cells, and the vault. The consolidation cells, four of them, are where the fuel rods are cut from the SFA frames and fittings. In the packaging cell, two of them, the rods are packaged separately and the frames and end fittings are compacted and packaged separately. The resulting packages, called waste packages, are closed by friction welding. The closed packages are stored in the vault until pick up by the underground. The vault accommodates 112 waste packages.

An overview of the cell operations for the reference concept is shown in Figure 7.1-13.

\section{Current Concept}

Programmatic changes have eliminated rod consolidation, and therefore, the consolidation cell.

Further, computer simulations done in FY 1993 have shown that doubling carts as lag storage creates severe bottlenecks. In-cell lag storage serviced by cell cranes is a more efficient lag storage. The carts, by the very nature of their operation, enforced a rigid link between the front and tail ends of the facility in the reference concept. The in-cell lag storage in the current concept effectively separates the two ends so that, for an adequately sized lag storage, delays in the tail end do not impact cask handling upstream. This improves cask turnaround time.

With the elimination of the consolidation cell and the carts plying between cells, the WHB in the current concept is a simpler facility.

Since 89 percent of the SFAs are expected to come in MPCs, inspection time is significantly reduced. For example, in the reference concept, which is designed for handling bare SFAs only, each SFA is inspected. Assume that the truck casks assumed in the reference concept are the GA-4 and GA-9. A GA-4 brings 4 PWR SFAs; a GA-9 brings 9 BWR SFAs. Assume that the mix of GA-4/GA-9 shipments is 50/50. Then the number of PWRs handled in the reference concept is: 94,322; number of BWRs handled: 212,224. Assume time per inspection per SFA: 5 minutes, which is optimistic. Then total time spent in SFA inspection with eight inspection stations is: 133 days, non-stop: that is, assuming round the clock operation. Clearly, and as computer simulations also showed during the simulation efforts of FY 1993, inspection consumes unreasonable time in the reference concept. The current concept does not eliminate the inspection but streamlines the process. In the preparation area, where the cask is prepared for unloading prior to its mating with the cell port, the cask cavity is sampled. If a cask shows indication of a breached SFA, then the SFAs of only that cask are inspected in the cell. Further, in the current concept, due to the MPC, inspection time is eliminated for the MPCs. 


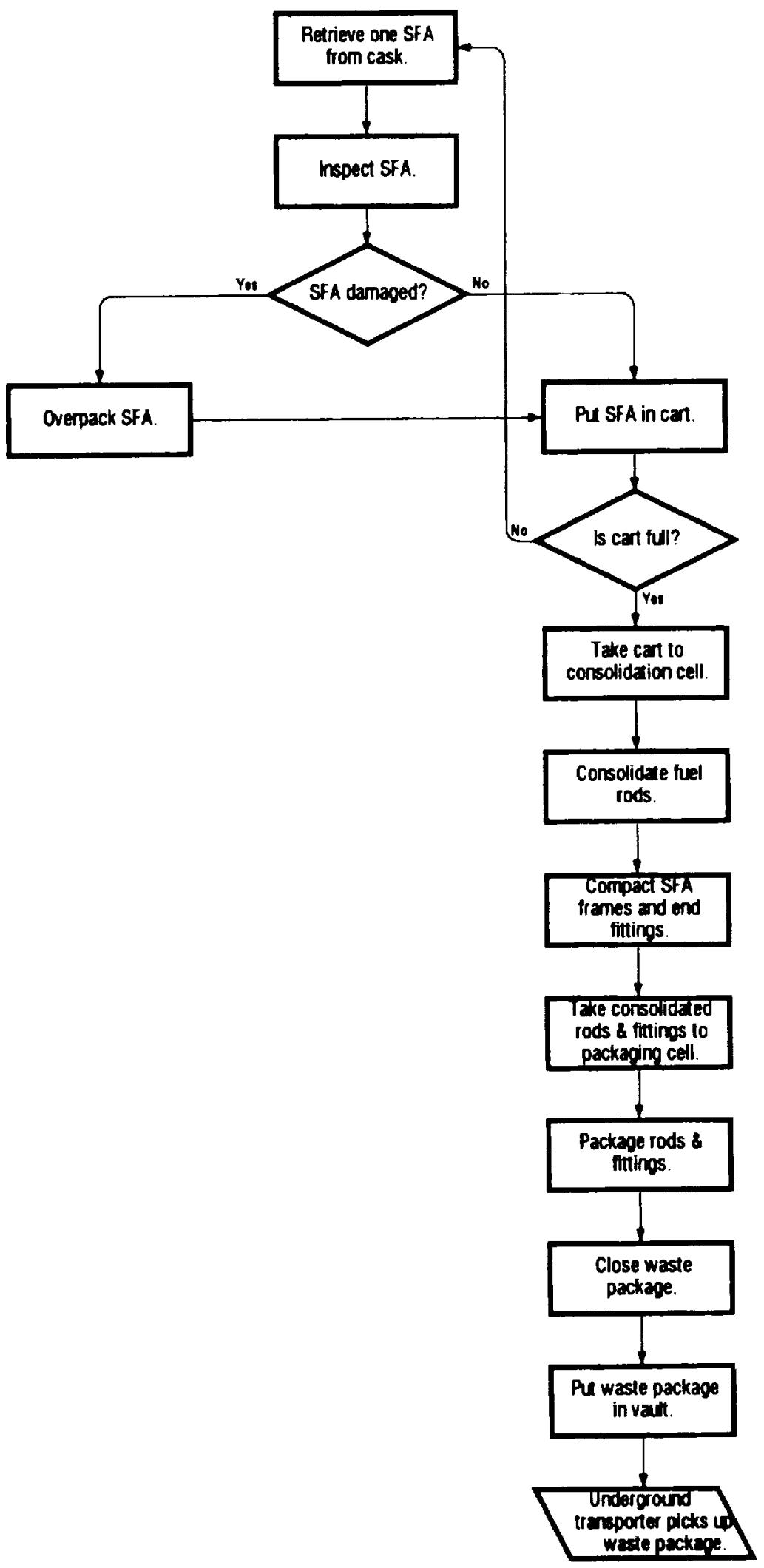

Figure 7.1-13. Reference Concept: Cell Operations 
The current concept has no carts. Further, the waste package in the reference concept accommodates 3 intact PWR and 6 intact BWR SFAs. (The term "intact" implies unconsolidated SFAs.) In the current concept, the waste package accommodates up to 21 intact PWR and 40 intact BWR SFAs. The larger waste package reduces the size of the vault. Computer simulations show that a vault capacity of 40 suffices for steady state operations between the surface and the underground.

An overview of the cell operations for the reference concept is shown in Figure 7.1-14.

\subsubsection{Design Methodology}

\section{Reference Concept}

The reference concept of the WHB was developed from the given shipment scenarios through largely manual computations. A list of operations was developed; times were assigned to the operations; interferences were checked; and the reference concept developed to suit the operations.

\section{Current Concept}

The current concept of the WHB has been developed through computer simulations of WHB operations. Computer simulations help design the WHB for realistic conditions of operations something quite difficult to achieve with manual and purely mathematical calculations.

The WHB receives hundreds of shipments of several different waste forms simultaneously. Waste arrives in casks with different operational features, such as on-carrier or off-carrier storage of personnel barriers and impact limiters. Shipments may come by rail or on truck. Each shipment has a different capacity. Each shipment competes with others for limited resources. Resources suffer breakdowns or simply go off line routinely for preventive maintenance. Some operations occur in series; others occur in parallel. Some shipments undergo lengthy operations such as weeping decontamination; other shipments move swiftly though the facility.

All these realistic conditions, operational, make it difficult for manual calculations to accurately size and optimize the WHB's resources. Computer simulation, on the other hand, takes all these realistic conditions into account. Therefore, computer simulations have been relied on extensively for the development of the current concept of the WHB.

The computer simulations were developed as follows.

First, detailed operations flow charts were developed. Flow charting is a superior method of sequencing operations rather than mere listings. The operations flow charts of the current concept show what operations occur when, for how long, and what resources the operations tie up. Serial and parallel operations are clearly marked. The flow charts also show decision points and the outcome of the decisions and the probabilities of the outcome. The probabilities are based on field data: for example, field data, reported in a paper based on data collected on actual cask shipments, suggests that the probability of a cask arriving weeping is 


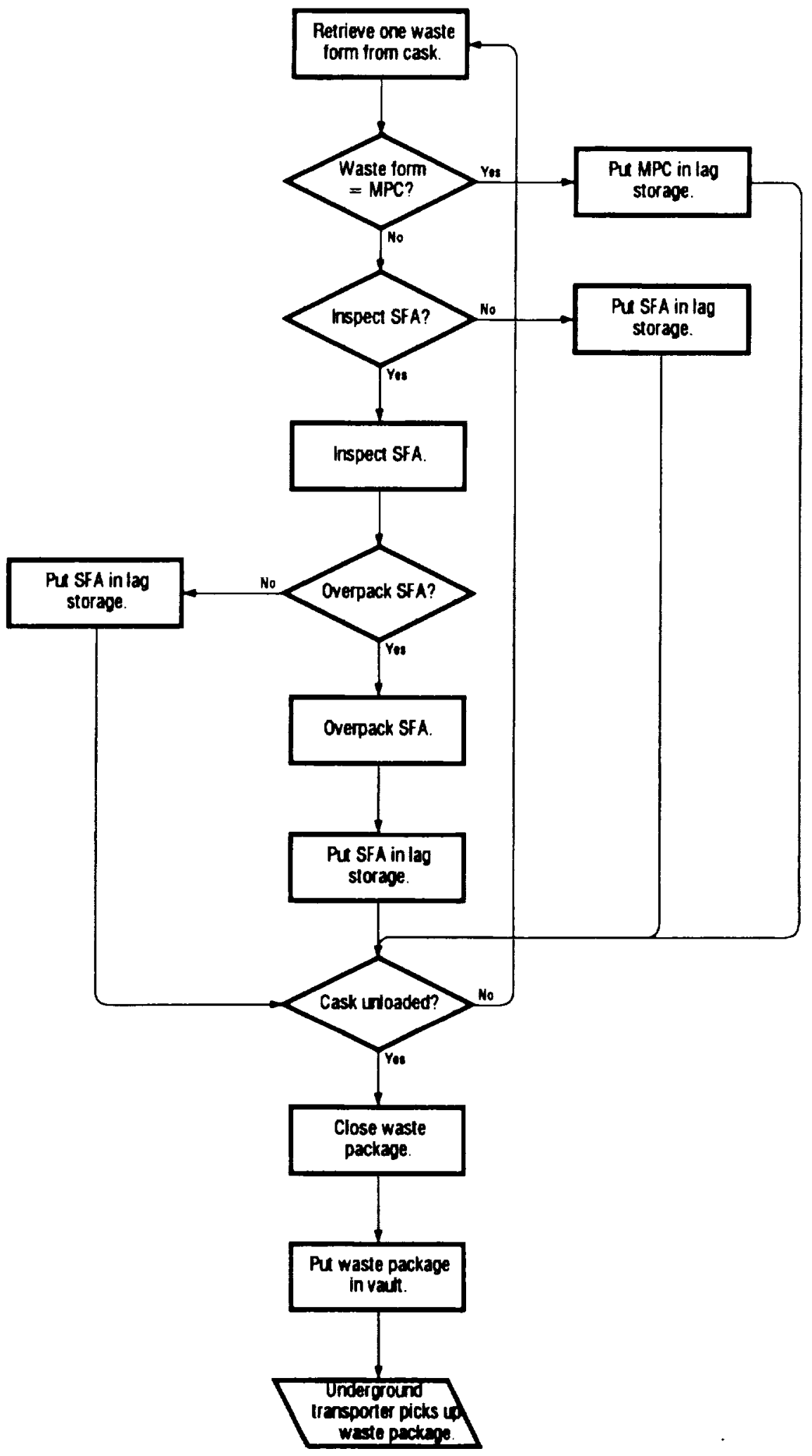

Figure 7.1-14. Current Concept: Cell Operations 
8 percent. This field data is reflected in the flow charts. Similarly, the mean time between failures and repair for key resources such as cranes, prime movers, etc. has been collected from existing DOE nuclear installations and put into the flow charts and simulations. Appendix E shows the WHB operations flow charts for the current concepts. The overall layout of the operations flow charts is shown in Figure 7.1-15.

Second, computer simulation is derived from the operations flow charts. The simulation is developed with an off-the-shelf, commercially available simulation software called Slamsystem. The simulation developed is verified and validated by systems modeling professionals, per quality assurance procedures. The verification and validation ensure that: (a) the simulation follows the logic of the operations flow charts; (b) operational durations and decision probabilities in the simulation are the same as in the flow charts; (c) all materials are accounted for: that is, a cask that enters the facility does indeed exit or is otherwise accounted for, and likewise for each waste form. The current concepts of the WHB are derived from this simulation effort. 


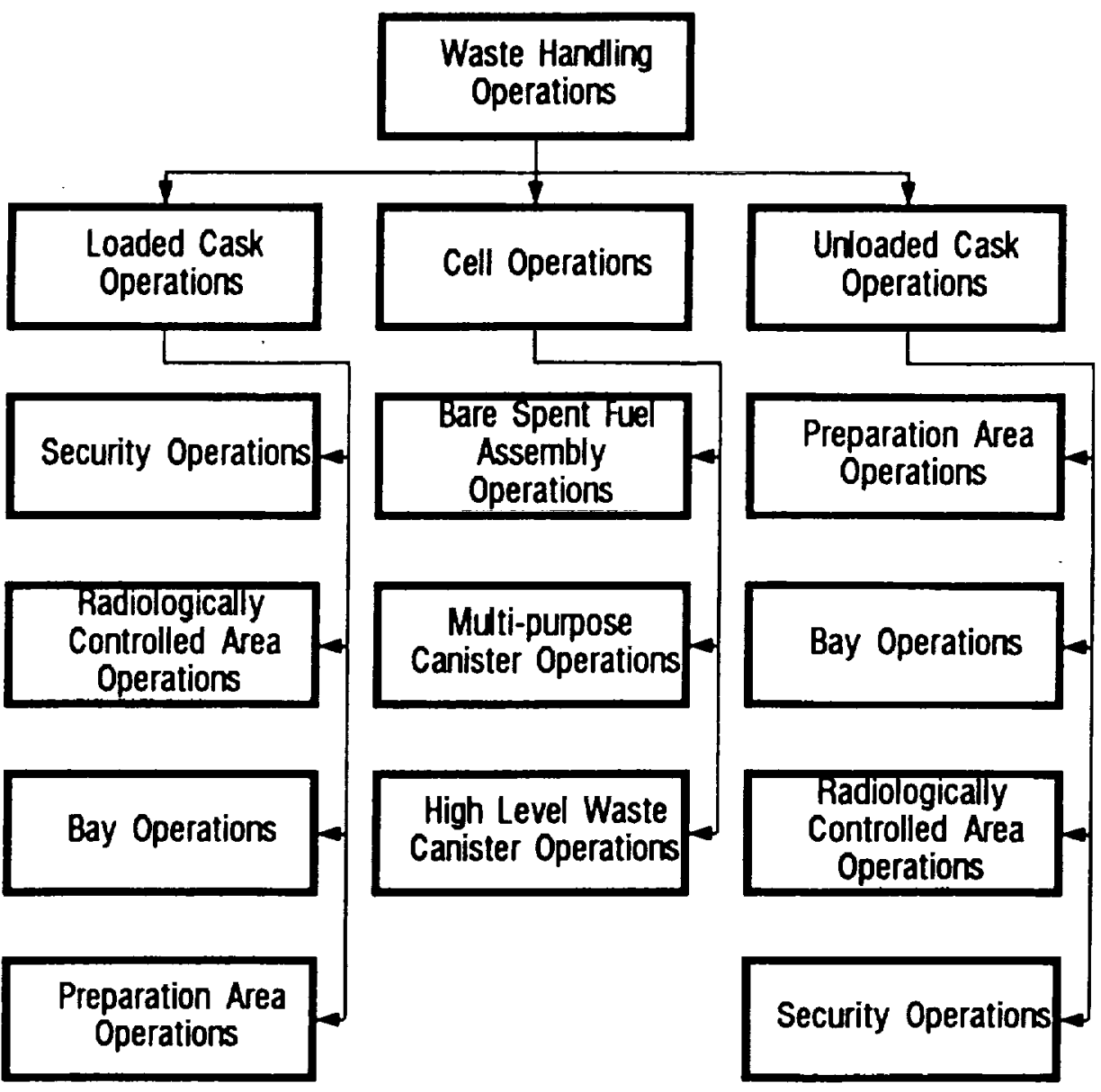

Figure 7.1-15. Current Concept: WHB Operations Flow Charts Layout 


\section{SUBSURFACE REPOSITORY DESIGN DESCRIPTION}

This report section summarizes much of the work completed by the repository subsurface design group during the 1994 fiscal year (FY94), and represents a portion of the ongoing, repository Advanced Conceptual Design (ACD) effort. Information is drawn from other ACD reports prepared and submitted during the year, and from other program studies, including the Exploratory Studies Facility (ESF) Title II design. Site specific data gathered by the

Surface-Based Testing (SBT) program has been included to the extent that it became available early enough for use in the designs presented herein.

The work that was performed in support of the repository subsurface designs presented in this section was of a conceptual nature. None of the repository layout work presented herein should be construed as having been developed through, or as a product of, detailed design evaluations. Rather, it should be regarded as the result of iterative thought processes that present ideas in a format that facilitates further review and refinement as the ACD program develops.

Geological and geoengineering information that is provided is based, in part, on a review of available literature and data specific to Yucca Mountain. The latest information from the SBT program is included to the extent that it became available early enough to be incorporated into the conceptual designs presented herein. This information has been collected in a design analysis (M\&O, 1994s) that presents topographic, structural contour, faulting, water table and other base maps that were used in developing the repository layouts included in this section. Many of these maps were developed using the Lynx geologic computer model, a program that has been approved for use in quality affecting work. However, the bulk of the geologic borehole data used by the model was not collected in accordance with an approved QA program. While much of the borehole data are of indeterminate quality, the information is the best that was readily available when the work was performed and its use is consistent with past YMP design efforts.

Current waste package ACD and systems studies efforts are evaluating a wide range of potential package configurations and capacities. The conceptual repository layout designs presented in this section utilize one of the larger, MPC-based package sizes. Ultimate selection of a recommended package configuration will influence the required subsurface opening sizes, so any dimensional data provided herein should be considered as very preliminary in nature. If the YMP program were to adopt one of the smaller (6 PWR assembly $+/-)$ waste packages, then entirely different layout concepts might be warranted.

Discussions of thermal considerations represent a compilation of the more relevant work that has been performed in the past, little of which considered in-drift emplacement of waste packages as a potential emplacement mode. The layout work described in this section emphasizes the in-drift mode, but does not have the support of detailed thermal, thermomechanical, and thermal-hydrological evaluations.

Rather than adopt a particular thermal loading as a design basis, the layouts that are presented were designed to maximize the utilization of available subsurface area consistent with a set of 
design assumptions and/or objectives. The minimum thermal loading that the available area could support, based on emplacement of an assumed total waste inventory, was then backcalculated using the net area available after standoffs and other, non-emplaced zones were subtracted.

Details regarding optimal emplacement drift spacing and waste package spacing are not provided. Determination of these parameters is part of a much larger problem involving the potential systems that are defined by specific waste package sizes and thermal characteristics; drift sizes; drift and package spacings; thermal loading strategies; host rock thermal, thermomechanical, and hydrologic properties; and thermal goals. Ultimately, through the use of broad ranging systems studies, a design will be developed that optimizes this system, consistent with meeting all of the final thermal goals and stability constraints that will bound the problem. Concepts presented in this report did not have the support of any such analysis.

The emplacement concepts and operational schemes discussed are very preliminary in nature and have not undergone detailed reviews with regard to personnel radiological safety or long term performance assessment considerations. They are presented as potential methods of storing the waste in configurations that include retrieval as one of the primary requirements that must be accommodated. The schemes are purely conceptual in nature and will likely be subject to much refinement or revision in the future.

The conceptual repository layout work presented in this section was performed by inspection and using engineering judgment. In other words, the geologic base maps (included in $\mathrm{M} \& \mathrm{O}$, 1994s) were used as control in an iterative process of manually sketching lines on overlay sheets until a layout was established that provided a logistical framework of subsurface openings that fit within various physical boundaries set by both the fundamental program requirements, and the objectives/assumptions adopted for the particular layout.

None of the layout work has benefitted from long-term performance evaluations, but results do not appear to differ significantly from previously baselined concepts in any way that is considered to be less capable of providing the long-term isolation that is needed.

A great deal of work remains to be performed in the area of repository subsurface design. This work requires the application of mining engineering techniques normally exercised in developing the layouts and operational systems for underground mines, but using a primary excavation tool, the TBM, that has historically been employed only in civil engineering tunnelling projects because of the reduced flexibility inherent in this excavation method. It is doubtful that the TBM has ever been used in what would be called a "production mode" in an underground mine, and certainly not on the scale that is necessary for an underground repository. If one contemplates the logistical problem of developing a functional repository layout that is readily constructable using TBMs, together with the inter-related, yet separate problem of defining an emplacement mode and technique that will perform well in terms of personnel radiological safety and waste isolation concerns, one can begin to appreciate the task that is ahead. 


\subsection{REFERENCE CONCEPTUAL REPOSITORY DESIGN}

A conceptual design of a potential, high-level nuclear waste repository at Yucca Mountain is described in Chapter 6 of the SCP (DOE,1988) and is based on evaluations presented in the SCP-CDR (SNL, 1987a). The configuration of the SCP-CDR repository layout, using the vertical emplacement mode, is shown in Figure 8.1-1. Another conceptual layout, carried as an alternative in the SCP-CDR, used a horizontal emplacement mode. The vertical mode waste emplacement geometry, the horizontal mode layout, and the horizontal mode emplacement geometry are shown on Figures 8.1-2, 8.1-3, and 8.1-4 respectively.

A later report, the Exploratory Studies Facility Alternative Study (ESFAS) (SNL, 1991a), evaluated 34 different, integrated ESF/repository configurations. The study concluded that the alternative identified as Option 30 was most preferred, based on a multi-attribute decision analysis that considered waste-isolation, operability, programmatic, and other features of the various designs. This option included two $7.6 \mathrm{~m}$ diameter ramps excavated by TBM and two $7.6 \mathrm{~m}$ diameter shafts for repository access. Figure 8.1-5 shows the general layout features of the Option 30 configuration (SNL, 1991a). This layout facilitated the use of the TBM excavation method for construction of ramps, access drifts, and emplacement drifts. Option 30 contained the dedicated main test level (MTL) area in the southeast area of the repository footprint, but was later modified to move the MTL into the northeast corner of the repository footprint and to include an optional shaft for site characterization purposes. The resulting layout was called "Modified Option 30."

The Modified Option 30 layout became the starting point for Title I ESF design via a document (YMP, 1991a) that also stressed the need to pursue development of other ESF/Repository layouts that incorporate all of the favorable waste-isolation design features identified in the ESFAS. The Modified Option 30 repository configuration (Figure 8.1-6) showed the north Topopah Spring Level (TSL) ramp at a slope of 9.52 percent and the main TSL drift sloping at 5.92 percent.

A revision to the slopes of the North Ramp and Main Drift was made during ESF Title I design. The revision consisted of changing the elevation of the "entry point," which is the point where the curve of the North Ramp ends and the TSL Main Drift begins. Reevaluation of the TSw $1 / \mathrm{TSw} 2$ geologic contact in drillhole cores allowed the entry point to be raised by $42.7 \mathrm{~m}$, thereby reducing the North Ramp slope to 6.9 percent and the TSL main drift slope to 4.7 percent. The configuration of the ESF and the potential repository in plan view were generally unaffected by the change in elevation at the entry point.

An enhanced ESF layout that offers numerous advantages to the Yucca Mountain Site Characterization Project (YMP) was developed by the CRWMS M\&O in 1993 and has been submitted to and accepted by the YMP Change Control Board (CCB). 


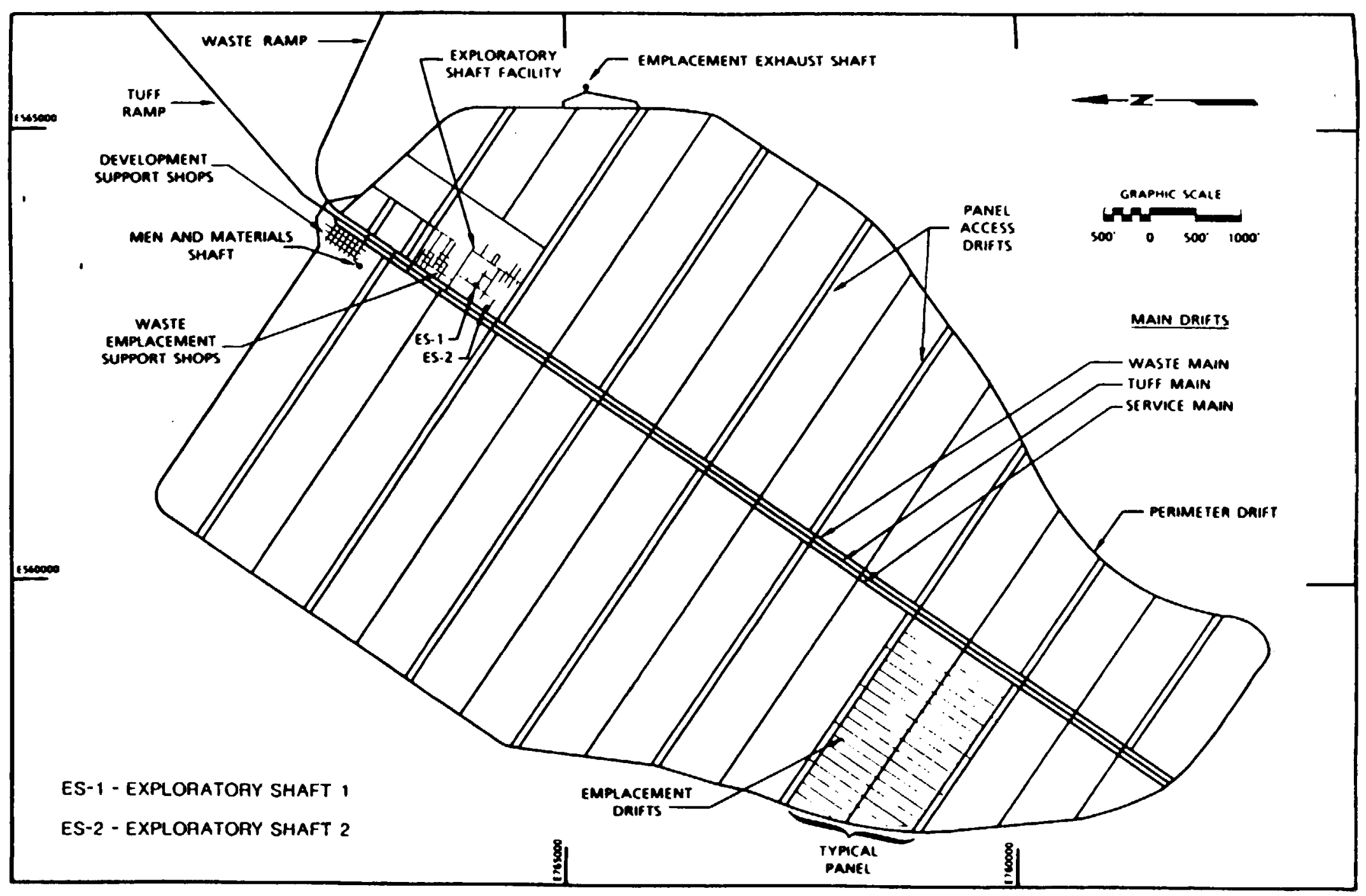

䢔

Figure 8.1-1. Repository Layout in SCP-CDR Using the Vertical Emplacement Mode 


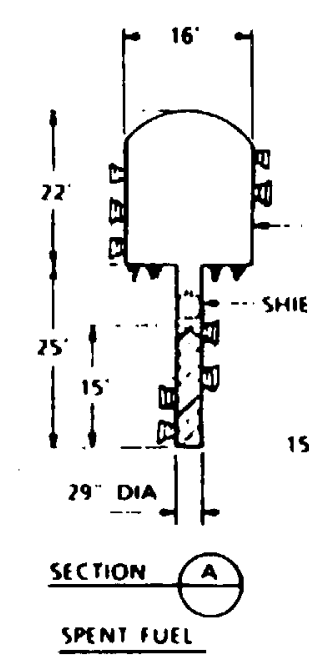

NoIE

DIMENSIONS SHOWN ARE EXCAVAItO

OIA

DIAME TER

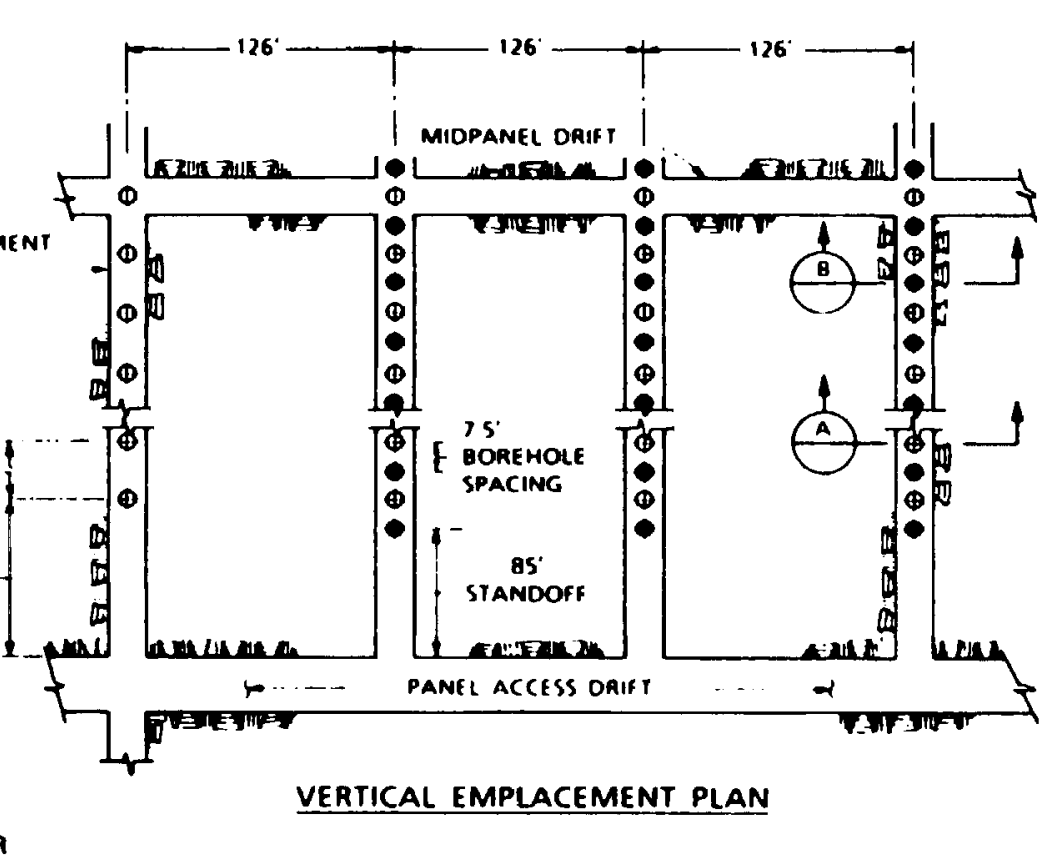

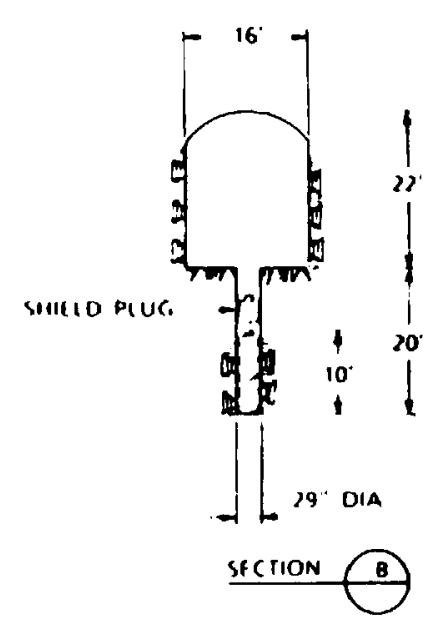

DE FENSE HIGH 


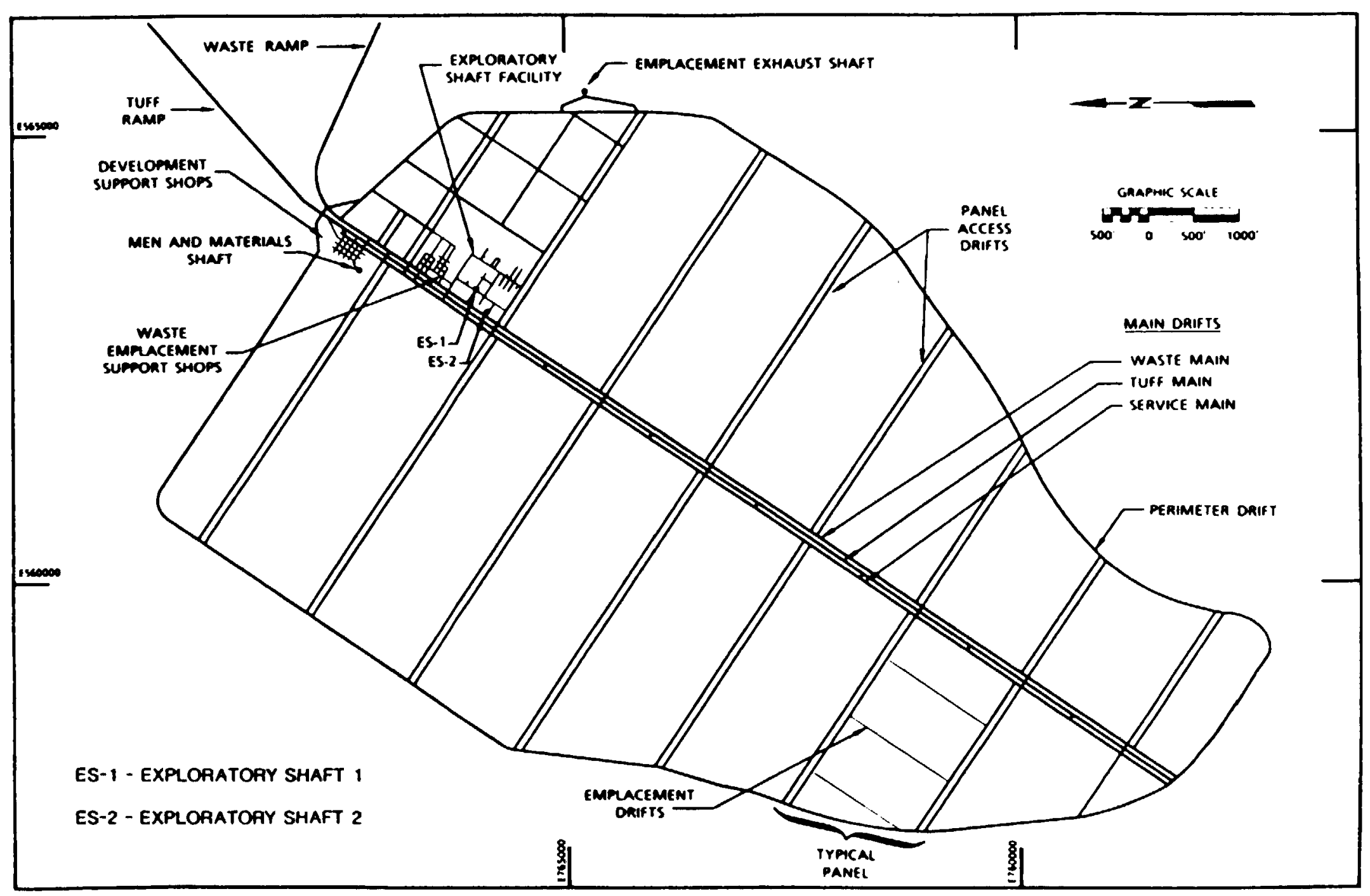

宽

Figure 8.1-3. Repository Layout in SCP-CDR Using Horizontal Emplacement Mode 

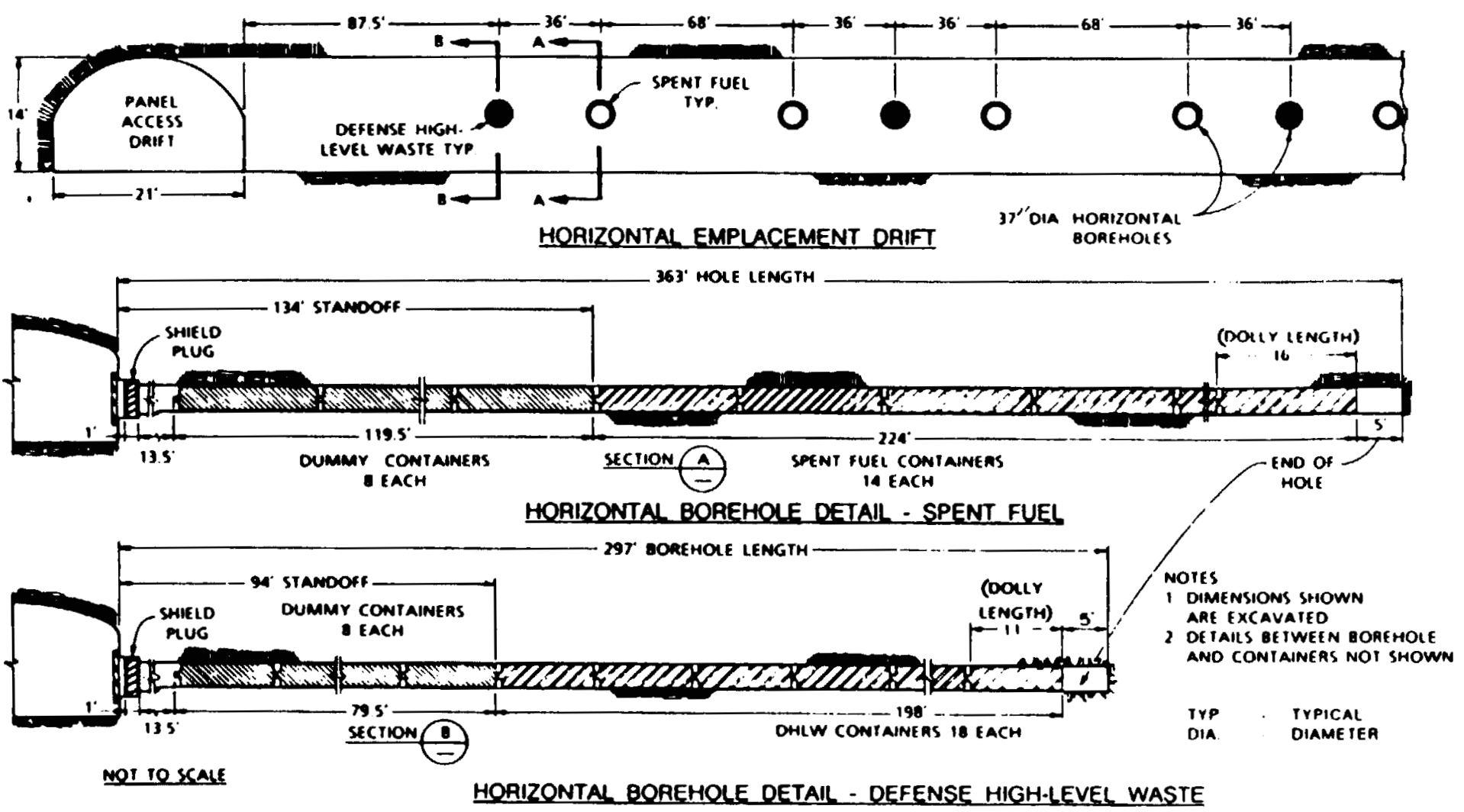

通

Figure 8.1-4. Horizontal Emplacement Mode in SCP-CDR 

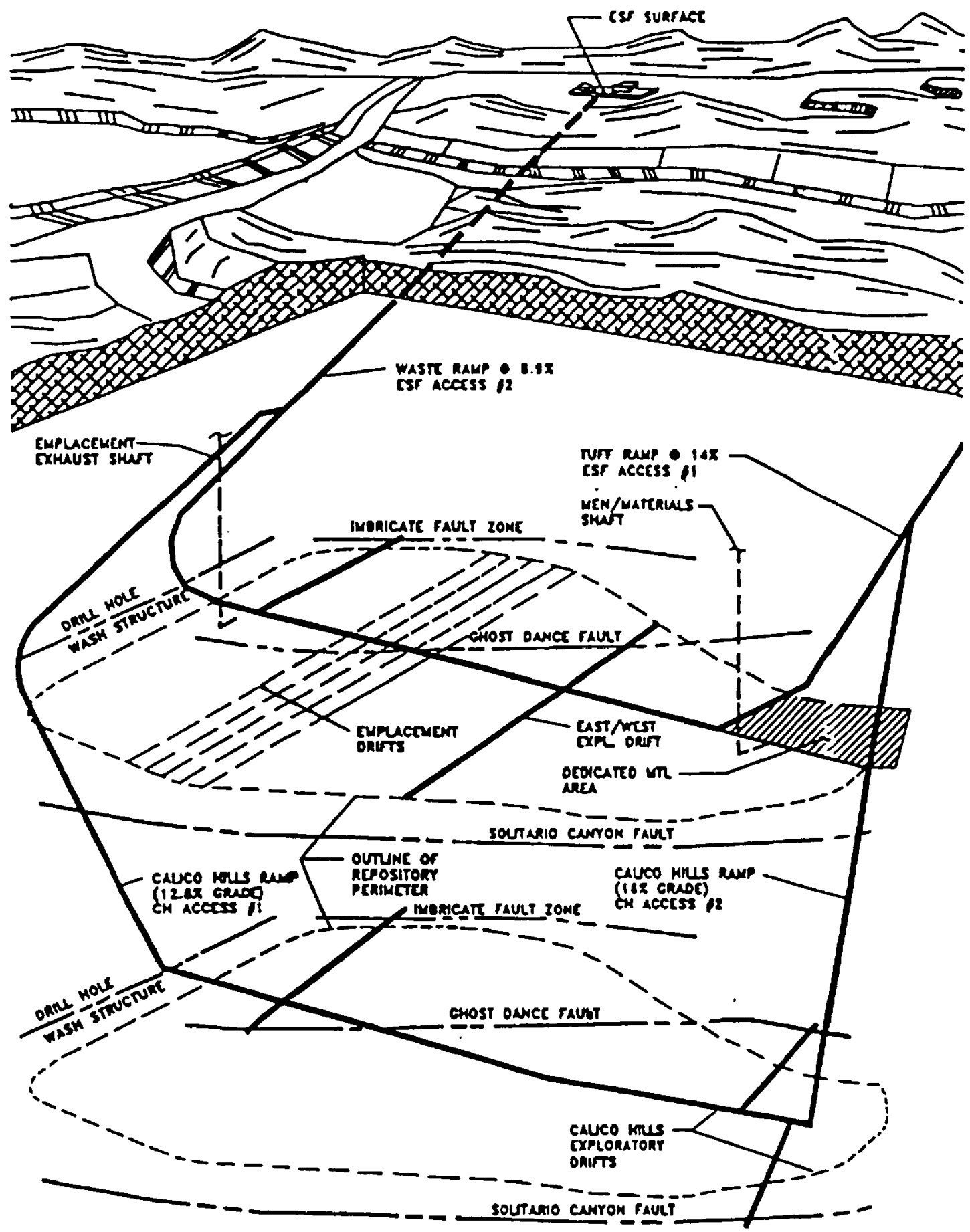

Figure 8.1-5. Repository Configuration Option 30 


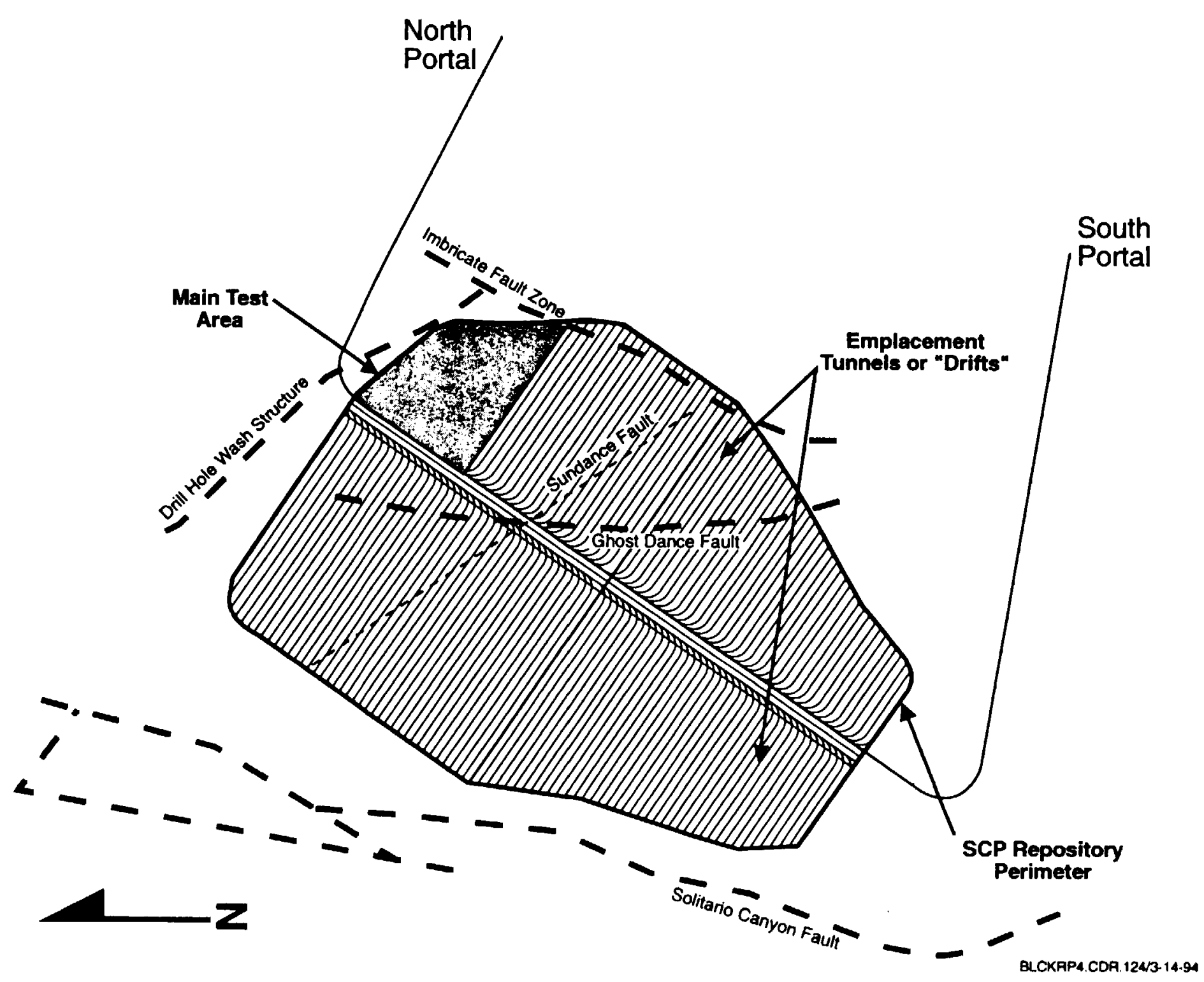

Figure 8.1-6. Repository Configuration-Modified Option 30 
Entitled, "Description and Rationale for Enhancement to the Baseline ESF Configuration" (M\&O, 1993e), the document proposes changes that are consistent with recommendations made in YMP (1991a), i.e., to examine potential ESF/repository layouts that incorporate waste-isolation attributes of other highly-ranked alternatives included in the ESFAS but which were not incorporated in the selected ESFAS option. Additionally, the repository subsurface design group completed a repository conceptual design report entitled Repository Subsurface Layout Options and ESF Interface (M\&O, 1993b) that was submitted to the DOE in December 1993. That report described various operational elements and features of the conceptual repository layout that was presented with the proposed ESF reconfiguration.

Finally, a new set of ESF/potential repository interface drawings (M\&O, 19940) was developed and submitted to the DOE on February 28, 1994, supported by a design analysis (M\&O, 1994a) that brought forward results from M\&O, 1993a and M\&O, 1993b. These drawings have been baselined and provide an interim reference for ongoing ESF Title II design regarding ESF/repository subsurface layout geometry and functional relationships. One of these drawings is presented here as Figure 8.1-7.

The current conceptual repository design, presented as the interim layout in Section 8.6.3, is considered to be a refinement to the baselined repository configuration presented in Figure 8.1-7. 


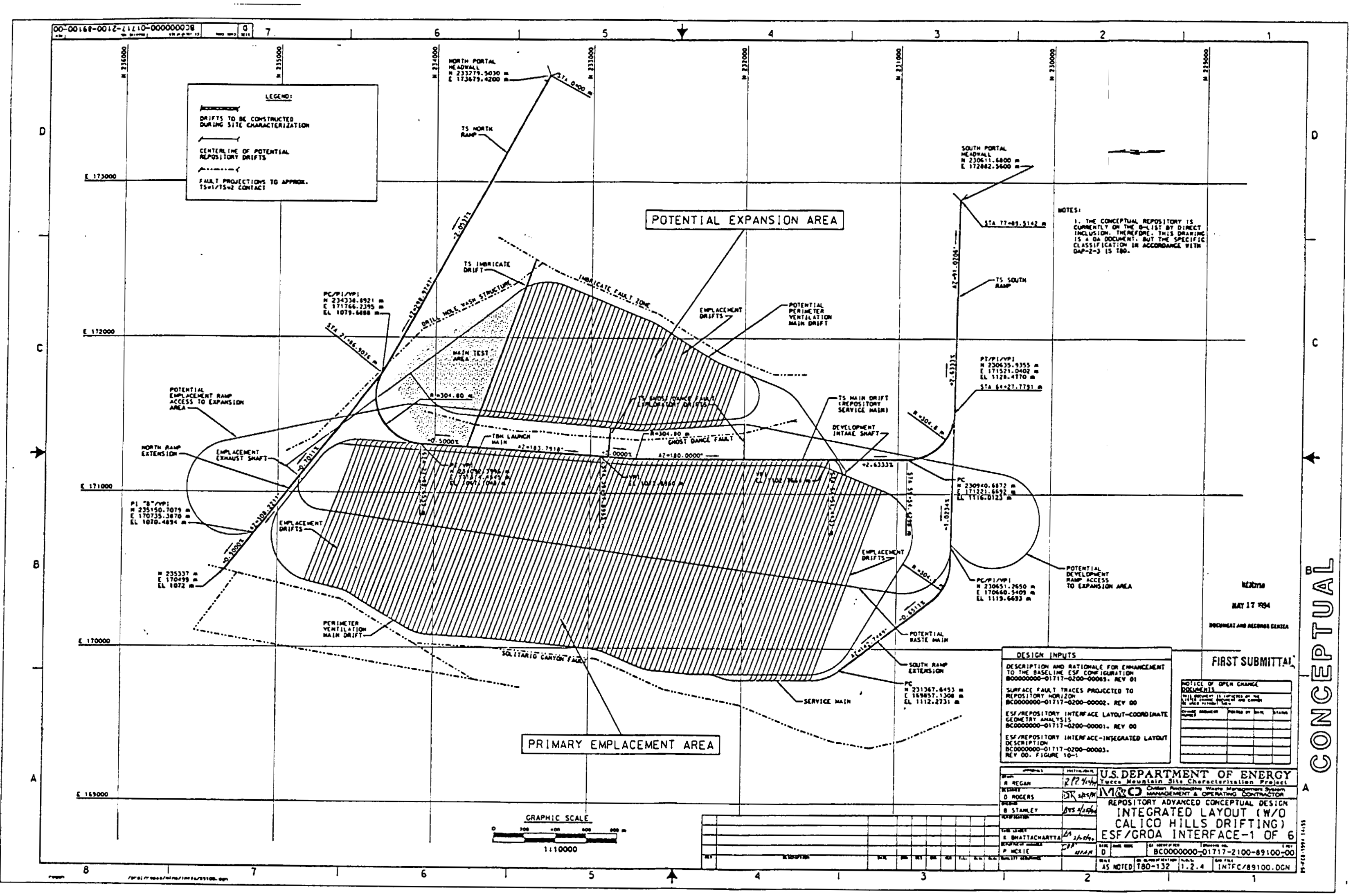

Figure 8.1-7

Conceptual Repository Layout Current Baseline 


\subsection{GEOENGINEERING CONSIDERATIONS}

\subsubsection{Repository Horizon Selection}

\subsubsection{Stratigraphic Criteria for Constructibility and Emplacement}

\section{A. Constructibility and Maintenance}

The TBM starter tunnel for the ESF North Ramp is in the upper lithophysal zone of the Tiva Canyon member described as having abundant lithophysae up to $300 \mathrm{~mm}$ in diameter (USBR, 1992). Actual percentages of lithophysal cavities are not known. Observations during excavation of the starter tunnel indicate that drilling holes and placing rock bolts are more difficult in ground containing lithophysae cavities. Drill holes tend to block off and additional grout is needed to anchor rock bolts. In addition, the starter tunnel work indicates that long-term maintenance of unsupported or lightly supported openings may be increased by ground with significant lithophysae. As a cautionary note, the near-surface location of the starter tunnel indicates that weathering could have aggravated the behavior of the high lithophysal ground. Conclusions based on these observations are thus preliminary. Moreover, a lithophysal cavity density that precludes an effective support system for repository development has not been identified.

Based on the ESF experience, there appear to be constructural and operational advantages, at least for certain support systems such as rock bolts, to locating underground openings as well as ground support elements in tuff that contains few or no lithophysal cavities. Thus, in regard to ground support for typical 7.6-m-diameter drifts, a 5-meter-thick zone containing less than 10 percent lithophysal cavities at the crown and sidewalls of an opening, is determined to be adequate for installation of rock reinforcement. A 5-meterthick zone allows for a nominal rockbolt length of $3.0 \mathrm{~m}$, such as planned for the North Ramp (M\&O, 1994t), plus an additional allowance for longer support elements should they be required.

\section{B. Rock Quality}

There are no empirical data yet available on the performance of TBM driven tunnels in the tuff at Yucca Mountain. Excavation of the TS North Ramp will provide the first information of this sort. Thus, the relationship between rock quality, as evidenced by RQD, Q-index, and RMR-index, and the behavior of openings has not been determined. Also, within the TSw2 there do not appear to be continuous zones or strata of uniform rock quality that could be used to define appropriate repository limits, therefore RQD and rock classification parameters are not considered useful as factors in determining suitable boundaries (Section 5.2).

\section{Thermal Property Considerations}

Based on information given in Section 5.2 on thermal conductivity, it appears conservative to avoid rock containing more than 10 percent cavities on the assumption that adverse temperature effects will result. 


\section{Thermal Goal Considerations}

Thermal goals cited in Section 8.3 and Table 8.3.1-1 require assessment of the effect of waste-induced temperature on the ground surface and on certain stratigraphic horizons. Vertical, as well as horizontal, adjustments may be required in repository configuration to meet these goals. For example, goals 4 and 5 are intended to limit surface temperature rise and surface uplift, respectively. Changes in repository elevation would be one way to control such perturbations. Goals 1 and 2, on the other hand, limit the temperature of the $\mathrm{CHn}$ and TSw 3 units, respectively, to less than $115^{\circ} \mathrm{C}$ in order that zeolites contained in these and lower strata not be altered. Analysis is required to determine specific standoff distances (mainly vertical, but perhaps horizontal as well) resulting from application of these goals. Results will depend on inputs such as thermal loads and repository layout geometry, but not directly on the definition of repository block limits as presented herein.

Preliminary analyses, done for the vertical emplacement mode (M\&O, 1993b, Section 5.1.4), have determined possible standoffs due to meeting goals 1 and 2 . The distance to the top of the TSw3 is considered critical in meeting these goals because the TSw 3 unit is shallower (closer to the repository horizon) than the $\mathrm{CHn}$; therefore, meeting the temperature goal for TSw3 automatically satisfies the goal for $\mathrm{CHn}$. Results show the relationship between local areal power density (LAPD) and the TSw $2 / T S w 3$ contact temperature. For LAPDs above $28.2 \mathrm{~W} / \mathrm{m}^{2}(114 \mathrm{~kW} / \mathrm{acre})$, the $115^{\circ} \mathrm{C}$ goal is exceeded at the TSw2/TSw 3 contact at a distance of $60 \mathrm{~m}$ or less from the repository horizon to the contact. For LAPDs of $22.2 \mathrm{~W} / \mathrm{m}^{2}$ ( $90 \mathrm{~kW} / \mathrm{acre}$ ), the critical distance is $40 \mathrm{~m}$. The influence of repository "edge effects," which serve to reduce temperatures at the margins of an emplacement area, may lessen the impact of this criterion in certain areas of the repository. More detailed analyses, for all applicable thermal goals, are required to provide an accurate basis for actual design standoffs.

\section{E. Potential Repository Block Limits}

Repository block limits given here are not intended to preclude or constrain the use of different criteria that may be developed as the result of future studies regarding the definition of repository block limits. Conclusions on repository block limits apply only to the current conceptual repository design (ACD) and are based on currently available data. In addition, conclusions apply to a potential repository development area generally defined by the primary area but not necessarily to potential expansion areas (Section 8.2.1.5). Limits for potential repository development in the vicinity of the primary area are summarized as shown below. (Repository block limits are not necessarily listed in the order of importance; section numbers are called out for reference.)

Lateral Limits - Lateral limits are defined mainly by faults plus standoffs applied to major faults. For example, Figures 5.1.2-3, 5.1.2-4, and 5.1.5-2 show fault traces that can be used to define repository limits at given elevations. Lateral limits are also set to the extent practical by standoffs from the major faults; for example, the 60 -meter standoff from presumed Type I faults and the 120-meter standoff on the west side of the Ghost Dance fault. The area available for repository development at a given elevation would lie outside the zone established by the fault trace and the appropriate standoff. 
In addition, the 200-meter overburden requirement (Figure 5.1.1-2) results in a lateral constraint.

Upper Limits - The 200-meter overburden requirement (Section 5.1.1 and Figure 5.1.1-2) establishes an upper vertical limit for defining the usable repository block for ACD.

Within the TSw1 and TSw2, there do not appear to be zones or strata with consistent RQD having sufficient lateral continuity to define appropriate repository limits; therefore, RQD and rock classification parameters do not appear particularly useful as factors in determining repository boundaries.

In regard to lithophysal cavity density, extensive zones of high cavity content $(>10$ percent) do not occur within the TSw2. Also, the three lithophysal zones mapped within the TSw 2 rarely contain greater than 5 percent lithophysal cavity content; therefore, the TSw 2 can be treated as one unit so far as lithophysal content is concerned. The apparent presence of a zone of relatively high lithophysal cavity density in the lowermost part of the TSwl unit appears to be one of the only stratigraphic features that could be considered an upper vertical bound to repository development due to possible waste emplacement and constructibility concerns. Such conclusions are tentative and are intended only as a preliminary assessment for conceptual design (ACD). Thus, more detailed criteria in regard to opening stability, constructibility, and waste emplacement are ultimately needed to determine the limitations of this lithophysal zone as an upper boundary. A possible outcome of further investigations could be that the entire TSw 1 unit is acceptable for repository development with the only bound being that due to overburden. The current approach, however, is to regard zones of relatively high lithophysal porosity as important to design.

For $A C D$, the upper limit for repository development, excluding accesses, is considered to be determined by a standoff of $5 \mathrm{~m}$ from the base of the zone marked on Figures 5.1.2-2, 5.1.2-5, and 5.2-1. as ">10 percent." Current data are insufficient to create a structure contour map of the base of the $>10$ percent zone; however, elevations of this surface are noted on Figure 5.1.2-3. In the northern part of the primary area, this surface ranges from 24 to $49 \mathrm{~m}$ above the TSw $1 / \mathrm{TSw} 2$ contact; while at the south end, the surface is $12 \mathrm{~m}$ (USW G-3/GU-3) above the TSw1/TSw2 contact.

Additional upper limits that must be considered are defined by the application of the thermal goals (Section 8.2.1 D). Adjustments to the vertical position of the repository layout could be necessary to meet these goals.

Lower limits - Even though there are no lithophysal cavities in the TSw3 (vitrophyre), and RQD values are consistently greater than 50 percent, brittle behavior may affect development of openings in the TSw3 (Section 5.2.1.2). Thus, avoidance of the TSw3 may be prudent for reasons of ground control. No standoff is considered necessary. Since the TSw3 is very thin in places (USGS, 1984c), the underlying CHnl unit (Calico Hills) could be encountered, although this appears to be a remote possibility. The CHn I unit is of relatively low strength (Section 5.2.1.2); therefore, it is considered prudent for excavation stability to establish a minimum standoff requirement from the $\mathrm{CHn} 1$ to 
provide ground of sufficient strength and thickness. A standoff of $5 \mathrm{~m}$ is arbitrarily selected for this purpose.

A lower limit for repository development is also defined by a thermal load standoff from the TSw 3 that is yet to be determined, since the required distance depends on repository thermal load, emplacement mode, and overall repository configuration (refer to Thermal Goal Considerations above).

Additional criteria, not yet evaluated, will study the presence of perched groundwater at the top of the TSw3 unit. A hydrologic assessment is required to determine the impact of the perched groundwater condition on repository development.

\subsubsection{Rock Parameters for Mechanical Excavation}

In addition to machine characteristics, the cutting performance of a tunnel boring machine in hard rock is primarily a function of unconfined compressive strength, tensile strength, abrasivity, joint frequency or RQD, and density. Physical and mechanical data for use in the design and production estimation of mechanical excavation systems are given in RSN (1992). Compiled in this report are mineralogical, porosity, density, strength, deformability, hardness, and abrasivity data from tests on intact samples of principal rock units at Yucca Mountain. For further details on data for mechanical excavation refer to SNL (1992b), and SNL (1992a). Rock parameters for the TSw 2 unit that are important to mechanical excavation are given in Table 8.2.1-1.

As mentioned in Section 5.1.2.1, lithophysal porosity appears to be the most mappable feature of the Topopah Spring member. Bulk density and intact (non-jointed) strength are correlative with porosity and thus variations in these properties can be anticipated on the basis of porosity. TSw2 has an intact compressive strength comparable to TSw 1 ; however, the strength of the lithophysae-rich TSw1 is only about one tenth of the intact TSw2 (YMP 1994a, Section 1.1322). RQD and joint frequency, although relatively consistent for thicknesses of TSw2 as great as 60 to $90 \mathrm{~m}$ according to data in SNL (1993c, Appendix C) is not laterally predictable (Section 5.2). Quartz content is uniform throughout TSw2 except in fractures where quartz content is much higher, for example 67 percent in one case.

\subsubsection{Preferred Orientation of Drifts}

The designation of a favorable drift alignment does not mean that other alignments are not feasible, but that, based on current information, drifts are likely to be more self-supporting along certain orientations. The preferred alignment for a drift relative to steeply dipping planar structures such as joints or faults is perpendicular to the joint or fault strike (SNL, 1987a, Section 6.4.2). Likewise, the preferred alignment for a drift that crosses the intersection of a shallow joint set and a steep joint set is perpendicular to the line of intersection.

Data in Table 5.1.6-1 show a joint set with dips from 10 to 20 degrees that appears in at least three of the borings. The intersection of this low-angled set with the steeply-dipping sets forms wedges and blocks that are a worst case for drifts oriented parallel to the line of 
intersection or close to the strike of the steeply-dipping joint sets. A parallel drift/jointintersection orientation also may result in an irregular profile due to overbreak. In addition, sidewall buckling could result where thin slabs occur between vertical joints parallel to the opening, although this is not as likely with a TBM-produced circular cross section.

A drift oriented perpendicular to a zone of jointed rock encounters the least amount of potentially unstable wedges or blocks. At drift/joint angles less than $90^{\circ}$ a greater length of jointed ground will be encountered. The length of jointed ground is increased 1.4 times at $45^{\circ}, 2$ times at $30^{\circ}$, and 3 times at $20^{\circ}$. For intersections less than $20^{\circ}$ the drift length in jointed ground increases rapidly. As a preliminary criterion, the preferred drift alignment is one that makes an angle of at least $30^{\circ}$ with the dominate joint orientations.

In the case of two intersecting joint sets, the line of intersection is steep, and the optimum orientation for drifts will be close to the bisector of the larger angle between the strikes of the joint sets (SNL, 1987a, Section 6.4.2). Applying the $30^{\circ}$ standoff, the most favorable drift alignments for the joint set trends in Table 5.1.6-1 are between $N 70^{\circ} \mathrm{W}$ and $S 75^{\circ} \mathrm{W}$.

Table 8.2.1-1. Rock Parameters Important to Mechanical Excavation

\begin{tabular}{|l|l|l|l||}
\hline \multicolumn{1}{|c|}{ Parameter } & \multicolumn{1}{c|}{ Mean } & \multicolumn{1}{c|}{ Range } & \multicolumn{1}{c|}{ Source } \\
\hline \hline $\begin{array}{l}\text { Unconfined } \\
\text { compressive } \\
\text { strength }\end{array}$ & $161 \mathrm{MPa}$ & 98 to $224 \mathrm{MPa}$ & $\begin{array}{l}\text { SNL (1993d, } \\
\text { Table 3-1) }\end{array}$ \\
\hline $\begin{array}{l}\text { Tensile strength } \\
\text { RQD }\end{array}$ & $3.62 \mathrm{MPa}$ & 0.35 to $10.67 \mathrm{MPa}$ & $\begin{array}{l}\text { SNL (1993d, } \\
\text { Table 6-2, rock } \\
\text { mass values) }\end{array}$ \\
\hline $\begin{array}{l}\text { Joint frequency } \\
\text { (volumetric) }\end{array}$ & $19.64 \mathrm{~m}^{-3}$ & 16 to $84 \%$ & $\begin{array}{l}\text { SNL (1993c, } \\
\text { Table 5-9) }\end{array}$ \\
\hline Bulk density & $2.297 \mathrm{~kg}^{-3} \mathrm{~m}^{3}$ & $\begin{array}{l}2.209 \text { to } 2.385 \\
\mathrm{~kg} / \mathrm{m}^{3}\end{array}$ & $\begin{array}{l}\text { YNL (1993c, } \\
\text { Table 3-12) }\end{array}$ \\
\hline Quartz content & $33 \%$ & 29 to 38\% $\%$ 1994, item \\
\hline
\end{tabular}




\subsubsection{Joint Parameters}

Joints are abundant in the tuff rock mass at Yucca Mountain, especially in the densely welded tuff of the Topopah Spring Member (SNL, 1993c, Section 6). Since the state of stress at the proposed repository horizon is relatively low, jointing is expected to control the mode of deformation of the underground openings (Section 5.1.3). Design analysis, therefore, must consider the effect of jointing. Empirical and analytical methods, used to examine excavation stability and select rock reinforcement, require joint parameters as input. The $Q$ and RMR systems, for example, are based on such joint-related parameters as RQD (Section 5.2), number of joint sets, joint roughness, and joint alteration. Additional parameters include rock intact strength, groundwater, and stress state. Numerical codes designed to model jointing require information on joint geometry such as orientation, spacing, and continuity as well as joint strength and stiffness properties.

Sources of joint data for the TSw2 unit are SNL (1991b, Section 12.2) and SNL (1993c and 1993d). Based on these sources and borehole data from current drilling (SNL, 1993a and 1994a), the TSw2 unit is a densely welded tuff with one to three near-vertical joint sets that account for the majority of joints and one sub-horizontal joint set that occurs infrequently. The frequency of joints dipping from 60 to $90^{\circ}$ ranges from 0.19 to 24.07 joints $/ \mathrm{m}$, which corresponds to joint spacings from $5.26 \mathrm{~m}$ to $41 \mathrm{~mm}$, respectively. Joint roughness ranges from smooth and undulating to discontinuous. Fracture fillings are thin and consist of manganese oxide and calcite.

Rock classifications for the TSw2 unit are given in Table 8.2.1-2 based on the above sources. These data and preliminary RQD values from Section 5.2 indicate a highly jointed rock mass. However, joint roughness and the lack of significant fracture fillings also indicate the TSw2 unit is an interlocking rock mass.

Table 8.2.1-2. Rock Classifications for the TSw2 Unit

\begin{tabular}{||l|l|l|l|l|l||}
\hline $\begin{array}{l}\text { TSw2 Rock } \\
\text { Quality Category }\end{array}$ & \multicolumn{1}{|c|}{1} & \multicolumn{1}{|c|}{2} & \multicolumn{1}{|c||}{3} & \multicolumn{1}{|c||}{5} \\
\hline \hline RQD & $\begin{array}{l}16 \\
\text { very poor }\end{array}$ & $\begin{array}{l}26 \\
\text { poor }\end{array}$ & $\begin{array}{l}41 \\
\text { poor }\end{array}$ & $\begin{array}{l}62 \\
\text { fair }\end{array}$ & $\begin{array}{l}84 \\
\text { good }\end{array}$ \\
\hline Q & $\begin{array}{l}0.21 \\
\text { very poor }\end{array}$ & $\begin{array}{l}0.57 \\
\text { very poor }\end{array}$ & $\begin{array}{l}1.94 \\
\text { poor }\end{array}$ & $\begin{array}{l}12.30 \\
\text { good }\end{array}$ & $\begin{array}{l}64.96 \\
\text { very } \\
\text { good }\end{array}$ \\
\hline RMR & $\begin{array}{l}49 \\
\text { fair }\end{array}$ & $\begin{array}{l}57 \\
\text { fair }\end{array}$ & $\begin{array}{l}62 \\
\text { good }\end{array}$ & $\begin{array}{l}73 \\
\text { good }\end{array}$ & $\begin{array}{l}82 \\
\text { very } \\
\text { good }\end{array}$ \\
\hline
\end{tabular}




\subsubsection{Expansion of the Usable Portion of the Primary Area}

Areas to the north, west, and south of the primary repository area are identified in the SCPCDR (SNL 1987a, Chapter 8, p. 8-14, "Usable area and flexibility evaluation") as proposed expansion areas. The areas are considered potentially usable because they are geologically similar to the primary area but await further characterization. This implies that the expansion areas are in the same category as the primary area and depend on further subsurface investigation to determine ultimate acceptability.

Except for the Ghost Dance fault zone, the primary area contains relatively few faults, most of which have minor offsets (20 m or less) and rare fault breccias (SNL 1987a). The potential expansion areas also have a relatively low fault density. For example, the boundary between the primary area and the expansion area immediately to the southeast is only approximate since the two areas are considered geologically similar. Available thickness of the TSw2 is not well documented in the expansion area, but indications are a suitable TSw2 thickness exists. Thus, there do not appear to be any stratigraphic or structural constraints to preclude using the expansion areas for repository development. 


\subsection{THERMAL CONSIDERATIONS}

\subsubsection{Thermal Goals}

To obtain a license to emplace nuclear waste, a potential repository must comply with certain performance standards for both postclosure and preclosure, and meet the performance goals established in the regulations. To demonstrate compliance with regulations it must be shown with "a reasonable assurance ... that the objectives and criteria will be met" based on "accelerated tests and predictive models that are supported by such measures as field and laboratory tests, monitoring data and natural analog studies. (10 CFR 60.101(a)(2))"

Performance measures are the parameters used to determine whether the potential repository system meets regulatory criteria and objectives. Thus, these performance measures should be used in the selection of system options. However, early in the design stages it is difficult, if not impossible, to predict the complete performance of the system due to lack of mature ("validated") predictive models and adequate test data. Additionally, performance standards have not been reestablished for the Yucca Mountain site since the EPA standards in 40 CFR 191 were remanded as not applicable to the Yucca Mountain site. EPA standards for Yucca Mountain are due to be repromulgated in late 1995. Therefore it is necessary, for the present, to define surrogate or derived criteria which if met, it is believed, should result in adequate performance of the potential repository and the natural and engineered barrier systems, and which could be used to evaluate and rank thermal loading options.

The SCP (DOE, 1988) attempted to define surrogate criteria that could be used to establish performance of the potential repository. The SCP started from the regulations and defined four steps which were: (1) functions; (2) processes; (3) performance measures; and (4) performance goals and confidence. The functions step comprised four functions, derived from 10 CFR 60.133 , which it was believed would provide compliance with the regulations. The fourth function focuses on postclosure performance and was the primary basis for developing a set of thermal goals for the potential repository. This function is stated as:

"Design thermal loading taking into account performance objectives and thermomechanical response of host rock. (10 CFR 60.133 (i), 10 CFR 60.133 (e) (2), and 10 CFR 60.133 (h))" (DOE, 1988)

Based on this function, process steps were identified describing how the function will be accomplished. Performance measures were developed which identify a parameter or measurement (temperature, for example) that will be used to determine how well the process is being performed. Finally, based on the performance measures, a goal was developed which provides a performance measure value allowing the process to be favorably resolved.

The SCP thermal goals established in 1988 were developed from knowledge existing at the time and, as a reference case, emphasized performance for waste emplacement in a vertical borehole. Since that time, new knowledge (data and theories) has become available and additional analyses of thermal loading have been performed. Additionally, other emplacement modes, such as in-drift emplacement, are being considered to accommodate larger WPs. New 
concepts such as "extended hot" are also being considered as possible methods to achieve improved waste isolation. The thermal goals established in the SCP were reevaluated to address these matters.

The DOE Yucca Mountain Site Characterization Project Office authorized a two-month effort to reevaluate the SCP thermal goals. This effort, conducted between March 24, 1993, and May 31, 1993, established a working group of experts that utilized existing information and performed limited analyses as necessary.

The objectives of the effort were to: 1) provide thermal criteria that would support the FY 1993 Thermal Loading Systems Study; 2) help focus planned testing and analysis efforts; and 3 ) acquire information that potentially could be used to initiate a change to the project technical baseline. The working group was organized into five teams plus Licensing/Regulatory and Performance Assessment. The five teams were composed of members with disciplines oriented towards thermal-hydrological, thermal-geochemical, thermal-mechanical, engineered barrier, and operations and safety considerations.

Fifteen thermal goals identified in various sections of the SCP were evaluated by the Working Group. The group recommended that two goals be deleted: 1) to keep borehole wall temperature less than $275^{\circ} \mathrm{C}$ and 2) keep the mid-drift temperature less than $100^{\circ} \mathrm{C}$. They recommended adding one goal to establish a thermal loading that would not degrade the Upper Paintbrush Tuff Formation (PTn) barrier, which consists of the Lowermost Tiva Canyon, Yucca Mountain, Pah Canyon, and Uppermost Topopah Spring Members (Vitric nonwelded). Two other thermal goals and a process statement were reworded to afford compatibility with any emplacement mode, not just the vertical borehole. A recommendation was made to increase the conservatism of a goal to limit potential surface impact by limiting temperature rise at the ground surface to less than $2^{\circ} \mathrm{C}$ rather than less than $6^{\circ} \mathrm{C}$.

Additionally, and probably more important, is that based on the evaluation, additional tests and analyses were recommended to reduce the uncertainty associated with some of these goals. A synopsis of these goals is presented in Table 8.3.1-1, and the details can be found in an M\&O report (1994u). These goals have been included in the CDA document. As further analyses and more test data (site and laboratory) become available the thermal goals will be reexamined and possibly revised.

\subsubsection{Repository Thermal Loading}

A great deal of work has been performed by various program participants to analyze and develop a thermal loading strategy for Yucca Mountain. Common units of measure used by original investigators included APD, or a synonymous term, ATL to relate the average initial heat generated by WPs at the time of emplacement to the two-dimensional space (area) occupied by the WPs in the subsurface. Units were in $\mathrm{kW} / \mathrm{acre}$, defined in the most basic 


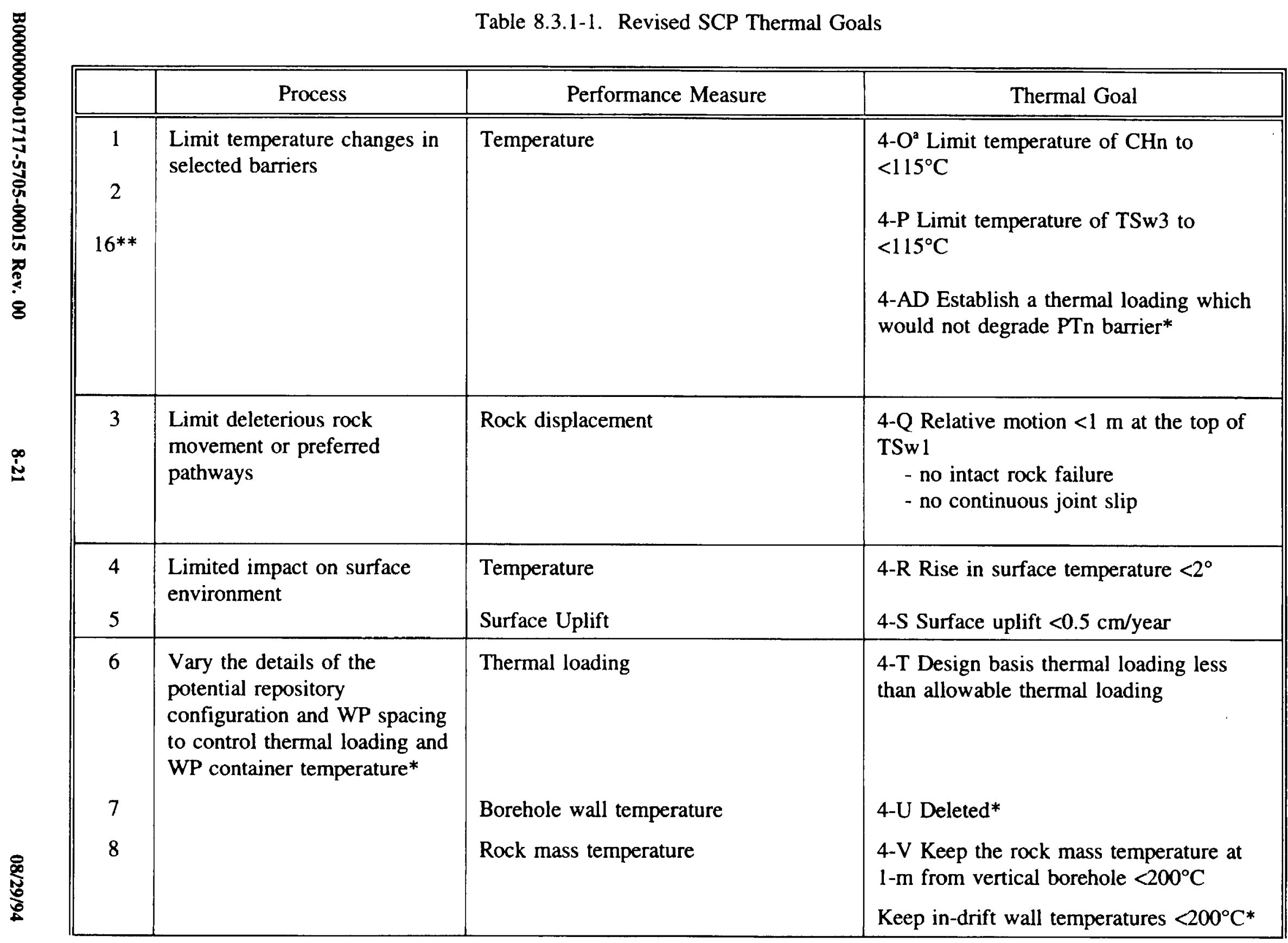


Table 8.3.1-1. Revised SCP Thermal Goals (Continued)

\begin{tabular}{|c|c|c|c|}
\hline & Process & Performance Measure & Thermal Goal \\
\hline 9 & $\begin{array}{l}\text { Limit potential for borehole } \\
\text { collapse }\end{array}$ & $\begin{array}{l}\text { Stress, deformation, factor of safety, } \\
\text { and potential rock fall }\end{array}$ & $\begin{array}{l}\text { 4-W Boreholes that do not load container } \\
\text { beyond limits imposed under Issue } 1.10\end{array}$ \\
\hline 10 & $\begin{array}{l}\text { Limit corrosiveness of } \\
\text { container } \\
\text { environment }\end{array}$ & $\begin{array}{l}\text { Time container is above boiling } \\
\text { temperature } \\
\text { of water }\end{array}$ & $\begin{array}{l}\text { 4-X Maximize the time the WP container } \\
\text { stays above boiling consistent with the } \\
\text { thermal strategy developed* }\end{array}$ \\
\hline 11 & $\begin{array}{l}\text { Limit degradation of fuel } \\
\text { matrix or cladding }\end{array}$ & Temperature & $4-Y$ Fuel cladding temperature $<350^{\circ} \mathrm{C}$ \\
\hline 12 & & Temperature & $\begin{array}{l}\text { 4- } \mathrm{Z} \text { High level radioactive waste } \\
\text { glass temperature }<500^{\circ} \mathrm{C}\end{array}$ \\
\hline 13 & Limit access drift temperature & Temperature & $\begin{array}{l}\text { 4-AA Temperature in access drift }<50^{\circ} \mathrm{C} \\
\text { for first } 50 \text { years, any emplacement } \\
\text { mode* }\end{array}$ \\
\hline 14 & $\begin{array}{l}\text { Provide for hydrologic } \\
\text { drainage }\end{array}$ & Temperature & 4-AB Delete* \\
\hline 15 & $\begin{array}{l}\text { Limit Emplacement drift } \\
\text { temperature (horizontal } \\
\text { borehole) }\end{array}$ & Temperature & $\begin{array}{l}\text { 4-AC Emplacement drift wall temperature } \\
<50^{\circ} \mathrm{C} \text { for first } 50 \text { years for horizontal } \\
\text { borehole }\end{array}$ \\
\hline
\end{tabular}

a 4-O indicates function 4 (thermal loading) and goal O. Original Table 8.3.2.2-4 of the thermal goals in the SCP went only to 4-X; the remainder of the goals from other areas of the SCP such as 1.10 were assigned a designator (e.g., 4-Z) consistent with the numbering system. * Revised from SCP Goal.

* Revised from SCP Goal 
form as the initial heat output of an individual, "average" WP divided by its area of influence in plan view. The area of influence has been referred to as the "unit cell" as shown in Figure 8.3.2-1 and is obtained by multiplying the emplacement drift spacing by the WP spacing. However, the APD/ATL approach has several shortcomings, primarily because it does not address the wide variability in the thermal characteristics of the waste stream.

The thermal output of a WP varies with time depending primarily upon its age (time out of reactor) and its burnup. Burnup varies from about 5,000 to $60,000 \mathrm{MWd} / \mathrm{MTU}$, depending upon the amount of fissile material consumed (or the amount of power produced) while the fuel was in the reactor. The majority of the heat generated by spent fuel WPs during the short-term (within 100 years out of reactor) is produced by radioactive isotopes created in the fission process. Spent fuel that was kept in a reactor for longer periods of time, i.e., higher burnup fuel, has produced more of these fission byproducts, and therefore results in higher initial heat output than spent fuel with lower burnups.

The high heat producing fission products decay in a relatively short period of time following removal from the reactor, resulting in lower package heat output with time as shown on Figure 8.3.2-2. The amount of time that spent fuel delivered to the repository has been "outof-reactor," the age, is predicted to vary from about 10 to 60 years (SNL, 1992c) based on waste emplacement beginning in the year 2010 (M\&O, 1994m).

Taking into account the two independent variables, age and burnup, together with variable MPC-based and other WP capacities ranging from approximately 3.8 to $9.0 \mathrm{MTU}$, results in initial heat outputs at the time of emplacement that could vary from about 0.5 to more than $25 \mathrm{~kW}$ per package $(\mathrm{M} \& O, 1994 \mathrm{n})$. It may be necessary to limit the maximum initial heat output of packages for transportation and disposal through methods such as derating (limiting the number of assemblies actually loaded into a canister) or aging so that thermal limits in the very-near-field are not exceeded. Repository operators will require some method or approach for spacing highly variable heat output WPs in the emplacement drifts that satisfies shortterm, near-field temperature limits as well as long-term performance goals associated with the thermal-mechanical/thermal-hydrological system.

Using a constant emplacement drift spacing, and spacing the WPs in the drift according to their initial heat output (the APD or ATL approach) would result in non-uniform thermal conditions in the repository after a relatively short period of time because of the extreme variability in the thermal decay characteristics of the waste. But predictive, long-term thermal-hydrological models require uniformity. In view of this problem and to overcome the shortcomings of the APD/ATL approach, recent work utilizes the concept of AML. Using the same unit cell definition but with units of MTU/acre, the AML method recognizes that WP heat output will be nearly the same after several hundred years for packages containing equal amounts of waste. This suggests package spacings based only on MTU content in order to provide more uniform thermal conditions over the long-term performance period. 


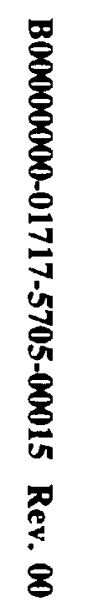

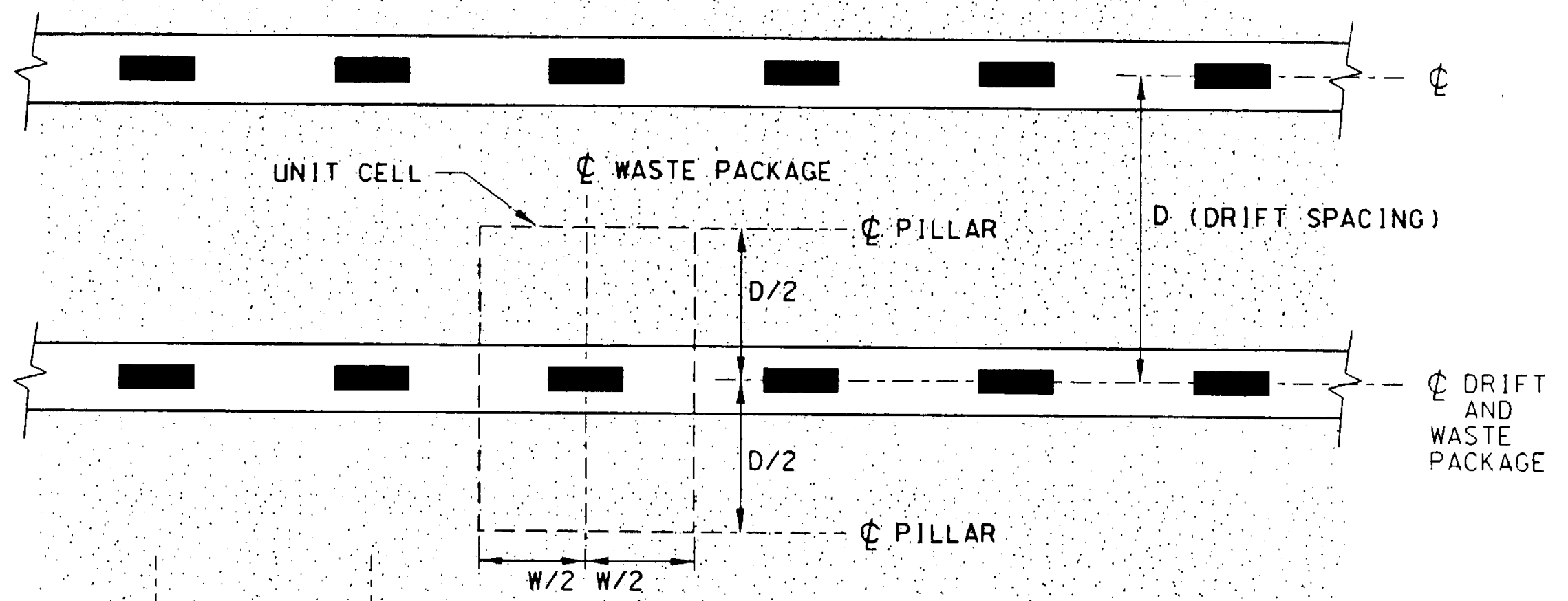

$\stackrel{\infty}{\mathscr{2}}$

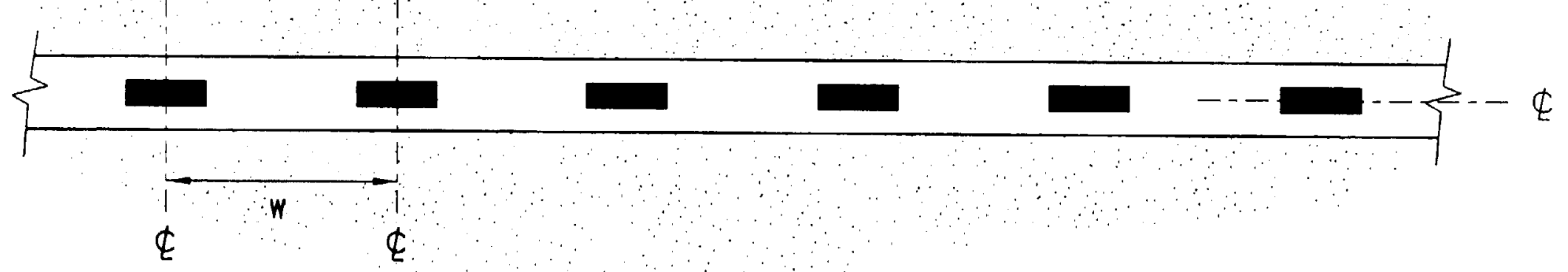

Figure 8.3.2-1. Unit Cell Concept 


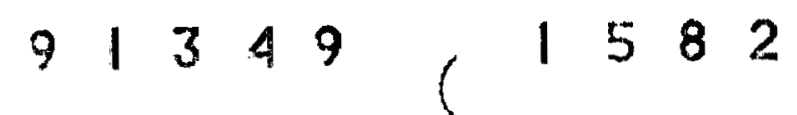

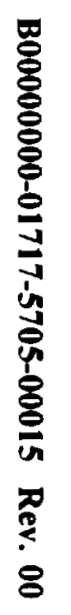

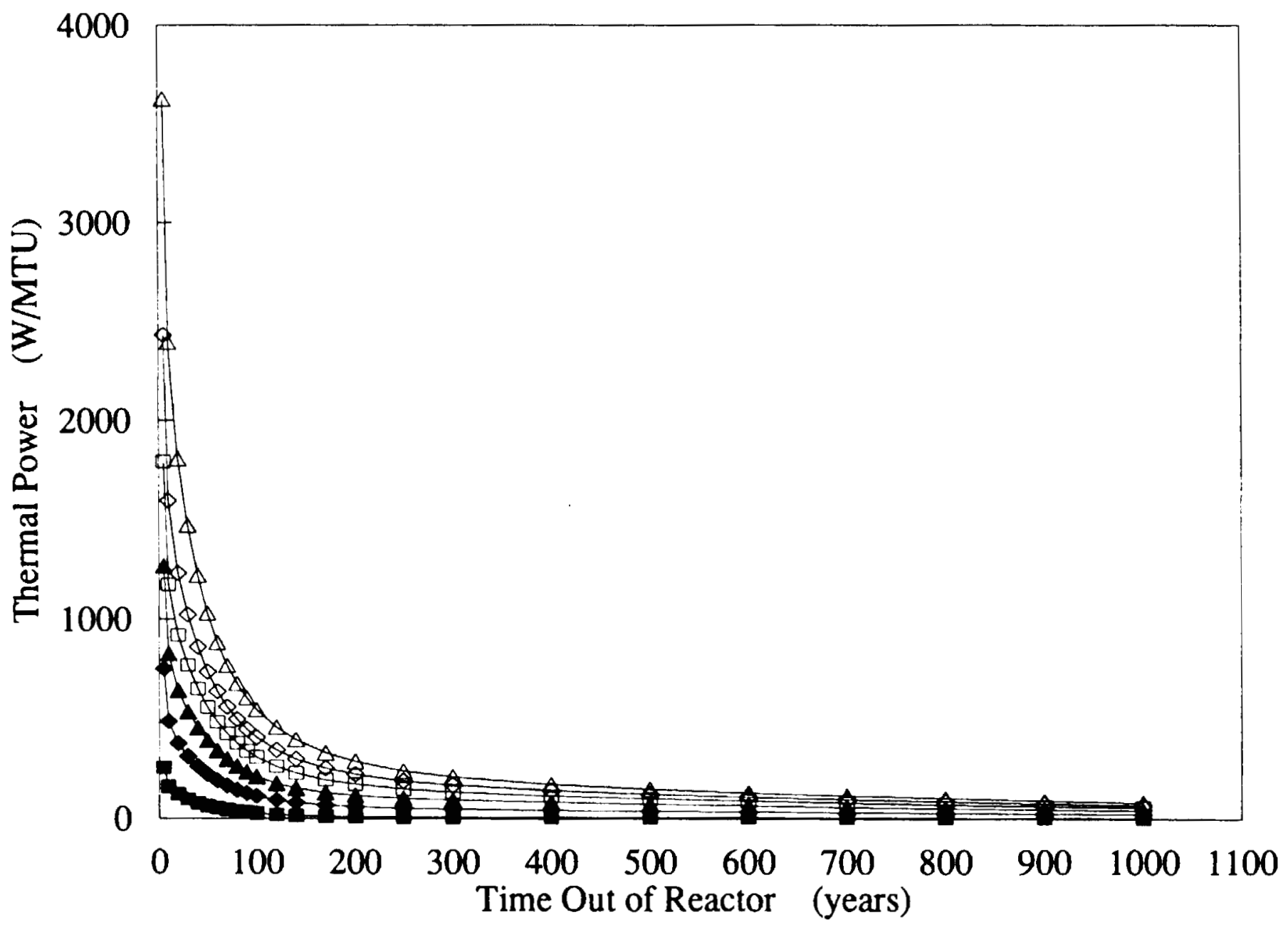

$\neg$ Bumup $=5 \mathrm{GWd} / \mathrm{MTU} \multimap$ Burnup $=15 \mathrm{GWD} / \mathrm{MTU} \multimap$ Bumup $=25 \mathrm{GWd} / \mathrm{MTU}$

$\multimap-$ Burnup $=35 \mathrm{GWd} / \mathrm{MTU} \rightarrow$ Burnup $=45 \mathrm{GWd} / \mathrm{MTU} \triangle \triangle$ Burnup $=60 \mathrm{GWd} / \mathrm{MTU}$

Thermal power is calculated based on power function for PWR SNF from Table 2, Sec. 2.1.1 of YMP (1994a)

Figure 8.3.2-2. Thermal Power Decay of Spent Nuclear Fuel 
The difficulty with the AML approach is that it does not address the short-term problem of young, and/or high burnup, high-initial-heat-output waste that might exceed near-field thermal limits if spaced the same as cooler fuel of the same MTU content. One way around this problem might be to set the emplacement drift spacing close enough to permit wider package spacings in the drifts. This method could be excessively costly (more emplacement drift required per package), and would not address potential effects associated with short-term nonuniformity in the repository thermal environment.

Another thermal loading approach is to use the total heat energy produced by a WP over given lengths of time as the "yardstick" from which package spacings can be derived. Termed the Equivalent Energy Density (EED) concept in Appendix G of the SCP-CDR (SNL, 1987a), this method promises to be a reasonable compromise between the APD/ATL and the AML approaches. A key element of concern using the EED method is the time, or "deposition period" over which the total thermal output is to be equalized. The total energy is obtained through integration and is equal to the area under the appropriate thermal decay curve (refer to Figure 8.3.2-2) over the desired deposition period.

With the EED approach, the two limiting cases with respect to time represent the APD/ATL and AML cases. In other words, if package spacings are based on the instantaneous thermal energy produced by packages at the time of emplacement, then there is no difference between results obtained using the EED method and those derived from an APD/ATL approach.

Conversely, if the total thermal energy produced over a very long period of time (for instance, 1 million years) were studied, EED results would differ very little from those obtained using the AML approach.

SNL (1992c) has evaluated different deposition periods ranging from 20 to 300 years in terms of the thermal effects at various near-and far-field points of interest. His work has indicated the importance of properly selecting a deposition period that provides acceptable compromise between short- and long-term performance goals.

Table 8.3.2-1 presents an example of WP spacings derived using the APD/ATL, the AML, and the EED approaches. The table represents a hypothetical case wherein the spacing of 21 PWR packages of differing initial heat outputs resulting from various ages and burnups are compared assuming a constant drift spacing of 22.5 meters. Package spacings derived using the EED method are provided for deposition periods of 50,100,300 and 1000 years.

Equivalency between the EED and the other methods is provided by setting package spacings equal for the case that best represents the design basis average fuel stipulated in the CDA (Key 004), a 21 PWR package (9.0 MTU) that is 22.5 years old, with $42,200 \mathrm{MWd} / \mathrm{MTU}$ burnup and an initial thermal output of $10.2 \mathrm{~kW}$. Based on this "average fuel," and an AML of $100 \mathrm{MTU} / \mathrm{acre}$, the equivalent APD/ATL would be $114 \mathrm{~kW} / \mathrm{acre}$. Given a 22.5 meter drift spacing, the spacing for this average package that will result in an AML of $100 \mathrm{MTU} / \mathrm{acre}$ or an APD/ATL of $114 \mathrm{~kW} /$ acre is 16.1 meters. Setting the EED spacing equal to 16.1 meters for this same average package, and then adjusting the EED spacings of the other, non-average packages so that their total energy contribution per unit area over various deposition periods is equal to that of the average case should provide, in theory, a more uniform thermal loading than either of the other approaches. 
The information in Table 8.3.2-1 shows a significant difference between package spacings derived using the AML approach and those obtained using the EED approach, even for the case using a 1000 year deposition period. Also notable are the trends observed in package spacings for different deposition periods when using the EED approach. WPs above the shaded line produce more thermal energy over the first 1000 years than does the "average package" represented by the shaded line. But the relative difference in energy output is more pronounced during the earlier years following disposal, which is why the EED package spacing decreases with increasing deposition periods, approaching the AML spacing as would be predicted. The two entries just below the shaded line produce more thermal energy during the first 1000 years than the average package, but because it is older waste with initial heat output that is equivalent to the average package, its thermal decay is on a flatter portion of a higher burnup decay curve, resulting in the relative difference in total thermal energy being more pronounced with increasing time, although eventually the package spacing should approach a constant value. The last two entries in the table represent packages that produce lower total thermal energy during the first 1000 years than the average package. Therefore, the package spacing increases with increasing deposition periods, approaching the AML spacing as the relative difference in total energy output decreases.

The CDA (M\&O, 1994m, Key 019) assumes two different thermal loading strategies for Yucca Mountain. One, a "hot" or "above-boiling" case is represented by higher loads in the range of 80 to $100 \mathrm{MTU} / \mathrm{acre}$. For average-age, average-burnup PWR spent fuel as defined above, this range of mass loading is equivalent to 91 to $114 \mathrm{~kW} / \mathrm{acre}$ ATL/APD at the time of emplacement. The alternative, or "low thermal load" is defined as mass loadings in the range of 25 to $35 \mathrm{MTU} / \mathrm{acre}$, equivalent to 28 to $40 \mathrm{~kW} / \mathrm{acre}$ ATL/APD at the time of emplacement for the average PWR fuel. Assuming a total inventory of 70,000 MTU (M\&O, 1994m, Key $003,005)$, the net subsurface emplacement area required for the 80 to $100 \mathrm{MTU} / \mathrm{acre}$ highloading case would be 875 to 700 acres respectively. The net emplacement area required for the 25 to $35 \mathrm{MTU} / \mathrm{acre}$ lower loading case would be 2800 to 2000 acres, far in excess of the area that can be developed within the confines of the primary area (located within Area 1 shown on Figure 8.3.2-3). According to M\&O (1993b), the net emplacement area that can be logically developed within the primary area is about 4,649,000 square meters (approximately 1150 acres). Based on the repository subsurface layouts included in that report, the primary area could accommodate only about 40 to 50 percent of the $70,000 \mathrm{MTU}$ inventory if the lower thermal load strategy is adopted, unless a facility is constructed to age the fuel prior to emplacement.

There is insufficient understanding regarding the long-term performance ramifications of higher versus lower thermal loading strategies to go forward with repository ACD using a single approach at this time. This is why the CDA has adopted the two thermal loading cases as mentioned above. This strategy is consistent with 10 CFR 60.21(c)(1)(ii)(D), which requires that alternatives to major repository features that are important to waste isolation be considered in the design of the facility. 
Table 8.3.2-1. Comparison of Waste Package Spacings Derived Using Different Loading Concepts

\begin{tabular}{|c|c|c|c|c|c|c|c|c|c|}
\hline \multicolumn{4}{|c|}{ WP Thermal Characteristics (1) } & \multicolumn{6}{|c|}{$\begin{array}{c}\text { WP Spacing in Meters } \\
\text { (Drift spacing assumed @ } 22.5 \mathrm{~m} \text { for all cases) }\end{array}$} \\
\hline \multirow{2}{*}{$\begin{array}{l}\text { Spent Fuel } \\
\text { Content } \\
\text { (MTU/pkg) }\end{array}$} & \multirow{2}{*}{$\begin{array}{l}\text { Fuel } \\
\text { Age } \\
\text { (yrs) }\end{array}$} & \multirow[b]{2}{*}{$\begin{array}{l}\text { Burnup } \\
\text { (GWd/MTU) }\end{array}$} & \multirow{2}{*}{$\begin{array}{c}\text { Initial } \\
\text { Thermal } \\
\text { Output } \\
\text { (kW/pkg) }\end{array}$} & \multirow{2}{*}{$\begin{array}{l}\text { APD/ATL } \\
\text { Concept } \\
(2)\end{array}$} & \multirow{2}{*}{$\begin{array}{c}\text { AML } \\
\text { Concept } \\
\text { (3) }\end{array}$} & \multicolumn{4}{|c|}{$\begin{array}{l}\text { EED Concept Using Various } \\
\text { Deposition Periods (4) }\end{array}$} \\
\hline & & & & & & $\begin{array}{l}50 \\
\text { yrs }\end{array}$ & $\begin{array}{l}100 \\
\text { yrs }\end{array}$ & $\begin{array}{l}300 \\
\text { yrs }\end{array}$ & $\begin{array}{c}1000 \\
\text { yrs }\end{array}$ \\
\hline 9.0 & 10 & 45 & 14.2 & 22.4 & 16.1 & 20.8 & 19.9 & 19.2 & 18.3 \\
\hline 9.0 & 20 & 55 & 14.2 & 22.4 & 16.1 & 22.0 & 21.6 & 21.3 & 20.5 \\
\hline 9.0 & 20 & 42 & 10.2 & 16.1 & 16.1 & 16.1 & 16.1 & 16.1 & 16.1 \\
\hline 9.0 & 30 & 49 & 10.2 & 16.1 & 16.1 & 16.5 & 16.6 & 17.2 & 17.4 \\
\hline 9.0 & 40 & 57 & 10.2 & 16.1 & 16.1 & 16.9 & 17.2 & 18.2 & 18.8 \\
\hline 9.0 & 40 & 25 & 4.0 & 6.3 & 16.1 & 6.8 & 6.8 & 7.5 & 8.6 \\
\hline 9.0 & 60 & 33 & 4.0 & 6.3 & 16.1 & 7.2 & 7.4 & 8.9 & 10.2 \\
\hline
\end{tabular}

(1) Approximate values for various 21 PWR MPC WPs.

(2) Package spacing to achieve $114 \mathrm{~kW} /$ acre based on initial thermal output.

(3) Package spacing to achieve $100 \mathrm{MTU} / \mathrm{acre}$ based on $9.0 \mathrm{MTU} / \mathrm{pkg}$.

(4) Total energy was calculated based on the thermal decay function listed in Table 2, Section 2.1.1 of YMP (1994a).

(5) Shading indicates thermal characteristics most closely conforming to design basis average fuel, and is used as a reference or datum from which EED spacings for non-average fuel is derived by proportioning to maintain equivalent total energy per unit area. 


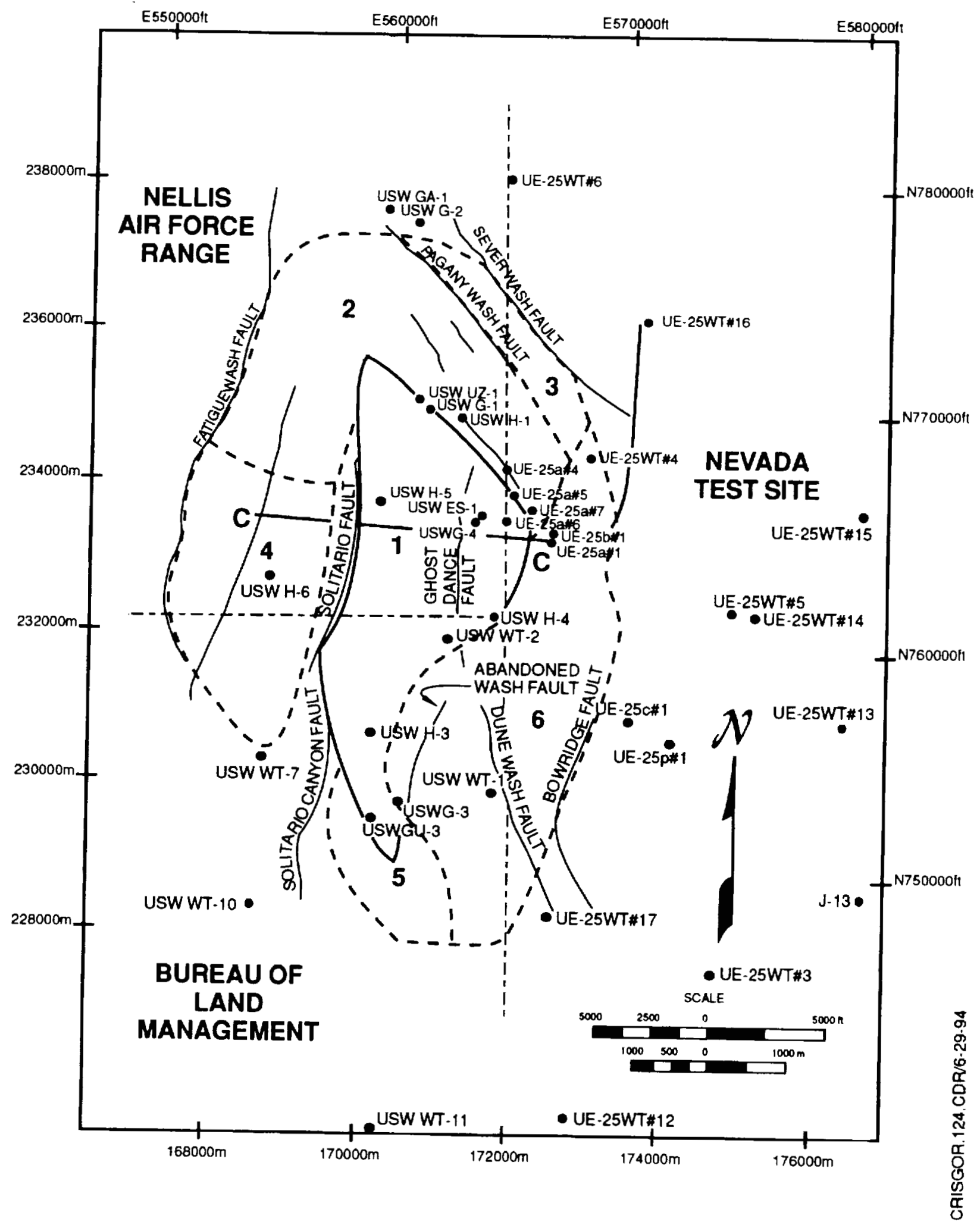

Figure 8.3.2-3. Potentially Usable Repository Areas Identified in SCP 
The following are several general observations hypothesized at this time:

A. If a higher thermal load strategy is adopted, the heat emitted by the WPs can be considered as a resource to aid in maintaining an extended low-humidity, elevated temperature environment in the vicinity of the packages to inhibit corrosion. This philosophy suggests that it may be desirable to "manage" the thermal environment during the operational period by moving the packages closer together prior to repository closure, i.e., after they have aged sufficiently to permit higher loadings without overshooting near-field temperature limits. Conceptual design of emplacement methods should recognize this potential need and be designed with sufficient flexibility to facilitate repositioning of the packages in the emplacement drift.

B. One key to accommodating higher loadings is to maintain a close enough emplacement drift spacing so that geometric considerations such as package length do not limit the loading to a value lower than what might otherwise be desirable. It is not suggested that emplacement drift spacing be set so close that the openings and pillars might be regarded as potentially unstable, but that the closest spacing judged to be stable over the long term be given ample consideration. Other factors being equal, the more closely spaced drifts permit emplacement of higher initial heat output packages because package spacings inside the drift increase with decreasing drift spacing. This may be an important factor in determining the maximum initial heat output package that can be accommodated, i.e., it may set a higher value for derating.

C. It is both unnecessary and impractical to vary emplacement drift spacing in order to achieve a particular thermal loading strategy. To do so will limit flexibility with regard to potential changes that might be considered during operations such as repositioning of packages to facilitate extended dryout or other thermal management decisions. It could also complicate development operational systems such as those that utilize a service platform concept as described in Section 8.7.7.1.

D. Thermal evaluations performed by LLNL (1994b) for a hot repository suggest that it may be desirable to vary the emplacement density so that higher thermal loads exist at the edges of the emplacement area (relative to the center) in order to mitigate effects associated with edge cooling.

E. In order to ensure wide enough spacings for the higher thermal energy packages and to permit close enough spacings for cooler packages that might otherwise be limited by their physical length (for in-drift emplacement), the preferred method is to intermingle packages of different waste types, quantities, and thermal characteristics in the emplacement drifts. A sizeable lag storage facility may be required, but the blending thus facilitated will tend to reduce the average package spacing, resulting in lower development costs (less emplacement drift required per package), while helping to establish a more uniform thermal environment across the repository.

F. The CDA (M\&O, 1994m, Key 020) assumes that a final decision regarding thermal loading will not be confirmed until sometime during repository operations. But most likely the drift spacing preferred for a higher thermal load repository is very different 
than that judged suitable for a lower thermal load repository, i.e., if close drift spacings are warranted for a high-loading case, then it would not be logical to use the same drift spacing for a low-loading case because the package spacing for much of the waste would exceed the drift spacing. However, the delayed decision may require that, initially, drifts are excavated at the high-loading spacing, but only every other drift is actually emplaced with waste in order to simulate a low-loading thermal environment. This would be very costly, but would maintain the requirement stipulating separation of emplacement and development ventilation systems (10 CFR $60.133(\mathrm{~g})(3))$, besides avoiding interference between the two very different operations if they were attempted in close proximity of one another.

G. Calculation of the total emplacement area required as a function of thermal loading, whether based on an AML approach (total MTU inventory divided by allowable MTU/acre) or an APD approach (total initial heat output of the inventory in $\mathrm{kW}$ divided by allowable initial $\mathrm{kW} / \mathrm{acre}$ ), can be somewhat misleading because of difficulties associated with determination of appropriate thermal characteristics for the "average package." Past work has used the thermal characteristics of an assumed average package in various thermal analyses directed toward derivation of upper limits for both the high and the low thermal loading scenarios. Peak temperatures reached within the first 100 years after emplacement, at various near-field points of interest, tended to limit the upper range of allowable thermal density. Obviously, if the "average package" used in these calculations is not truly representative of the entire inventory, then the derived thermal loadings and resultant area requirements are incorrect. The EED approach provides a better method for determination of both the "average package" and the total area requirements. The average package can be defined from the average total thermal energy output of an individual waste package over an appropriate deposition period, calculated by dividing the total thermal energy output of the entire inventory during the deposition period by the total number of packages. Total emplacement area requirements can be derived by dividing the allowable energy density (determined by converting the results of thermal analyses performed for the "average package" used in past work to an allowable EED) into the total thermal energy output of the entire inventory during an appropriate deposition period. If the average package (21 PWR, 22.5-year old, $42.2 \mathrm{GWd} / \mathrm{MTU}$ burnup) used in most percent calculations is actually "hotter" than what a truly average package would be, then chances are that the total emplacement area required calculated using the EED approach will be somewhat smaller than that calculated using other methods.

H. Regardless of the thermal load that is determined to be appropriate for Yucca Mountain, it is important to adopt an approach toward derivation of WP spacing that is consistent between various investigators and that addresses the entire range of potential WP thermal characteristics. This is necessary in order to support efforts geared toward determination of an appropriate emplacement drift spacing that provides the necessary flexibility to accommodate the range of package variability over a range of thermal loads. Closer emplacement drift spacings tend to widen individual package spacings for a given thermal load, which, while potentially more costly, may be necessary in order to achieve some of the higher loadings currently under consideration in the program. The wider package spacings should help mitigate 
thermal "spikes" caused by packages that generate more thermal energy than the average case, while helping to eliminate conditions in which the cooler-than-average packages cannot be spaced close enough to achieve a desired loading due to physical, geometric constraints. The EED approach promises to provide results that will maintain compliance with thermal limits while providing a more uniform thermal environment.

\subsubsection{Standoff of WPs from Access Drifts}

Defined as the distance that WPs are set back from the nearest accessway, a thermal buffer, or "standoff distance" is desirable in order to limit the maximum rock temperature in the access drift. This is considered important in terms of both the working environment in the access drift and the influence that elevated temperatures might have on the stability of the drift. While few studies have been performed to determine appropriate standoffs as a function of thermal loading, past repository layouts, such as in the SCP (DOE, 1988), have allowed adequate standoff to limit the access drift wall temperature to less than $50^{\circ} \mathrm{C}$ for the first 50 years after waste emplacement.

Table 8.3.3-1 is derived from various sources as indicated therein and summarizes standoff distances for both the vertical and horizontal waste emplacement modes as defined in the SCP. The standoff for the vertical emplacement cases is the distance from the centerline of the closest emplacement borehole to the panel access drift wall, whereas for the horizontal emplacement cases, it is the distance from the end of the closest WP to the wall of the emplacement drift. Based on the data shown, standoff distances for vertical emplacement range between 28 and 34 meters for thermal loadings of approximately 17.3 to $23.0 \mathrm{~W} / \mathrm{m}^{2}$ (70 to $93 \mathrm{~kW} /$ acre). Standoff distances for horizontal emplacement are 33 to 41 meters for loadings of approximately $17.3 \mathrm{~W} / \mathrm{m}^{2}(70 \mathrm{~kW} /$ acre $)$. 
Table 8.3.3-1. Summary of Drift Standoff Distance for Vertical and Horizontal Emplacement

\begin{tabular}{|c|c|c|c|c|c|c|c|c|c|}
\hline $\begin{array}{l}\text { Empl. } \\
\text { Mode }\end{array}$ & $\begin{array}{c}\text { Initial } \\
\text { Heat } \\
\text { Output } \\
\text { (kW/pkg) }\end{array}$ & $\begin{array}{c}\text { Waste } \\
\text { Age } \\
\text { (yr) }\end{array}$ & $\begin{array}{l}\text { LAPD } \\
\left(\mathrm{W} / \mathrm{m}^{2}\right)\end{array}$ & $\begin{array}{l}\text { Borehole } \\
\text { Dia. } \\
\text { (cm) }\end{array}$ & $\begin{array}{l}\text { Drift } \\
\text { Wdth. } \\
\text { (m) }\end{array}$ & $\begin{array}{c}\text { Borehole } \\
\text { Spacing } \\
\text { (m) }\end{array}$ & $\begin{array}{l}\text { Drift } \\
\text { Spacing } \\
\text { (m) }\end{array}$ & $\begin{array}{c}\text { Stand } \\
\text { off } \\
(\mathrm{m}) .\end{array}$ & Ref \\
\hline vert. & 3.0 & 10 & $\sim 17$ & 74 & 4.9 & 4.6 & 38.4 & 28 & 1 \\
\hline vert. & 3.0 & 10 & $\sim 19$ & 71 & - & 4.9 & 32.6 & 34 & 2 \\
\hline vert. & $2-4$ & 10 & $19-23$ & 74 & - & $2.9-6.9$ & 30 & 30 & 3 \\
\hline hori. & 3.0 & 10 & -17 & 94 & 7.0 & 20.7 & 228 & 41 & 1 \\
\hline hori. & 3.0 & 10 & $\sim 17$ & 79 & - & 33 & - & 35 & 2 \\
\hline hori. $^{b}$ & $6-12^{\mathrm{c}}$ & 10 & $20-26$ & 94 & - & $7.2-18.2$ & 65 & $35^{\mathrm{s}}$ & 3 \\
\hline hori. & - & 10 & $\sim 17$ & 84 & 5.5 & 31 & - & 33 & 4 \\
\hline
\end{tabular}

Notes:

a) Standoff refers to the panel access drift for vertical emplacement and to the emplacement drift for horizontal emplacement, unless otherwise noted. Only spent fuel is considered.

b) Short horizontal emplacement.

c) Total borehole loading.

d) This value is for panel access drift.

References:

1-DOE, 1988

2-SNL, 1985a

3-SNL, 1991c

4-SNL, 1987b 
Studies have not been conducted to evaluate standoff distances for thermal loads of less than $17.3 \mathrm{~W} / \mathrm{m}^{2}(70 \mathrm{~kW} / \mathrm{acre})$ or higher than $24.7 \mathrm{~W} / \mathrm{m}^{2}(100 \mathrm{~kW} / \mathrm{acre})$. However, it appears that standoff distances for loadings of 5 to $28.2 \mathrm{~W} / \mathrm{m}^{2}$ (20 to $114 \mathrm{~kW} /$ acre) may remain in the same range, within approximately 10 meters deviation for different WP and drift spacings.

To date, standoff distances for in-drift emplacement have not been evaluated. Since the temperature distribution around an emplacement drift is similar for both the vertical and the in-drift emplacement modes, it may be expected that standoff distances for both of these modes will also be similar. However, it must be pointed out that the studies mentioned above did not consider the cooling effect of ventilation air in the access drifts (panel accesses or mains, as applicable to the layout) and most used smaller packages containing younger waste. Future work should consider ventilated access drifts as results could differ significantly from the unventilated case.

In addition to limiting rock temperatures in the access drift, the standoff also serves as a radiation buffer between packages emplaced in the open emplacement drift and personnel working in the access drift, supplementing the shielding afforded by a radiation door or other fixture situated across the end of the emplacement drift. While it is generally accepted that radiation dose rates fall off as a function of the square of the distance from the source, detailed analyses need to be performed to confirm the actual dose level at the ends of the emplacement drift.

For purposes of this initial report, a standoff distance of $35 \mathrm{~m}$ is used (refer to Figure 8.3.3-1), and is considered conservative in recognition of the fact that previous analyses did not consider the cooling effect of ventilation air in the access drift.

\subsubsection{Thermal and Hydrothermal Models}

A number of different organizations are involved in thermal analyses and have developed a number of codes. The following is a partial list of groups involved in thermal modeling for the YMP:

- Buscheck and Nitao (LLNL), using V-TOUGH

- Pruess and Tsang (LBL), using TOUGH2

- Ryder (SNL), using COYOTE and an analytical solution package

- Mishra, Reeves and Lingineni (M\&O), using V-TOUGH, TOUGH2 AND FEHM

- Bahney (M\&O), using ANSYS.

The word code refers to a numerical program for solving partial differential equations describing heat and/or fluid flow, whereas the word model refers to the application of a code to a specific problem.

A brief synopsis of the contributions of the various groups is as follows:

Pruess and Tsang (of LBL) have developed repository-scale radial ( $\mathrm{r}-\mathrm{z}$ ) and Cartesian (x-z) coordinate models for coupled heat and fluid flow which are TOUGH and TOUGH2. 


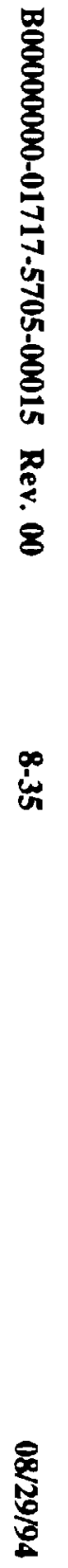
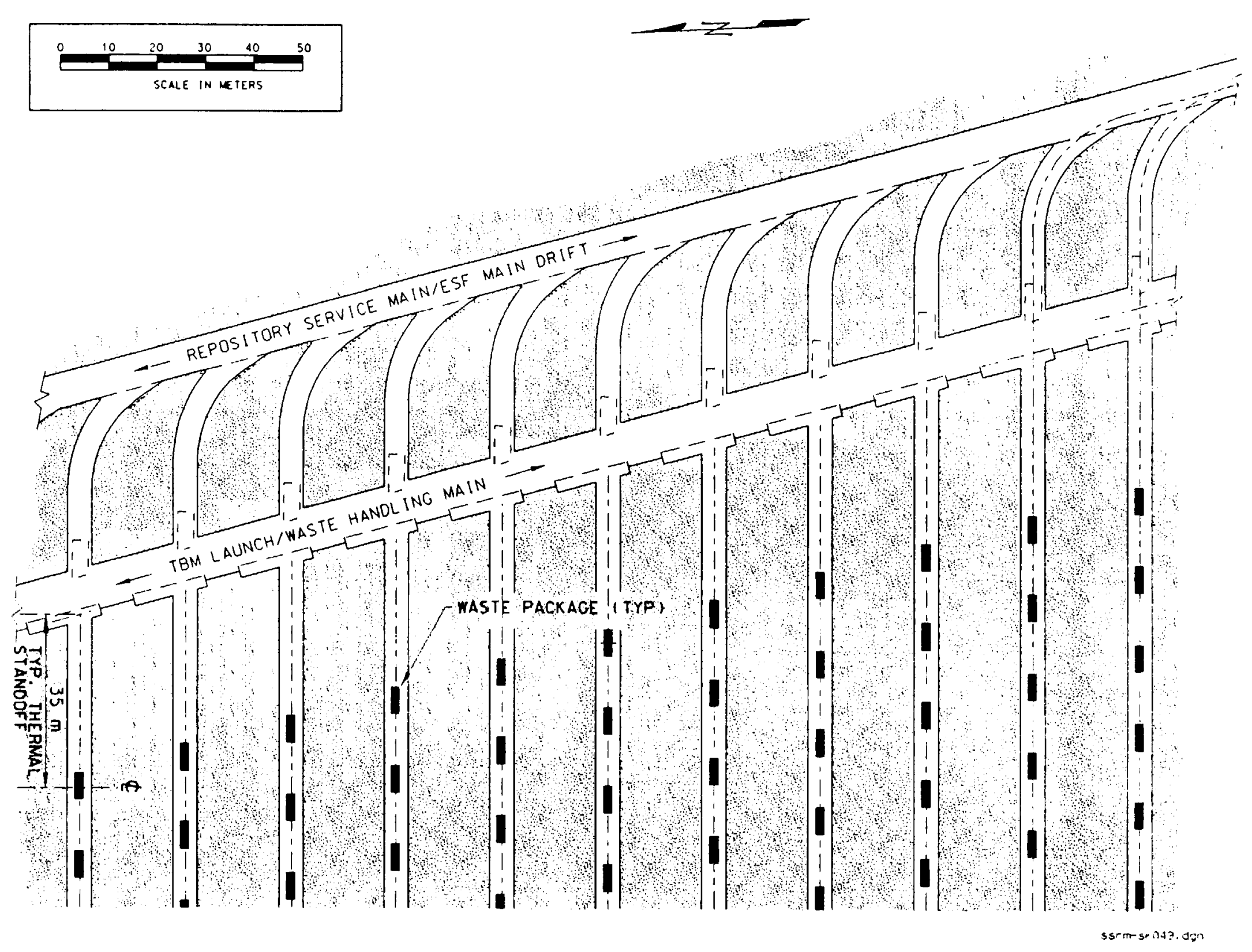

Figure 8.3.3-1. Thermal Standoff from Waste Handling Main Drift 
They have also performed some scoping calculations to address the issues of heterogeneity and spatial variability.

Buscheck and Nitao (of LLNL) have developed several 2-D axisymmetric ( $r-z$ ) models to simulate repository-scale coupled heat and fluid flow which is the V-TOUGH code. They have also developed some two-dimensional, cross-section $(x-z)$ models to simulate heat and fluid flow at the drift-scale, and also to provide pre-test predictions for thermal tests.

Ryder (of SNL) has developed several models of heat flow (conduction-only calculations) incorporating the three-dimensional emplacement geometry of individual canisters.

Mishra (of M\&O-PA) developed a panel-scale $r-z$ model of coupled heat and fluid flow to predict temperature and saturation distributions for the M\&O's TSPA-1993 calculations. Reeves and Lingineni (of M\&O-PA) are developing models of coupled heat and fluid flow at the WP/drift scale for improving the representation of the near-field thermohydrologic environment in the next iteration of the TSPA.

Bahney (of M\&O-WP) has implemented heat flow models to predict temperatures within the emplacement drift and inside the WPs.

The codes described above broadly fall into two groups:

- TOUGH2, V-TOUGH and FEHM can simulate coupled heat and fluid flow

- COYOTE and ANSYS are limited to heat transfer calculations.

V-TOUGH was developed from TOUGH, the predecessor of TOUGH2. All three codes are based on the integrated finite difference formulation and essentially have the same capabilities in terms of process modeling. FEHM is based on the finite element method and can model virtually all of the processes included in the TOUGH-family of codes.

COYOTE is a finite-difference and ANSYS a finite-element code for modeling heat transfer processes, and have similar capabilities.

A comparison of TOUGH2 and FEHM (and similar codes) is presented in a recent report by the M\&O (1994k). Note that TOUGH2 is currently being used at LBL to develop the threedimensional site-scale unsaturated zone flow model (groundwater only), and FEHM is planned for use at LANL to develop the three-dimensional site-scale unsaturated zone transport model (groundwater and radionulides).

A thermal model comparison exercise was done in 1993 on the hydrothermal models. The main finding from this comparative exercise was that the repository-scale $r-z$ models of Buscheck and Nitao and Pruess and Tsang, as well as the panel-scale model of Mishra, produce very similar results. This was not surprising in view of the fact the input parameters to the various models were mostly similar (based on SNL, 1986), the codes were similar (TOUGH family), and all models used the equivalent continuum assumption (fractures and matrix lumped into an equivalent medium). 
A comparison of the heat conduction codes COYOTE and ANSYS was done informally in 1994. The results showed a reasonably good comparison once input parameters were standardized.

The main difference between the various analyses is from the interpretation of model results, i.e., in generalizing the repository-scale results to near-field conditions and in assuming the validity of the equivalent continuum and other simplifying assumptions. The role of nonequilibrium fracture flow, rock heterogeneity, spatial variability in thermal loading, ambient infiltration, etc., in affecting the predictions of simpler models have recently been discussed in the LBL report by Pruess and Tsang (1994).

There are limits to the applicability of computationally convenient, equivalent-continuum based, repository-scale, two-dimensional axisymmetric models of heat and fluid flow at Yucca Mountain. It is possible that these limits may have already been reached--particularly in view of the schedule for site suitability determination in the Proposed Program Approach.

Assuming heater test results may not be available in the time frame of interest (and in any case, they could be inconclusive), there is an urgent need to carefully design the next generation of numerical analyses addressing thermohydrologic performance.

\subsubsection{Opening Stability}

Assessment of opening stability depends on estimates of thermal loads, but must also include determination of in situ loads and seismic loads since the effect on repository structures depends on combinations of the three load types. Of the three load types the greatest uncertainty is associated with thermally induced stress since the prediction of magnitude, distribution, and effects of thermal stress depend mainly on numerical methods of analysis. In contrast, for in situ and seismic loads, empirical methods can often provide sufficient basis for design.

In the following, stability of subsurface openings at Yucca Mountain is reviewed with regard to the potential for surface subsidence, emplacement drift behavior, and the behavior of accesses, namely ramps and shafts.

\subsubsection{Extraction Ratio Considerations}

A simple means to estimate pillar loads and evaluate subsidence of the ground surface is the "tributary area" approach which uses the concept of "extraction ratio" (Brady and Brown, 1985, Chap. 3; Bieniawski, 1984, Chap. 9). The approach is applied to the analysis of rectangular pillars in a mining layout subjected mainly to in situ overburden load. This method is overly conservative for repository design and should be followed up by more detailed analysis, however, it provides a preliminary assessment of rock mass stability for different emplacement drift spacings.

Basically, the ratio of excavated volume to total volume of a mineral deposit is defined as "volumetric extraction ratio." If the system of openings is mainly horizontal in extent, the ratio is "areal extraction ratio" (or simply "extraction ratio") and is equal to the excavated area (in plan view) divided by the total area considered. Average pillar stress for an 
essentially rectangular system of underground openings can be expressed as a function of extraction ratio and in situ vertical stress. The larger the extraction ratio the greater the pillar stress. When pillar stress exceeds pillar strength, pillar failure will occur, which in some circumstances may cause subsidence of the ground surface.

To limit the potential for subsidence in WP emplacement areas, extraction ratios of less than 30 percent for vertical emplacement and less than 10 percent for horizontal emplacement have been recommended as design goals according to Section 8.3.2.2 of the SCP (DOE, 1988).

For other areas, such as shop and support areas, these limits are not applied. For the in-drift emplacement concept assumed in the current repository $\mathrm{ACD}$, the maximum extraction ratio for openings in the emplacement drift area is assumed to be 30 percent (M\&O, 1994m, DCSS-006 ). Pillar stability in the emplacement area is enhanced by not exceeding this extraction ratio since the induced pillar stress remains quite small compared with the strength of the rock (the TSw2 unit) at the repository location. In addition, the potential for surface subsidence is minimized with a 30 percent extraction ratio and a typical overburden depth of $300 \mathrm{~m}$.

\subsubsection{Drift Stability}

The response of emplacement drifts at Yucca Mountain subjected to combined in situ and thermal loads has been examined in preliminary analyses by SNL (1987b) for horizontal and vertical emplacement modes. In general, thermally induced stress, caused by the heat output of emplaced WPs at the repository horizon, has been found to cause a pronounced increase in compressive stress in the roof and floor of an emplacement drift and may produce tensile stress in the drift sidewalls. The analyses indicated general stability despite areas of overstressed rock and joint movement.

The effects of thermal loading on ground support have been examined by SNL (1991b) who studied emplacement drift stability and ground support for the SCP-CDR (SNL, 1987a) layout (vertical emplacement). Results are given for a range of ground conditions for combined in situ, seismic, and thermal loads. In the analysis, criteria could not be met for maximum compressive strain for poorer rock types and tensile strength for better rock types. In addition, evaluation of rockbolt and shotcrete stresses shows that allowable stresses for these components are exceeded in most cases. Indications are that shotcrete may not by suitable for emplacement drifts, and alternative support systems, such as rockbolts and mesh, should be considered.

Drift stability has also been examined for in-drift emplacement in a study by SNL (1992d). The study uses the following inputs and assumptions: (1) local areal power density (LAPD) of $24.7 \mathrm{~W} / \mathrm{m}^{2}$, (2) WPs containing 21 PWR assemblies using 30 year old fuel with an average burnup of $33 \mathrm{GWd} / \mathrm{MTU}$, (3) emplacement drifts with a diameter of $7.92 \mathrm{~m}$ on $30.5 \mathrm{~m}$ centers with an extraction ratio of $26 \%$, and (4) an in situ horizontal stress assumed to be 0.5 times the vertical stress.

Results of the SNL study (1992d) show that the maximum tangential stress after excavation ranges from 17 to $22 \mathrm{MPa}$ for rock mass categories (RMC) of 1 (extremely poor), 3 (poor), and 5 (good). However, after 75 years of waste emplacement the maximum stress 
reaches 79 to $90 \mathrm{MPa}$, considerably greater than the excavation-induced stress. Figure 8.3.5-1 shows the stress distribution around the opening for an LAPD of $24.7 \mathrm{~W} / \mathrm{m}^{2}$ and an RMC of 3. The increase in stress in the roof and floor as well as the change of stress state in the sidewall from compression to tension due to the thermal loading can be seen in the figure. However, no intact rock failure was predicted for any of the three rock mass categories used in the analysis. Although areas of potential joint slip occur around the drift, predicted magnitudes of slip are small and general instability is not indicated. Results also indicate that vertical joint apertures above and below the drifts close significantly with the application of thermal load to the rock mass.

The burnup and age of the fuel used in the SNL study (1992d) are not the same as stated in the CDA (M\&O, 1994m, Key 004) - 22-year-old average fuel with a $42.2 \mathrm{GWd} / \mathrm{MTU}$ burnup - but the general behavior of the openings predicted by the study is expected to be similar for the same thermal loading. In addition, since the size of the emplacement drift $(5 \mathrm{~m})$ and extraction ratio ( 22 percent) for the current repository ACD study are smaller than those used by SNL (1992d), the current ACD emplacement drift is expected to be stable both after excavation and after waste has been emplaced for thermal loadings up to $24.7 \mathrm{~W} / \mathrm{m}^{2}$. For thermal loads greater than $24.7 \mathrm{~W} / \mathrm{m}^{2}$, no thermomechanical studies have been performed.

If drift cooling is necessary, such as rapid cooling for retrieval (see Section 8.12.5), ventilation effects on drift stability are expected to be more pronounced for in-drift emplacement than for vertical and horizontal emplacement, especially for the larger WPs with high thermal outputs that are now being considered. Since larger and hotter WPs are considered for in-drift emplacement, a larger quantity of ventilation air will be necessary to cool an emplacement drift. Consideration should be given to the effect of thermal gradients that may be produced during rapid cooling.

\subsubsection{Shaft and Ramp Stability}

Shafts and ramps are located at the periphery of emplacement areas at locations where thermally-induced stress and displacement are expected to be lower than in emplacement areas. As a consequence of their locations, there is less potential for thermally-induced instability of these accesses. Preliminary information on rock behavior around repository shafts and ramps subjected to thermal loading is provided in the work by SNL (1987b), SNL (1991b), and SNL (1990). General conclusions from these studies regarding shafts and ramps are:

- Thermally-induced horizontal stress is greatest at the repository horizon and immediately adjacent to the emplacement area

- Thermally-induced stress rapidly decays away from the emplacement area, however, standoff should be considered to maintain low thermal loads at shaft locations

- There is little potential for the development of new fractures in the rock mass 
- There is potential for joint activation in the vicinity of openings, however, regions of joint activation are localized at the roof and sidewalls.

Recent studies by Bonabian (M\&O, 1994j) regarding ESF North Ramp design estimate low thermal loads for the North Ramp during a repository operational life of 100 years. No failure is predicted and loads are small relative to strength for ground support consisting of rock bolts and shotcrete. Current ESF design philosophy anticipates the installation of additional support to accommodate changes in repository thermal loading.

\subsection{EXCAVATION METHODS AND EQUIPMENT}

Early repository conceptual design studies, including SNL (1984a) and the SCP-CDR (SNL, 1987a), focused on the use of traditional drill/blast techniques for repository emplacement drift and panel access drift excavation. In the SCP-CDR, the use of mechanical excavation techniques (the TBM) was limited to the main access ramps and drifts and the perimeter ventilation drifts. Comments and concerns expressed by the U.S. Nuclear Regulatory Commission (NRC, 1989), the Nuclear Waste Technical Review Board (NWTRB, 1990), regarding the large-scale use of drill/blast excavation concepts resulted in a programmatic shift toward emphasizing the use of mechanical excavation techniques for practically all areas of repository subsurface design.

Comments and concerns expressed regarding the use of drill/blast techniques included:

- Excess fracturing of the wall rock could potentially produce pathways for radionuclide migration.

- Blasting by-products could compromise long-term repository performance.

- Opening stability could be compromised, necessitating more extensive ground support measures and increased opening maintenance requirements.

- Potentially, greater excavation productivity could be achieved using mechanical excavation techniques such as the TBM.

The ESF Alternatives Study was undertaken in 1989 (SNL, 1991a) and evaluated numerous, integrated ESF/potential repository layouts, including options that emphasized mechanical over drill/blast methods. The selected option from that study proposed the use of TBMs for the majority of ESF and repository development and was used as a basis for preparing a revised ESF Title I Design Summary Report (YMP, 1993g). This report included ESF/Repository interface drawings that were based on the use of TBMs for the excavation of all subsurface openings except for shafts (drill/blast) and minor support and testing/training facility development (unspecified mechanical excavation).

This report section discusses primary excavation methods, as well as several smaller-scale, secondary techniques that are available for minor excavations. A distinction is made between primary and secondary methods, and the suitability of various methods or machines in either a primary or secondary mode is addressed. More in-depth descriptions for most methods, 
along with diagrams and figures, may be found in SNL (1992b). Performance predictions in Yucca Mountain tuff formations targeted for potential repository development can be found in SNL (1992b) and SNL (1992a).

\subsubsection{Primary Method}

For repository design, the TBM is considered to be the preferred, primary method of excavation because of its potential for excavating large or small diameter openings at advance rates far in excess of those attainable using other excavation methods in the relatively high strength rock typical of the TSw2 thermomechanical unit, and because these machines produce relatively smooth excavated surfaces with minimal rock damage.

Compared with drill-and-blast methods, flexibility for development of alternative subsurface layouts using TBM designs produced by most major manufacturers is limited because of the machine and backup system's inability to make sharp or short-radius turns, and because of difficulties associated with moving the TBM intact from one location to another.

Tunnel boring machines, by nature of design, excavate fixed diameter circular openings. This can be considered a potential disadvantage of using TBMs in cases where the primary operating functions that a subsurface opening must accommodate may not be efficiently suited to the circular cross-section produced. In some instances, portions of an opening excavated using a TBM may have to be enlarged, or otherwise modified for the intended purpose. For example, the floor of a 7.6 meter diameter opening excavated using a TBM may require up to one meter of fill to create the same operational envelope available in the 6.7 meter high by 5 meter wide vertical emplacement openings included in the SCP conceptual design. In this example, the TBM opening would produce approximately one-third more excavated rock to handle and dispose of compared to the custom shaped rectangular opening.

However, the benefits of using a TBM for the development of a repository at Yucca Mountain far outweigh any potential disadvantages. Various advantages of using this excavation system are summarized as follows:

- Minimized wall rock fracturing or damage

- Elimination of blasting by-products which could impair waste isolation performance

- Circular shaped opening is optimal in terms of long-term stability

- Potential for higher productivity/lower unit costs substantially enhanced when compared to any other large-scale excavation method in the TSw2 unit.

\subsubsection{Tunnel Boring Machine Excavation Method}

In hard rock excavation, the TBM system consists of several key components that, together, form a unique excavation method. The main component is the TBM, a robust machine that weighs, for instance, an estimated 635 tonnes in the case of the 7.62 meter diameter machine recently manufactured for the YMP site characterization program. Each TBM is built to the 
diameter of the tunnel for which it was originally intended; major modification is necessary to change its diameter and can only be considered in small increments relative to the original diameter of the machine.

Hard rock TBMs function by thrusting a rotating, full-face, circular cutterhead against the rock surface in the direction of opening advance. The cutterhead is outfitted with disc-type cutters appropriate for breaking the material to be excavated. The thrust necessary for loading the cutters to the level necessary to effect rock breakage is supplied by hydraulic propel cylinders, one end of which is attached to the cutterhead support; the other end is attached to a set of grippers. The grippers are located some distance back from the cutterhead support and function by using large, radial acting hydraulic cylinders to press two or more gripper pads, or shoes, against the excavated surfaces of the opening. The total force generated by the grippers is on the order of two to three times the total exerted by the propel cylinders. The resistance to sliding friction which is generated between the gripper shoe and the rock surface is what anchors the machine to react to the propelling thrust necessary to advance the cutters a slight distance into the rock face. The length of a TBM, in proportion to its diameter, varies according to its design and/or manufacturer, but is usually on the order of one to three tunnel diameters.

Behind the TBM, and pulled along by it, is a string of decks called, interchangeably, the "trailing floor," "trailing gear," "gantry," "backup system," or simply, "backup." These decks provide space for materials and supplies offloading and storage, house various pieces of support equipment such as the electrical transformers, and serve as the muck handling interface between the TBM and whatever system is used to transport the muck to the surface. These backup systems can be on the order of 100 meters or more in length, depending upon the various operational functions they are required to support.

Another major equipment component in a TBM excavation system is the muck removal or handling system. Continuous conveyor systems are gaining acceptance in the commercial market, but their use has been limited to straight tunnels or those with long radius curves. The alternative, and more commonly used method, has been muck train setups, where an underground locomotive is used to move trains of two to four muck cars into and out of the subsurface or to a shaft.

The final major system component, the service system, includes the equipment used to transport various elements of ground support (rock bolts, ring steel, lagging, etc.), TBM lubrication supplies and replacement parts, utilities piping, electrical supplies and equipment, ventilation ductwork and fans, rail and ties, personnel, etc., into the tunnel. Rail-based transport cars are used more or less universally to supply TBM headings whenever possible as rail lends itself to the delivery of a large volume of material using a single locomotive as the prime mover. In tunnels using precast concrete segments for full-circle support, or in the invert to form a stable or wider roadway, special rail cars are usually fabricated to transport the segments, forming a major portion of the overall materials transport equipment fleet.

Figure 8.4.1-1 is an artist's rendition of the 7.62 meter diameter TBM and backup purchased for the site characterization program at Yucca Mountain. 


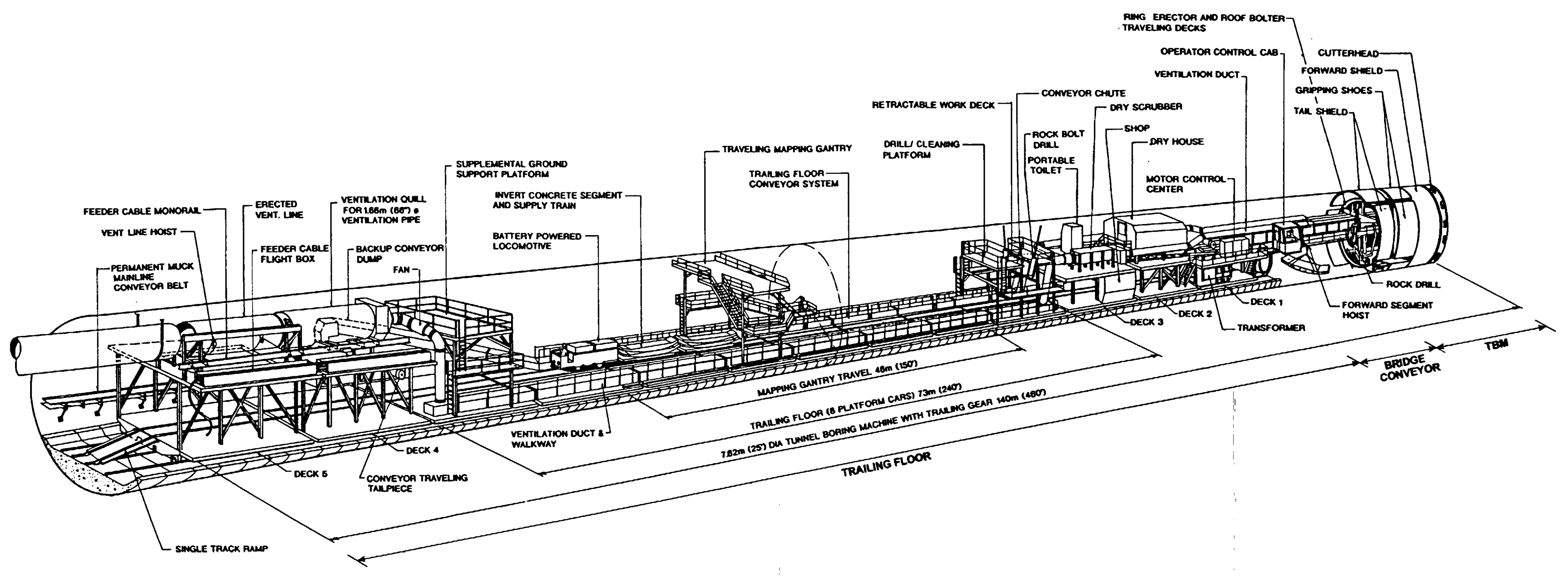

TUMAEL BOAING MACHIME WITH TRALLING GEAR AND MAPPING GANTAY

YUCCA MOUNTAIN PROUECT

Figure 8.4.1-1

Three Dimensional Sketch of CTS Tunnel Boring Machine With Trailing Gear 
The Robbins Co. of Kent, Washington, has developed a small diameter TBM with a portable launch mechanism called the "Borpac." This machine uses pneumatic packers as grippers and is designed for small diameter applications (approximately 2 meters or less) where clearances are inadequate for conventional TBM operating systems to function.

\subsubsection{Secondary Methods}

\subsubsection{Excavation by Roadheader or Roadheader Variations}

Early designs of roadheaders for underground applications were of relatively lightweight construction, and as a consequence, were only applicable to softer rock conditions of approximately $70 \mathrm{MPa}$ unconfined compressive strength (UCS) or less. To increase the possible range of application, the weight and power of these machines was increased, and boom designs were changed in an effort to economically cut the higher strength rocks. Longcantilever soft rock booms used in-line "milling" (spiral auger) heads, and a boom mounted cutter motor as a load carrying member. These were replaced for harder rock formations with stiff, heavy-duty, cylinder supported booms outfitted with transverse "ripper" cutting heads and the practice of using the motor as a load carrying member was eliminated. Machines of this design (refer to Figure 8.4.2-1) are now considered to be capable of economically cutting some rock formations in the 60 to $100 \mathrm{MPa}$ UCS range (Whittaker, 1990) and, in some cases, as high as $130 \mathrm{MPa}$ UCS (Kogelmann, 1992).

The degree of fracturing in the rock formation is an important factor in determining the applicability of roadheaders. More fracturing in the rock formation can enhance cutting performance. For rock formations above $150 \mathrm{MPa}$ UCS, successful excavation cannot be guaranteed (Whittaker, 1990). Presently, carbide-tipped picks are considered to be one of the limiting factors for rock cutting, although special picks tipped with carbide and diamonds have cut rocks up to plus $200 \mathrm{MPa}$ UCS (Kogelmann, 1992, and Whittaker, 1990). It should be pointed out however, that while the higher strength rocks may have been cut on a limited basis in various research and development type tests, many roadheaders have failed when used to excavate in the harder, $100 \mathrm{MPa}$ plus rock types on a day-in, day-out basis.

Table 8.4.2-1 presents basic geomechanical data for the TSw2 thermomechanical unit. Unconfined compressive strength data are from drill holes USW A-1, USW G-1, USW G-2, USW GU-3, and USW G-4, as listed in SNL (1993d, p. B-2), as well as RIB data (YMP, 1994a, R3, Section 1.1322). Some published strength values are from tests on saturated samples (SNL, 1984d), which may underestimate the strength of the in-situ rock. Ranges of the degree of fracturing are also presented, based upon data presented in SNL, (1993c, pp. 23 and D-6) for the same drill holes, both per linear meter of core and as a function of unit volume of rock. Prudence must be exercised when applying the referenced data to roadheader suitability, as the strengths and fracturing indicated may not be fully representative of the materials which may be encountered during excavation. 


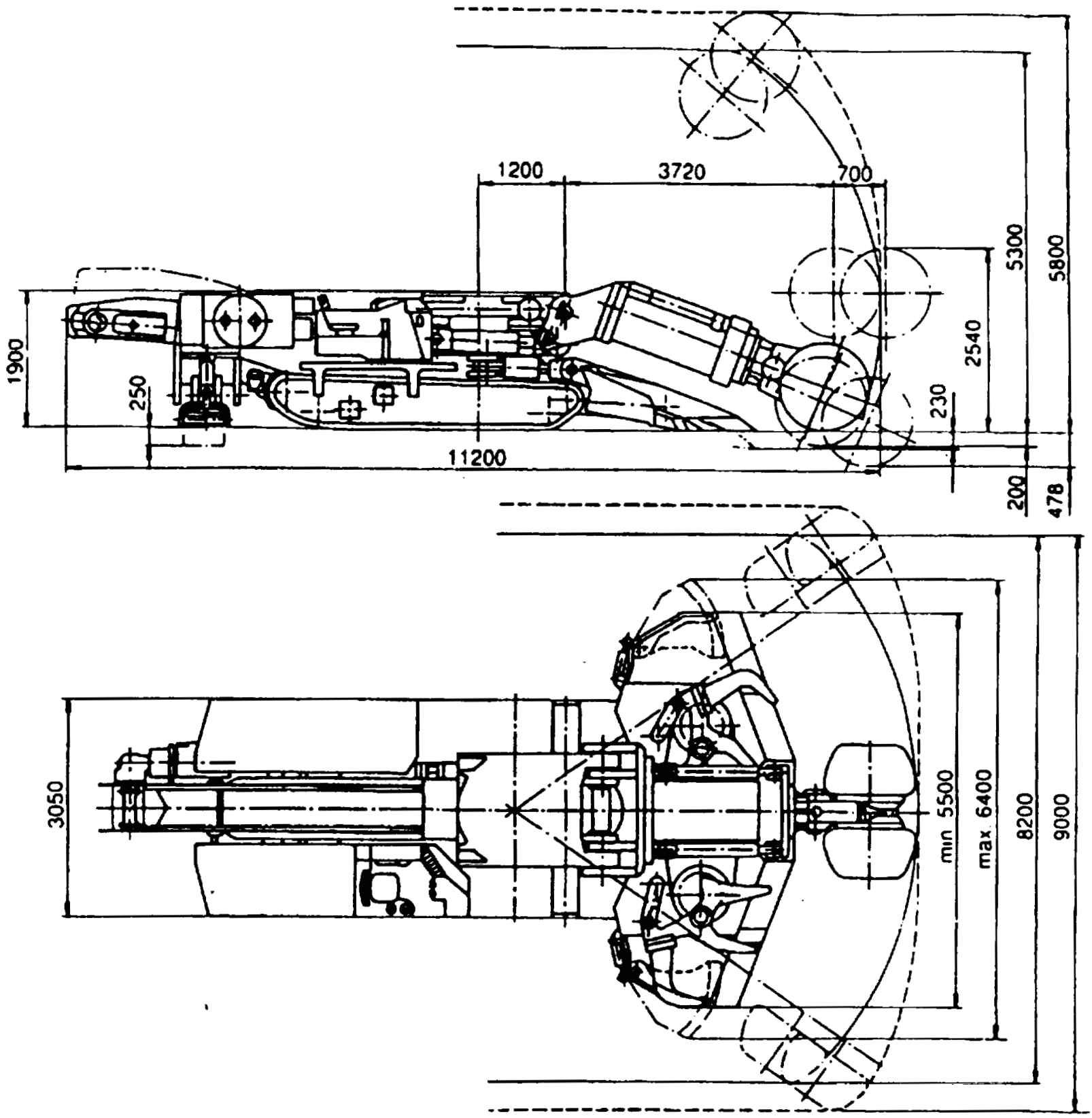

Figure 8.4.2-1. AM-105 Roadheader 
Table 8.4.2-1. Unconfined Compressive Strength and Fracture Data

\begin{tabular}{|c|c|c|c|c|}
\hline & $\begin{array}{c}\text { SNL (1993d) } \\
\text { Unconfined } \\
\text { Compressive } \\
\text { T/M Unit }\end{array}$ & $\begin{array}{c}\text { RIB } \\
\text { Strength Ranges } \\
\text { Unconfined } \\
\text { Compressive } \\
\text { Strength Ranges } \\
(\mathrm{MPa})\end{array}$ & $\begin{array}{c}\text { Linear Fracture } \\
\text { Frequency } \\
\text { Ranges } \\
\text { (per meter) }\end{array}$ & $\begin{array}{c}\text { Volumetric Fracture } \\
\text { Frequency Ranges } \\
\text { (per cu. meter) }\end{array}$ \\
\hline \hline Range & $12-326$ & Not Listed & $1.7-5.7$ & $5.4-40.6$ \\
\hline $\begin{array}{c}\text { Mean/ } \\
\text { Std. Dev. }\end{array}$ & $161 \pm 63$ & $155 \pm 59$ & 3.0 & 19.6 \\
\hline
\end{tabular}

From examination of Table 8.4.2-1, portions of the TSw2 unit appear to be in the range of suitable application of roadheaders; however, "average" strength material is above the range where successful excavation of the material can be guaranteed. Based upon predictions of roadheader performance previously made for the TSw 2 unit, it is currently considered that the TSw2 unit would require a machine with capabilities that are at the edge of, or go beyond, current roadheader technology, and that low productivities and associated high costs would result (SNL, 1992b). The degree of fracturing within the formation may help extend the limits of practical applicability somewhat.

Specific testing on fully representative samples of all types of TSw2 material that could be encountered during repository construction is required to make an actual determination of roadheader suitability. At the present time, a standard, heavy-duty commercial roadheader is not considered to be suitable for use as a production (primary excavation) machine, but may be useful as a tool for secondary excavations (SNL, 1992a, p. 4-31).

A promising development is underway at the Colorado School of Mines (CSM) research facility that may result in secondary, mechanical excavation tools that are useful for repository development and that are targeted toward cutting the higher strength rocks typical of the TSw2 unit. The CSM researchers (Friant et al., 1993) have designed and tested a small diameter $(127 \mathrm{~mm})$ disc-type cutter as shown on Figure 8.4.2-2. The "mini-disc" cutters have been installed and tested on a small diameter $(813 \mathrm{~mm})$ cutting head that functions like a TBM cutterhead. Designs for larger cutterheads, on the order of 1500-2000 mm diameter, have also been developed. For these designs, the mini-disc cutters would be mounted on the face and sides of the rotating head to permit cutting in both a sumping mode and in a slewing mode.

A conceptual design has also been developed by CSM for an "alcove miner" that can be transported on a railcar and set up to excavate alcoves of various dimensions starting from a 7.6 meter diameter drift. The alcove miner would be outfitted with the mini-disk cutterhead and is designed to excavate to a depth sufficient to provide a starter cut for a heavy-duty roadheader, allowing the roadheader to work without blocking traffic in the larger, 7.6 meter diameter opening and providing anchoring positions for the roadheader's stabilizing jacks. 


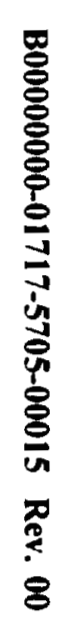

$\underset{\infty}{\infty}$

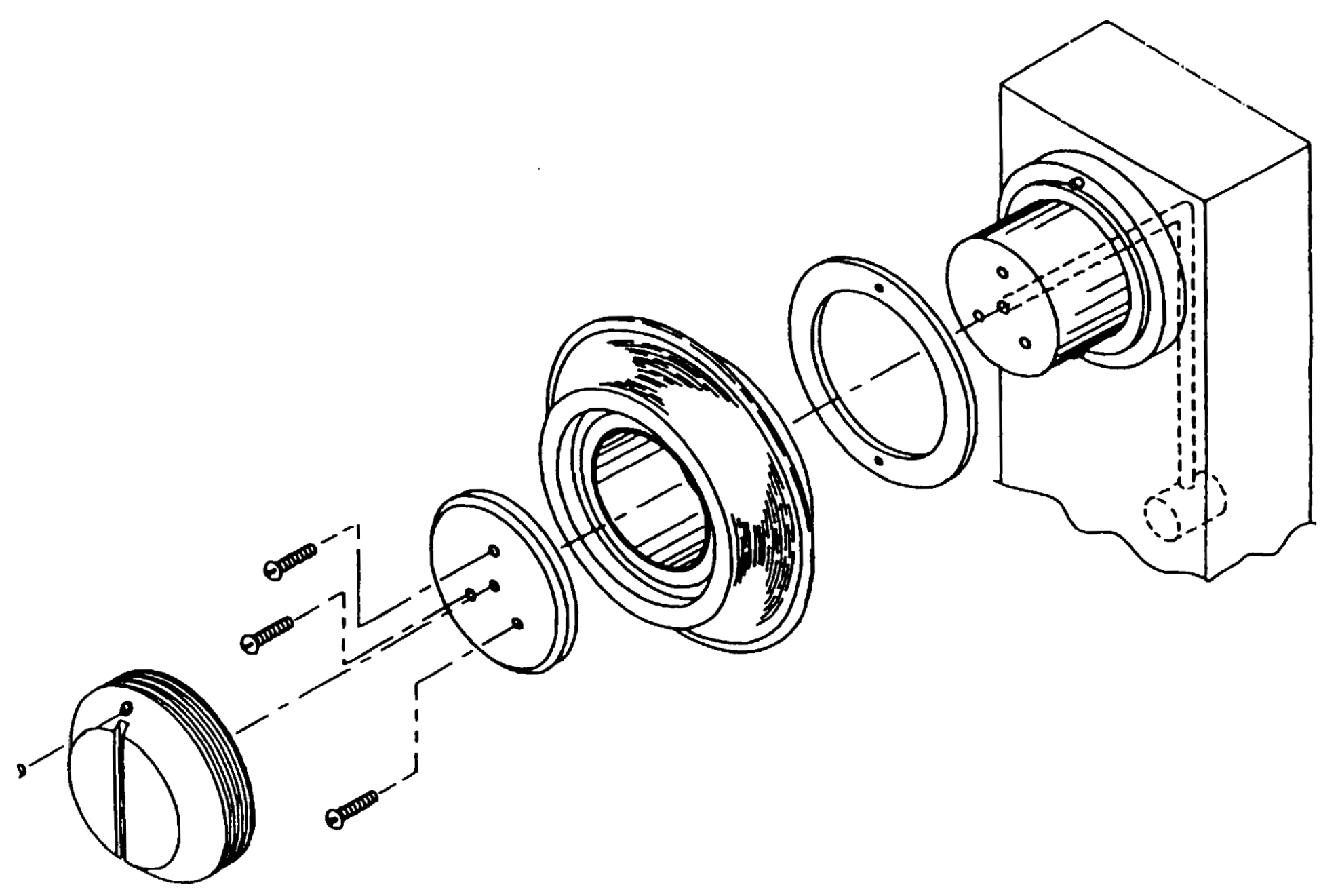

递

Figure 8.4.2-2. Colorado School of Mines Small Diameter (127 mm) Minidisc Cutter 
Preliminary designs for adapting the mini-disc cutter to a roadheader cutting head are also being investigated (Rostami, et al., 1993); results so far look promising. The CSM work is being performed in support of, and under a contract funded by, the YMP.

\subsubsection{Excavation by Mobile Miner}

The Mobile Miner (Figure 8.4.2-3) is a relatively new mechanical excavator developed by the Robbins Company for both soft and hard rock formations. The Mobile Miner consists of a heavy, tracked carrier with a massive cutter boom to which a rotating cutting wheel is attached. The cutting wheel rotational axis is perpendicular to both the main axis of the machine and the direction of heading advance. The boom moves up and down and from side to side while the cutter wheel rotates. The cutting wheel is equipped with a single row of cutters around its perimeter. It is the only machine currently available, other than a roadheader, that can mechanically excavate rectangular shaped openings in rock. It can also produce a pseudo-arched profile by incorporating a different cutting boom configuration.

The Mobile Miner is a partial-face cutting machine (compared to a TBM which is a full-face machine), and because of this, it cannot match TBM production rates (SNL, 1992b, p. 1-2). The nominal minimum opening size for the smallest available machine is $3.5 \mathrm{~m}$ by $3.5 \mathrm{~m}$ (12 $\mathrm{m}^{2}$ ). The Mobile Miner's size and weight limit mobility and make its use questionable as a machine for secondary excavation.

\subsubsection{Excavation by Boring Machines Other Than TBMs}

Some boring machines use rock fragmentation techniques similar to a TBM, but they differ in their method of applying thrust to the cutting head. The TBM advances its thrust reaction point (the grippers) along the drift as it advances; other boring machines thrust from a fixed reaction point, and are therefore limited in terms of the horizontal distance they can bore. Another distinction is that operating personnel usually work within the TBM opening during excavation, while personnel are not normally inside of an opening being excavated by a nonTBM boring machine. (An exception is the V-mole discussed below.)

Boring machines other than a TBM might be applied to repository construction in the following ways:

- Shaft development using raise boring, or pilot boring with down-hole reaming

- Horizontal long boreholes (small diameter) for emplacement of low heat output WPs

- Vertical boreholes for emplacement of low heat output WPs

- Short ventilation cross-cuts or raises. 


\section{$913496\left(\begin{array}{lllll}1 & 6 & 0 & 7\end{array}\right.$}

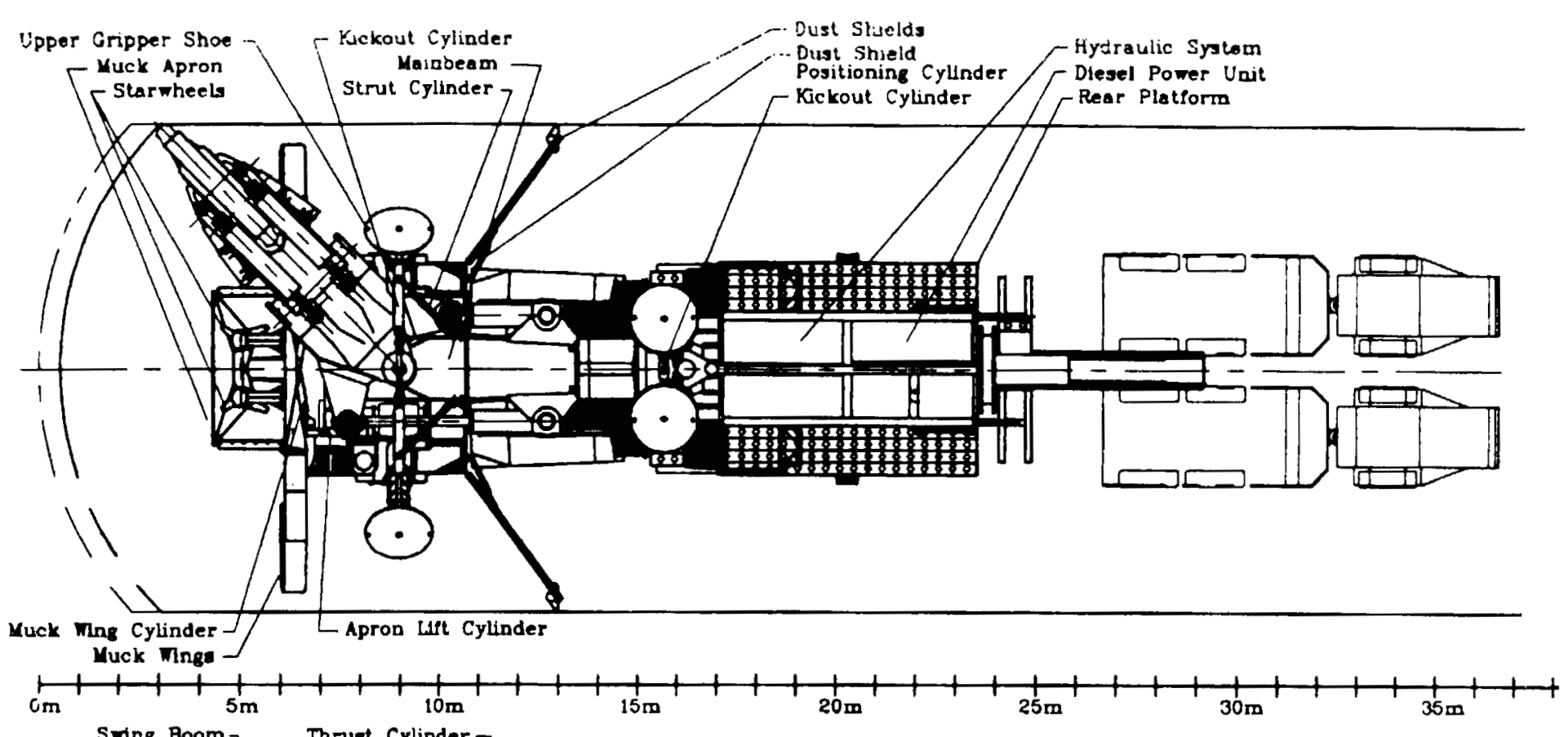

近

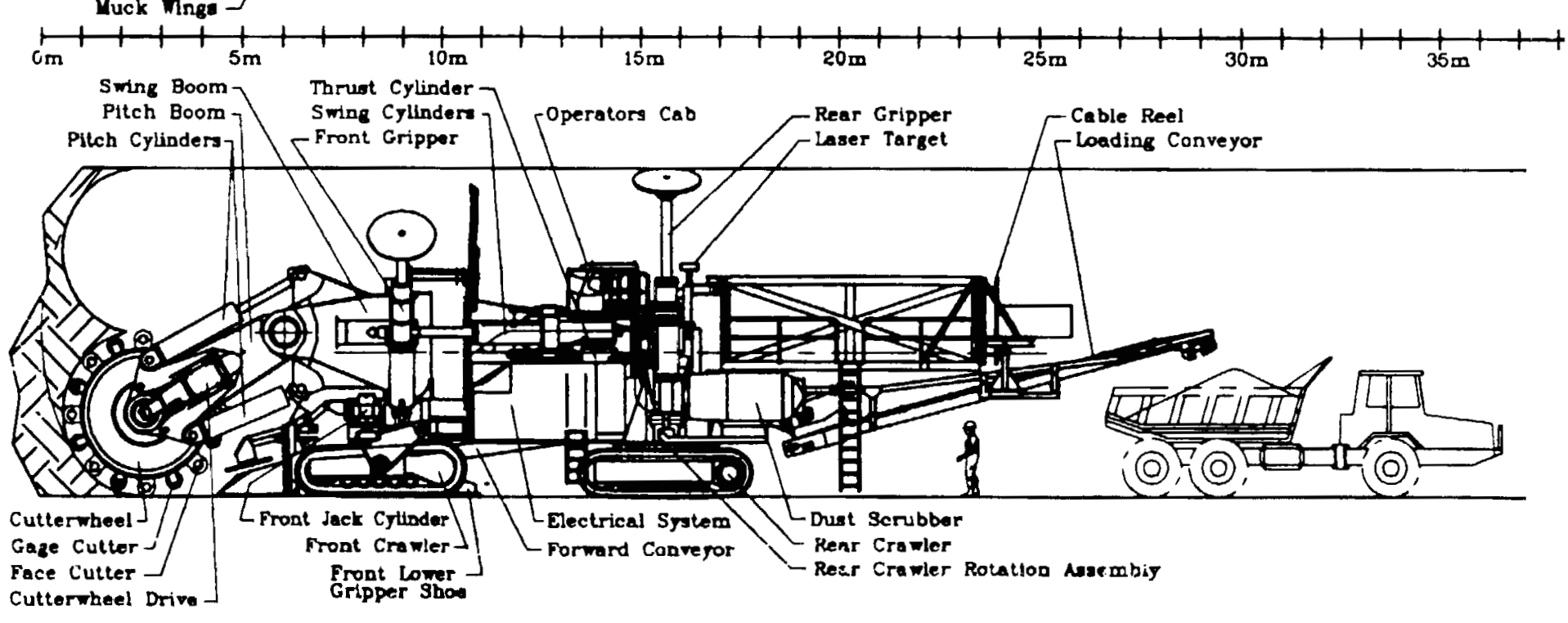

Figure 8.4.2-3. Mobile Miner Developed by U.S. Robbins Company 
Two other types of boring machines that may be usable at the repository include:

- A conventional type boring machine where the cutting head receives its thrust in the direction of advance through a string of steel drill pipe extending from a vehicle or thrusting device blocked into the access opening.

- A "raise boring" or back-reaming type machine where the cutting head receives its thrust through a string of steel drill pipe pulled through a previously drilled pilot hole.

A third type of boring machine that operates vertically but employs gripping/thrusting features similar to a TBM is the V-mole, as shown on Figure 8.4.2-4. The V-mole is a machine that is considered potentially applicable at Yucca mountain for repository shaft construction (M\&O, 1993a, p. 6-4). However, given the emphasis on minimizing the introduction of water into the repository during construction and limited historical success in dry muck removal from blind shaft boring operations, use of the V-mole in a pilot bore and ream shaft construction mode is considered to be most viable. In this mode a pilot bore would be constructed with a raise boring machine as discussed above, and the V-mole would ream the pilot bore to the full shaft diameter. Cuttings would drop down the pilot bore during shaft reaming.

Several other shaft reaming machines, which in principle operate similarly to the $\mathrm{V}$-mole, are also considered applicable if shaft diameters do not exceed approximately 6 to $7 \mathrm{~m}$ (M\&O, 1993a, p. 5-98). These machines use a drill string to provide vertical and in some cases circular movement in the shaft.

\subsubsection{Minor Excavations Using Other Methods}

While mechanized excavation will undoubtedly retain favor as the preferred, principal repository excavation method, there is still the possibility that specific applications will favor the drill/blast technique because of its flexibility and its suitability in creating custom excavation shapes or profiles. Some potential applications of the drill/blast method include:

- Invert excavation to obtain a squared off floor

- TBM launch chambers

- Specific test room alcoves

- Sub-surface shops and utility room alcoves

- Excavation of raises

- Excavation of shaft sumps.

The state-of-the-art using controlled blasting has developed to a point that allows the excavation of fairly precise openings with little wall rock damage. Such methods use closely spaced, accurately drilled holes in a pattern that reduces wall rock damaging fractures. 


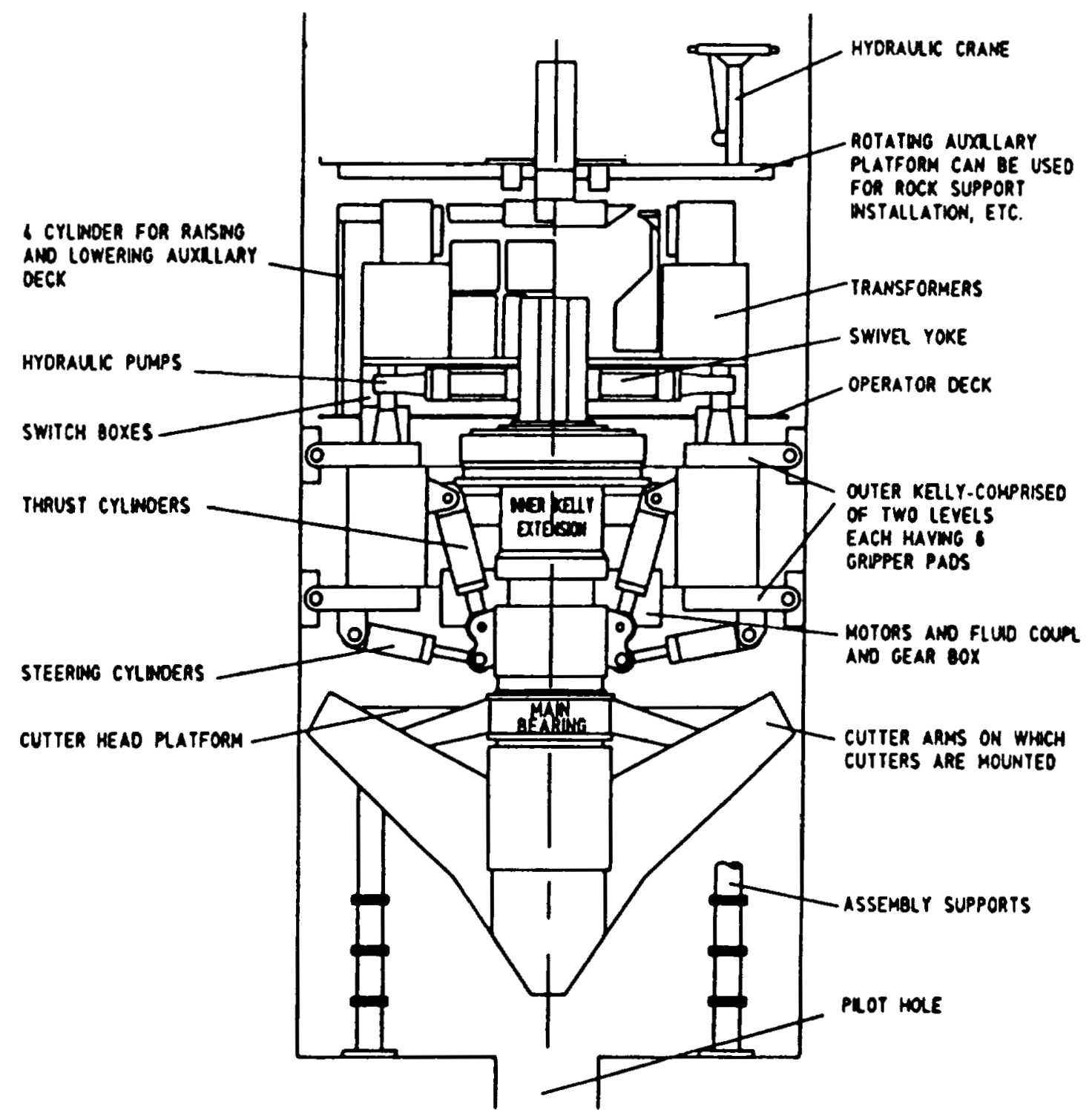

Figure 8.4.2-4. Wirth "V-Mole" Shaft Reaming Machine 
By-products of blasting include: dust, oxides of carbon, oxides of nitrogen, and other compounds. Potentially, significant quantities of these could combine with moisture to produce corrosive agents or agents that may help to mobilize radionuclides. In addition to fracturing of the wall rock, this consideration suggests minimizing drill/blast methods to small, specialized applications.

A new, pseudo-drill/blast technique that offers advantages in terms of energy efficiency and limited flyrock problems is called the Penetrating Cone Fracture (PCF) method (Micke, et al., 1994). This recent development is predicated upon the initiation and propagation of a controlled fracture from the bottom of a shallow and rapidly pressurized borehole. A stepped bit is used to drill a hole to a depth of approximately $450 \mathrm{~mm}$ to $750 \mathrm{~mm}$. The hole is then pressurized using a "mine gun," which is inserted to the bottom of the drill hole and which fires a charge of commercially available gun propellant. Expansion of the propellant gases results in a rapid increase in pressure at the bottom of the hole, causing fractures that extend radially from the bottom of the hole toward the face of the excavation, and resulting in a cone shaped depression in the rock face. Flyrock is substantially reduced when compared with conventional blasting operations.

The PCF technology has been developed by Sunburst Excavation, Inc. of Denver, Colorado. Sunburst has teamed with Swiss and German firms which manufacture the ITC/Schaeff carrier, a tracked unit equipped with a backhoe style boom used to gather muck onto a loading apron, then conveys the material to the rear of the carrier and discharges it into truck beds or other haulage equipment. As shown on Figure 8.4.2-5, the muck gathering boom is outfitted with a variable flow hydraulic impact breaker used for perimeter trimming and breaking oversized rocks, while a second boom has been added to carry the drill and mine gun used for primary breakage.

The mine gun equipment and technology is still in the developmental stage, but offers enhanced flexibility and shows sufficient promise to warrant ongoing monitoring of performance as it enters its first commercial application driving a development opening for the Perseverance Nickel Mine in Western Australia beginning in mid to late 1994.

Other, non-blast, pseudo-mechanical methods that are available for local, specialized excavations include: (1) drilling and hydraulic splitting, (2) drilling and chemical agent splitting, (3) ultra-high pressure water jet cutting, or (4) a technique using drilling and a splitting system known as the Core Cracker." As depicted in Figure 8.4.2-6, the "Core Cracker" system uses a principle known as impact hydraulics, where a soft metal sphere is placed in a short hole $(1 \mathrm{~m} \pm$ deep) and is deformed using a hydraulic impact hammer. The deformed metal produces high pressures at the bottom of the hole which are sufficient to break a conical section of rock away from the rock face (Klemens and Hodson, 1991). 
PCF BOOM

品

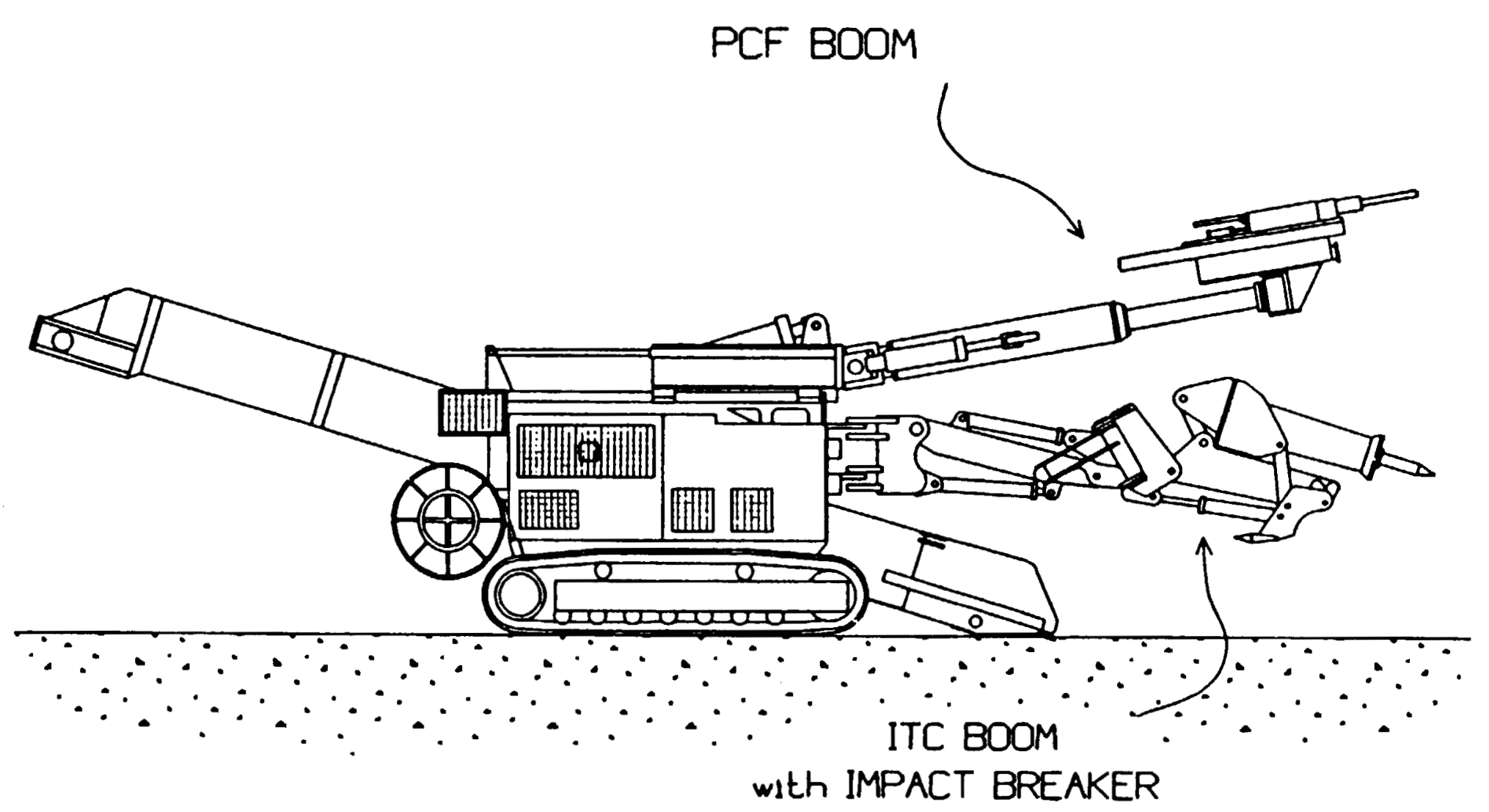

Figure 8.4.2-5. Sunburst Excavator with ITC/Schaeff Carrier 


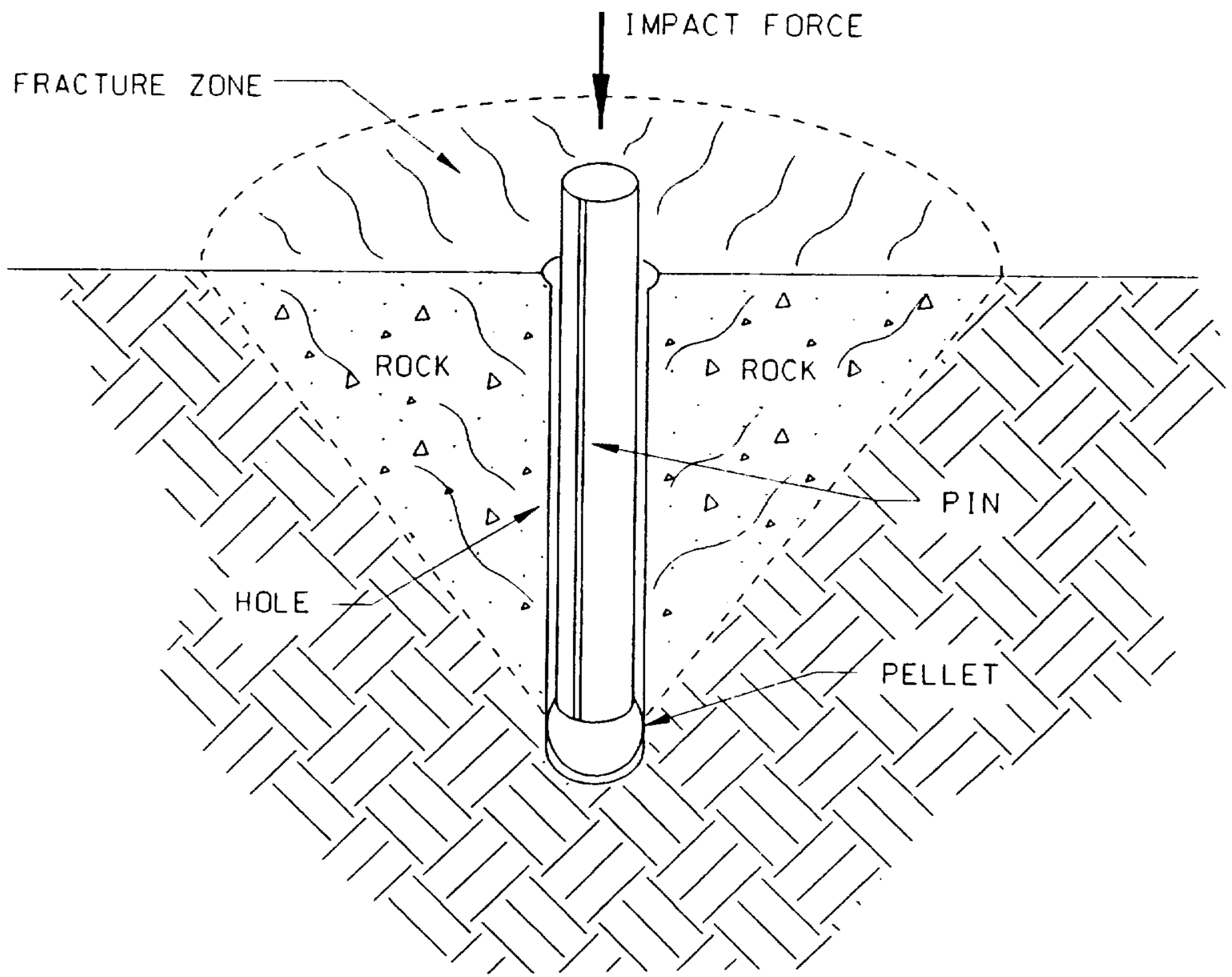

Figure 8.4.2-6. "Core Cracker" System Excavation Principle 


\subsection{WASTE EMPLACEMENT CONCEPTS AND CONSIDERATIONS}

Three major waste emplacement concepts have been considered in past conceptual repository design studies: vertical borehole, horizontal borehole, and in-drift emplacement. Both the vertical and horizontal borehole emplacement methods were considered and developed as a part of the SCP-CD (SNL, 1987a). In the vertical borehole emplacement concept, one small single-purpose canister-based WP was placed in a vertical borehole located in an emplacement drift floor. Multiple boreholes were located within an emplacement drift. In the horizontal emplacement mode, the same type of WPs were placed in a horizontal borehole located in the emplacement drift walls. A short borehole was used for a single or a few packages and a long borehole for multiple WPs. Multiple boreholes were located on each wall of the emplacement drift.

More recently, one of the most significant changes affecting emplacement (and retrieval) is the adoption of MPC-based WPs. Significant considerations include:

- Individual WP concepts resulting in package weights of up to approximately 86 tonnes, and diameters of approximately 1.8 meters, impact all areas of waste transport and emplacement design. As a comparison, the heaviest WPs in the SCP-CD were in the range of 6 tonnes.

- WPs containing as many as 21 PWR or 40 BWR spent nuclear fuel assemblies, with individual initial package heat outputs of more than $10 \mathrm{~kW}$, are being given strong consideration. As a comparison, the SCP-CD type packages were estimated to have initial potential heat output in the range of $3 \mathrm{~kW}$ per package.

Figure 8.5-1 is a pictorial weight comparison of the current 21 PWR MPC WP concept and the WP adopted in the SCP-CD.

Studies by SNL (1992e) have indicated that a WP with a heat output of more than $5 \mathrm{~kW}$ may not be suitable for emplacement in a borehole sized just large enough for insertion. This work has been confirmed by preliminary thermal analyses prepared in support of various WP ACD studies, which showed that WPs containing 12 or more PWR spent fuel assemblies will generate sufficient heat to exceed the current maximum thermal constraint of $350^{\circ} \mathrm{C}$ at the canister centerline if emplaced in a borehole.

Since numerous other studies are available for discussions of vertical and long horizontal borehole emplacement, and because of thermal limitations as discussed in the preceding paragraph regarding the size of packages that can be emplaced in boreholes, this report will not attempt to address these emplacement modes further. Rather, discussions will be limited to emplacement modes which can accommodate the large diameter, high heat output MPCbased WPs that are currently in the process of being baselined in the YMP program. 


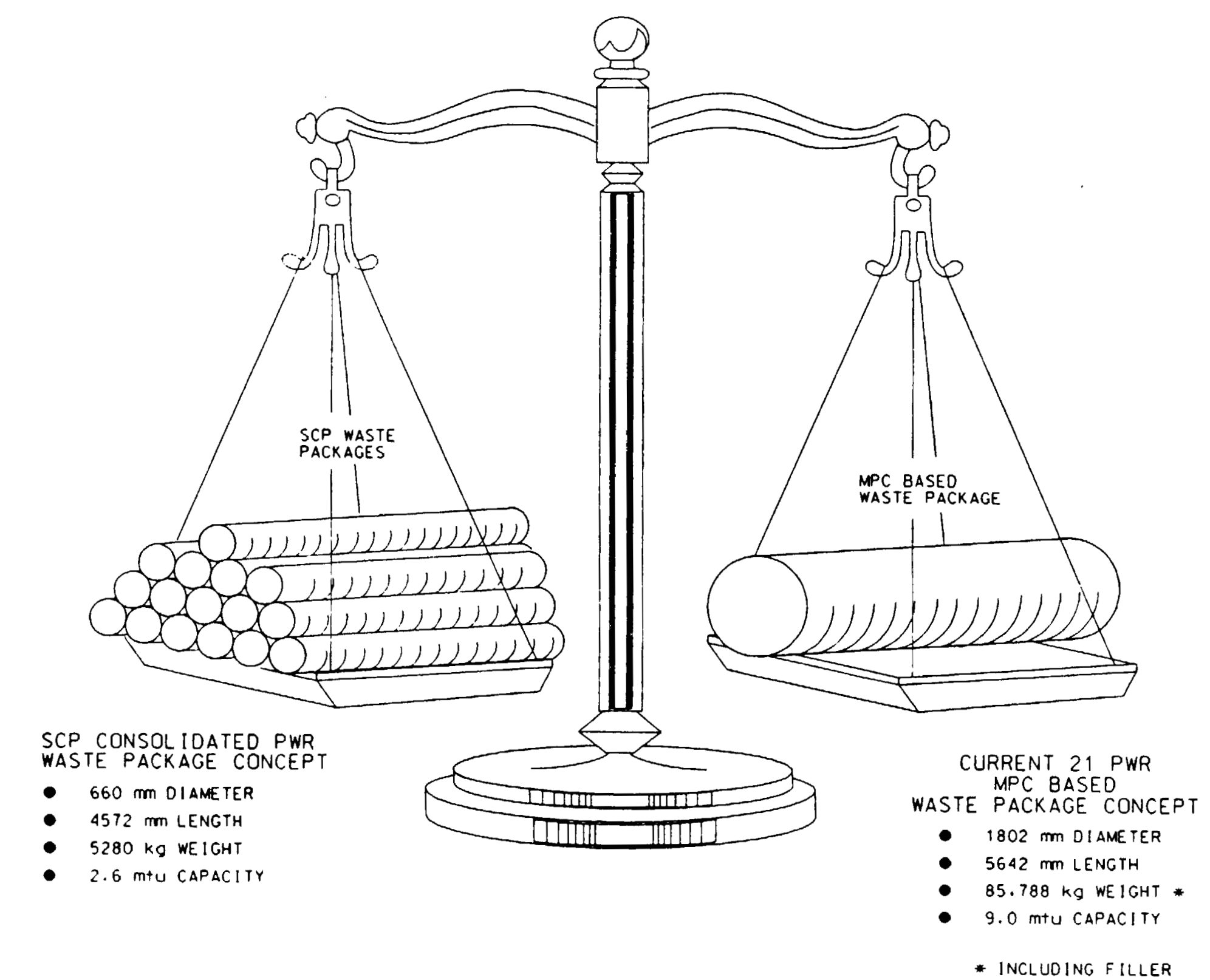

冬

Figure 8.5-1. Pictorial Weight Comparison of 21 PWR MPC Based WP and SCP-CD WPs 
Various in-drift emplacement concepts have been developed as a result of these changes in WP characteristics with limited studies performed in FY 1993 (M\&O, 1993b and M\&O, 1993c) and FY 1994 (M\&O, 1994b).

\subsubsection{General Emplacement Concepts}

Six general alternative concepts that are applicable to emplacement of large diameter, high heat output, MPC-based WPs have been given preliminary consideration in ACD. The basic emplacement configurations can be divided into two broad categories: in-drift and alcove. The general configurations of the six alternatives, minus such details as drift size, shielding method, and WP spacing, are shown in Figure 8.5.1-1.

A. Center-In-Drift - The Center-In-Drift concept consists of WPs placed on the centerline of a horizontal emplacement drift. The concept was used as the basis for developing ESF/Repository interface drawings in early FY 1994 (M\&O, 1994o).

B. Off-Center-In-Drift - The Off-Center-In-Drift concept consists of WPs placed sufficiently far off the center of an emplacement drift to permit movement of WPs for selective retrieval operations, repositioning of packages for thermal management, or operation of maintenance equipment for minor repairs next to emplaced WPs.

C. In-Sub-Drift - The In-Sub-Drift concept is a variation of the Center-In-Drift concept and consists of a moderate length horizontal emplacement sub-drift excavated between two emplacement access drifts. Multiple WPs are placed on the centerline of the subdrift.

D. In-Short-Perpendicular-Alcove - The In-Short-Perpendicular-Alcove concept is a variation to the general in-drift concept, and consists of one or two WPs emplaced in a horizontal alcove excavated adjacent, and at a $90^{\circ}$ angle, to an emplacement access drift.

E. In-Short-Parallel-Alcove - The In-Short-Parallel-Alcove concept consists of a long and relatively narrow alcove excavated in the rib of an emplacement access drift. The WP is oriented in the alcove with its longitudinal axis parallel to the emplacement access drift.

F. In-Short-Angled-Alcove - The In-Short-Angled-Alcove concept is identical to the InShort-Perpendicular-Alcove concept, except that the alcove is excavated at a $45^{\circ}$ angle to the emplacement access drift.

General advantages and disadvantages for each of the six concepts are summarized in Table 8.5.1-1. Sections 8.5.1.1 and 8.5.1.2 provide more specific discussions of the relative merits and shortcomings of both the in-drift and alcove emplacement concepts. 

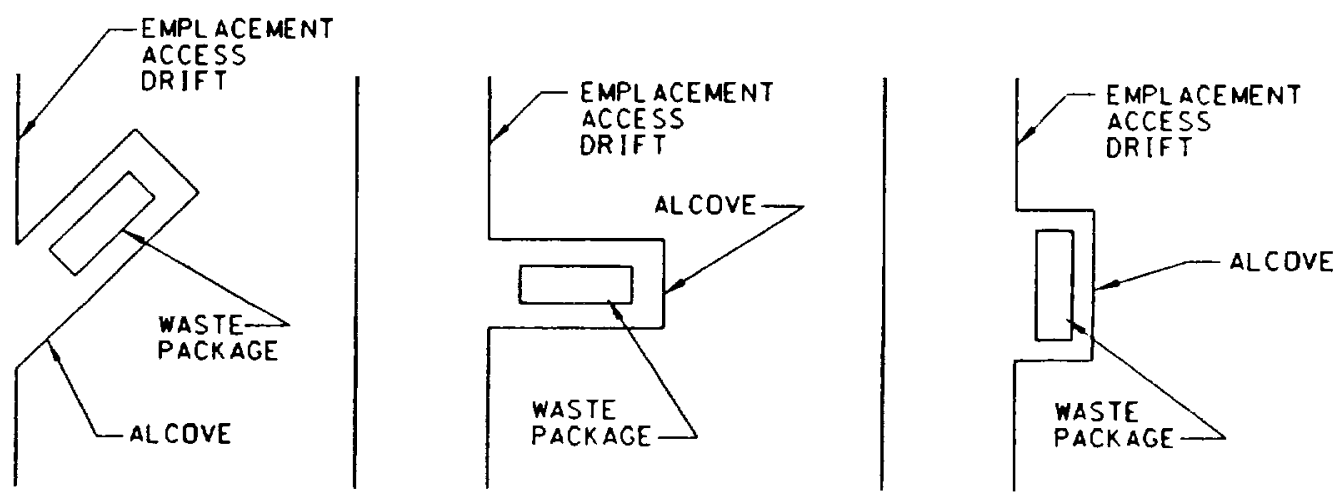
Table 8.5.1-1. Comparison of Initial Emplacement Concepts

\begin{tabular}{|c|c|c|c|}
\hline \multicolumn{2}{|c|}{$\begin{array}{l}\text { Emplacement } \\
\text { Configuration }\end{array}$} & Advantages & Disadvantages \\
\hline & $\begin{array}{l}\text { Center-In- } \\
\text { Drift }\end{array}$ & $\begin{array}{l}\text { Good opening stability characteristics with } \\
\text { small drift diameter. } \\
\text { Minimal secondary excavation. } \\
\text { Smallest emplacement opening size. } \\
\text { Excavation and emplacement simplicity. } \\
\text { Conducive to emplacement/retrieval } \\
\text { remote handling. } \\
\text { From a cost standpoint, drifts are } \\
\text { individually shielded rather than individual } \\
\text { alcoves, thus reducing the total amount of } \\
\text { shielding fixtures required. } \\
\text { Flexibility to adjust WP spacing if needed. } \\
\text { Drift cooling by ventilation is } \\
\text { straightforward. } \\
\text { Good heat transfer characteristics. }\end{array}$ & $\begin{array}{l}\text { Unless a large opening size is used, } \\
\text { retrieval of individual WPs and } \\
\text { maintenance and repair of emplacement } \\
\text { drifts could be very difficult to accomplish } \\
\text { unless the WPs are first removed from the } \\
\text { drift. } \\
\text { Backfilling would be more difficult than } \\
\text { for alcove concepts. }\end{array}$ \\
\hline & $\begin{array}{l}\text { Off- } \\
\text { Center-In- } \\
\text { Drift }\end{array}$ & $\begin{array}{l}\text { Good opening stability characteristics with } \\
\text { small drift diameter. } \\
\text { Minimal secondary excavation. } \\
\text { Emplacement simplicity. } \\
\text { Conducive to emplacemenUretrieval } \\
\text { remote handling. } \\
\text { Drift shielding advantages identical to (1). } \\
\text { Good flexibility to adjust WP spacing if } \\
\text { needed or to place WPs side-by-side in } \\
\text { special cases. } \\
\text { Selective WP retrieval is possible. } \\
\text { More conducive to minor drift repair and } \\
\text { maintenance without package removal if } \\
\text { this is considered feasible from a } \\
\text { personnel radiological safety viewpoint. } \\
\text { Drift cooling by ventilation is } \\
\text { straightforward. } \\
\text { Good heat transfer characteristics. }\end{array}$ & $\begin{array}{l}\text { Compared to Center-In-Drift, requires } \\
\text { either a greater amount of primary } \\
\text { excavation due to a greater emplacement } \\
\text { opening size, and/or greater invert fill } \\
\text { quantities. } \\
\text { Backfilling would be more difficult than } \\
\text { for alcove concepts. }\end{array}$ \\
\hline
\end{tabular}


Table 8.5.1-1. Comparison of Initial Emplacement Concepts (Continued)

\begin{tabular}{|c|c|c|c|}
\hline \multicolumn{2}{|c|}{$\begin{array}{l}\text { Emplacement } \\
\text { Configuration }\end{array}$} & Advantages & Disadvantages \\
\hline & $\begin{array}{l}\text { In-Sub- } \\
\text { Drift }\end{array}$ & $\begin{array}{l}\text { Similar to (1), except that secondary } \\
\text { excavation and shielding will be greater. } \\
\text { Similar to (4), but retrieval and backfill } \\
\text { advantages less pronounced as sub-drift } \\
\text { length increases, although term "alcove" } \\
\text { does not apply. } \\
\text { WP emplacement could be performed } \\
\text { from either side of the sub-drift. }\end{array}$ & $\begin{array}{l}\text { Similar to (1), but less pronounced as sub- } \\
\text { drift length decreases. } \\
\text { Similar to (4), but less pronounced, } \\
\text { although term "alcove" does not apply. } \\
\text { Uses larger amounts of available storage } \\
\text { area. } \\
\text { Difficult to obtain uniform repository-wide } \\
\text { heat distribution. } \\
\text { Increased excavation requirements. }\end{array}$ \\
\hline (4) & $\begin{array}{l}\text { In-Short- } \\
\text { Angled- } \\
\text { Alcove }\end{array}$ & $\begin{array}{l}\text { WP isolation from travelway possible. } \\
\text { Selective WP retrieval possible. } \\
\text { Backfill operations in the access drifts } \\
\text { adjacent to the alcoves are relatively } \\
\text { simple. }\end{array}$ & $\begin{array}{l}\text { Requires a substantial amount of } \\
\text { secondary excavation. } \\
\text { Alcove excavation will be more difficult to } \\
\text { accomplish than a drift. } \\
\text { Could require large emplacement alcove } \\
\text { opening size to meet thermal goals. } \\
\text { Requires a large amount of shielding if } \\
\text { individual alcove shielding is used. } \\
\text { Little flexibility to adjust WP spacing if } \\
\text { needed. } \\
\text { Backfill operations in the alcoves may be } \\
\text { difficult. } \\
\text { Cooling of alcoves could be difficult. }\end{array}$ \\
\hline (5) & $\begin{array}{l}\text { In-Short- } \\
\text { Perpendic- } \\
\text { ular- } \\
\text { Alcove }\end{array}$ & $\begin{array}{l}\text { Same as (4). } \\
\text { Can accommodate a higher thermal load } \\
\text { than (4). }\end{array}$ & Same as (4). \\
\hline & $\begin{array}{l}\text { In-Short- } \\
\text { Parallel- } \\
\text { Alcove }\end{array}$ & Same as (4). & $\begin{array}{l}\text { Similar to (4). } \\
\text { Very difficult to shield individual alcoves } \\
\text { because of large door areas required. } \\
\text { Opening stability could be a problem } \\
\text { because of long roof spans. }\end{array}$ \\
\hline
\end{tabular}




\subsubsection{In-Drift Emplacement}

In-drift emplacement can basically be defined as WPs placed horizontally within a drift. This general form of emplacement is a key assumption currently made in the CDA (M\&O, 1994m, Key 011).

In-drift emplacement concepts vary primarily by three general characteristics: 1) where the WP is situated in the drift, 2) how the WP is permanently supported in the drift once emplaced which closely relates to the choice of emplacement equipment, and 3) by the length of the drift. Of the three characteristics, 1) and 2) have the greatest influence on the diameter of the drift, and characteristic 3 ) has the greatest influence on the overall configuration of the repository layout.

For large, MPC-based WPs such as those containing approximately 21 PWR or 40 BWR spent fuel assemblies, the diameter of the emplacement drift must be sufficient to provide adequate surface area to allow for effective transfer of heat radiated from the WP. This heat must be conducted away through the rock mass at a rate sufficient to maintain a package core temperature that does not exceed thermal limits.

Preliminary thermal analyses have indicated that WPs placed on the drift centerline and containing up to 21 PWR fuel assemblies, assuming 22 year old average fuel with a 42.2 GWd burnup as stated in the CDA (M\&O, 1994m, Key 004), should maintain core temperatures within acceptable limits in a 4.3 meter diameter drift. High heat output packages, typically those containing 21 PWR fuel assemblies, will generally control the minimum opening size design unless special provisions for cooling by aging or ventilation are used. It is not practical, using a TBM as the machine for primary excavation (M\&O, 1994m, DCSS-005), to provide minor adjustments in drift diameter based upon the lower heat output of packages such as $12 \mathrm{PWR} / 24 \mathrm{BWR}$ (M\&O, 1994d).

The method of WP support also has an influence on the drift diameter due to the type of emplacement equipment that must be used. From an equipment standpoint, the emplacement drift diameter must permit the passage of the WP and prime mover through the drift.

Prime movers considered at this stage of ACD include a locomotive and a self-propelled gantry and are discussed in greater detail in Section 8.7.2.2. Equipment surveys have indicated that underground locomotives that could be used for pushing or pulling a cartmounted, 21 PWR WP placed on rail in the center of the opening would fit inside drift diameters as small as 3.7 meters, but as discussed above, thermal constraints will generally limit the minimum drift size. A $4.3 \mathrm{~m}$ diameter drift has been advanced in previous studies using rail car emplacement (M\&O, 1993b, p. 5-44).

Several gantry concepts developed during ACD for placement of WPs in the center of the drift suggest an emplacement drift diameter of approximately $5.0 \mathrm{~m}$. This diameter is based upon the estimated operating envelope required for the gantry, plus an additional allowance of $700 \mathrm{~mm}$ outside of the operating envelope for ground support and excavation misalignment tolerance. 
In-drift emplacement concepts allow good flexibility in terms of repository thermal management, both for initial placement and for subsequent WP spacing adjustments, subject to some limitations when packages are closely spaced. The potential need for flexibility to allow WP spacing adjustments after emplacement is discussed in Section 8.3.2.

In-drift emplacement can readily accommodate a mixed waste stream consisting of SNF WPs containing both $21 \mathrm{PWR} / 40 \mathrm{BWR}$ assemblies and $12 \mathrm{PWR} / 24 \mathrm{BWR}$ assemblies, and high level WPs containing 4 DHLW canisters as currently defined in M\&O (1994d).

Of the six alternative concepts identified in Section 8.5.1, three involve in-drift emplacement: Center-In-Drift, Off-Center-In-Drift, and In-Sub-Drift. The first, Center-In-Drift, currently uses two variations or modes relating to how the WP is emplaced. One variation includes placement of the WP resting on a permanently emplaced rail cart. This configuration is termed "In-Small-Drift-on-Rail" (ISDOR). The second variation places the WP on permanent pedestals and is termed "In-Small-Drift-on-Pedestal" (ISDOP).

The ISDOR concept utilizes rail systems for emplacement of WPs on permanent railbound carriers in the emplacement drift. Obvious advantages of using rail transport include: the ability to accommodate extremely heavy loads without proportional increases in the carrier's operating envelope, as compared with rubber-tired vehicles, and the relative ease with which railbound systems can be reliably automated or controlled from remote locations. Railbound systems in which the WP carrier remains with the package also facilitate retrieval in a relatively straightforward manner, although it has not yet been determined what the long-term effectiveness of rail cars permanently emplaced in a hot and high radiation drift environment would be, particularly in regard to retrieval.

The ISDOP concept places WPs on permanent pedestals that are prepositioned in the drift and is considered as an alternative to the ISDOR method. The choice of pedestal dimensions, material type, and the number required per package, as well as whether to premanufacture or construct them in place, has not been addressed at this point. Gantry emplacement equipment concepts have been developed to accommodate this type of WP support (M\&O, 1994b).

The Center-In-Drift emplacement concept has the following positive features:

- Compared to an alcove concept, requires the smallest opening size, resulting in the lowest excavation and backfill (if used) volume

- Excavation and emplacement operations are relatively straightforward

- Compared to alcove concepts, would likely require a lesser amount of total shielding

- Excavation costs are significantly lower when compared to alcove concepts

- Drift/package configuration provides good heat transfer area to the surrounding rock

- Relatively small drift diameter enhances opening stability 
- Allows good flexibility to adjust WP spacing for thermal management or to avoid local geologic features.

On the other hand, there are several potentially negative features to the Center-In-Drift concept, when used with a relatively small drift (such as the $4.3 \mathrm{~m}$ diameter described in M\&O, 1993b and M\&O, 1994a), coupled with the long length of each emplacement drift:

- Selective retrieval of WPs for such reasons as a breached WP or performance confirmation is relatively difficult. All WPs in an emplacement drift preceding the package to be retrieved would need to be moved out of the emplacement drift and stored temporarily in another location. However, the need to perform selective retrieval of a breached WP appears to be unlikely. According to assumption EBDRD 3.2.5.1.2.B.1 in the CDA (M\&O, 1994m), packages are to be designed with a less-than $2.2 \times 10^{-3}$ percent incidence of breaching during the preclosure period. For a total of approximately 12,000 packages, this equates to less than one package breached. Performance confirmation activities which might require selective retrieval is a subject not well defined to-date. Its effect on the need for selective retrieval can therefore not be fully established.

- Access to sections of the emplacement drift without first removing any intervening packages would be difficult, if not impossible, if drift maintenance and repair were required. Again, temporary removal and storage of WPs would be needed. For maintenance of only an isolated section of drift, package removal only up to the area requiring repair may be needed. For complete drift maintenance, the entire drift would need to be emptied. However, considering the difficult nature of performing maintenance in an emplacement drift while unshielded WPs are present, drift maintenance with packages present may not be practical even if sufficient room were available.

- Limited access space around the WP may make backfill (if used) operations and consistent backfill placement quality potentially difficult to achieve.

The Off-Center-In-Drift concept is presented as a variation of the basic Center-In-Drift concept. The concept consists of WPs placed sufficiently far off the center of an emplacement drift to provide an operating corridor alongside a line of emplaced WPs. This would permit passage of a WP being individually retrieved, would permit minor drift repair and maintenance equipment to move alongside a line of emplaced WPs, or would permit repositioning of packages for thermal management using a remotely operated locomotive on the clear track. This locomotive could be equipped with a special coupling device that could reach over to the adjacent track to move packages one at a time.

The Off-Center-In-Drift concept is in many ways similar to the Center-In-Drift concept. Considered to be a compromise concept, Off-Center-In-Drift improves on some of the potentially negative features that are inherent to the Center-In-Drift concept. As with the Center-In-Drift concept, WPs can be placed on permanently emplaced rail carts or on pedestals, although pedestal support may require a larger diameter opening. 
Positive features of the Off-Center-In-Drift concept include:

- Compared to an alcove concept, requires a smaller opening size, and a lower excavation and backfill (if used) volume

- Excavation and emplacement operations are relatively straightforward

- Compared to alcove concepts, would likely require a lesser total amount of shielding

- Excavation costs are significantly lower when compared to alcove concepts

- Drift/package configuration provides good heat transfer to the surrounding rock

- Relatively small drift diameter enhances opening stability

- Allows good flexibility to adjust WP spacing for thermal management or to avoid local geologic features

- Individual retrieval of WPs is possible without moving all WPs preceding the package to be retrieved out of the emplacement drift (see center-in-drift-discussion, above)

- If determined to be feasible from a personnel safety or operational standpoint, access to sections of the emplacement drift would be available if minor drift maintenance and repair is required without temporary removal and associated temporary storage of WPS

- Allows the flexibility for side-by-side emplacement of WPs for special emplacement cases or as a tool for thermal management at repository closure.

A negative feature of the Off-Center-In-Drift concept is that limited access space around the WP may make backfill (if used) operations and consistent backfill emplacement quality potentially difficult to achieve.

The In-Sub-Drift concept is basically a variation to a Center-In-Drift repository layout configuration, rather than a significantly different emplacement alternative. The In-Sub-Drift concept is similar to Center-In-Drift in that WPs are placed in center of the drifts, yet the drift length is much shorter. Due to its short length, the flexibility to adjust WP spacing is reduced. Also, because of its short length, more shielding doors will be required than with the Center-In-Drift or Off-Center-In-Drift concepts, and a considerable amount of disposal area would be lost to the system of access drifts and thermal buffers, if needed. It has similarities to several of the alcove concepts discussed in Section 8.5.1.2 because WPs are isolated from the access drift by shielding doors placed at each end of the sub-drift, but since the sub-drift is longer than an alcove, the alcove concepts have advantages with respect to selective retrieval of WPs. 


\subsubsection{Alcove Emplacement}

Alcove emplacement is an alternative that is somewhat analogous to the vertical borehole mode of the SCP-CD. However, considerations in alcove design and applicability related to the size and heat output of current WP concepts make a direct comparison misleading. Although emplacement of WPs in an alcove is not currently a key YMP assumption, this concept is being examined to meet requirements such as those mandated by $10 \mathrm{CFR}$ $60.21(\mathrm{c})(1)(\mathrm{ii})(\mathrm{F})(6)$ regarding identification and justification for the selection of variables that are determined to be probable subjects of license applications. Of the six alternative emplacement concepts identified in Section 8.5.1, three involve alcoves.

In order to simplify the discussions in this section, the concepts of AML and initial APD assuming an average WP with 22 year old fuel and a burnup of $42.2 \mathrm{GWd}$; $(\mathrm{M} \& \mathrm{O}, 1994 \mathrm{~m}$, Key 004) are used. As was discussed in Section 8.3.2, this approach may be an oversimplification given the variability likely to be present in the waste stream. Nevertheless, these terms are useful to illustrate limitations inherent with alcove emplacement. The discussions also incorporate several types of MPC-based WPs as follows: 21 PWR/40 BWR, 12 PWR/24 BWR, and 4 DHLW (M\&O, 1994d).

During preliminary evaluations of the alcove concepts, several factors were found to be particularly significant. One factor was that for a given thermal load, in order to maintain an extraction ratio of less than 30 percent in the emplacement areas, there are limitations on the number of WPs that can be accommodated in a single alcove, or there are limitations on the number of alcoves that can be excavated. The significance of the 30 percent extraction ratio was discussed in Section 8.3.5.1, and it is currently recognized as a YMP limit (M\&O, 1994m, DCSS-006).

Another significant factor in alcove emplacement is that the stability of the pillars between neighboring alcoves will be reduced due to the superpositioning effect of stress concentrations if they are spaced too closely. From a long-term stability viewpoint, a rule-of-thumb is that alcoves located on the same side of the emplacement access drift (see Figure 8.5.1-1) should be spaced three times the alcove width for the perpendicular or angled alcove concepts, or three times the alcove length for the parallel alcove concept.

Considering the discussions in previous paragraphs, the In-Short-Parallel-Alcove concept has three major shortcomings. The first is the long length of the alcove, which greatly reduces the AML (or initial APD) that can be emplaced if an extraction ratio of less than 30 percent and reasonable pillar sizes between alcoves are to be maintained. This is exacerbated if DHLW is placed in the same alcove, which requires a greater alcove length. The maximum AML and initial APD that a WP containing average SNF (M\&O, 1994m, Key 004) can be emplaced at in the parallel alcove concept, without violating the above two considerations, are shown in Table 8.5.1-2 for several potential combinations of WP emplacement configurations.

For comparison, key assumptions specify that AMLs in the high range of 80 to 100 MTU/Acre (19.8 to $24.7 \mathrm{kgU} / \mathrm{m}^{2}$ ) and in the low range of 25 to $35 \mathrm{MTU} / \mathrm{acre}$ (6.2 to 8.6 $\mathrm{kgU} / \mathrm{m}^{2}$ ) be considered (M\&O, 1994m, Key 019). As can be seen from the values in 
Table 8.5.1-2, it is not feasible to meet the high range AML assumptions with the parallel alcove concept without violating the general extraction ratio or pillar width criteria.

A second major shortcoming of the parallel alcove concept is the long roof span that would be present from the far edge of the emplacement access drift (see Figure 8.5.1-1) to the edge of the alcove, approximately $13 \mathrm{~m}$, and the inherent potential for reduced opening stability.

The third major shortcoming of the parallel alcove concept is the physical size of the shielding that would be necessary to isolate the waste in the alcove from personnel in the access drift adjacent to the alcove. Shielding could be provided by doors located at the entrance of the alcove; however, for an alcove containing both SNF and DHLW packages, massive doors would be necessary, on the order of $20 \mathrm{~m}$ long by 4 to $5 \mathrm{~m}$ high. Splitting the doors into halves would alleviate the problem somewhat, but nevertheless, the concept is still considered to be impractical over others available because of both the potential cost and weight of each door.

The In-Short-Angled-Alcove concept has one major shortcoming. As in the case of the parallel alcove concept, the AML or initial APD that can be achieved can greatly limit the feasibility of this concept. For the angled alcove concept, the maximum AMLs and initial APDs that waste can be emplaced at without violating maximum extraction ratio or minimum pillar considerations are also shown in Table 8.5.1-2 for several potential WP emplacement configurations.

Again, referring to the values in Table 8.5.1-2, it is not feasible to meet the high range AML assumptions of 80 to $100 \mathrm{MTU} / \mathrm{Acre}\left(19.8\right.$ to $\left.24.7 \mathrm{kgU} / \mathrm{m}^{2}\right)$ with the angled alcove concept without violating the general extraction ratio or pillar width criteria.

The In-Short-Perpendicular-Alcove concept also has one major shortcoming, similar to the angled alcove concept. The maximum AMLs and initial APDs that waste can be emplaced at in the perpendicular concept, without violating maximum extraction ratio or minimum pillar considerations, are shown in Table 8.5.1-2 for the same combinations of WP emplacement configurations as the other alcove concepts.

From the values in Table 8.5.1-2, the high range AML assumption of 80 to $100 \mathrm{MTU} /$ Acre ( 19.8 to $24.7 \mathrm{kgU} / \mathrm{m}^{2}$ ) cannot be consistently met for all required types of WPs without violating the general extraction ratio or pillar width criteria.

The most significant conclusion that can be drawn from the discussions in this section is that the key assumption to develop a surface/subsurface configuration that will accommodate a primary high thermal load of 80 to 100 MTU/Acre (91 to $114 \mathrm{~kW} /$ Acre) (M\&O, 1994m, Key 019) cannot reasonably be met with alcove emplacement. To meet the assumption would require more detailed analyses that consider higher extraction ratios and reduced pillar width criteria, and the ramifications of making such changes. 
Table 8.5.1-2. Maximum AML and Initial APD for Alcove Concepts

\begin{tabular}{|c|c|c|c|c|c|}
\hline \multicolumn{2}{|c|}{$\begin{array}{l}\text { Emplacement Concept/WP } \\
\text { Configuration }\end{array}$} & $\begin{array}{l}\text { Alcove } \\
\text { Length } \\
\text { (m) }\end{array}$ & $\begin{array}{c}\text { Alcove Spacing' } \\
\text { (m) }\end{array}$ & $\begin{array}{c}\text { Maximum Achievable } \\
\mathrm{AML}^{23.4} \\
\left(\mathbf{k g U} / \mathbf{m}^{2}\right)\end{array}$ & $\begin{array}{c}\text { Maximum Achievable } \\
\text { Initial APD } \\
\left(\mathrm{W} / \mathrm{m}^{2}\right)\end{array}$ \\
\hline \multicolumn{6}{|c|}{ Parallel $^{\star}$} \\
\hline & $\begin{array}{l}21 \mathrm{PWR} / \\
40 \mathrm{BWR}\end{array}$ & 10 & 30 & 14.3 & 16.3 \\
\hline (1) & $\begin{array}{l}12 \text { PWR } \\
24 \text { BWR }\end{array}$ & 10 & 30 & 8.4 & 9.6 \\
\hline (1) & $\begin{array}{l}21 \text { PWR } \\
40 \text { BWR Plus (1) } 4 \\
\text { DHLW }\end{array}$ & 15 & 45 & 9.6 & 10.9 \\
\hline (2) & $\begin{array}{l}12 \text { PWR/ } \\
24 \text { BWR }\end{array}$ & 17 & 51 & 9.8 & 11.1 \\
\hline \multicolumn{6}{|c|}{ Angled ${ }^{6,7}$} \\
\hline (I) & $\begin{array}{l}21 \mathrm{PWR} \\
40 \mathrm{BWR}\end{array}$ & 10 & 15 & 16.5 & 18.8 \\
\hline (I) & $\begin{array}{l}12 \mathrm{PWR} \\
24 \mathrm{BWR}\end{array}$ & 10 & 15 & 9.7 & 11.0 \\
\hline (1) & $\begin{array}{l}21 \text { PWR/ } \\
40 \text { BWR } \\
\text { Plus (1) } 4 \text { DHLW }\end{array}$ & 15 & 15 & 14.1 & 16.0 \\
\hline (2) & $\begin{array}{l}12 \text { PWR } \\
24 \text { BWR }\end{array}$ & 17 & 15 & 15.6 & 17.7 \\
\hline \multicolumn{6}{|c|}{ Perpendicular" } \\
\hline (1) & $\begin{array}{l}21 \mathrm{PWR} / \\
40 \mathrm{BWR}\end{array}$ & 10 & 15 & 22.1 & 25.1 \\
\hline (1) & $\begin{array}{l}12 \text { PWRJ } \\
24 \text { BWR }\end{array}$ & 10 & 15 & 12.9 & 14.7 \\
\hline (1) & $\begin{array}{l}\text { 2I PWR } \\
40 \text { BWR } \\
\text { Plus (I) } 4 \text { DHLW }\end{array}$ & 15 & 15 & 18.0 & 20.5 \\
\hline (2) & $\begin{array}{l}12 \text { PWR } \\
24 \text { BWR }\end{array}$ & 17 & 15 & 19.6 & 22.3 \\
\hline
\end{tabular}

Notes:

I) The minimum allowable center-to-center alcove spacing, for stability reasons, is set at 3 times the alcove length for the parallel concept and three times the alcove width for the angled and perpendicular concepts.

2) The above AMLs are calculated to achieve an extraction ratio of 0.30 .

3) Only SNF is considered in the calculation, DHLW has been neglected.

4) $1 \mathrm{MTU} / \mathrm{Acre}=1 \mathrm{kgU} / \mathrm{m}^{2} \times 4.047$.

5) The initial APDs in the table, resulting from a particular AML, are calculated based upon 22 year old average SNF with a 42.2 $\mathrm{GWd} / \mathrm{MTU}$ burnup, and a conversion factor of $1.137 \mathrm{~kW} / \mathrm{MTU}$ as derived from $\mathrm{M} \& \mathrm{O}$ (19930). (1 $\mathrm{MTU}=1000 \mathrm{kgU}$ ).

6) The alcove width is set at $5 \mathrm{~m}$, and the emplacement access drift width is set at $8 \mathrm{~m}$ to approximate the width of shielding door cutout excavations.

7) Alcoves are oriented at $45^{\circ}$ to the emplacement access drift. 
If such criteria modifications were determined feasible in the future, of the three alcove concepts, the perpendicular configuration or a similar variation to it will allow the greatest flexibility to achieve the highest thermal load while leaving the greatest amount of intact rock.

When comparing the In-Short-Perpendicular-Alcove concept to the in-drift emplacement concepts of Section 8.5.1.1, the major positive feature of the concept include:

- Individual retrieval of WPs is possible without moving other emplaced WPs.

The major negative features of the perpendicular alcove concept include:

- Requires a greater volume of primary excavation (the emplacement access drifts) and a substantially greater amount of secondary excavation (the alcoves) than in-drift concepts. Excavation difficulty is increased. Construction costs are expected to be significantly higher than in-drift concepts.

- Requires a greater backfill (if used) volume than in-drift concepts because both alcoves and emplacement access drifts must be backfilled compared to just the emplacement drifts. Backfill costs are expected to be higher as a result.

- The closed space of an alcove provides less rock surface area for heat transfer to the surrounding rock compared to in-drift concepts.

- Compared to in-drift concepts, opening stability potential will be reduced by the potential for stress concentration due to the sharp corners of the alcove.

- An enormous amount of shielding, and resulting higher cost, will be required if each alcove is shielded.

- Does not allow flexibility to adjust WP spacing for different thermal loadings or to avoid local geologic features, without abandoning an alcove.

A more comprehensive study of alcove emplacement including preliminary operational aspects was made in support of 1994 system studies. Details of this work can be found in a $1994 \mathrm{M} \& O$ report (M\&O, 1994b).

\subsubsection{Interim Emplacement Configuration(s)}

Consistent with the CDA (M\&O, 1994m, Key 011), in-drift emplacement in a horizontal mode is used as the basis for repository layout and emplacement operations discussions in later sections of this report. In-drift is preferred over alcove emplacement at this time for two major reasons: 1) Alcove emplacement does not provide sufficient flexibility to accommodate the higher range, 80 to $100 \mathrm{MTU} /$ acre thermal loading case stipulated in the CDA (M\&O, $1994 \mathrm{~m}$, Key 019), 2) The constructed cost of alcove emplacement, based on engineering judgment, is expected to be significantly higher than with in-drift emplacement. It is recognized that final selection of an emplacement mode during $A C D$ requires a more 
comprehensive evaluation of radiological safety, total life cycle costs, as well as other operational factors and occupational safety issues. This work will be performed at a later date as design concepts are more completely developed.

Given that in-drift emplacement is used as the basis for further discussions in this report, the choice of where to place the WPs in the emplacement drift, how they are to be handled inside the drift, and how they are to be permanently supported remain to be addressed. As indicated in Section 8.5.1.1, advantages for both the Center-In-Drift and Off-Center-in-Drift Concepts are similar. The Off-Center-In-Drift concept offers the flexibility for limited access through the emplacement drift that the Center-In-Drift concept cannot provide unless a larger drift is used. But personnel radiological safety issues suggest that access alongside WPs may not be a truly desirable feature, while material handling and drift and WP monitoring issues suggest that such access may warrant consideration. Further evaluations are needed in this area.

The decision to permanently emplace the packages on wheeled carts, on pre-installed pedestals, or perhaps some combination of these two concepts is another area that needs further evaluation. Whether to use a locomotive/cart handling system or a gantry/pedestal system to carry out the emplacement operation inside the drift must also be further analyzed.

Rather than adopt a particular variation of the general in-drift concept at this time, it is suggested that an emplacement drift diameter be selected for use in ongoing ACD work that is as small as practical but that offers sufficient flexibility to accommodate several specific indrift emplacement configurations.

Based on preliminary locomotive/cart and gantry/pedestal equipment concepts that have been developed, indications are that a $5.0 \mathrm{~m}$ diameter drift provides a reasonable operating clearance allowance for these variations of in-drift emplacement, and provides additional space for ground support and excavation misalignment tolerance. Therefore, an excavated diameter of $5.0 \mathrm{~m}$ is used for emplacement drifts in the layouts and discussions presented hereafter in this report. Examples using this diameter are shown in the emplacement drift cross sections of Figures 8.5.2-1, 8.5.2-2, and 8.5.2-3. 


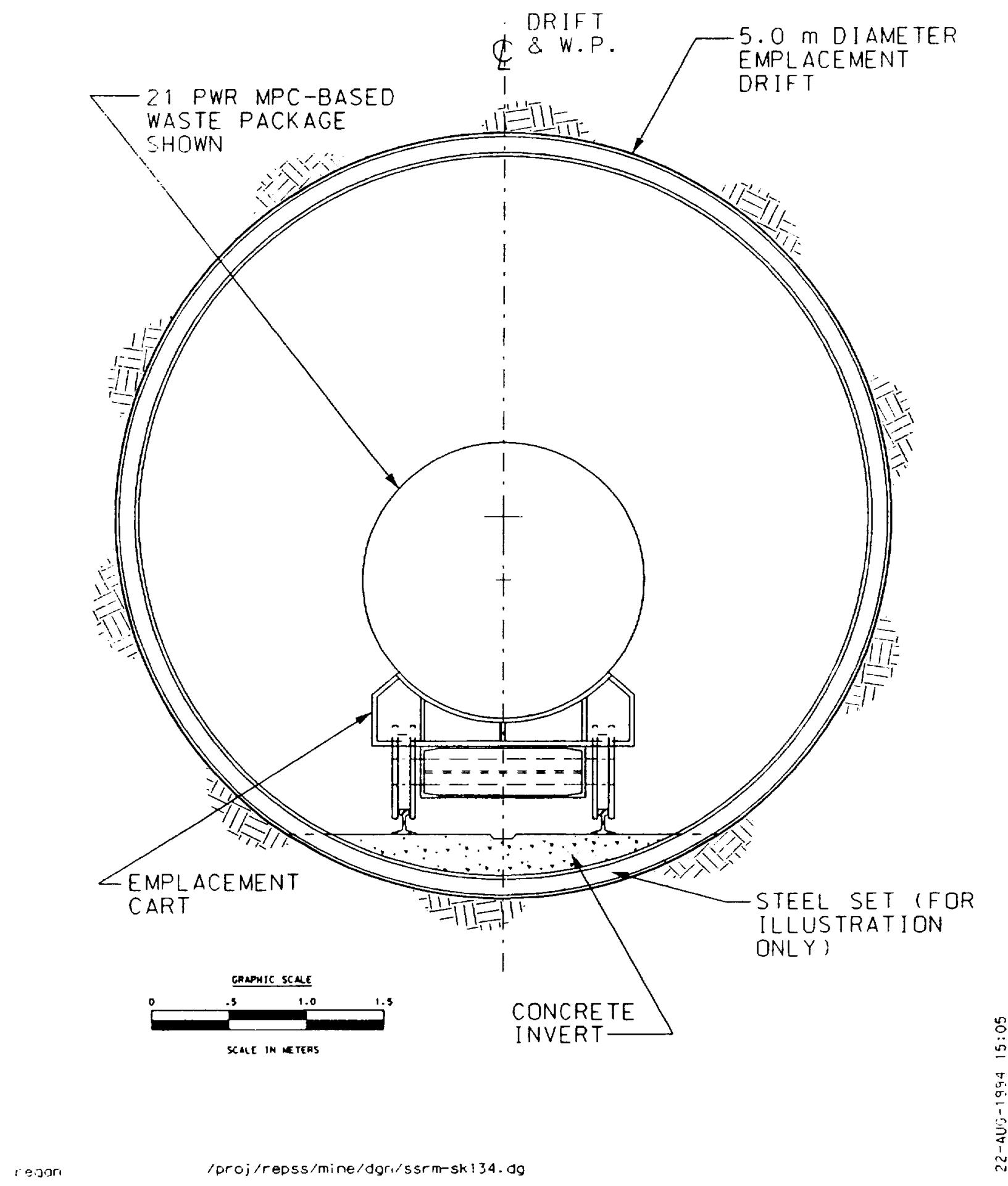

Figure 8.5.2-1. Emplacement In-Small-Drift-On-Rail Cart - Cross Section 


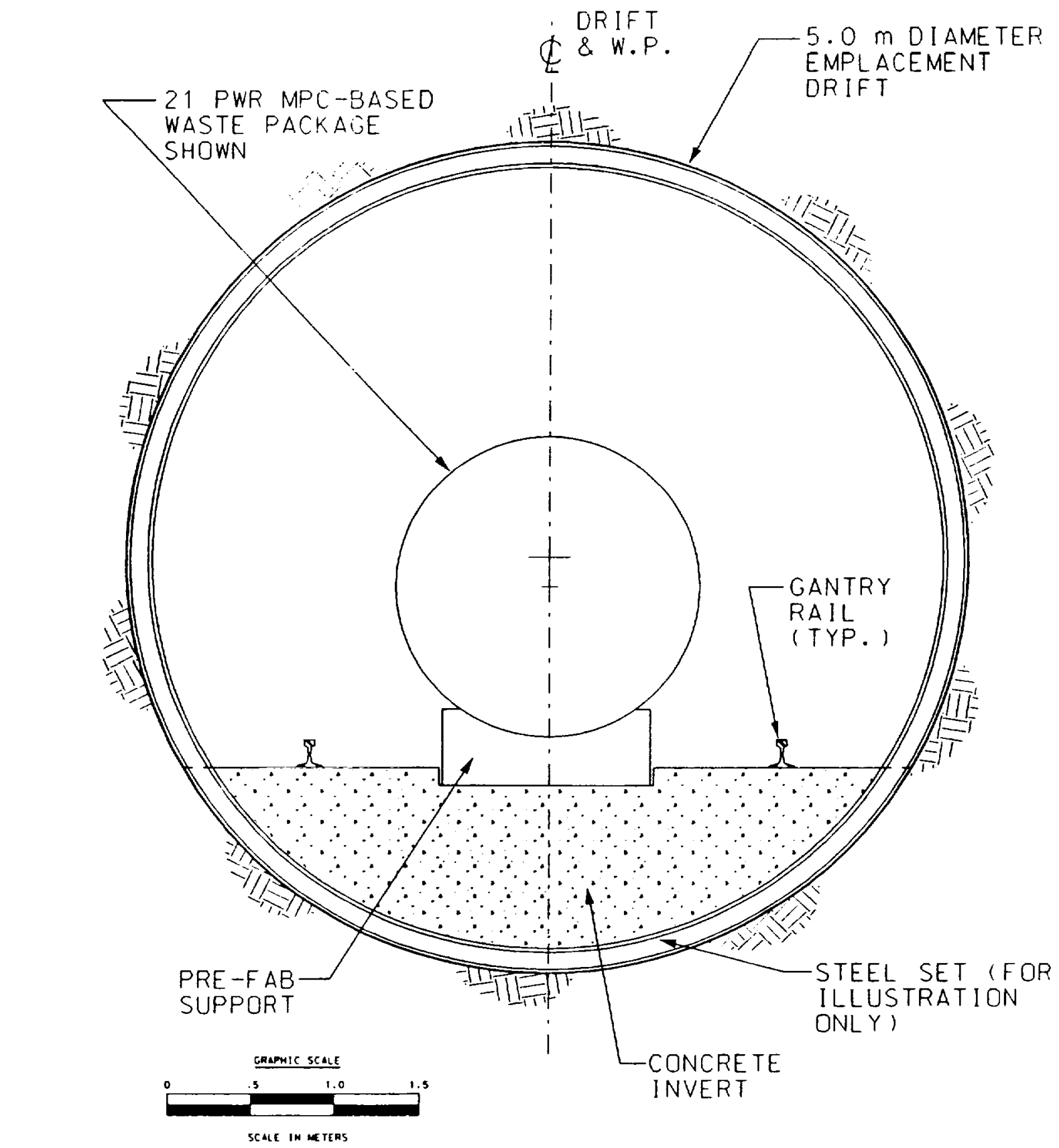

regon

/proj/repss/mine/dgn/ssrm-sk $128 . d g$

Figure 8.5.2-2. Emplacement In-Small-Drift-On-Pedestal - Cross Section 


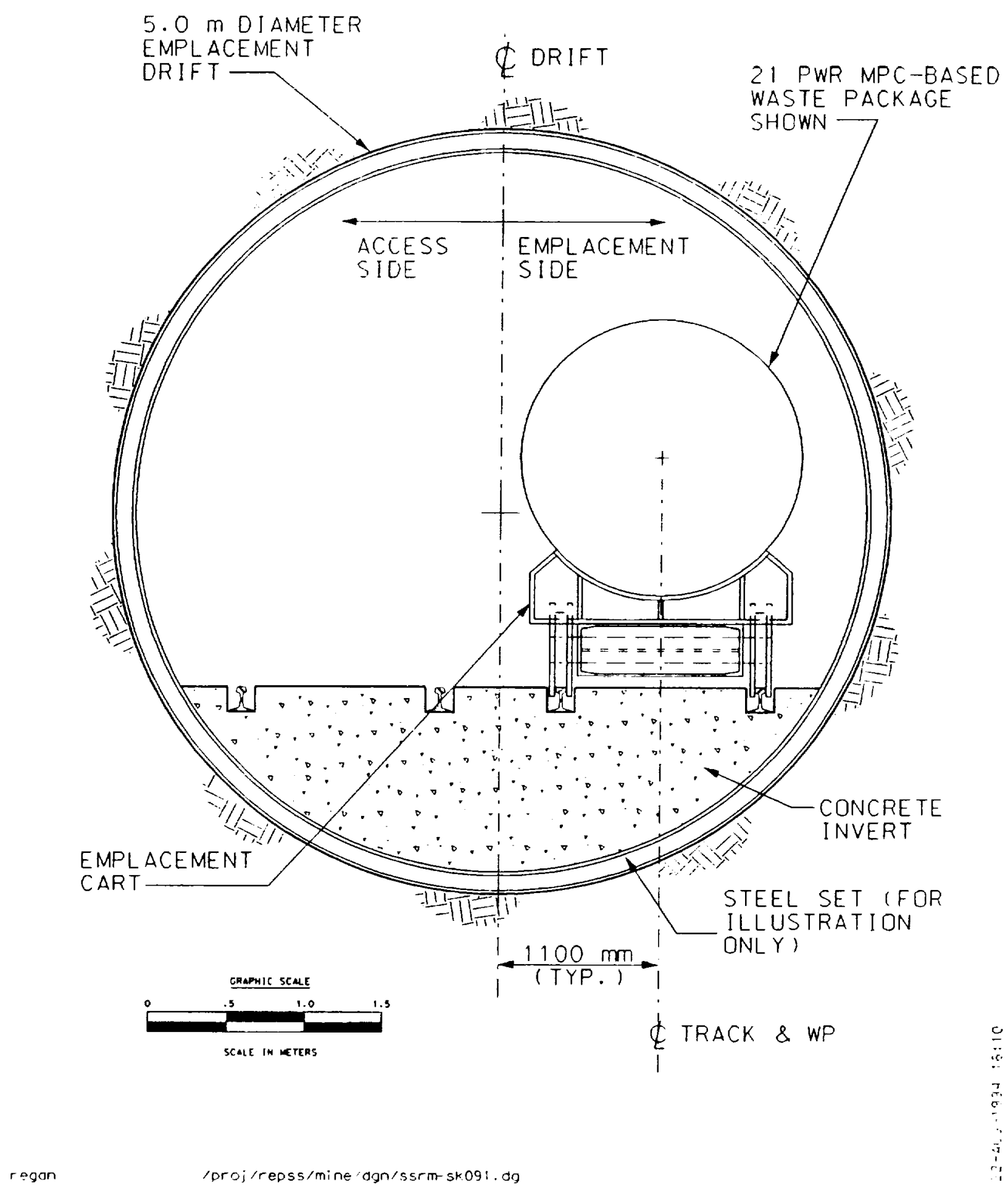

Figure 8.5.2-3. Emplacement Off-Center-In-Drift-On-Rail Cart - Cross Section 


\subsection{REPOSITORY SUBSURFACE LAYOUT}

Two layout concepts are discussed in this report and are applicable to in-drift emplacement of MPC-based WPs. The concepts are presented in varying degrees of detail in the subsections below. One concept, termed Option I, is considered as a refinement of the ESF/repository interface layouts made in FY 1993 and early 1994. These layouts were originally discussed in Section 8.1. A presentation of the general layout features and design objectives for the Option I concept is made in Section 8.6.1. The second concept, termed Option II, used many attributes of the Option I concept but contains several areas of significant difference which are compared. An interim layout is selected from the two in which to base the presentation of design concepts in later sections of the report, and a detailed functional description of all openings in the interim layout is presented. Finally, a design concept for maximizing the potential emplacement capacity of the primary area of Area 1 (refer to Section 8.2.1.4) is outlined.

\subsubsection{General Layout Features and Design Objectives}

Consistent with past repository conceptual designs, a primary feature guiding development of repository ACD layouts is provision for the separation of subsurface ventilation systems, a basic program requirement listed in 10 CFR $60.133(\mathrm{~g})(3)$. Strict compliance with this requirement leads to a design that divides subsurface operations into two separate systems, separated by physical barriers. Operations in one half, the "development side," involve the construction of emplacement drifts and other work that prepares dedicated areas for emplacement of nuclear waste. Operations in the other half, the "emplacement side," include the actual transportation of the nuclear waste to the subsurface and its emplacement. Each "side" has two separate accesses to the surface that also serve as primary ventilation airways and as alternate means of egress.

Another feature included in the ACD layouts presented in this report results from a program requirement directing the development of an integrated ESF/Repository design (DOE, 1985). Pre-ACD efforts culminated in preparation of the Exploratory Studies Facility Alternatives Study (ESFAS) (SNL, 1991a), a comprehensive assessment of 34 different options for development of an integrated ESF/Repository design. The document (YMP, 1991a) that brought forward results from the ESFAS as a basis for Title I ESF design, stressed the need to pursue development of ESF/Repository layouts that incorporate all of the favorable design features identified in the ESFAS (none of the 34 options met all of the favorable design features). Consistent with recommendations made therein, an enhanced ESF layout that met all of the favorable features identified in the ESFAS, and that offered numerous constructibility/operability and scientific advantages to the program, was developed by the M\&O and submitted to the YMP Change Control Board (CCB) in 1993. Entitled, "Description and Rationale for Enhancement to the Baseline ESF Configuration," (M\&O, 1993e) it was accepted by the CCB in FY 1994 and has been incorporated into YMP's baseline documents. A report describing the conceptual repository layout that was integrated with the enhanced ESF layout was submitted to DOE in December 1993 (M\&O, 1993b). The repository concept presented in that report formed the primary basis for a set of six 
ESF/Repository interface drawings that were submitted to DOE in February 1994 $(\mathrm{M} \& \mathrm{O}, 19940)$, and that are in the process of being incorporated into YMP's baseline documents.

Besides addressing the fundamental program requirements listed in Section 3.2, and the general features described in the preceding paragraph, development of the repository layouts and operational concepts described in the sections that follow were predicated on incorporation of the design assumptions (some might also consider these to be design objectives or concepts) listed below into functional repository subsurface designs. Most of the items listed are CDA assumptions (M\&O, 1994m) that are more fully developed interpretations or ideas representing proposed methods of complying with various program requirements. References to specific requirements listed in Section 3.2 and/or specific CDA assumptions are provided inside brackets where appropriate.

All of the assumptions listed will require verification as the site characterization and ACD programs develop. Because the assumptions work together to provide the logistical framework for the integrated layouts described herein, they are considered to be used throughout the subsurface sections of this report unless otherwise noted.

A. Utilize Primary Area Identified by Previous Work - Develop a repository layout that generally fits and utilizes most of the region identified as Area 1 in Figure 8.3.2-3. (M\&O, 1994m, Key 022)

B. Utilize TSw2 Thermomechanical Unit for Repository Horizon - Location of an upper boundary for the repository horizon is principally influenced by the requirement to provide a minimum overburden of $200 \mathrm{~m}$ (10 CFR 960.4-2-5 (d)); an upper stratigraphic control is not clearly defined. Current borehole data indicates that an upper limit based on an increase in lithophysae porosity may exist in the TSw1 unit from 12 to $49 \mathrm{~m}$ above the TSw1/TSw2 upper contact (M\&O, 1994s). However, even though lithophysae porosity of the TSwl unit appears greater than the TSw2, there is as yet no definitive basis for favoring one unit over the other. Also, differences between the TSw 1 and the TSw2 units on the basis of rock quality are not consistent. However, due to uncertainty about differences in mechanical and thermal characteristics between TSw 1 and TSw 2 units, the TSw $1 / \mathrm{TSw} 2$ contact is assumed to be an upper limit for the repository horizon, so long as (with the exception of main ramps and shafts) all subsurface openings conform to the minimum $200 \mathrm{~m}$ overburden requirement. The TSw 2 unit provides adequate thickness for the repository and there do not appear to be stratigraphic zones within the TSw 2 that would limit repository development. The TSw $2 / T S w 3$ contact is an assumed lower limit to repository development that helps maximize the distance above the water table in the primary area and the thickness of underlying zeolitic strata. [M\&O, 1994m, DCSS 003; RDRD: 3.7.5.H; 3.7.5.E.3; 3.7.5.E.7]

C. Utilize Lynx Model for Definition of Geologic Surfaces - Structural contour, surface topography, water table, and other base maps included in Section 5, and originally defined in a $1994 \mathrm{M} \& \mathrm{O}$ analysis (M\&O, 1994s), were used in developing the repository layouts included herein. These maps were developed and plotted using 
the Lynx computer model, a program that has been approved for use in quality affecting work. However, the bulk of the geologic borehole data used by the model were not collected under an approved QA program. While much of the borehole data are of indeterminate quality, the information is the best that is available and its use is consistent with past YMP-conceptual design efforts. Assume that products generated by the Lynx model are of sufficient accuracy to support development of conceptual repository layouts and integrated ESF layouts that will not require significant changes as more geologic data become available and/or new geologic models evolve.

D. Maintain Linkage with Previous Work - Develop a layout that accomplishes objectives regarding ESF/Repository integration as outlined in the ESFAS (SNL, 1991) and that, as a minimum, embodies all of the favorable features identified for Option 30 in that document. Maintain the portal location and the azimuth of the North Ramp as currently defined in ESF Title II design (YMP, 1994b). [RDRD: 3.7.5.E.4]

E. Standoff from Faults - To the extent practical, situate main drifts and emplacement drifts in such a manner that they are not intersected by the primary faults shown on Figures 5.1.2-3 and 5.1.2-4. Based on engineering judgment, allow a minimum 120 $m$ standoff between the main trace of the Ghost Dance Fault and main drifts situated to the west of the fault. Allow $60 \mathrm{~m}$ minimum standoff for main drifts on the east side of the Ghost Dance and from other main faults, the assumption being that information gathered during site characterization will provide sufficient definition of actual fault locations and character at the repository horizon to make greater standoff distances unwarranted. [M\&O, 1994m, key 023; RDRD: 3.7.5.E.2; 3.2.6.2.5; 3.7.5.E.3; 3.7.5.E.7]

F. Utilize Flat/Horizontal Gradients in Emplacement Drifts - Orient emplacement drifts with flat gradients in order to maximize safety and operational stability of emplacement and retrieval processes. [M\&O, 1994m, DCSS 009; RDRD: 3.2.5.2.2.A; 3.2.1.4.B; 3.7.5.E.1; 3.7.5.H]

G. Use an In-Small-Drift Emplacement Concept - As presented in Section 8.5.1.1, 5.0 m diameter emplacement drifts can accommodate several variations of in-drift emplacement. Lacking definitive evaluations necessary to support selection of a specific emplacement concept, use $5.0 \mathrm{~m}$ excavated diameter emplacement drifts in the preparation of $\mathrm{ACD}$ layouts in order to maintain flexibility in design. Besides the obvious advantages that small diameter drifts offer in terms of opening stability and ground support requirements, this concept also helps maximize rates of progress in the construction of emplacement drifts while minimizing the amount of excavated tuff, all of which lends itself to minimizing the cost of repository development operations. Additionally, the various concepts support retrieval in a straightforward manner and could be automated relatively easily. [M\&O, 1994m, key 012,016 , 017; RDRD: 3.2.5.2.2.A; 3.7.5.E.2; 3.2.6.2.5; 3.7.5.E.5; 3.7.5.E.1; 3.2.1.4.B; 3.7.5.0.1; 3.7.5.D; 3.7.5.P.2; 3.7.5.P.3] 
H. Use Conventional Rail Transport for both Emplacement and Development Operations - Larger, heavier WPs make transport on conventional rail systems a practical option or solution. In addition, TBM operations are almost universally supported by railbound equipment. Conventional rail (sometimes termed adhesion rail) systems rely on the friction developed between steel wheels and steel rail to provide the resistance necessary to facilitate both starting (acceleration) and stopping (deceleration) of the trains. To a large extent, the safety of operations in these systems relates to the maximum gradient upon which the trains are required to operate. For purposes of this layout, limit the maximum grade on main ramps to 3.0 percent or less and the maximum grade "on block", e.g., main drifts used for emplacement drift access, to 2.0 percent or less. [M\&O, 1994m,DCSS 009; RDRD: 3.7.5.E.1; 3.7.5.F.5; 3.7.5.P.2]

I. Maintain Straight Emplacement Drifts - Each variation of in-drift emplacement described in earlier report sections requires the use of a rail system to carry the heavy, MPC-based WPs inside the emplacement drifts. One of the more likely upset conditions that can occur using rail haulage is derailment of the WP carrier. To the extent possible or practical, the emplacement drifts should be designed perfectly straight so that the likelihood of a derailment is minimized, thereby enhancing the reliability of transport inside the drift. For those emplacement concepts that use a permanent cart for both moving and final support of the packages, straight drifts represent a significant cost savings as the carts do not have to be manufactured with any turning capability, thus greatly simplifying their design and fabrication requirements. This feature also has significant implications in terms of radio- or laser-based control systems that might be considered in future work. Excavation using TBMs is also simplified. [RDRD: 3.2.5.2.2.A; 3.7.5.E.5; 3.7.5.E.1; 3.2.1.4.B; 3.7.5.O.1; 3.7.5.D; 3.7.5.P.2; 3.7.5.P.3]

J. Maximize the use of TBMs as the Principal Excavation Tool - The layout should accommodate excavation by TBM as the primary development tool, both for main drifts and emplacement drifts. Where practical, curves or other features should permit muck removal by conventional conveying systems. For long term installations, assume (based on engineering judgment) that curves should use a $305 \mathrm{~m}$ radius, but not less than $180 \mathrm{~m}$ if use of the longer radius is impractical. [M\&O, 1994m, DCSS 010; RDRD: 3.7.5.G.2; 3.2.5.2.2.B]

K. Minimize the number of Main and Secondary Access Drifts - Previous designs (SNL, 1987a; PBQ\&D, 1989) have utilized extensive systems of main and secondary access drifts that tend to consume space, create potential thermal perturbations, prolong construction schedules, and ultimately, raise costs. A simplified layout that reduces the number of main and secondary access drifts while meeting all of the fundamental program and safety requirements is considered (engineering judgment) to be highly desirable. [RDRD: 3.2.5.2.2.A]

L. Provide a Common Drainage Point for all Main Drifts - Ensure that all main drifts are sloped to facilitate water drainage to a common underground location for pickup and removal to the surface. [RDRD: 3.7.5.I; 3.2.3.2.2.A.11.a] 
M. Waste Inventory - Assume a waste stream totaling 70,000 MTU. [M\&O, 1994m, Key 003,005]

N. Areal Mass Loading (AML) - Rather than adopt a specific AML as a design basis, develop a repository layout that utilizes essentially all of the primary area (Area 1 in Figure 8.3.2-3). Calculate the storage capacity in MTU based on the resulting emplacement area available using a low AML of 25 to $35 \mathrm{MTU} / \mathrm{acre}$ and using a high AML of 80 to 100 MTU/acre. [M\&O, 1994m, Key 019]

O. Intermingling of Waste - Assume that HLW packages will be delivered on an asneeded basis so that they can be positioned in-between the SNF packages in the emplacement drifts, eliminating the need for additional emplacement drifts to accommodate the HLW inventory. Further, assume that there will be no restrictions regarding the intermingling of waste forms in the drifts.

P. WP Dimensions - Assume that the largest WP is $1802 \mathrm{~mm}$ in diameter, $5642 \mathrm{~mm}$ long, and weighs approximately $86,500 \mathrm{~kg}$ when loaded with 21 PWR SNF assemblies and filler material. [M\&O, 1994m, EBDRD 3.7.1.J.1 and 3.7.1.J.2]

Q. Subsurface Transport of WPs - Assume that the WPs will be transported along access routes in the subsurface inside a specially designed transport cask shielded to reduce radiation exposure to "stand-beside" levels. Assume that the packages are mounted on the emplacement carts and loaded into the cask in the waste handling building on the surface. [CDA Key 032, 033; DCS-003; RDRD: 3.2.5.2.2.B]

R. Emplacement Operations Equipment and Procedures - Assume that the conceptual emplacement operations and equipment discussion provided in Section 5.1.7.4.2 of M\&O, 1993b, represents a workable concept that could be engineered to provide adequate levels of reliability and personnel radiological safety. [RDRD: 3.2.5.2.2.A; 3.2.5.2.2.B]

S. Construction Materials in Emplacement Drifts - Assume that the use of a permanent, cast-in-place concrete invert, permanent steel rail, and steel or concrete ground support elements in the emplacement drifts does not pose insurmountable performance problems in terms of long term waste isolation. [M\&O, 1994m, DCSS 027; RDRD: 3.7.5.E.1; 3.7.5.E.7; 3.7.5.P.3]

T. Backfilling of Emplacement Drifts - Assume that backfilling of the emplacement drifts will not be required, but do not design a layout that precludes the possibility of being able to backfill if later work indicates a need for backfilling. Assume that if backfilling of the emplacement drifts is required, then it can be postponed until after the retrieval option is no longer a consideration. Also, assume that a backfill material will be selected that can either be pumped up to $700 \mathrm{~m}$ horizontally using conventional concrete pumping or similar equipment, or pneumatically conveyed over similar distances, and that the drift will not have to be completely filled to the crown. [M\&O, 1994m, Key 046, RDRD: 3.7.5.E.2; 3.7.5.E.5] 
U. Emplacement Drift Spacing - Adopt an emplacement drift spacing of $22.5 \mathrm{~m}$, to be used as an example in describing the operational interfaces of various drifts and for diagrammatic purposes, recognizing that drift spacing must be determined in conjunction with optimization of a system comprised of parameters that also include package spacing, drift diameter, thermal loading, thermal goals, potential variability in thermal characteristics of the waste stream, etc. [RDRD: 3.7.5.P.1]

V. Standoff of WPs from Access Drifts - Defined as the distance that WPs are set back from the nearest accessway, a thermal buffer, or "standoff distance" will limit the maximum rock temperature in the access drift. This is considered important in terms of both the working environment in the access drift and the influence that elevated temperatures might have on the stability of the drift. Based on results from various studies as discussed in Section 8.3.3, assume a standoff distance of $35 \mathrm{~m}$ between the centerline of the closest SNF WP and the closest rib in both the waste handling and the perimeter main drifts. This is considered fairly conservative since studies performed to evaluate this parameter have recommended similar distances and have not taken into account the cooling effect of ventilation air in the access drifts. [M\&O, 1994m, DCSS 023; RDRD: 3.7.5.E.1; 3.3.6.1.B]

W. Maximum Extraction Ratio - To promote long term opening stability and for purposes of conservatism, assume an upper limit extraction ratio of 30 percent in the emplacement drift area. This limit does not apply in the mains or other areas where waste is not emplaced. [M\&O, 1994m, DCSS 006; RDRD: 3.7.5.E.2]

X. Standoff from Vitrophyre - To prevent heating of the TSw3 and CHn units above the thermal goal of $115^{\circ} \mathrm{C}$ (Table 8.3.1-1), assume that a standoff of approximately $30 \mathrm{~m}$ between the WPs and the TSw $2 / T S w 3$ contact is sufficient when the nearest approach is along an edge of an emplacement area, but that the majority of the emplacement area should be at least $60 \mathrm{~m}$ above the TSw2/TSw 3 contact. [RDRD: 3.7.5.E.3; 3.7.5.E.7]

Y. Secondary Excavation Methods - As discussed in Section 8.4.2.1, currently available roadheader type mechanical excavation equipment offers the flexibility needed for performing miscellaneous, low-volume secondary excavation tasks, but is not well suited for excavating rock with physical characteristics as anticipated in the TSw2 unit. Also discussed is the fact that research being conducted by the Colorado School of Mines (under a YMP contract) involving adaptation/modification of current cutter disc technology to roadheader machines, and development of a design for a specially configured alcove miner, promises to augment the capabilities of those secondary mechanical excavation methods that offer the flexibility necessary for creating custom excavation profiles. It is assumed that this or similar equipment will be fully developed, tested, and will be available for repository construction, thereby eliminating the need to utilize drill and blast techniques to perform secondary excavation tasks. [M\&O, 1994m, DCSS 005; RDRD: 3.7.5.G.2]

Z. Emplacement Drift Orientation - Assume that, relative to in-situ stress and joint orientations, the alignment of openings such as the main drifts and ramps, which can 
be accessed and maintained throughout all phases of the repository program, is considered to be of considerably lower priority than the alignment of emplacement drifts, where heat and radiation pose formidable problems if maintenance is required. Based on the discussion of preferable drift orientations as outlined in Section 8.2.1.3, assume a bearing for emplacement drifts of N72W. [M\&O, 1994m, DCSS 001; RDRD: 3.7.5.E.2]

AA. Monitoring of Emplacement Drifts - Assume that monitoring and instrumentation equipment can be designed to travel along trackways suspended from the crown of the emplacement drift or in other locations that permit necessary monitoring activities to be conducted remotely, but can be removed as necessary to allow personnel to perform routine maintenance on this equipment without physically entering the emplacement drift. [RDRD: 3.2.5.2.2.B; 3.7.5.P.3]

BB. Air Quality - Assume that ventilation of all excavation operations will be provided by exhausting auxiliary fan/duct systems that will discharge through dust scrubbers into the service main and/or launch main airstreams. Assume that the efficiency of the scrubbers is sufficient to allow routine maintenance, travel, and other work to be conducted without special concerns regarding worker health and safety related to air quality in these openings.

\subsubsection{Alternative Layout Configurations}

Alternative layout configurations must be investigated as a part of repository ACD to address variations precipitated by different emplacement concepts, opening sizes, and layout objectives. Two different general layout configurations have been developed that are applicable to the emplacement modes discussed in Section 8.5.2. The first layout, designated Option I, uses the same layout concepts originally developed as a part of ESF/Repository interface work in FY 1993 and 1994 (M\&O, 1993b; M\&O, 1994a), with refinements in certain areas to enhance operational aspects and to conform to a new geologic model that contains later drilling information. The Option I layout incorporated the design objectives listed in Section 8.6.1 and is discussed briefly in Section 8.6.3, followed by more thorough descriptions in later report sections. The second, designated Option II, is an alternative to the Option I layout that provides a different method for developing a repository using TBMs, including a means for developing larger diameter emplacement drifts and a configuration that might have significantly different radiological safety aspects than the Option I layout. The Option II layout is discussed in Section 8.6.2.1.

\subsubsection{Conceptual Repository Layout - Option II}

An Option II layout concept, which is a variation primarily in the method in which emplacement drifts are configured, was developed in FY 1994. One "panel" of emplacement drifts illustrating the concept is shown in the left side of Figure 8.6.2-1. Other aspects of this figure are discussed later in this section. A complete repository layout using the Option II configuration has not been developed to-date; however, in Figure 8.6.2-1, a typical "panel" consisting, for example, of nine emplacement drifts is shown. Fewer drifts could be excavated in a panel if desired, but it is felt that nine drifts are close to a practical maximum 
limit, primarily due to the resulting loss of disposal area. This is because the innermost emplacement drifts move further into the emplacement area as the number of drifts in the panel increases.

The basic configuration shows, for example only, emplacement drifts spaced at $40 \mathrm{~m}$ centers and curves within the emplacement drifts at a $100 \mathrm{~m}$ radius. In an actual layout, the drift spacing would be established based upon thermal loading and other requirements. The emplacement drift curve radii would be established by the curve performance limitations on the TBM. Curve performance limitations are based upon many factors, many of which are particular to a TBM manufacturer's design or machine set up. Factors include the size of the opening, length of the machine, internal construction within the TBM (such as length of the main beam or ability to articulate), length from the cutting head face to the cutting head pivot point, and the design of the muck handling components within the trailing gear (such as length or segmental design of the bridge conveyor).

The Option II concept uses the same perimeter boundary (i.e., the perimeter and service main drifts shown in Figure 8.6.3-1) as the Option I concept. Because of this, a number of the key design objectives associated with the Option I are also met in the Option II concept. Significant differences between the two concepts are discussed, and compared in general terms, below.

A. Utilize an In-Small Drift Emplacement Concept - The Option II layout can be used with either of the proposed emplacement configurations outlined in Section 8.5.2. However, because of differences in TBM launching concepts, the Option II layout is not restricted to small diameter emplacement drifts, because it does not rely on a mechanized approach for TBM launching as in the Option I layout. Due to the emplacement drift entry differences and curves located in those drifts, some design differences in emplacement and backfill equipment would be required compared to the Option I layout.

B. Use Conventional Rail Transportation for Both Emplacement and Development Operations - Curve radii within the Option II concept emplacement drifts, while smaller than those used in the Option I layout, are judged to be suitable for rail operations throughout.

C. Minimize the Number of Main and Secondary Access Drifts - The Option II layout uses the same service main and perimeter main drifts, as well as shaft and ramp configuration as the Option I layout. A TBM Launch/Waste Handling Main, used in the Option I layout and discussed in greater detail in Section 8.6.4.4 is not incorporated into the Option II layout. The amount of secondary access drifting is generally comparable between the two concepts. For example, main drift crosscuts in the Option I layout are replaced by access crosscuts into the panel in the Option II concept.

D. Maintain Straight Emplacement Drifts - Design features discussed below that are associated with the Option II layout dictate that curves in portions of the emplacement drifts are required; therefore, straight emplacement drifts are not maintained. 
The second purpose of the Option II was to develop a configuration that would offer significantly different approaches to several key aspects associated with the Option I layout. The different approaches are summarized below. As with any concept, some features may be more or less desirable, depending upon viewpoint and the degree of importance placed upon a particular feature. Presentation of such differences may eventually be useful to serve as a vehicle to reinforce the final selection of one particular concept over another.

Concept for Launching TBMs - A key aspect in developing any realistic layout concept which assumes TBM development as the primary excavation tool (M\&O, 1994m, DCSS-005) is a method of developing the many emplacement drifts without excessive TBM launching costs. In general, costs for launching are incurred in varying degrees: 1) when a TBM must be repeatedly disassembled and reassembled, 2) when a TBM must be moved frequently over long distances, unless a mechanized approach is available to move the machine more or less intact, and 3) when extensive excavations are required to launch a TBM each time.

The Option II layout uses an approach in which TBM launches are minimized to the extent possible, which is a function of the spacing of the emplacement drifts and the curve radii within the emplacement drifts. For the spacings $(40 \mathrm{~m})$ and radii $(100 \mathrm{~m})$ shown in Figure 8.6.2-1, nine emplacement drifts can be excavated with only six launches, if desired. For comparison, with a nine drift panel, if the curve radii were held at $100 \mathrm{~m}$ but the drift spacings were reduced to $20 \mathrm{~m}$, nine emplacement drifts would require nine launches. If the curve radii were reduced to $40 \mathrm{~m}$ (requiring a non-conventional TBM not produced by most major manufacturers) and the drift spacing was $20 \mathrm{~m}$, two launches would be required, and so on. In other words the number of launches increases as the spacing decreases for a fixed radius or as the radius increases for a fixed spacing.

In the Option II concept, the movement of the TBM between launch points is minimized while developing a panel. As stated earlier, the nine drifts shown in Figure 8.6.2-1 comprise one panel. Once a TBM breaks through into the access cross cuts at the center of the panel, the machine is moved forward only a relatively short distance (the move requires some rotation of the TBM to align with the new launch point), as discussed later in this section. TBM moves between panels will require some disassembly and reassembly to occur.

The Option II concept requires separate excavations for TBM launches, compared to the mechanized launch tube concept described in Section 8.7.1 for the Option I layout. These excavations are generally included as a part of the emplacement drifts to minimize their cost impact.

Using the basic Option I premises for thermal loading and emplacement drift spacing (Items $\mathrm{N}$ and $\mathrm{U}$ in Section 8.6.1), the Option II layout geometry, which is configured to some extent to facilitate TBM launching, has several ramifications which are disadvantages inherent in the Option II concept.

The first ramification is that, although the Option II concept can meet both the high and low thermal loading scenarios (Item N), it may not, as configured in Figure 8.6.2-1, utilize the available disposal area as efficiently as the Option I concept; comparison calculations have not been performed to determine the extent. A potential reason for this is because the total 
standoff from the center of the service and perimeter mains to the emplaced WPs is $150 \mathrm{~m}$ in the Option II configuration (refer to Figure 8.6.2-3, which is discussed later in this section). As a comparison, the Option I concept uses approximately $119 \mathrm{~m}$ of total standoff. Some additional disposal area is also lost due to the center access drift leading into each panel which will require WP standoffs in each emplacement drift which connects to it. The extra length added due to the curves of the emplacement drifts may reduce the impact of the above features somewhat.

The second ramification is that to incorporate the $22.5 \mathrm{~m}$ drift spacing philosophy of the Option I concept (Item U) would require either nine TBM launches if $100 \mathrm{~m}$ emplacement drift curve radii were maintained, or the curve radii could be reduced to $40 \mathrm{~m}$ which would require only two launches in a nine drift panel. The ramifications of the first approach are that a higher launching cost would result, but a relatively conventional TBM design could be used to excavate the emplacement drifts with $100 \mathrm{~m}$ radius curves. The ramifications of the second approach are that launching costs would be reduced, but a non-conventional TBM design, as mentioned earlier, would be required to excavate the emplacement drifts with $40 \mathrm{~m}$ radius curves.

The Option I layout premise regarding favorable drift orientation (Item $\mathrm{Z}$ in Section 8.6.1) is generally met by Option II emplacement drifts for the majority of their length, but the curved portion of the emplacement drifts would not fall within a favorable orientation window (Figure 5.1.6-1). A secondary window, which could potentially be considered favorable by examination of Figure 5.1.6-1, brackets an average orientation of approximately $\mathrm{N} 10 \mathrm{~W}$. Some portions of the emplacement drifts connecting into the center access drifts would meet this secondary potentially favorable orientation.

Sequence for Emplacement Drift Development - Development begins first by excavation of the service and perimeter main drifts. After the perimeter and service mains are excavated, panel development can begin. The left side of Figure 8.6.2-1 shows launch points for the TBM, as discussed above, as well as the overall sequence of emplacement drift development (numbers 1 thorough 9) in each "panel".

Prior to the emplacement drift development in a panel, the chamber for the initial TBM launch into the panel, and the center access crosscuts are excavated by techniques such as a roadheader. The center cross cuts are both stopped short of their intersection with the outer emplacement drift, as represented in Figure 8.6.2-1, Early Stage Development". This allows the option for continuous emplacement drift TBM excavation without a launch, until the full $90^{\circ}$ curve of the emplacement drift can no longer be excavated because of TBM curve performance limitations.

As discussed earlier, this example assumes a $100 \mathrm{~m}$ minimum curve radius as the performance limitation, which allows the first four emplacement drifts to be excavated using a single launch. The "Later Stage Development" portion of Figure 8.6.2-1 shows the point where the fourth drift is nearing completion. At completion, the TBM breaks into the center access crosscut and is moved into the second launch point (The first being the initial launch into the emplacement panel) which has been developed ahead of that time. Five successive breakthroughs and launches occur in a similar manner as each emplacement drift is excavated 
until the final breakthrough of the center emplacement drift occurs into the end of the cross cut. At this point, the TBM is disassembled as required based upon opening sizes and travel clearances and moved to the next nine drift panel.

The development of the access crosscuts and launch chambers on each side of the panel requires careful integration of those activities with emplacement drift TBM excavation, muck handling, and supplies transportation operations. The general principle for development of the center access crosscuts is that they are advanced in stages as the emplacement drifts in the emplacement panel are completed. In general, using Figure 8.6.2-1 for reference, if the emplacement drift is being advanced toward the service main side of the panel, the center access crosscut on the service main side is being advanced. This advance includes short emplacement drift stubs for the TBM to break into, as well as excavation of that portion of the following emplacement drift that will serve as the next launch chamber. Examples of these excavations are shown on the service main side in the "Later Stage Development" portion of Figure 8.6.2-1.

Exceptions to this general development sequence are when the TBM is excavating the "first loops" of the emplacement panel spiral. Using the configuration shown in Figure 8.6.2-1, the "first loops" would consist of the first four drifts that are developed after the first launch but before the second launch. In this stage of panel development, access crosscut development would occur opposite the direction of TBM advance (i.e. crosscut development on the perimeter main side when the TBM is heading toward the service main side). An example of when this advance would be necessary is shown on the perimeter main side of the panel in the "Early Stage Development" portion of Figure 8.6.2-1.

From a practical standpoint, to carry out an excavation operation as described will require some flexibility in the scheduling of personnel and will require worker skill versatility. Crosscut excavation operations could be scheduled during shutdowns such as a weekend, with the crosscut advanced as far as possible during the shutdown period. Alternately, emplacement drift excavation operations could be temporarily suspended for several shifts while the crosscut is advanced using the TBM crew to accomplish the conventional excavation operations. This type of scheduling and worker flexibility is common in underground mining operations.

The Option II concept allows the capability to conduct simultaneous development and emplacement operations; although, two full emplacement panels would need to be completed prior to the start of emplacement operations. One panel would be available and used for emplacement. The second panel would have finish construction operations being conducted such as invert and shielding door construction. A third panel would then be under excavation at that time.

Muck Handling Options - A current assumption in the CDA is to use conveyors for muck handling where practical (M\&O, 1994m, DCSS-010). The Option II concept is configured to allow the flexibility to use a mix of conventional and specialty conveyors to accomplish this. Figure 8.6.2-2 provides a general plan for muck haulage with the Option II concept. As shown in that figure, an extensible troughed belt conveyor (M\&O, 1993d, p. 5-17 to 5-20) is located in the service main drift. This conveyor handles muck from a portion of the panel 


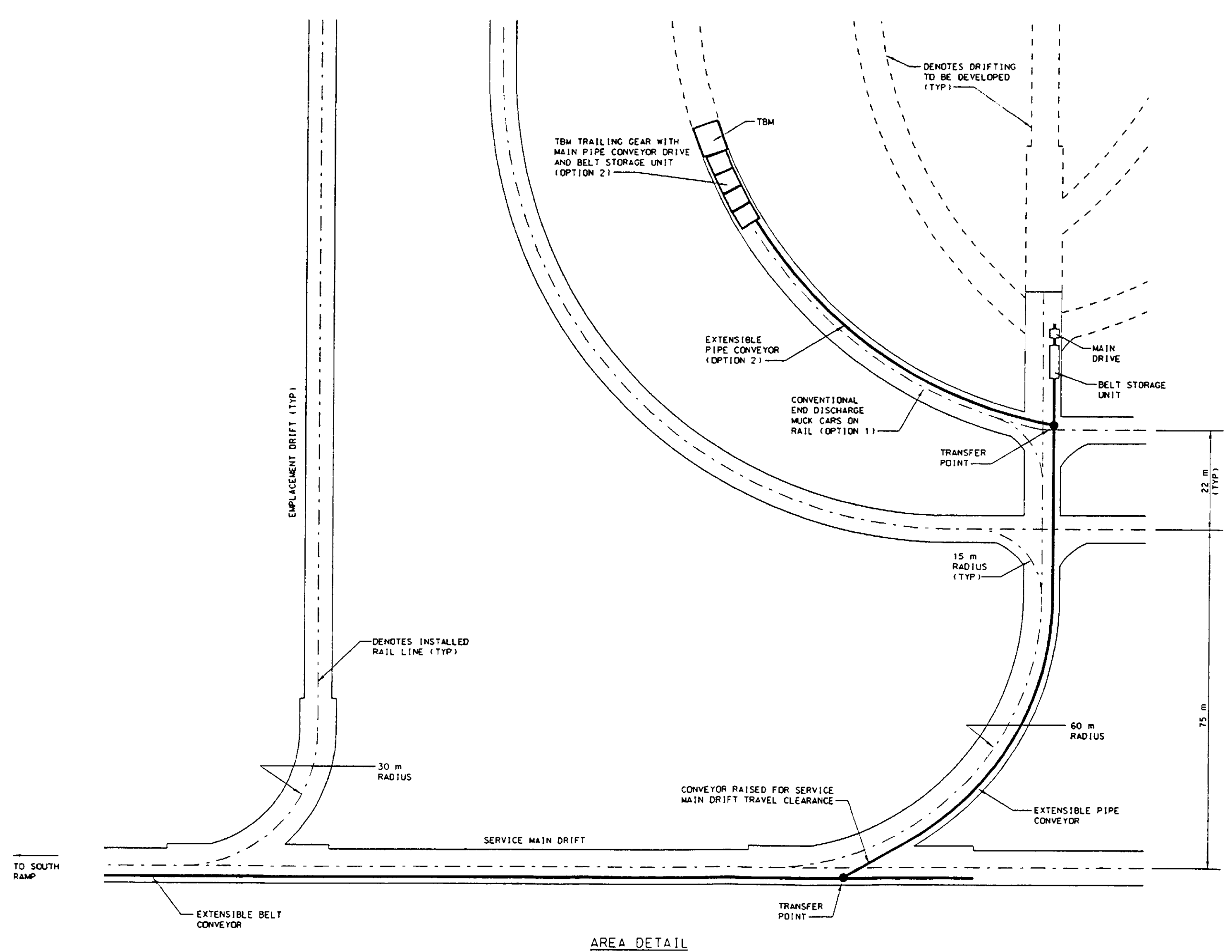

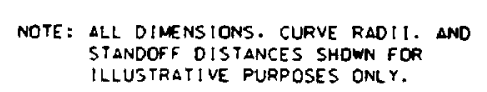

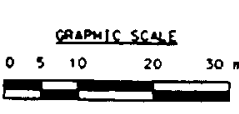

Figure 8.6.2-2

ALTERAAE LAYOUT SHOWING
MUCK HANDL ING CONF ILURATION

\begin{tabular}{l|l} 
R REGAN & OESINEEO D EINARSON \\
\hline
\end{tabular} 
development and continues up the South Ramp to the surface. A similar extensible conveyor would be installed in the perimeter main drift.

Within the panel, located in the center access crosscut, is a pipe conveyor (M\&O, 1993d, 5-14 to 5-17) equipped to operate as an extensible belt system, as shown in Figure 8.6.2-2. A pipe conveyor is a specialty system seeing growing emergence in industrial applications as an alternative to conventional troughed belt conveyors. It would be capable of negotiating the majority of the curves designed into the Option II. At the loading point, a pipe conveyor is open in a conventional trough form, after which, it is formed into a pipe shape for the transport length with the material being handled completely enclosed. At the end of the transport run, and just before the discharge pulley, the belt again opens, thus allowing materials to be discharged in a normal fashion. The belt again forms into a pipe for the complete return run. A pipe conveyor with an extensible belt system was studied and was considered to be a feasible alternative to the conventional belt system that was installed on the recent Boston Harbor TBM tunnel project (M\&O, 1993u).

As the crosscut is advanced into the panel, the pipe conveyor tail, magazine sections, and transfer point would be moved in as required. Modular design of such components would enhance the capability to perform this activity. An identical, extensible pipe conveyor would also be installed in the access crosscut in the perimeter main side of the panel.

In some cases the configuration of a layout, particularly the inclusion of small-radius curves, and the size of the openings, make the use of a conveyor impractical in certain areas. An example of such a case is where, in a layout similar to Option I, the use of conveyors for muck handling was judged to be impractical (M\&O, 1993d, p. 5-44). Rail car muck haulage is used in the Option I concept for emplacement drift muck haulage as (discussed further in Section 8.7.1.2).

The Option II concept allows the use of either rail car muck haulage or an extensible pipe conveyor system, as discussed above, in the emplacement drifts. An example of these options is shown in Figure 8.6.2-2. If rail haulage was used, end discharge type muck cars (M\&O, 1993d, p. 5-26) would be the most practical way of loading directly onto the pipe conveyor in the center access crosscuts.

A key feature of the Option II layout is that muck haulage and supplies transportation (as shown in Figure 8.6.2-1) alternates between the perimeter and service main sides of the panel through the center access crosscut. For example, when the TBM is advancing toward the perimeter main side of the panel, muck and supplies are transported out of the panel on the service main side, and vice versa. An exception to this is when the first emplacement drift in the panel is being excavated. The muck and supplies route is shown in this case under "Early Stage Development" in Figure 8.6.2-1. For this first drift, muck haulage could be by rail using the configuration of the first launch point shown in Figure 8.6.2-1. If an extensible pipe conveyor was used, the curve in the first drift launch chamber is too small for operation of this type of belt system, as drawn in Figure 8.6.2-2. To accommodate such a belt, the curve at the first launch point would need to reflect those shown for the center access crosscuts. An approach may be to use rail haulage for the first drift and pipe conveyor 
haulage for the remaining emplacement drifts, but flexibility for this would need to be designed into the trailing sections of the TBM.

Radiation Environment at the Emplacement Drift Entrances - The Option II concept is configured in a manner such that the radiation sources in most emplacement drifts can be isolated by a combination of several methods. Three methods are used to isolate the source: engineered shielding, distance, and engineered and natural barriers. Engineered barriers include things like corners or minimized direct line of site. Natural barriers include the rock pillars in the emplacement area. Features incorporated into the Option II concept that would potentially mitigate radiation exposure using the above three methods are shown in Figure 8.6.2-3.

To achieve a greater assurance of radiation safety, the trade-off may result in a higher constructed repository cost and somewhat less efficient use of available disposal area to achieve these or other similar types of radiation mitigating features. This trade-off requires very comprehensive evaluations, not included in work scopes to date. If the above described or other engineered features could successfully control radiation levels at the waste handling drift to within acceptable limits, it may be possible to have controlled but relatively unrestricted human access in drifts adjacent to the emplacement drifts as a part of normal emplacement side operations.

\subsubsection{Interim Layout Configuration}

An objective comparison of all aspects of the Options I or II layouts has not been made at this time. Comprehensive personnel radiological safety and/or waste isolation performance evaluations of either layout, as well as representative cost comparisons, have not yet been conducted. In addition, many design aspects of the Option II layout have not been developed to the same level of detail or refinement as for the Option I layout. Work of this nature will be performed to define needed details, and the strengths and weaknesses for each of these layouts, as well as any additional layout configurations that may be developed as ACD progresses, will eventually be evaluated.

Lacking this additional work, and because it is felt that the Option I layout has been sufficiently refined to establish it as a workable concept that maintains linkage with current ESF design, the Option I layout shown on Figure 8.6.3-1 is used as the representative case under the terminology "Interim Layout," and is used as the basis for various discussions and descriptions presented subsequently in this report. A description of the major openings associated with the interim layout are presented in Section 8.6.4, followed by discussions of operational concepts and other features in later report sections.

\subsubsection{Interim Layout Description}

\subsubsection{North Ramp}

The North Ramp's initial function will be to provide first time access to the repository horizon to support site characterization activities. It may also be used as a launch point for exploratory drifting access to the underlying Calico Hills unit. 

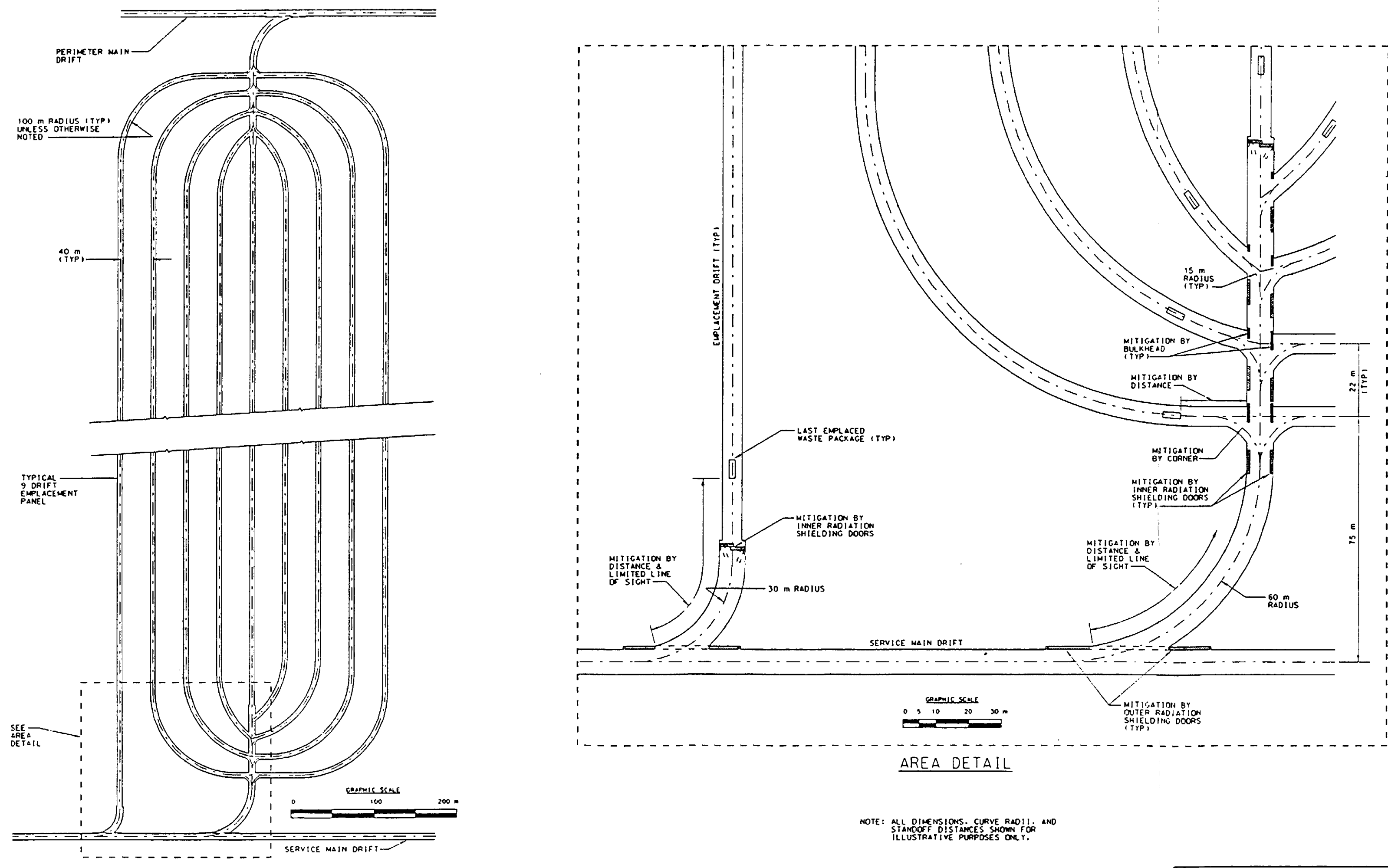

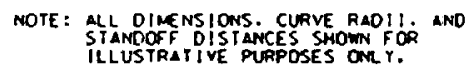

Figure 8.6.2-3

Alternate Layout Using Features: Which

Potentially Mitigate Radiation Exposure

\begin{tabular}{|l|l|}
\hline ORaAm R REGAN & oesicaeco D E INARSON \\
\hline
\end{tabular}

\begin{tabular}{|l|l}
\hline SKE TCG MMASR & CAO FIIE SSRM-SK 123. DCN \\
\hline
\end{tabular} 


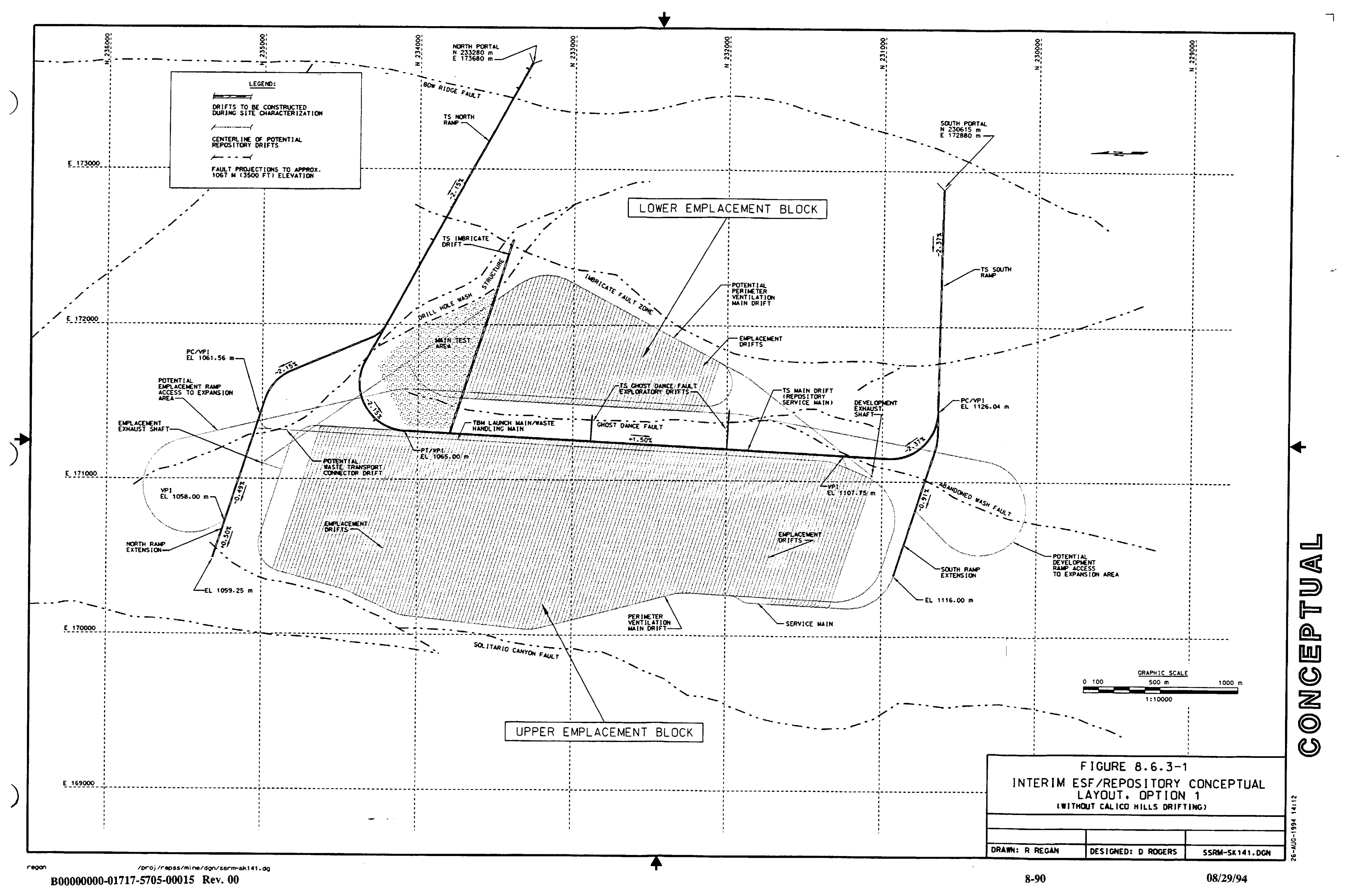


The ramp will be $7.62 \mathrm{~m}$ in diameter. The location of the North Ramp Portal and the alignment and diameter of the ramp were fixed during ESF Title II design (YMP, 1994b). A starter tunnel for launching a $7.62 \mathrm{~m}$ diameter TBM has been constructed.

In the interim repository layout, the North Ramp serves as the primary access for transportation of WPs to the subsurface from the waste handling building. The North Ramp also serves as the primary corridor for the transportation of personnel, equipment, and materials to support emplacement operations and serves as the primary intake airway for the emplacement side.

The gradient of this ramp was minus 8.9 percent in the SCP-CDR (SNL, 1987a). Later geologic interpretations that raised the TSw1/TSw2 contact in the northern portion of the primary area allowed the gradient to be decreased to minus 6.9 percent during ESF Title I design. The gradient of the North Ramp in the layout shown on Figure 8.6.3-1 is minus 2.15 percent (M\&O, 1994p), beginning at a point just inside the starter tunnel, extending through the curve that leads into the service main, and ending at the intersection of the curve with the service main.

The North Ramp could be configured for repository emplacement operations as shown in the general cross section on Figure 8.6.4-1. Utilities installed in the ramp and shown in that figure are discussed in Section 8.10.3. The ramp includes two rail lines with one electrical trolley. The purpose of the inner rail line is to provide a rail corridor for the locomotive that serves as the prime mover for the WP transport cask carrier.

The transport cask carrier will be a relatively simple railcar used to carry the cask from the waste handling building to an emplacement platform situated at the entrance to an emplacement drift. The carrier will require a relatively wide wheel base for lateral stability because of the wide, heavy load of the transport cask with contained WP. The outer two tracks are therefore included to provide a wide running base for the carrier.

A single trolley is used as the ramp should not receive high personnel and materials transportation traffic during emplacement operations. In addition, from a safety standpoint, it would probably not be desirable to have two-way traffic in the ramp while transporting a WP to the subsurface. Thus, the ramp will require controlled access as described in Section 8.7.2.1, and potentially, signaling systems may be necessary to enhance ramp operational safety.

\subsubsection{North Ramp Extension}

The North Ramp extension will be excavated during the site characterization phase of the YMP program. Its initial function is to provide an east-west crossing of the potential repository block to explore for north-south trending geologic features and to examine the Solitario Canyon Fault. It can also be used for access to test alcoves or drifts that could be located in the upper half of the TSw2 unit along the lower reaches of the alignment. 

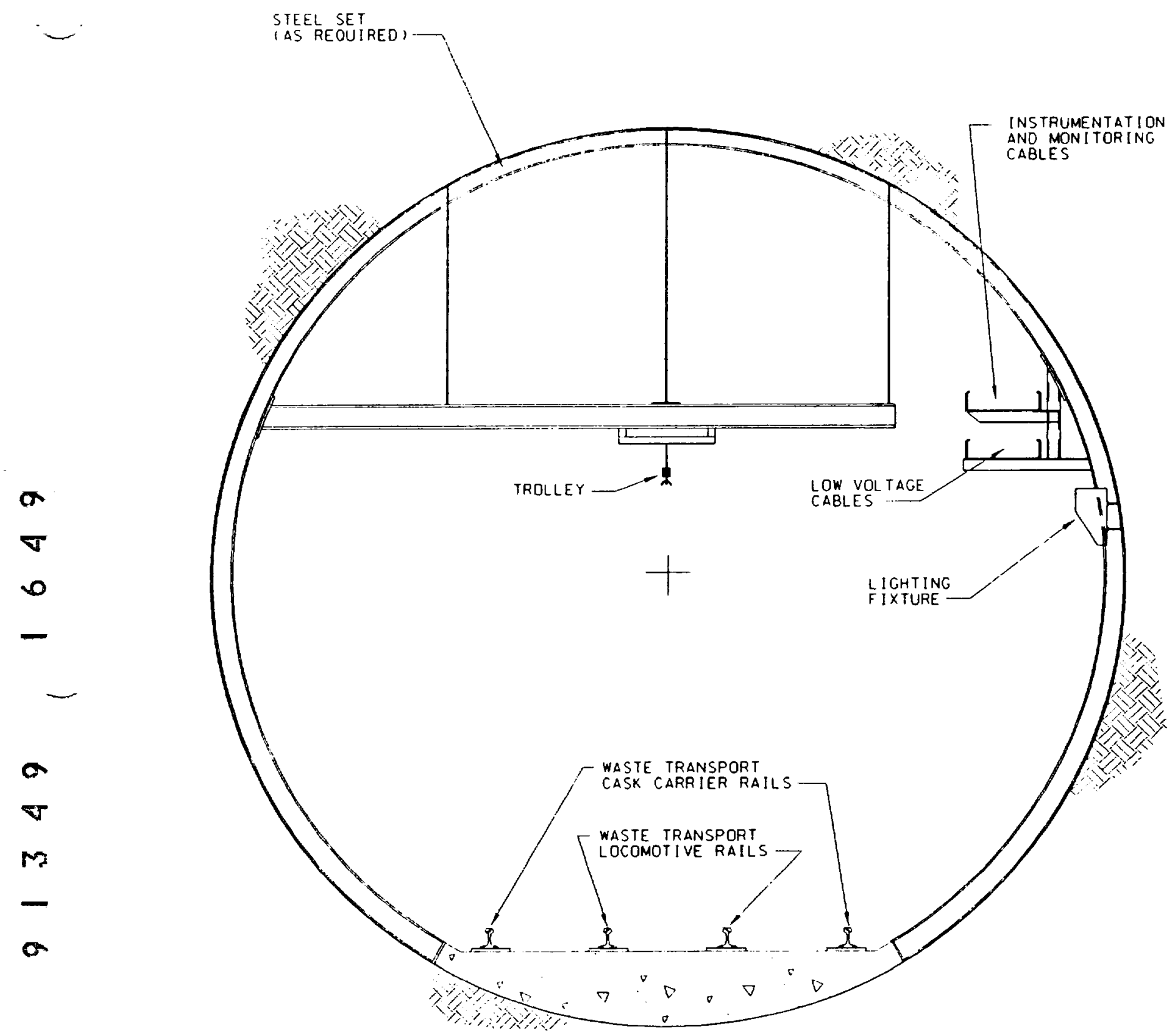

( VIEW LOOK ING DOWN GRADE)

GRAPHIC SCALE

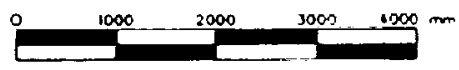

Figure 8.6.4-1. North Ramp Cross Section (During Emplacement Operations) 
The configuration of the North Ramp extension as shown on Figure 8.6.3-1 differs significantly from that shown on Figure 8.1-7, which represents the current baseline for this opening. The changes in alignment were made to enhance the utility of this opening in the potential repository by providing an alternate means of accessing the waste handling main for WP transport and to provide repository construction access for this main via the potential waste transport connector drift indicated on Figure 8.6.3-1. The reconfiguration also permitted the repository emplacement area to be extended further north, increasing the area available for emplacement, and partially offsetting area lost in the southwest corner of the emplacement block as discussed in section 8.6.4.5. The realignment is also beneficial to the site characterization effort for the following reasons:

A. The intersection formed between the North Ramp and the turnout for this drift as currently baselined (Figure 8.1-7) was located at the approximate point where the Drill Hole Wash Structure is predicted to cross the North Ramp alignment. The reconfiguration moves the turnout farther east in an attempt to avoid potentially difficult ground conditions at the intersection. Because of difficulties associated with accurately predicting the location of the Drill Hole Wash Structure, the proposed location of this turnout will have to be field verified during construction.

B. The close proximity of the North Ramp extension to the repository perimeter main, as currently baselined has potential test/repository interferences, and therefore does not provide a great deal of flexibility with respect to potential test alcoves or drifts that might be located off the extension. The realignment moves the extension further away from the perimeter main and should provide more flexibility regarding the layout of test alcoves and/or drifts.

C. The point where the North Ramp extension crosses the Solitario Canyon Fault was not changed, but the azimuth used in the longer leg of the realignment to access that point was set the same as shown on Figure 8.6.3-1 for the potential emplacement drifts (288 degrees). This may be advantageous in terms of correlation between testing data and potential repository design.

D. The realignment avoids potentially difficult tunneling conditions that could have been experienced using the current alignment. The baselined alignment shown on Figure 8.1-7 runs in close proximity and sub-parallel to the Drill Hole Wash Structure along much of its length. The proposed realignment avoids this condition, but does cross the Structure at a high angle about midway along the reach. Combined with the crossing of the Drill Hole Wash Structure that will be made in the lower portion of the North Ramp, the second crossing facilitated by the realignment will provide better understanding of this structure in the immediate area and should help define limits for repository openings in nearby areas.

Based on cross-sections generated by the Lynx geologic model as described in M\&O (1994s), the realignment would traverse about the same horizontal distance within the TSw2 as the baselined configuration, but will expose slightly more of the unit because the alignment terminates at a lower point in the stratigraphic column. 
A negative feature of the realignment is that the total length of the North Ramp extension would increase by approximately $408 \mathrm{~m}$ relative to the current baseline configuration. However, this increase is offset by a $828 \mathrm{~m}$ decrease in the length of the South Ramp extension (see Section 8.6.4.8), resulting in a net $420 \mathrm{~m}$ decrease in the combined lengths of these two drifts.

Figure 8.6.4-2 is a section showing the position of the North Ramp and the extension relative to geological and other surfaces generated by the Lynx computer model.

During repository operations, this ramp extension could provide access to a centrally located, dedicated waste emplacement main, if such is determined to be necessary based on retrieval, backfilling or other concerns. If lower thermal loadings or other conditions result in a need to develop emplacement areas on the east side of the Ghost Dance Fault, then this extension would provide a launch point for driving an emplacement operations access ramp to the lower block. (An emplacement block located east of the primary block would be significantly lower in elevation due to the eastward dip of the formation.)

The diameter of the extension would be 7.62 meters, consistent with other openings that serve as primary accesses and airways in the integrated layout.

\subsubsection{Service Main}

Except for a short reach extending north from the intersection with the bottom of the North Ramp, the remainder of the service main would be excavated during site characterization where it is called the "TS Main Drift" or the "North-South Drift."

This opening is the primary feature in the integrated layout that controls the gradient of all other main drifts and of the North and South Ramps. It also controls the elevation of the emplacement drifts.

One of the key assumptions listed in the CDA (M\&O, 1994m, Key 023) is to avoid emplacement drifts crossing major faults such as the Ghost Dance Fault. Since the larger area available for emplacement is west of the Ghost Dance Fault, this led to a basic design decision to locate the service main west of, and to orient the service main more or less parallel to, the Ghost Dance Fault. Because very little is known about the character of the Ghost Dance Fault at depth, and because it is doubtful that much additional information will become available prior to excavation of the service main during site characterization, it was decided that a minimum 120 meter standoff distance should be allowed between the drift and a projection of the main surface trace of the fault to the repository horizon.

The dip of the Topopah Spring Unit is basically to the east. Therefore, in order to accommodate the design assumption/objective dealing with flat-lying emplacement drifts, it was necessary to situate the service main high in the TSw2 in order to provide for maximum utilization of the unit when horizontal emplacement drifts are extended to the west. 


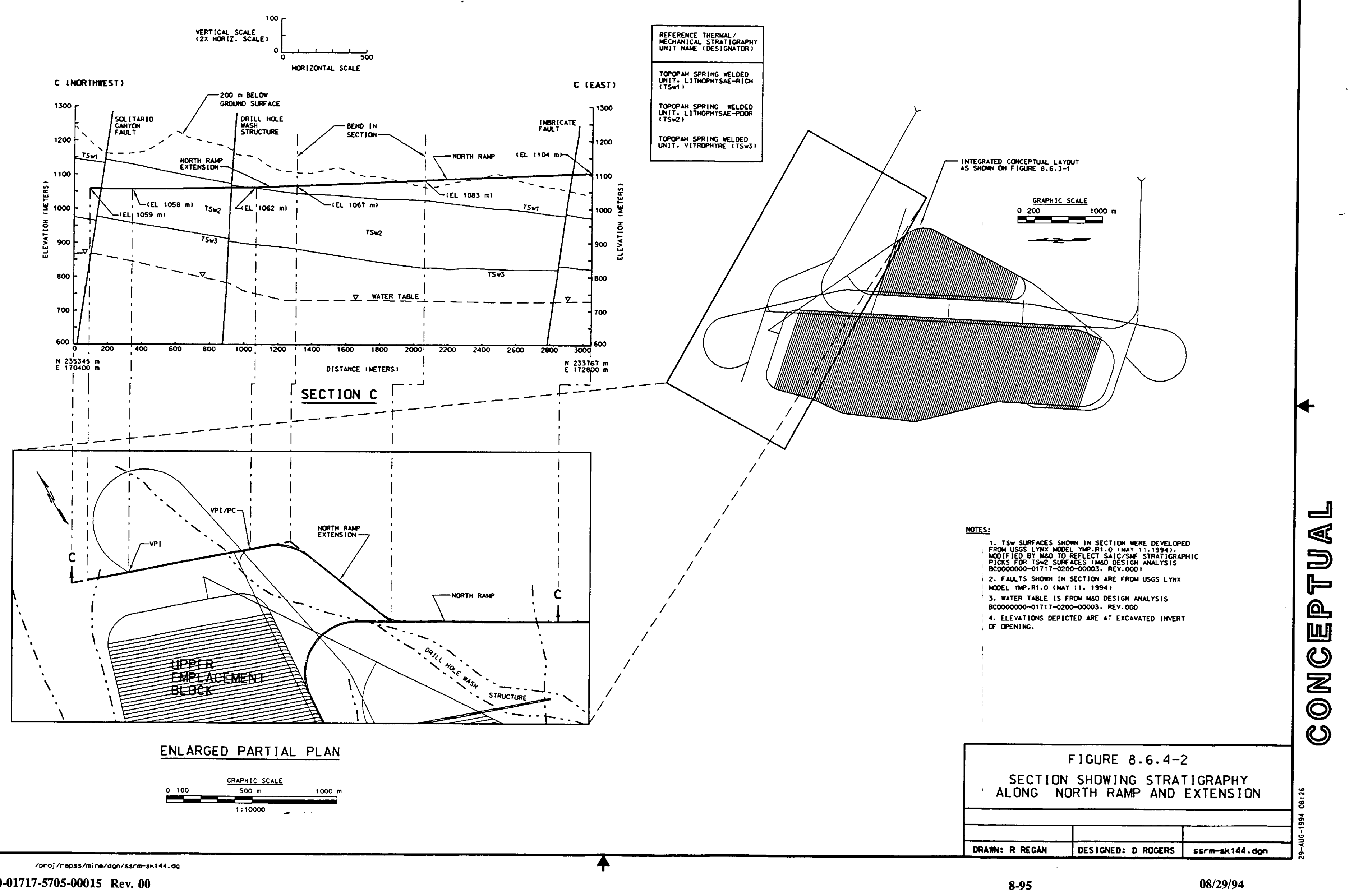


As shown on Figure 8.6.4-3, the service main slopes upward to the south at 1.50 percent to the bottom of the South Ramp. Based on the structure contour map presented as Figure 5.1.2-3 in Section 5.1.2, the crown of the service main is located immediately below the TSw1/TSw2 stratigraphic contact at the north end of the layout, and is approximately 37 meters below this contact at the bottom of the South Ramp.

The alignment and grade of the service main as shown on Figure 8.6.3-1 and 8.6.4-3 have been revised from that shown in the baselined ESF/Repository interface drawings (M\&O, 19940). Consistent with a comment made by the repository subsurface design group during the 90 percent review of ESF Design Package 2C, the alignment of the TS Main Drift/Repository Service Main has been straightened, eliminating the slight bend located at the approximate mid-point, in order to enhance and simplify various operational aspects relating to repository development and emplacement processes--primarily those dealing with service and TBM launching equipment and waste emplacement equipment. Based on similar reasoning and using the structure contours defined by the current Lynx geologic model (see Figure 5.1.2-3), the grade break in the main drift (from 0.5 percent to 2.0 percent) has been eliminated; a constant grade of 1.50 percent is now used.

During repository operations, the service main would function as the primary, on-block accessway for development operations personnel, equipment, and materials haulage, and would provide space for utilities installation and a conveyor system for transporting excavated tuff away from the active emplacement drift development area. It would accommodate a movable, raised platform upon which numerous rail switching tracks and crossovers would be mounted to facilitate simultaneous access into several different emplacement drifts in varying stages of construction.

In the southern portion of the upper emplacement block, a short section of service main is located in the southwest corner of the potential emplacement block. This feature of the layout was necessitated by a need to begin a climb in the eastern side service main away from the southeast corner of the emplacement area in order to minimize the grade of the South Ramp and maintain a gradient under 2 percent in the service main. An equally importance consideration was to avoid an area of less than $200 \mathrm{~m}$ cover in the southeastern corner. In this section of the upper emplacement bock, the operational functions of the TBM launch main and the ventilation perimeter main would reverse. That is when emplacement drifts are developed in this area of the upper block, the emplacement drift TBMs would traverse the block from west to east as opposed to the normal each to west direction.

The service main would also function as a primary ventilation airway in both emplacement and development operations.

\subsubsection{TBM Launch Main/Waste Handling Main}

The TBM Launch Main/Waste Handling Main is oriented parallel to the service main and the two are interconnected by crosscuts at each emplacement drift location. This opening would be constructed during the initial phase of repository construction, prior to emplacement of waste. It would be 9.0 meters in diameter, an increase from the 7.62 meter diameter mentioned in M\&O, 1993b and M\&O, 1994a. This change was necessitated by the greater 

length MPC-based WPs relative to the multibarrier package concept ( 5.6 meters versus 5.0 meters) and adoption of 5.0 meter diameter emplacement drifts in lieu of the 4.3 meter diameter drifts used in the previous work.

The function of this main in development operations, as implied by its name, would be to provide space for mechanized launching (see Section 8.7.1.1) of a 5.0 meter diameter TBM for excavation of emplacement drifts. Launching eliminates the need to construct individual launch chambers at each emplacement drift location. It is conceivable that the service main could provide this function, thereby eliminating the need for construction of an additional large diameter opening. However, it is highly probable that more than one TBM will be required in order to maintain a sufficient rate of emplacement drift construction to support the waste receipt schedule. Without a dedicated launch main, it would be extremely difficult to launch one TBM while servicing another from the same primary access opening due to interference between the two operations.

In emplacement operations, this main would serve as the primary, on-block waste handling drift on the emplacement side of the repository. Its diameter would be sufficient to permit rotation of the WP subsurface transport cask (in a horizontal plane) to align the WP with an emplacement drift opening.

This opening would also serve as a primary ventilation airway for both development and emplacement operations.

\subsubsection{Perimeter Ventilation Main}

The perimeter ventilation main functions as a primary ventilation airway in both development and emplacement operations. It would be 9.0 meters in diameter and would be excavated during the initial stages of repository construction, prior to waste emplacement. As with the launch main, the diameter of this drift has been increased relative to that described in previous work (M\&O, 1993b and 1994a) to facilitate handling of the MPC-based WPs and the 5.0 meter diameter emplacement drift TBMs.

In addition to providing ventilation, this main also affords an alternate means of access to the emplacement drifts for carrying out instrumentation monitoring, performance confirmation, or similar tasks that might interfere with actual emplacement activities being conducted in the waste handling main. It would also serve as a backup means of access to retrieve or extract WPs in the unlikely event of a rock fall or other off-normal condition that might occur in an emplacement drift. During emplacement drift backfilling operations (if backfilling is determined to be necessary), this opening would be utilized extensively as a means of delivering backfill to the western half of the emplacement drifts, thereby reducing the distance that backfill conveyance devices inside the emplacement drifts would be required to deliver the backfill material.

On the development side of the repository, this opening provides space for specialized equipment to retrieve the smaller diameter emplacement drift TBMs as they complete each drive across the block. The perimeter main also provides a route for the TBMs to be 
transported back to the east side (except as noted in Section 8.6.4.3) of the repository, into the launch main, to begin another emplacement drift.

The location of this drift is determined by physical conditions of the site. Along much of the northern half of the alignment, its location in plan was established by allowing for a 60 meter standoff from the Solitario Canyon Fault (M\&O, 1994m, Key 023). Toward the south end, however, it was necessary to limit westward extension of emplacement drifts in order to maintain at least 30 meters standoff between WPs along the edge of the thermal buffer zone adjacent to this opening and the TSw $2 / \mathrm{TSw} 3$ contact. The structure contours generated by the Lynx geologic model (refer to Figure 5.1.2-4) show this contact at a significantly higher elevation in this area when compared to the IGIS model that was used as the basis for locating this drift in M\&O, 1993b and M\&O, 1994a. The effect of this change is a reduction in available emplacement area.

Since flat-lying emplacement drifts are at the same elevation where they intersect the perimeter main as they are at the east end where they join with the launch main, and since grades in the launch main parallel those in the service main (the basis for elevations in the service main was discussed in Section 8.6.4.3), grade control in the perimeter main is determined by elevations in the service main throughout the emplacement area. At the south end of the layout, the perimeter main would slope up to a high point to facilitate drainage. At the north end, the perimeter main would slope downward to a collection sump located at the emplacement operations ventilation shaft. Section 8.9 discusses repository drainage in greater detail.

The curved portions of the perimeter main at the north and south ends of the repository block are configured to provide for ease of constructibility through the use of long radius curves. At the south end of the block, the main is situated to avoid increased faulting and areas where the 200 meter cover restriction becomes limiting. At the north end of the layout, it is located just south of the Drill Hole Wash Structure at the point where the main curves to meet the service main.

\subsubsection{Waste Emplacement Drifts}

The diameter of waste emplacement drifts in the interim layout is 5.0 meters, for reasons discussed in Section 8.5.2. These drifts provide space for emplacement of WPs on pedestals using a gantry, or on railbound carts in the center or to one side of the emplacement drift.

As concluded in Section 8.2.1.3, the optimum orientation of subsurface openings at Yucca Mountain from a ground control or stability point of view appears to lie between bearings of N70W and S75W, with approximately east-west being the most favorable direction. The waste emplacement drifts in the interim layout are oriented at a bearing of $\mathrm{N} 72 \mathrm{~W}$, near one edge of this most favorable "window" and forming a $75^{\circ}$ intersection with the launch/waste handling main. It is considered important that the emplacement drifts be aligned within this window in order to minimize support requirements and to reduce chances that ground support maintenance will be required after emplacement of WPs. In other words, the alignment of openings such as the main drifts and ramps, which can be accessed and maintained throughout all phases of the repository program, is considered to be of considerably lower 
priority than the alignment of emplacement drifts, where heat and radiation pose formidable problems if maintenance is required.

The N72W orientation selected for this layout was based on a desire to stay inside the favorable window and resulted from graphical inspection that indicated a best fit to the physical shape of the available area and TSw2/TSw 3 structure contours on the west side of the Ghost Dance Fault, while maintaining what is judged to be a stable angle of intersection with the main drifts. The selected orientation also helped maximize the length of individual emplacement drifts, which is desirable for operational reasons relating to the use of TBMs as the primary excavation tool. Longer drifts mean lower costs and greater average advance rates because less time is spent in a moving/launching mode, thereby enhancing the utilization of each machine. Additionally, the number of emplacement doors or other fixtures at the entrance to each emplacement drift are minimized.

The basic operational concepts utilized by the interim layout will accommodate other emplacement drift orientations inside the favorable window. Future work should investigate optimization of emplacement drift alignment.

A primary objective in developing the layout was to maintain level gradients in the emplacement drifts to facilitate safety and equipment operational stability aspects of emplacement activities. While this goal has been attained in the layout, future work should investigate introduction of shallow slopes ranging between 0.25 percent and 0.75 percent to provide drainage out of these drifts as stipulated in the CDA (M\&O, 1994m, DCSS-009).

Determination of the optimum spacing for emplacement drifts involves a great deal of design analysis to weigh the effects of WP physical characteristics, variability in thermal characteristics and resultant WP spacings against drift diameter and spacing, against various thermal loads and thermal goals, and against long-term drift stability. Closer emplacement drift spacings enhance flexibility in terms of the maximum thermal loading that can be achieved, especially important with the lower thermal energy output packages, but tends to raise costs because a greater unit length of emplacement drift is required per package. However, flexibility is considered crucial because of the limited understanding regarding the thermal loading issue that is available at this point in the ACD effort. For this reason, an emplacement drift spacing of 22.5 meters is used in the interim layout shown on Figure 8.6.31 , and is considered to be a minimum in terms of the long term stability of the pillars and intersections formed where the emplacement drifts and crosscuts intersect the two main drifts along the east side of the layout. A great deal of work remains to be performed in this area.

\subsubsection{South Ramp}

The South Ramp will be excavated during site characterization. It will be 7.62 meters in diameter. The ramp includes a 305 meter radius curve which connects to the service main and completes the primary loop to be excavated during ESF construction.

In the interim layout the South Ramp serves as the primary access for transportation of personnel, equipment and materials to the subsurface for support of repository development operations. It would also serve as the main ventilation intake airway for the development 
side of the repository. This configuration was identified as a potential alternative concept in M\&O, 1993a, (p. 5-51) and differs from concepts presented in M\&O, 1993b and M\&O, $1994 \mathrm{a}$.

Title I ESF design (YMP, 1993g) located the south portal next to the nose of a ridge on the southeast flank of Yucca Mountain. As presented in M\&O, 1993b and M\&O, 1994a, and for purposes of the interim layout, the same ridge was utilized but the portal was moved downhill and farther to the east in order to maintain a slope on the ramp of less than 3.0 percent, consistent with the CDA (M\&O, 1994m, DCSS-009), but still above the probable maximum flood plain. The resulting slope of the ramp is minus 2.37 percent.

The ramp was oriented by inspection to lie directly beneath the spine of the portal ridge, a practice generally considered to be favorable in terms of opening stability. When extended straight into the mountain, this orientation gave a reasonably good fit with the emplacement block area and kept gradients comfortably beneath the 3.0 percent maximum.

The South Ramp could be configured during repository development as shown in the general cross section of Figure 8.6.4-4. Utilities installed in the ramp and shown in that figure are discussed in Section 8.10.3. The ramp is configured with two electrical trolley rail lines, one for downgrade and one for upgrade haulage. Two tracks will minimize the potential for a bottleneck to develop in the ramp during materials transport, the function that will require the greatest use of the track. Safety will also be enhanced because the same track will not be used for travel in opposing directions under normal operations. Two tracks will also add flexibility to transport personnel and materials if one track is damaged or in need of maintenance, prior to repairs, without completely shutting down the supply corridor to the development area.

A second feature that could be incorporated into the design of a two-rail line system is the use of the outer rails of the two tracks or the inner rails of the two tracks as "wide-load" rail lines. This concept would be useful when moving large items into or out of the repository. Examples include service platforms, major TBM components and launching equipment, and other uses where a wider wheel base carrier may be advantageous.

\subsubsection{South Ramp Extension}

The South Ramp extension continues in a westerly direction for approximately 180 meters . from its point of intersection with the South Ramp. It then curves northwest and enters another tangent section, approximately 900 meters in length, that terminates in a final curve that turns the ramp extension North. At this point, it connects to a short section of service main that parallels, and then intersects, the ventilation perimeter main. The ramp extension is 7.62 meters in diameter, consistent with other main drifts in the layout that function as primary accesses and ventilation airways, but are not used for waste emplacement operations or for TBM launching and retrieval. Figure 8.6.4-5 is a section taken along the South Ramp and South Ramp extension showing the relationship between these drifts and geological and other surfaces plotted using the Lynx computer model. The layout of this drift as shown on Figure 8.6.4-5 differs significantly from that shown on Figure 8.1-7. The change is a result 


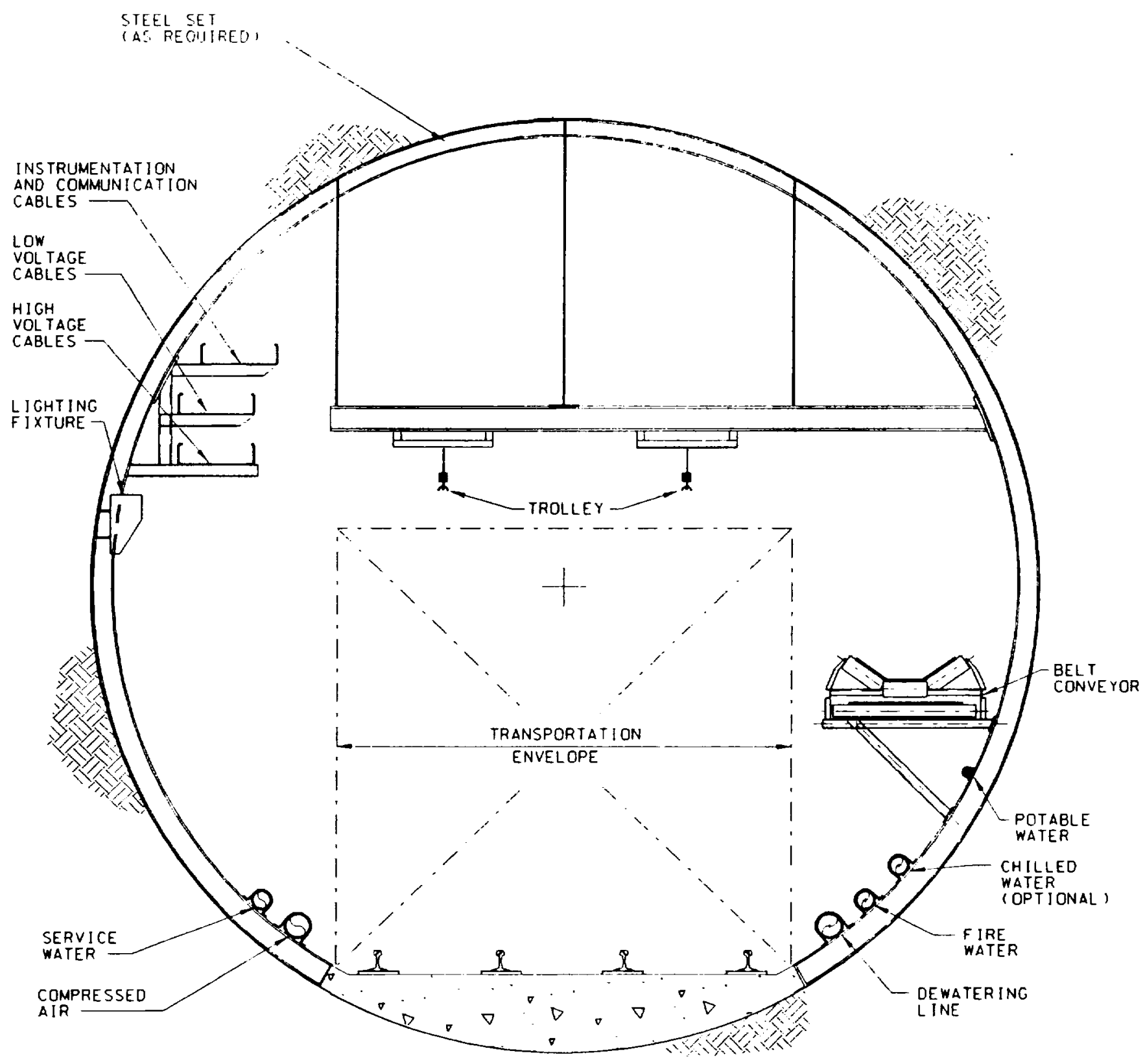

( VIEW LOOK ING DOWN GRADE)

GRAPHIC SCALE

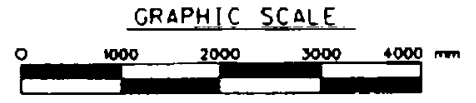

Figure 8.6.4-4. South Ramp Cross Section (During Development Operations) 


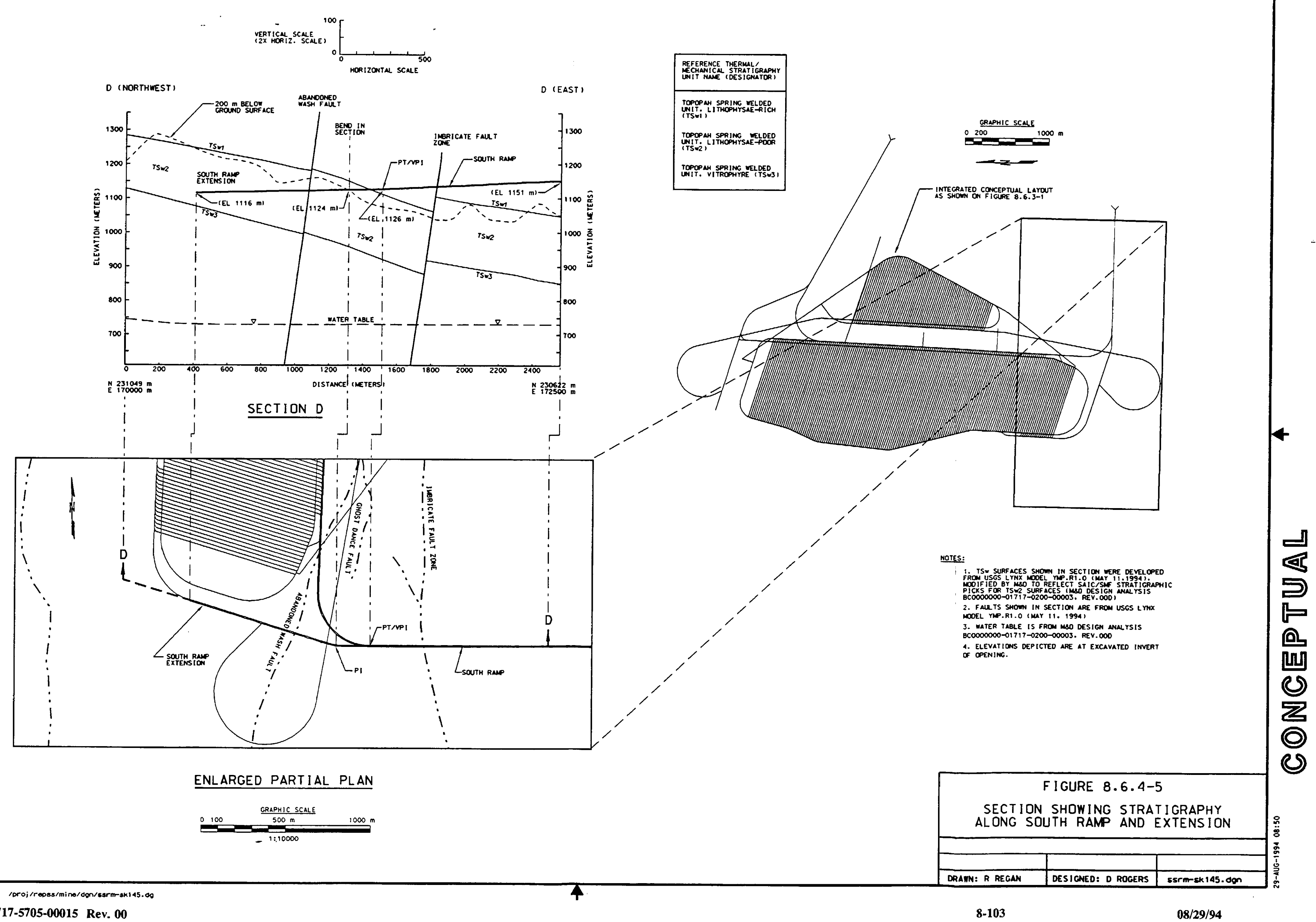


With the exception of the final curve, the extension would be excavated during site characterization to provide a second east-west crossing of the potential repository block to explore for major, north-south trending geologic features. It may be used as a launch point for exploratory drifting access to the underlying Calico Hills unit. Because it traverses most of the TSw 2 unit, approaching within approximately 40 meters of the underlying vitrophyre, this drift might also be utilized for numerous site characterization tests in the TSw2 unit.

During repository operations, this drift would provide access to the short section of service main located on the west side of the potential repository block. It would function as a primary ventilation airway for development operations during the period when the adjacent section of service main is supporting emplacement drift excavation.

If lower thermal loadings or other conditions result in the need to develop an emplacement area east of the Ghost Dance Fault, then this extension provides a launch point for driving a development operations access ramp to a lower block. (An emplacement block located east of the primary block would have to be significantly lower due to the eastward dip of the formation.)

\subsubsection{Development Side Ventilation Shaft}

A ventilation shaft is included in the interim layout and is the primary development side exhaust airway. The primary reason for this is if electric trolley (rather than diesel) powered locomotives are used, then personnel and materials transport can be better accomplished in an intake airway, i.e., in the South Ramp.

The shaft is conceptually located on the southeast flank of Yucca Mountain, adjacent to an access road leading to the crest. This position gives the shaft a depth of approximately $210 \mathrm{~m}$ from the collar to the invert of the upper emplacement block shaft station, excluding an additional allowance for a sump. More comprehensive shaft siting studies will be performed to investigate this site as well as several other potentially suitable sites located on the southern end of the upper, or primary emplacement block.

The required inside diameter of this shaft is preliminarily estimated to be $4.1 \mathrm{~m}$. This estimate is based upon the minimum shaft size necessary, allowing for a small amount of area reduction for shaft utilities, to carry a design air volume of $217.6 \mathrm{~m}^{3} / \mathrm{s}$ (Section 8.8 .1 ), plus a 20 percent contingency allowance, at a maximum velocity limit of $20.3 \mathrm{~m} / \mathrm{s}$ (M\&O, 1994m, DCSS-0016). A 20 percent contingency provides the flexibility to provide a third TBM operation for emplacement drift excavation if necessary, plus provide a small reserve without exceeding shaft velocity limits. A third TBM operation could become necessary if scheduling delays were encountered during construction or if accelerated development was needed.

Without the contingency airflow, a normal air velocity of approximately $17 \mathrm{~m} / \mathrm{s}$ would be present in the shaft at a $4.1 \mathrm{~m}$ diameter. This velocity equates favorably with a range of general economic airflow velocities of 18 to $20 \mathrm{~m} / \mathrm{s}$ for concrete lined shafts free from steelwork (Burrows, 1982, p. 272). An excavated diameter of approximately $4.5 \mathrm{~m}$ would provide a nominal $200 \mathrm{~mm}$ thick allowance for a permanent concrete lining or other ground support method. 
Since there are two shafts planned (see Section 8.6.4.10) in the interim repository layout, and since a mechanical shaft excavator is a preferred and feasible approach to construct the shafts (M\&O, 1993a, pp. 5-1 \& 6-4), standardization of shaft diameters should be investigated, from a cost savings standpoint. This would mean that the development shaft size would be increased to match the emplacement side ventilation shaft lined diameter of $6.1 \mathrm{~m}$ and excavated diameter of $6.7 \mathrm{~m}$ (Section 8.6.4.10).

To potentially achieve such a cost savings, however, would require that the two shafts be scheduled to be excavated sequentially during initial repository construction and under a single contract. This concept has merit because shaft construction using mechanical excavators is a specialty construction item. A relatively small number of contractors have the proven experience and equipment necessary to perform this type of work. Machine mobilization and demobilization cost savings would result, shaft lining cost savings could potentially result through the use of the same set of concrete forms (or optionally precast segment sizes), work deck, and plant for both shafts. Labor costs would not be significantly different between the two sizes, however, material costs for lining and excavation would increase for the development shaft.

Since the shaft excavated volume would increase by more than 200 percent if the size were increased, a more rigorous cost analysis would be necessary to determine if a true savings would exist. In addition, the waste isolation ramifications of such an increase would need to be investigated. In the absence of these investigations, the preliminary finished size for the development side exhaust shaft is set at $4.1 \mathrm{~m}$ diameter. A general cross section of the shaft is shown in Figure 8.6.4-6. Utilities installed in the shaft and shown in that figure are discussed in Section 8.10.3.

The $4.1 \mathrm{~m}$ diameter development shaft described above is smaller than that used for the development side personnel and materials/development intake shaft in the SCP-CD repository design (SNL, 1987a), which had a lined diameter of $6 \mathrm{~m}$. A primary reason for the difference was that the SCP-CD shaft size was controlled by operational requirements for hoisting rather than ventilation.

\subsubsection{Emplacement Side Ventilation Shaft}

An emplacement side ventilation shaft will function as the only ventilation exhaust airway on the emplacement side of the repository. It is conceptually located in the interim layout on the nose of a ridge located between Drill Hole and Teacup Washes and has a depth of approximately $310 \mathrm{~m}$ to the upper emplacement block. More comprehensive shaft siting studies are required to investigate the geologic suitability as well as the radiological safety and waste isolation aspects of the site.

If the shaft were sized only to support emplacement side operations as described in Section 8.8.2 plus a reasonable contingency, a relatively small lined diameter of approximately $3.7 \mathrm{~m}$ would result based upon general economic airflow velocities of 18 to $20 \mathrm{~m} / \mathrm{s}$ in concrete lined shafts free from steelwork (Burrows, 1982, p. 272). But this size is considered too small to reasonably accommodate potentially higher quantities that might be needed for emplacement drift cooling. 

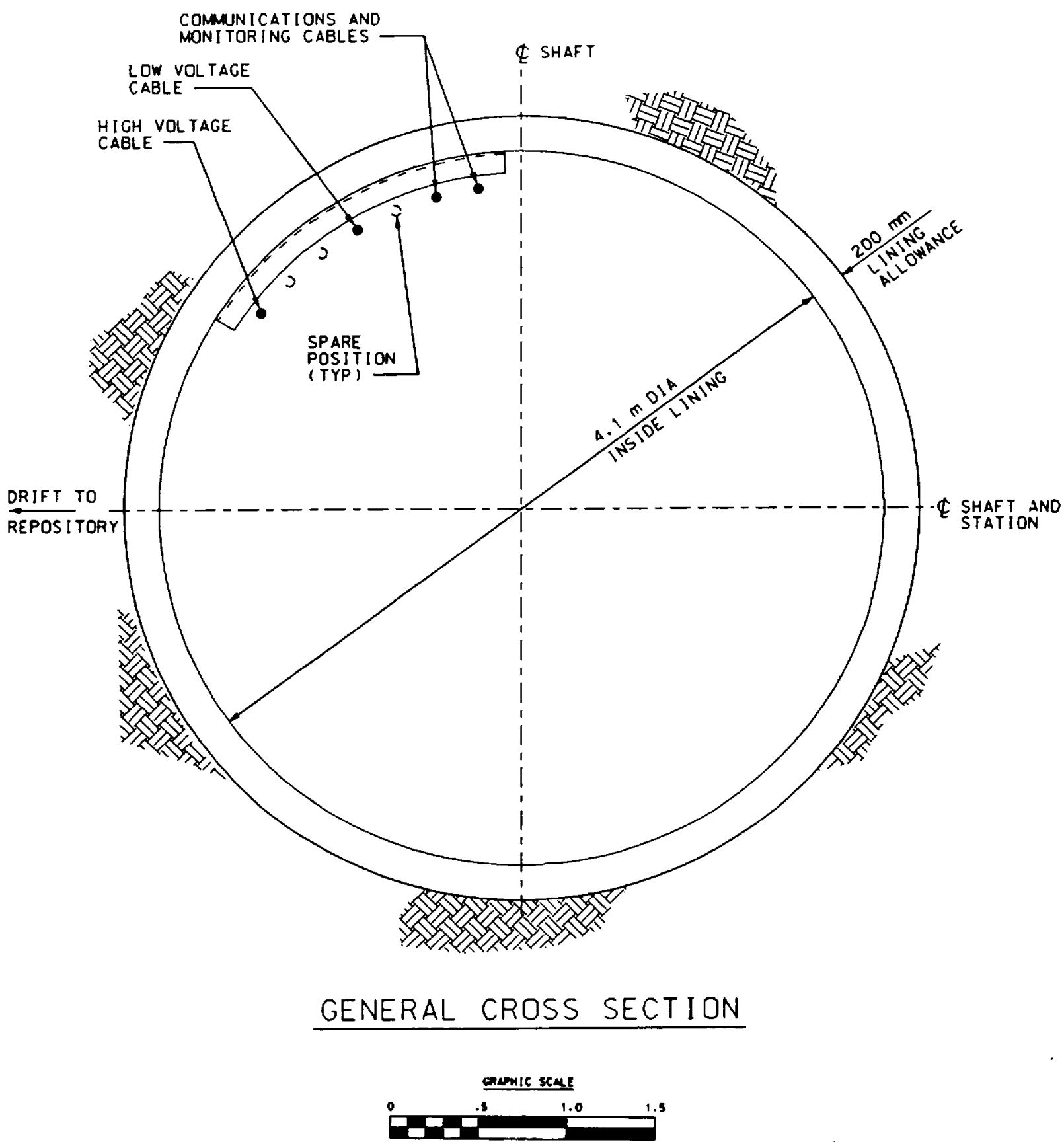

SCME IN METES

Figure 8.6.4-6. Development-Side Exhaust Shaft-Cross Section 
To allow for emplacement drift cooling, which may be needed for retrieval or other activities such as WP performance confirmation or thermal management, the shaft is conceptually sized by using the lower value from two approaches. The approaches are summarized in Table 8.6.4-1, and use as their basis the current ventilation air velocity limitations included in the CDA (M\&O, 1994m, DCSS-016). The two approaches consider the following:

A. The maximum intake air quantity that can be obtained, based upon opening sizes and air velocity limits, for all surface-based openings into the repository that could be used as intake air paths once all development operations are completed.

B. The maximum exhaust air quantity that can be expelled, based upon opening size and air velocity limits, from all available subsurface exhaust airways (i.e., the perimeter main and other minor drifting in the interim layout configuration).

The value obtained from the second approach is the limiting quantity that could be exhausted from the shaft based upon current project ventilation velocity limitations using the ventilation network for the interim layout without adding additional subsurface exhaust airways or revising current project velocity limitations. A quantity of $584 \mathrm{~m}^{3} / \mathrm{s}$ (minus the $33 \mathrm{~m}^{3} / \mathrm{s}$ shop flow that goes directly to exhaust) would be sufficient to cool approximately three drifts at a time at a relatively high flow per drift of $150 \mathrm{~m}^{3} / \mathrm{s}$ (see Section 8.12.5).

If the quantity of $584 \mathrm{~m}^{3} / \mathrm{s}$ is used, and a velocity limit in the shaft is set at $20 \mathrm{~m} / \mathrm{s}$, the lined diameter of the shaft is $6.1 \mathrm{~m}$. The $20 \mathrm{~m} / \mathrm{s}$ velocity is at the high range of economic velocities for shafts free from steelwork (Burrows, 1982, p. 272) and is virtually at the current velocity limit of $20.3 \mathrm{~m} / \mathrm{s}$ (M\&O, 1994m, DCSS-016). This size is comparable to that used for the emplacement exhaust shaft in the SCP-CDR repository design which had a lined diameter of $6 \mathrm{~m}$ (SNL, 1987a). An excavated diameter of approximately $6.7 \mathrm{~m}$ would result using a nominal $300 \mathrm{~mm}$ thickness allowance for a permanent concrete lining or other ground support method. 
Table 8.6.4-1. Preliminary Emplacement Side Ventilation Shaft Size Basis

\begin{tabular}{|l|c|c|c|c|c|}
\hline Airway & $\begin{array}{c}\text { Excavated } \\
\text { Diameter } \\
(\mathrm{m})\end{array}$ & $\begin{array}{c}\text { Gross } \\
\text { Area } \\
\left(\mathrm{m}^{2}\right)\end{array}$ & $\begin{array}{c}\text { Approximate } \\
\text { Net Area }\end{array}$ & $\begin{array}{c}\text { Maximum } \\
\text { Velocity }\end{array}$ & $\begin{array}{c}\text { Maximum } \\
\text { Airflow } \\
\text { Quantity } \\
\left(\mathrm{m}^{3}\right)\end{array}$ \\
\hline \hline North Ramp
\end{tabular}

1) Approximate allowance for ground support, permanently installed utilities and equipment, and invert (as applicable).

2) Based upon current project maximum values as stated in the CDA (M\&O, 1994m, DCSS016).

\subsubsection{Lower Emplacement Block}

The emplacement area situated between the Ghost Dance Fault and Imbricate Fault systems is called the "lower block" because it is situated at an elevation that is approximately 70 meters lower than the primary, or "upper" emplacement block situated to the west as shown in Figure 8.6.4-7.

The lower block was designed using the same objectives that were used for the upper block. The design objective that specifies flat-lying emplacement drifts was the main "driver" that led to the "step" down from the primary block, due to the eastward dip of the TSw2 unit. The selected horizon was established by: 1) picking a location for the farthest north emplacement drift that would leave adequate space for the ESF Main Test Area (MTA); 2) overlaying surface topography on the structural contours for the TSw $1 / T S w 2$ contact; 3) and establishing an elevation for this drift that was near the top of the TSw 2 unit while complying with the 200 meters cover requirement and then iterating through several main drift layouts that satisfied all of the objectives and requirements listed in Section 8.6.1.

The upper block would be fully emplaced before emplacement operations move to the lower block. Operationally, the development and emplacement schemes in the lower block would 


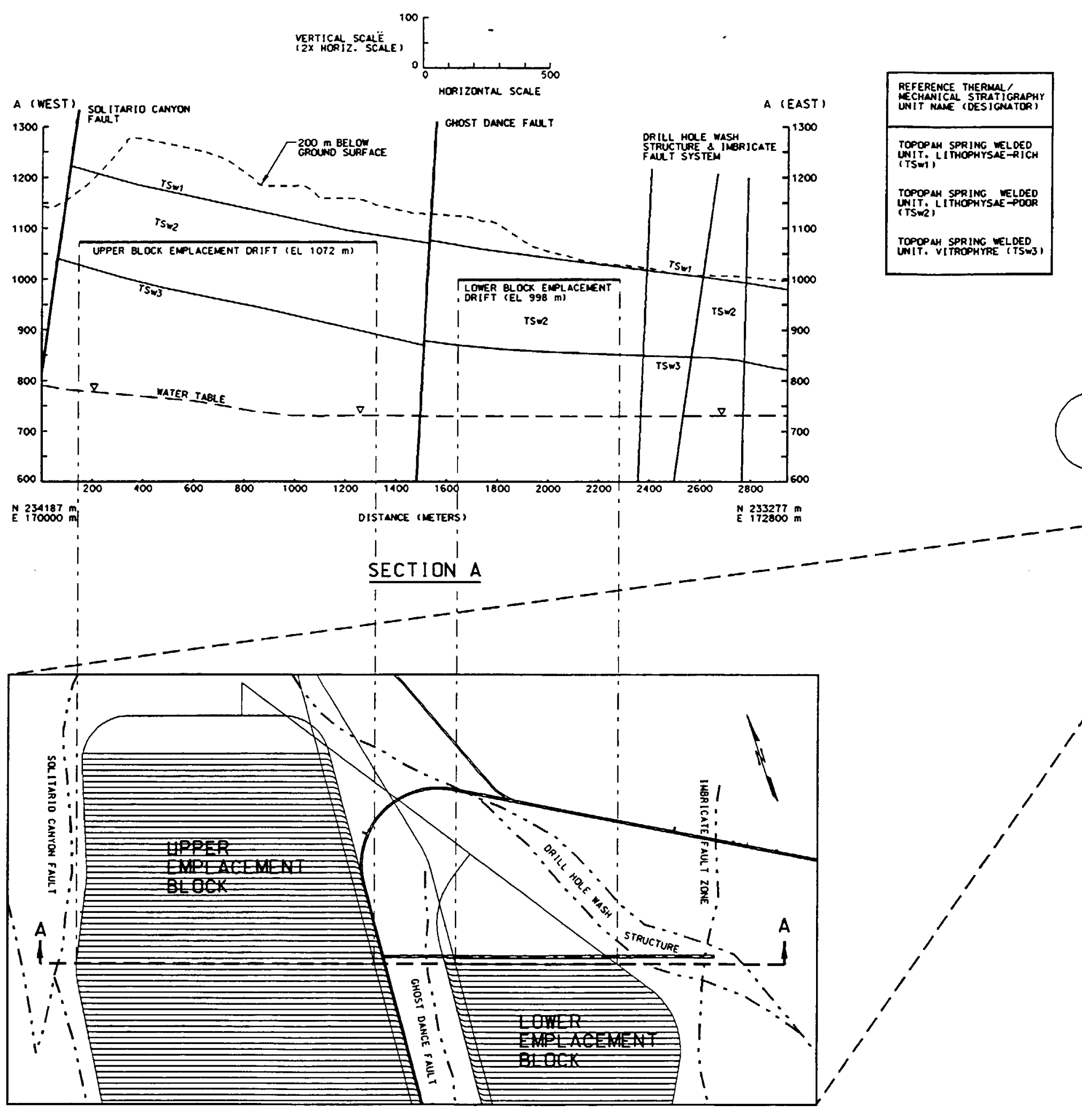

ENLARGED PARTIAL PLAN

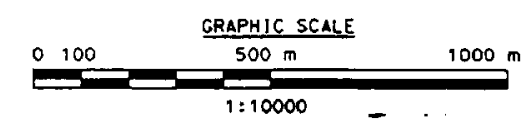

FIGURE 8.6.4-7

NOTES:

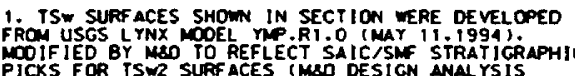

2. FAUL TS SHOW IN SECTION ARE FROO USCS In

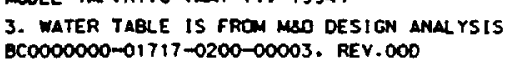

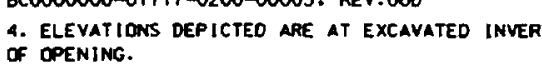
SECTIJN THROUGH UPPER
AND LOWER EMPLACEMENT BLOCKS \begin{tabular}{|l|l|l|}
\hline & & \\
\hline DRAM: R REGAN & DESICNED: D ROCERS & SSrm-SK 142. Ogn \\
\hline
\end{tabular} 
be the same as for the primary block. Both operations would proceed from North to South, and the functions of the various drifts would be the same.

Access to the lower block would be provided using minus 3.00 percent ramps that originate from the lower reaches of those connecting the primary block to the surface. Additionally, the two ventilation shafts would connect to the lower block emplacement area main drifts.

It is envisioned that construction of the ramps and the main drifts for the lower block would be carried out as a more or less independent operation on the development side of the repository during development and emplacement of the upper block. The North Access Ramp to the lower block would be developed from the bottom up in order to maintain separation of ventilation systems. Both shafts would be sunk to full depth at the time of original construction.

Depending upon the amount of emplacement area that may be required, it should be pointed out that development of a separate emplacement block in the area shown may not be the best choice. Access ramps and main drift requirements, in relation to the reduced length and number of emplacement drifts that are provided, could be excessive when compared to other potential expansion areas (Figure 8.3.2-3). Thermal and thermal-hydrological concerns may also exist due to possible interactions between the upper and lower blocks. 


\subsection{DESCRIPTION OF SUBSURFACE OPERATIONS}

Operational concepts associated with the interim layout are described in this section, first for the development and then for the emplacement side of the repository. Development concepts discussed include the excavation, excavated tuff handling, and transportation methods for personnel and supplies. Emplacement operations descriptions begin with an overall presentation of radiological boundaries for the emplacement side. A philosophy for crossing radiological boundaries that interface with both the development and emplacement sides is presented, and this philosophy forms the basis for several preliminary concepts presented in other sections of the report. Other preliminary concepts are presented for in-drift emplacement operations using two different methods of WP support and associated emplacement equipment. A brief discussion of key aspects associated with emplacement drift monitoring, and personnel and supplies transport in the emplacement side is also made.

\subsubsection{Development Operations and Equipment}

Development side operations in the repository will commence several years before approval of the license application with the NRC to emplace waste is granted. In the SCP-CD, this period was estimated at six years. The following subsections present a basic summary of several key operations in the development side using the interim layout shown in Figure 8.6.3-1 as the basis. A more up-to-date estimate of preemplacement construction has not been developed yet during ACD. After approval to emplace waste is granted, development and emplacement side operations will be conducted concurrently until all portions of the repository have been constructed. This period would be completed prior to completion of emplacement operations and would be scheduled to minimize premature capital expenditures.

\subsubsection{Excavation System Description}

Figure 8.7.1-1 presents the arrangement of subsurface openings comprising the upper block of the interim layout. As mentioned in Section 8.6, excavation of the TBM launch main, the perimeter ventilation main, and the ventilation shafts would occur during the initial stage of repository construction, prior to emplacement of waste. Excavation of the short section of service main located just north of the bottom of the North Ramp, and the short section in the southwest comer that joins with the South Ramp extension, would also occur at this time.

Upon completion of this system of main drifts, or "mains," excavation of emplacement drifts would begin. Emplacement drift construction would begin at the north end of the layout and would proceed sequentially toward the south. It is envisioned that the construction of approximately 10 to 25 emplacement drifts would have to be completed prior to emplacement of waste in order to facilitate access to the waste handling main, to establish proper ventilation circuitry and to allow erection of substantial stoppings or bulkheads in the mains to provide physical separation of development and emplacement operations.

Figure 8.7.1-2 is an enlarged view showing the typical arrangement of openings in the service main/launch main portion of the layout. Prominent features on this figure include the crosscuts that interconnect the service and launch mains. Excavation of each of these crosscuts would precede excavation of its adjoining emplacement drift, as the crosscut 


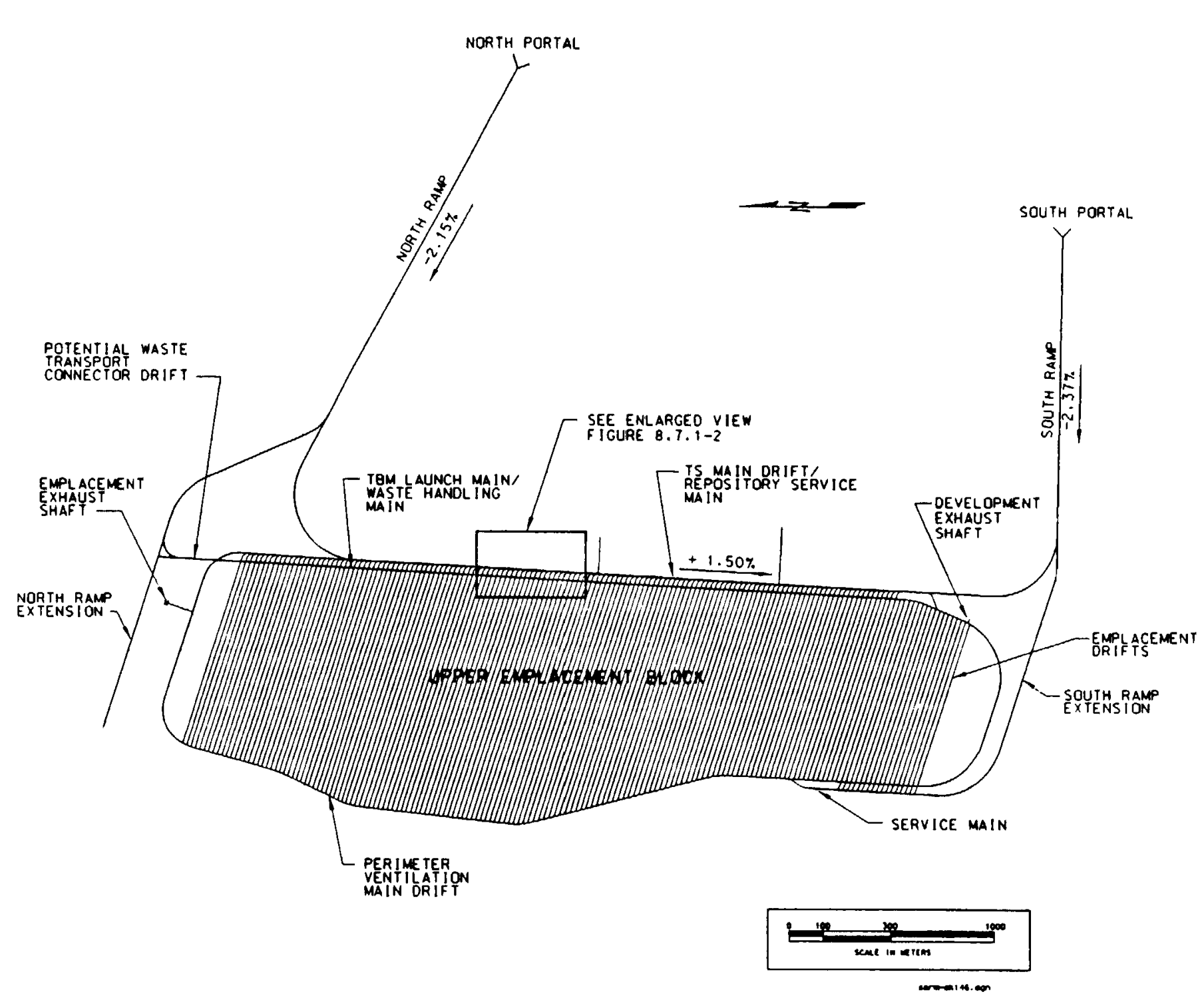

Figure 8.7.1-1. Conceptual Repository Layout Upper Emplacement Block 


\section{$91349<1570$}

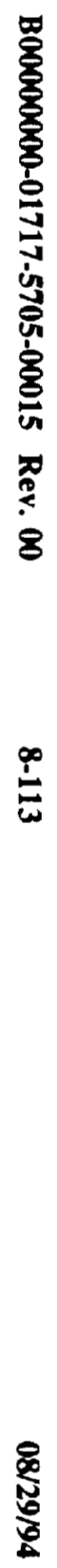

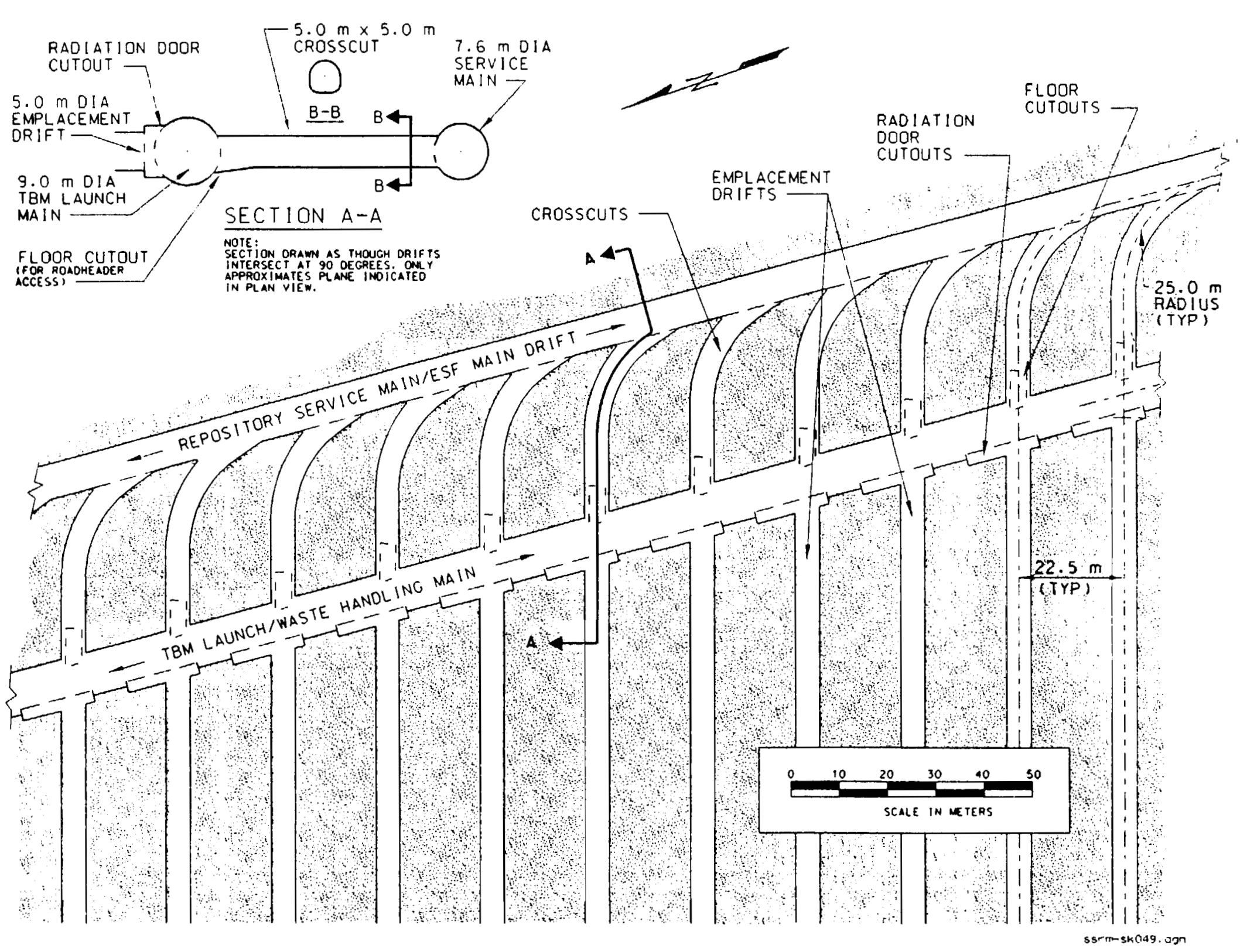

Figure 8.7.1-2. Detailed Layout of Drifting in Service/Launch Mains Areas 


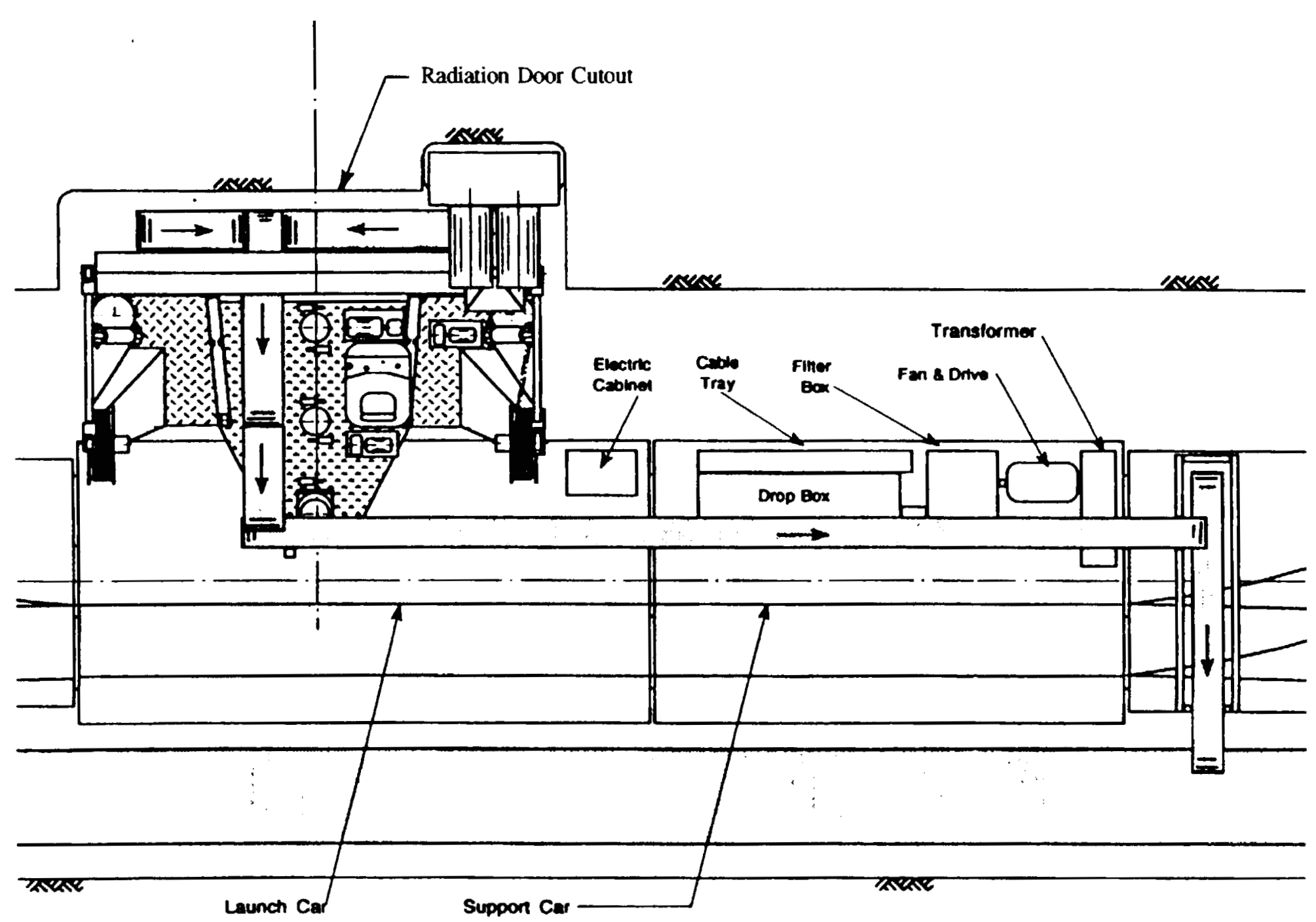

芯

Figure 8.7.1-3. Plain View of CSM Alcove Miner at Radiation Door Cutouts 
provides the development operations access link between the emplacement drift and the service main. The crosscut is curved ( 25 meter radius) to permit installation of a railway system to support TBM excavation of the emplacement drift and to service follow-on construction in the emplacement drift necessary to prepare it for receiving WPs.

It is envisioned that excavation of the crosscuts would be performed using a specially designed alcove miner to create a starting cut for a heavy-duty roadheader that would then be used to complete the rest of the crosscut. Section 8.4.2.1 discussed the limitations of currently available roadheader machines in the TSw2 unit, but also pointed out that the Colorado School of Mines (CSM) has designed both an alcove miner and a special cutting head for a roadheader that uses mini-disc cutters rather than conventional "pick" style bits. It is assumed that this, or similar technological advances, will be fully developed, tested, and available for repository secondary excavation tasks. A specialized, forward gripper, unshielded TBM may also be adapted for this requirement, but for purposes of this discussion it is assumed that the alcove miner and a modified, heavy-duty roadheader will be developed.

Both the alcove miner and the roadheader would operate out of the launch main and would advance the crosscut toward the service main. This approach would minimize disturbance to operations associated with actual emplacement drift excavation/construction and would help prevent contaminated ventilation air exhausted from these operations from polluting the air stream used by the other operations. Crosscut excavation would be maintained several positions ahead of emplacement drift excavation. Roadheader muck would be discharged onto a segmental conveyor or into a shuttle car and would then be transferred into a railbound muck car situated in the closest crosscut accessible from a switching platform located in the service main. The muck car would then travel to and discharge in the primary conveyor feeder located in the service main.

Another feature shown on Figure 8.7.1-2 is an enlargement, or cut-out, in the launch/waste handling main at the mouth of each emplacement drift. These are for installation of concrete filled radiation doors, approximately one meter thick, that cover the entrance to each emplacement drift and provide shielding for emplacement operations personnel on the emplacement side of the repository. Excavation of each cut-out and the starter cut for the adjoining crosscut would be performed sequentially from north to south during development operations by the alcove miner shown on Figure 8.7.1-3. Cut-outs for radiation doors are also required at the opposite ends of the emplacement drifts. These would be excavated one at a time by an alcove miner immediately following removal of the TBM as it completes each emplacement drift. This will permit utilization of the ventilation duct system already hung in the drift, for exhausting dusty air generated during cut-out excavation.

A single alcove miner/roadheader operation should provide sufficient coverage of crosscut and radiation door cut-out excavation to support two TBMs performing emplacement drift excavation. When a TBM is brought into the launch main to begin excavation of another emplacement drift, the alcove miner, roadheader, and various support equipment would be temporarily moved into a crosscut to permit the TBM carrier to pass. 
Construction of an emplacement drift involves several successive stages as follows:

A. Launch TBM.

B. Excavate emplacement drift with TBM, installing precast concrete invert segments, rail, utilities, and permanent ground support as the machine advances.

C. Following completion of drift excavation, install any additional permanent ground support deemed necessary and construct a cast-in-place concrete invert to support a permanent rail system used to facilitate waste emplacement, while removing utilities and other materials originally installed to sustain excavation process. (Utilities and other materials that are removed would be reused in other emplacement drifts that are being excavated at the same time.) This work would be performed on a retreat basis, i.e., from the far end of the emplacement drift, back toward the service main.

D. Install permanent rail and supports or trackway for remote video monitoring, instrumentation equipment, or similar devices in the emplacement drift.

E. Construct radiation doors at the ends of the emplacement drift.

In order to permit all of the work outlined above to be performed concurrently, it is necessary to provide construction access to at least five emplacement drifts at any given time. In reality, probably twice that number would be needed, (i.e., access to ten emplacement drifts might be desirable) in order to permit adequate flexibility during development operations.

To accommodate access to multiple emplacement drifts in varying stages of construction, a switching or service platform as depicted on Figures 8.7.1-4, 8.7.1-5, 8.7.1-6, and 8.7.1-7 would be utilized. This platform would be designed and fabricated to include the following attributes:

A. The platform would be fabricated in sections, six to fourteen meters long, to facilitate transportation into the subsurface and to permit repositioning of the platform one or two sections at a time, if necessary. Adjacent sections would be joined using simple pin connections.

B. Each section would be outfitted with steel wheels to facilitate moving the platform in individual or multiple sections along rail attached to precast concrete segments in the service main invert.

C. Sections would be equipped with lifting and anchoring systems that allow the platform to elevate and be supported by its wheels for relocating or repositioning, then set down on adjustable, fixed supports to relieve wheel loads and accommodate temporary anchoring of the platform to the invert and walls of the tunnel to provide stable working conditions. 


\section{$91349 \quad(1675$}

总

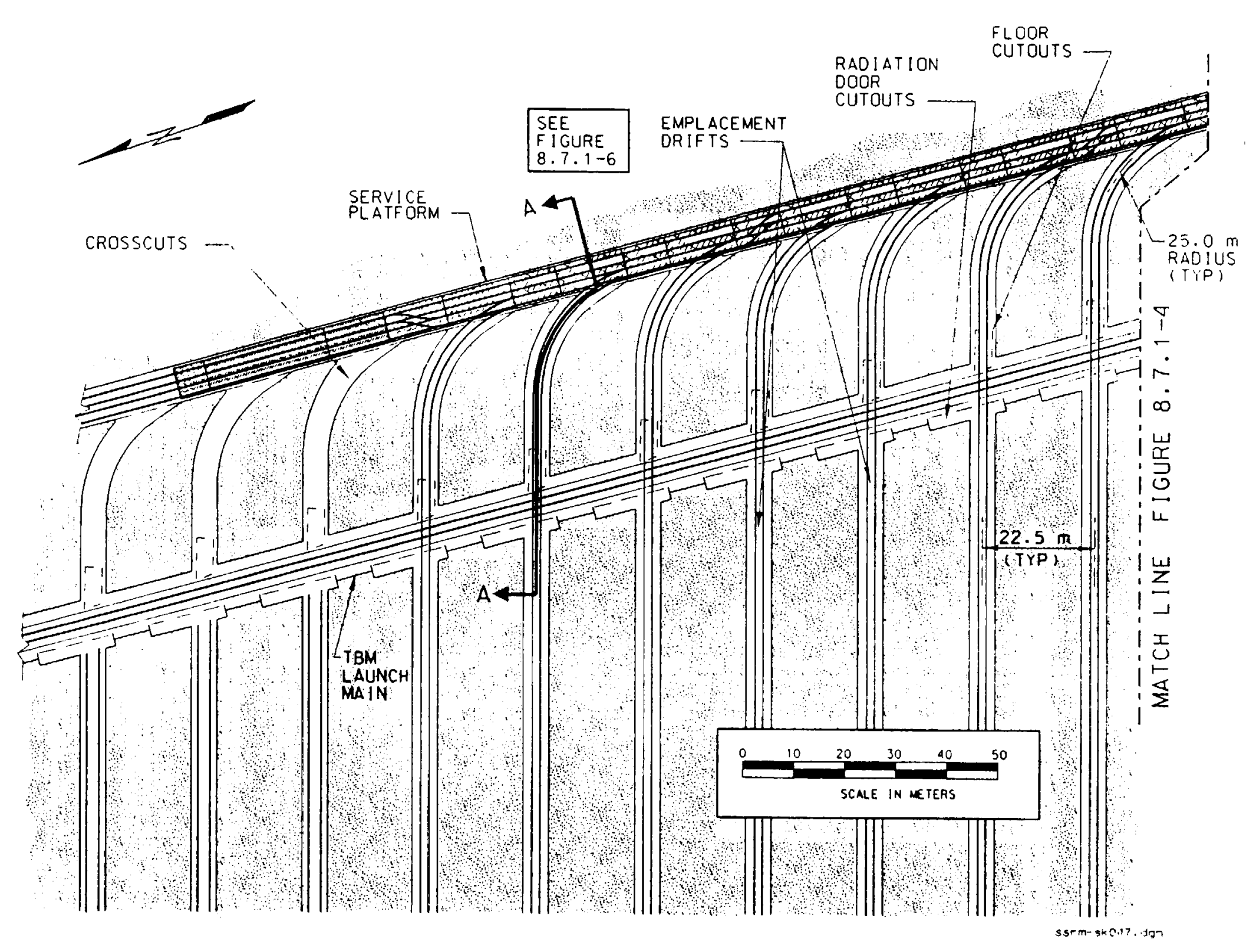

Figure 8.7.1-5. Service Platform-South End 


\section{$91349 \quad 1 \quad 1676$}

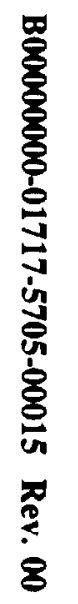

$\stackrel{\infty}{\frac{1}{\sigma}}$

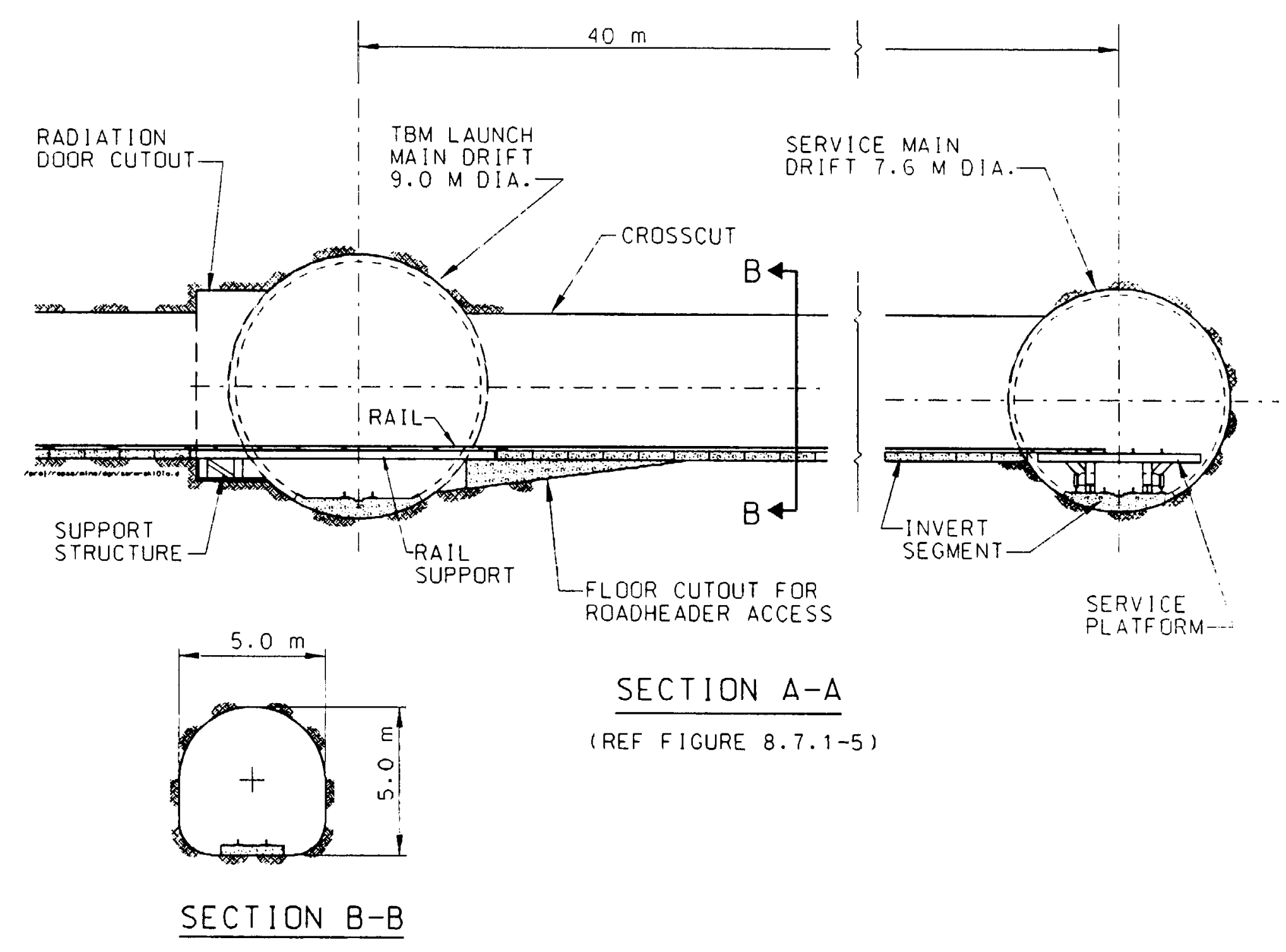

Figure 8.7.1-6. Service Platform-Section Through Crosscut 


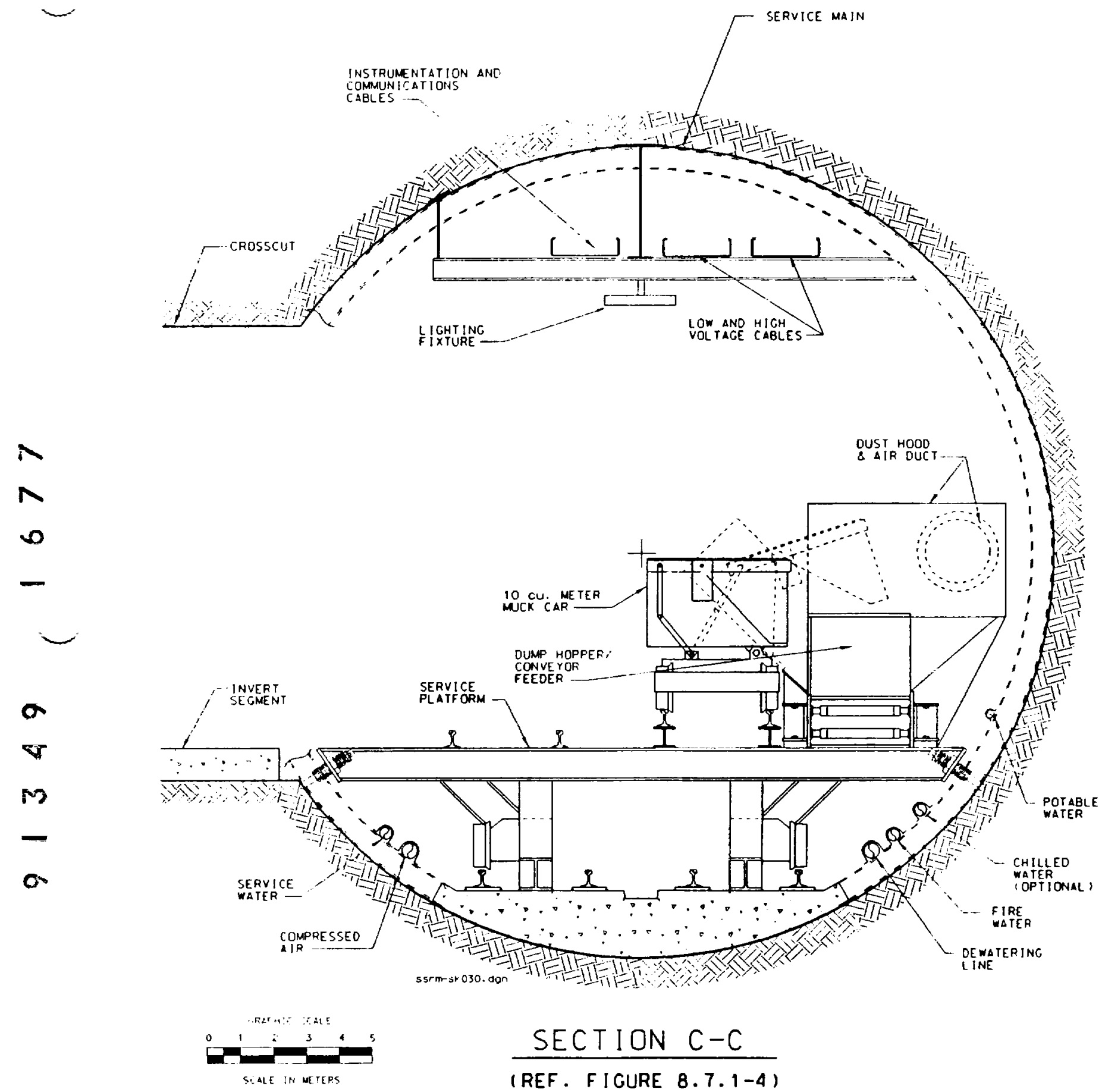

Figure 8.7.1-7. Service Platform-Muck Car Dump Point 
D. The top of the platform would be decked with expanded metal or a similar, nonskid surface and would have two sets of rail trackway installed. Rail switches would be installed on one track and spaced to coincide with the centerline spacing of the crosscuts and emplacement drifts. Crossover switches would be installed to permit access from one trackway to the other.

E. Racks or similar devices would be mounted along various sections of the platform to accommodate temporary storage of pipe, rail, fanline and other utilities or materials used in construction of the emplacement drifts.

F. A train dump and conveyor feeder station would be located at the south end of the platform to facilitate offloading of excavated muck from the emplacement drifts and crosscut excavation onto a conveyor system for transport out of the tunnel.

G. Each end of the platform would terminate in a ramp section that allows trains to transition from the permanent rail system attached to the tunnel invert, to the elevated railway attached to the top of the platform.

Figures 8.7.1-4 and 8.7.1-5 show the platform situated to provide rail access to ten crosscuts and their adjoining emplacement drifts at one time. Four or five of these drifts would be in various phases of construction following excavation. The remainder would either be in the process of being excavated or next in line for excavation. The southernmost crosscut accessed by the platform would be used by the crosscut/cut-out excavation operation for muck and materials haulage.

Postexcavation construction in the emplacement drifts would be scheduled so that it keeps pace with the rate of TBM excavation of the drifts. When excavation of the last emplacement drift accessible from the platform is completed, the platform would be moved to the south and repositioned so that drifts requiring postexcavation construction are accessed from the north end of the platform, while the south end is situated to permit access to four or five more drifts to be excavated. The platform would be moved periodically toward the south in this manner throughout most of the repository operational period, until construction of the emplacement drifts is completed.

As mentioned above, actual emplacement drift construction begins with "launching" the TBM. Traditionally, this task has been accomplished by excavating a short starter tunnel or "launch chamber" beforehand, using non-TBM methods, then constructing gripper pads made of concrete or timber to provide reaction points for the grippers, so they in turn can provide a reaction for the thrust necessary to propel the machine forward. For most tunnels this is a one-time operation; a more mechanized approach is not warranted.

The interim layout, however, requires numerous launchings of the emplacement drift TBMs. In order to simplify these launchings without having to perform costly and time consuming starter tunnel excavation, emplacement drift TBMs for the interim layout would be designed with a relatively small length to diameter (aspect) ratio, on the order of 1.25:1.0 or lower, not including the machine conveyor and tail shield sections which can be designed to permit easy removal and reinstallation. (The aspect ratio for the 7.62 meter diameter TBM being 
built for the ESF program is approximately $1.28: 1.0$, with tail shield and machine conveyor removed.) This criteria would permit the 5.0 meter diameter emplacement drift TBMs to be rotated in the 9.0 meter diameter launch main without the need for additional excavations. Given a relatively short TBM, all that is needed to facilitate launching from the larger diameter opening is a mechanical framework that will stabilize the machine and provide a reaction for thrust as it begins boring. A mechanized approach for accomplishing this task in a relatively short period of time is depicted on Figures 8.7.1-8, 8.7.1-9, and 8.7.1-10.

A typical launch would be performed as follows:

A. The TBM would be moved to the launch site inside a steel cylinder called a "launch tube." While moving, the machine and tube would remain in longitudinal alignment with the various access drifts along the transportation route. The launch tube would be attached to a turntable mounted on top of a specially designed rail carrier. The machine would be positioned inside the tube such that the center of gravity for the TBM coincides with the center of the turntable bearing. This permits stable rotation of the TBM/launch tube assembly on the carrier at the launch site.

B. Prior to moving the TBM into the launch area, a short, truncated cylindrical steel section called a "transition tube" would be positioned on a flat, concrete "grade slab" placed beforehand along the bottom of the radiation door cut-out excavation. The base of the transition tube would be flat and would be outfitted with three hydraulic, vertical positioning jacks. The transition tube would be aligned to the proper line and grade for the emplacement drift.

C. As the launch tube encasing the TBM approaches the launch area, it would be rotated and moved into alignment with the transition tube. Hydraulic outrigger jacks on the launch tube carrier would be used to stabilize and support the weight of the TBM and launch tube. The transition tube and launch tube would then be joined using bolts or clamps and short, 50 to $100 \mathrm{~mm}$ thick spacers between the mating ends of the tubes. (The gap occupied by the spacers allows positioning of the launch tube without disturbing the alignment of the transition tube.)

D. A hydraulic cylinder attached to one end of the launch tube is used to extend a primary thrust reaction shoe against the wall of the launch main. The shoe support is locked into position on the slide along which it travels. Two horizontal clamp cylinders attached to the opposite end of the launch tube are then rotated from their transport position and attached to the transition tube using steel links and pins. The clamp cylinders are then extended against the face of the radiation door cut-out.

E. The launch structure is now clamped in place and supported by the seven vertical support jacks. The machine conveyor and necessary trailing floor sections are brought in through the crosscut and connected to the TBM. 


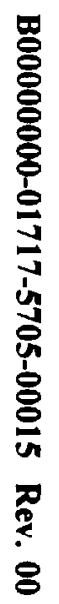

$\stackrel{\infty}{\text { i }}$

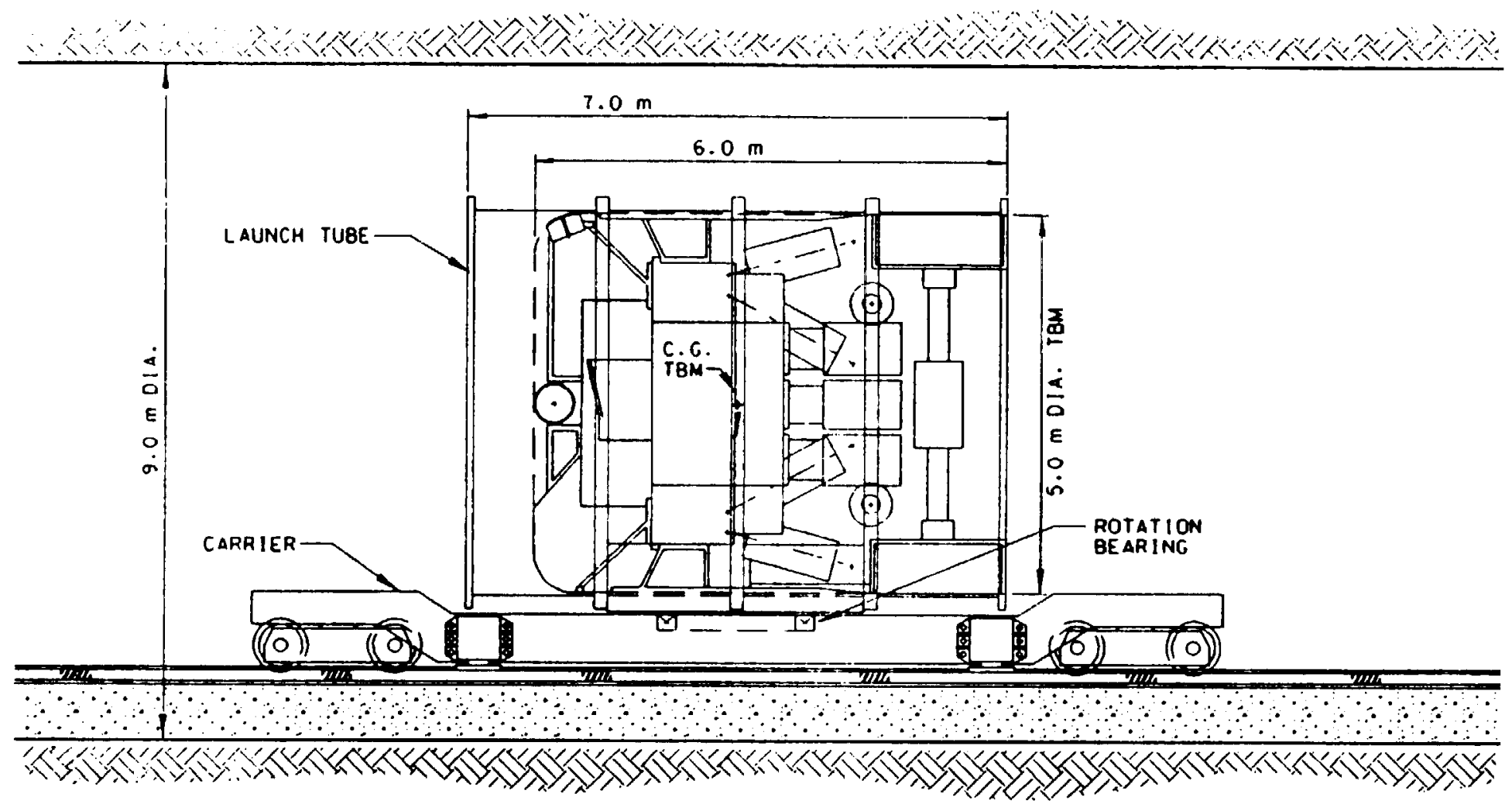

NOT DRAWN TO SCALE

Preliminary TBM and Launching Equipment Concepts Furnished Courtesy of Construction and Tunneling
Services. Inc.. Kerit.wa 


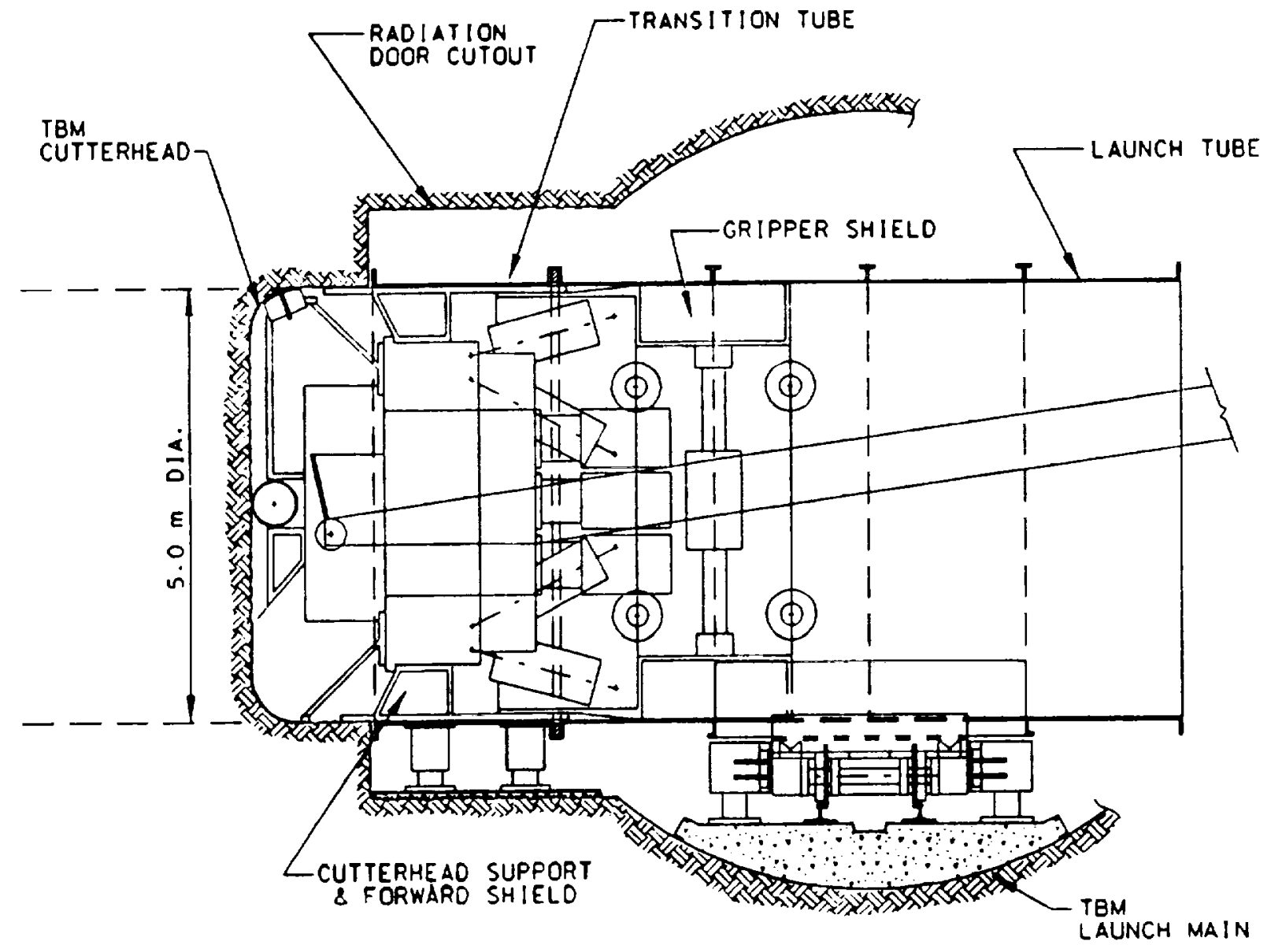

\section{NOT DRAWN TO SCALE}

Preliminory TBM and Lounching Equipment Cancepts Furnished Courtesy of Construction and Tunneling services. Inc.. Kent. WA

Figure 8.7.1-9. TBM Launch-Partial Side View 


\section{$91349(1682$}
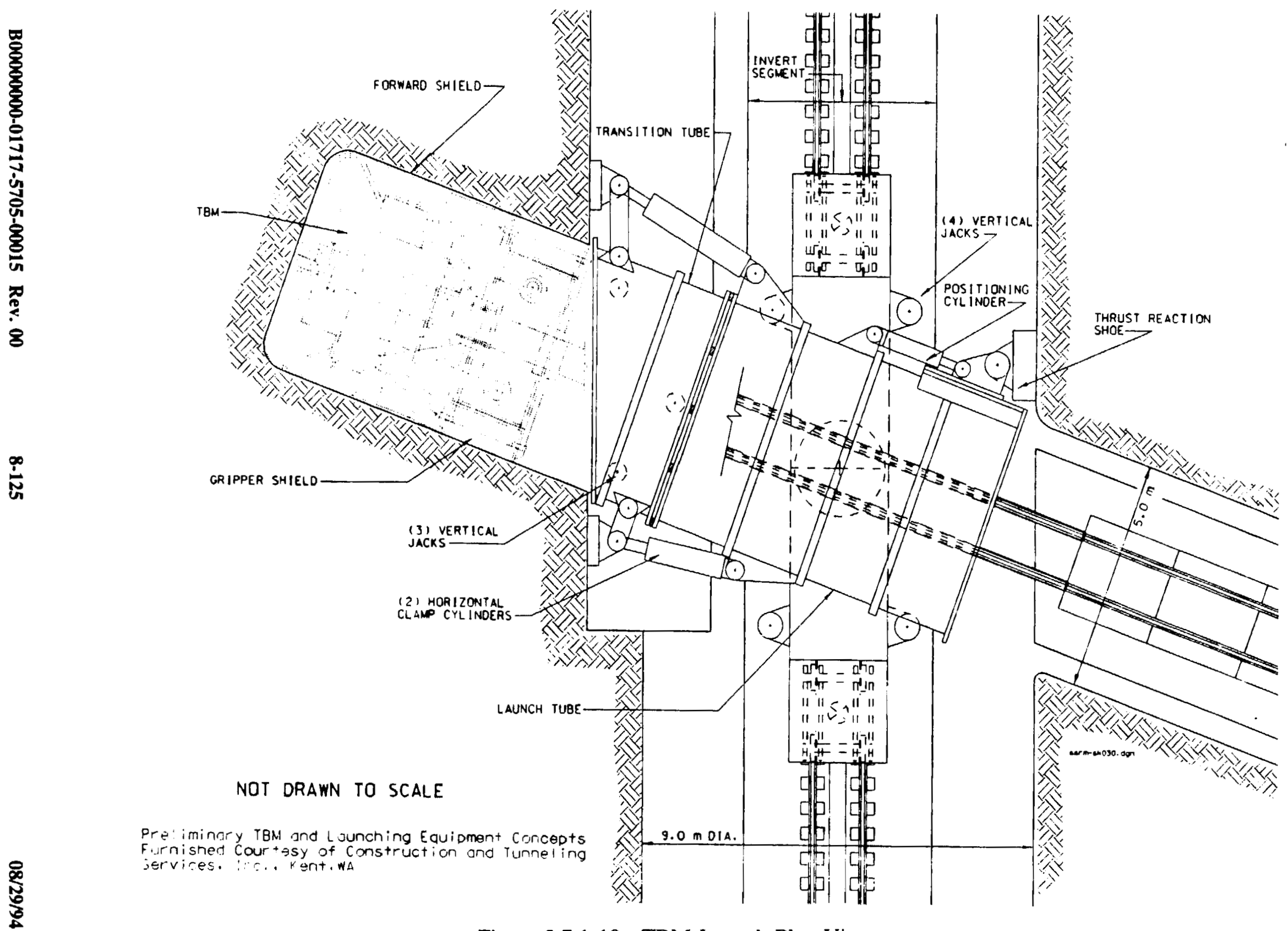

Figure 8.7.1-10. TBM Launch-Plan View 
F. The TBM is advanced to the face by lightly gripping the launch tube, but when boring begins, the cutterhead thrust is reacted by retractable "chock" mechanisms mounted inside the tubes. The TBM is advanced forward into the rock in this manner until the grippers pass beyond the end of the transition tube, then extensible struts would be used between the grippers and the last set of chocks until the machine has advanced far enough beyond the initial face to allow pressuring up the grippers without concern for the breaking of rock corners inside the cut-out.

G. After the TBM has advanced sufficiently along the alignment, the remaining sections of the trailing floor are brought from the perimeter main into the service main, and then through the appropriate crosscut and connected to the TBM. The trailing cars ride on rail temporarily laid through the launch and transition tubes. When all of the trailing floor sections are fully in the emplacement drift, the launch structure is disassembled. The transition tube is moved to the next emplacement drift location and the launch tube is moved back into the perimeter main, ready to retrieve the next TBM. A simple support bridge is installed across the launch main to facilitate installation of rail for train traffic into and out of the emplacement drift.

H. As a TBM completes its drive across the emplacement block, it will "hole-out" at the perimeter ventilation main. As soon as the cutterhead is fully into the larger diameter opening, the machine would be backed up slightly, muck would be cleared away from the intersection, and the launch tube would be brought into position on its carrier to retrieve the TBM. A short transition piece would be installed to bridge the bottom of the gap between the end of the emplacement drift and the launch tube, and the TBM would advance into the tube. The tail shield and the machine conveyor would be disconnected from the TBM. The launch tube/TBM assembly would be rotated into longitudinal alignment with the perimeter main and would be moved back to the launch main to begin a new drift. The TBM conveyor, tail shield and the trailing floor cars would be pulled out of the drift and moved out of the way until the TBM is ready to resume boring.

Excavation of the emplacement drifts with the TBMs would be performed in typical, hard rock tunnelling fashion. Muck haulage out of the 900 to 1200 meter long emplacement drifts would be performed using conventional muck trains. Two muck trains would support each TBM operation. Considering the short drift length, and the problems associated with positioning a conveyor belt storage magazine and transfer conveyors in the crosscuts and/or service main, use of a continuous conveyor system to move the muck out of the drifts is considered impractical.

It is envisioned that the muck trains would consist of a locomotive, four each 8 to 10 cubic meter muck cars, and supply cars as needed. In a commercial tunnel, the locomotives would probably be diesel powered. However, due to uncertainties associated with diesel exhaust and its potential effects on waste isolation, electric trolley, or even battery locomotives could be used in this layout since the emplacement drifts are flat-lying and the one-way haul distance is relatively short. A "California switch," a raised, wheeled platform containing two sets of parallel track, with ramps and crossover switches located at each end would be maintained in 
close proximity to the end of the trailing floor in order to minimize TBM downtime that results when a loaded train leaves the trailing floor and an empty one takes its place.

As the TBM advances, most elements of the permanent ground support would be installed immediately behind the machine, unless a shotcrete or concrete lining is determined to be necessary. Utilities necessary to support the tunneling operation would also be installed as the drift advances. These would include ventilation duct, electrical power and communications cables, a process water pipeline, and a compressed air pipeline.

After the TBM "holes" into the perimeter main, and both it and the trailing floor are removed from the emplacement drift, the cut-out for the radiation door at the end of the drift would be excavated as described earlier. The ventilation duct could then be removed from the drift, since "flow-through" ventilation is available.

Postexcavation construction in the drift could commence following removal of the duct. This work would involve removal of utilities and the excavation rail system, cleanup of the invert, and construction of a cast-in-place concrete floor. It may also include installation of additional ground support or lining. These tasks would be performed in a retreat mode, i.e., in short, distinct reaches in order to maintain the availability of utilities and access rail to the work location, leaving an essentially finished product behind. When the work has been completed back to the service main, an emplacement rail system would be installed on top of the finished concrete. Final installation of various supports, brackets, trackways, or other fixtures necessary to accommodate remote monitoring and instrumentation devices, as well as those items that might be needed to facilitate backfilling or sealing, would then be performed. The drift would be cleaned as necessary, radiation doors would be constructed at each end, and the drift would enter a stand-by mode until turned over to the emplacement operations side of the repository.

Separation of the development and emplacement sides of the repository would be accomplished by erecting "substantial stoppings" that seal against air movement and obstruct equipment passage in the perimeter main, the launch main, and the service main. (It would be desirable to provide for personnel passage through these stoppings to allow an alternate means of escape in case of a fire or other emergency condition as discussed in Section 8.7.2.1). When a new group of emplacement drifts is to be turned over to emplacement operations, new stoppings would be erected at the appropriate location by crews on the development side, then the old stopping would be dismantled by crews on the emplacement side. It may be desirable to design a rolling or movable stopping which could save time and materials as the stopping locations are changed. In this manner, compliance with the separate ventilation systems requirement is maintained.

Inherent in the interim layout is a great deal of flexibility regarding scheduling the turnover of completed emplacement drifts to the emplacement operations side. The panel concept utilized in past work (DOE 1988) required, as a minimum, that development of an entire panel, containing numerous emplacement drifts, be completed before any of the individual drifts inside the panel could be turned over to emplacement operations. The interim layout, on the other hand, could turn over a single drift if necessary-- although it may not be very cost 
effective to do so because of the work associated with moving the location of the substantial stoppings.

As a general note, it should be pointed out that a key feature that lends credibility to the interim layout is the use of large diameter access drifts, or mains, in conjunction with small diameter emplacement drifts. This concept not only facilitates mechanization of the launching process for starting TBM excavation of the emplacement drifts, it also affords a means of recovering the TBM when the drift is completed and provides a route for moving the machine, basically intact, to the starting location for the next drift. It is conceivable that, with practice, development crews could accomplish the recover-move-launch task inside of a week, given this relative difference in drift sizes and the mechanized launch process described above. Layout concepts that do not provide ample space to perform these tasks could require dismantling the TBMs at the end of each drive, moving individual components to the new launch location, and reassembling the machines in larger diameter openings that have been constructed beforehand by other means. This work could require several months to complete even if the distance moved is only a few hundred meters.

Another key aspect of the interim layout is the flexibility afforded by the parallel service and launch mains. These work together to provide a system that can vary the productivity required of development operations in response to changes in the waste receipt schedule. Additional TBMs can be brought on line if necessary without causing major disruptions to the development scheme.

While it lacks certain optimization, the interim repository development scheme described above is considered to be a realistic scenario, sufficiently flexible to be safely constructed and operated in an efficient, productive manner.

\subsubsection{Excavated Tuff Handling}

As discussed in the preceding section, excavated tuff or "muck" from emplacement drift excavation would be transported in muck cars to a conveyor feeder dump point in the service main. The relatively short length of the emplacement drifts coupled with space restrictions and abrupt corners makes the use of conveyor haulage out of the emplacement drifts both unwarranted and impractical. Muck car haulage is a proven and long-standing method of muck transport in TBM tunnelling operations and is only recently being rejected in favor of conveyor haulage in longer tunnels. In a contract tunneling operation, the additional capital and initial installation costs of a conveyor system can be offset by the operating efficiency inherent in a belt haulage system, resulting in economic viability if the length and configuration of the tunnel are acceptable.

A belt conveyor located in the service main would transport material from the feeder located at the muck car dump point (Figure 8.7.1-7) on the service platform to the South Ramp and then up the ramp to a transfer point located on the surface. Another conveyor system would then carry the excavated tuff to a storage area where it would be stockpiled for potential use as backfill or contoured and topsoiled for permanent disposal. 
A scoping evaluation (M\&O 1993d) of material handling systems including equipment options and preliminary ranges of throughput rates was made in 1993 for a repository layout similar to the interim layout in this report. The excavated tuff handling system concepts presented here are consistent with earlier conclusions developed in that report. More definitive and up-to-date descriptions that include equipment sizes and throughput rates for the muck handling and storage system will be determined as repository ACD progresses.

\subsubsection{Transportation of Personnel and Supplies}

As mentioned in previous sections, transportation access for personnel, materials and supplies necessary for emplacement and development operations in the interim layout would be via the North and South Ramps, respectively. Transportation requirements of this nature will be much greater in the South Ramp due to increased materials and supplies quantities associated with repository construction on the development side. Pre-ACD conceptual repository designs such as the SCP-CDR (SNL 1987a) equipped the development side shaft with hoisting facilities to provide these services. However, given the integrated rail haulage concept and the relatively short travel distance from the south portal to the development side shaft location in the interim layout, it is judged that personnel and materials hoisting in this shaft are not warranted. This is because transportation times would probably increase due to increased handling times associated with loading/offloading of the shaft conveyance. More definitive evaluations remain to be performed in this area.

At the start of each shift, development crews and other subsurface workers would board a mantrip car(s) (a railcar equipped with several enclosed seating compartments) on the surface and would be pulled by a locomotive to their respective workplaces in the subsurface. Once there, they would relieve crews going off shift at the work area, who would travel back to the surface in the mantrip(s).

For the most part, materials and supplies would be taken underground aboard flatcars pushed by locomotives down the South Ramp, into the service main, and onto the service platform where they would be directed into the appropriate emplacement drift. As mentioned in Section 8.7.1.1, many of the temporary items such as piping, ventilation duct, invert segments, etc., would be reused as construction is completed in the emplacement drifts. Most of the materials transportation in the South Ramp, then, would be permanent ground support or similar items that remain in the emplacement drifts over the long term.

Future ACD efforts will analyze transportation requirements in greater detail, including locomotive and rolling stock fleet requirements, personnel transportation requirements and overall throughput requirements.

\subsubsection{Emplacement Operations and Equipment}

Preliminary operating concepts for the emplacement side of the repository are presented in the following subsections. The general boundaries of the radiologically controlled area in this side of the repository are discussed. As emplacement and development operations must be conducted concurrently for a number of years, as mentioned in Section 8.7.1, a general philosophy regarding the radiological boundary interfaces between the two sides of the 
repository is presented. Two preliminary emplacement concepts, introduced in Section 8.5.1.1 and considered by engineering judgment to be applicable to in-drift emplacement of a large MPC based WP, are discussed in greater detail, along with conceptual designs for emplacement equipment to support those operations. A brief discussion of key aspects associated with emplacement drift monitoring, and personnel and supplies transport in the emplacement side is also made.

\subsubsection{Radiologically Controlled Areas and Boundaries}

The entire emplacement side of the subsurface repository, in broad terms, will represent a radiologically controlled area. The overall subsurface boundaries of such an area would begin at the point where subsurface transport casks are loaded at the surface waste handling building (as discussed in Section 7.2), continue to the north portal (M\&O 1994m, Key 047), and then extend down the North Ramp, which is proposed as the waste transportation corridor.

An additional subsurface radiological boundary would begin at the emplacement side exhaust shaft surface ventilation plant, continue through the surface air ducting and shaft collar structure, and extend down the shaft to the elevation of the emplacement horizon(s).

On the elevation of the emplacement horizon(s), the entire active emplacement side would be a radiologically controlled area. The boundaries would extend from the emplacement horizon entry point(s) at the north (waste) ramp and the emplacement side exhaust shaft.

During repository development, the boundaries would also begin at the substantial ventilation stoppings shown in Figure 8.8-1 of Section 8.8.2. After all development side construction operations are completed and the stoppings are removed, the boundaries would be extended to the collars and portals of all shafts and ramps leading into the repository.

A key philosophy which must be established early in the repository design process is how and why a radiological boundary would be crossed, as this relates to the normal movement of personnel, supplies and equipment to support the various repository operations. An establishment of such a philosophy is particularly necessary to allow the design of the repository for simultaneous development and emplacement operations.

Using the interim layout, a proposed approach during the phase of simultaneous operations is that the stoppings separating the development and emplacement sides would not be crossed for any reason except during an emergency or accident condition, or to conduct specific preapproved activities. In other words, crossing the stopping is not considered to be a normal occurrence.

If crossing a stopping were the safest alternative during an accident or emergency situation, establishment of a buffer or safe zone on both sides of each stopping should be considered. The purpose of the buffer or safe zone would be to allow the option for safe crossing in either direction and to provide sufficient space to use as a holding area for personnel until further movement can be coordinated by implementation of an emergency response plan. This aspect is likely to be more critical for personnel crossing from the development to the emplacement side because of radiological safety considerations. 
A buffer or safe zone could be created by several means. One alternative could be keeping sufficient distance from the stopping to potentially hazardous operations while maintaining the area in a fresh air stream. A second could be to place a specially designed mobile facility, similar to a refuge station, on either side of each stopping. Mobility of such facilities would be advantageous as they could be moved as the stoppings are repositioned during development operations.

In keeping with the philosophy established by the previous paragraphs, a proposed approach for the transport of personnel, equipment and supplies into the development and emplacement sides is that they would be separated at all times. Each side would therefore have its own transport routes. Transport routes are discussed further in Section 8.7.1.3 for the development side and Section 8.7.2.4 for the emplacement side.

A key point to be established for the emplacement side will be the coordination of waste transportation activities with personnel and supplies transport through the North Ramp and on into the emplacement area. Several ways to address this could be the establishment of personnel and materials transport "time windows." Such time windows could be established when waste transportation operations would not be in a sequence where personnel would come in contact with a transport cask in route to the emplacement area or during some other critical phase of the emplacement sequence. This may be a readily feasible option for two reasons. Due to the size of the WPs being considered in ACD, the daily volume of WPs to be emplaced will be low. The number of personnel to be transported into and out of the emplacement area would also be low because the philosophy presented above would help to ensure that only the personnel absolutely essential to the emplacement side operations would be present in the emplacement area at any time during normal operations.

Although not addressing personnel transport, another option may be to transport a sufficient stock of materials and equipment to underground warehousing areas in the emplacement side on a shift where waste transportation operations will not be conducted. Such a shift could be a regularly scheduled maintenance shift.

Additional work to further define radiological boundaries and control measures during the above described phase, as well as later phases of repository operations, will be performed as ACD progresses.

\subsubsection{Subsurface Waste Emplacement Operations and Monitoring}

The emplacement operations concepts described in the following subsections have been developed without the benefit of thorough evaluations relating to personnel radiological safety, including analysis of the radiation environment inside the emplacement drift, and in the waste handling main with and without the radiation shield door in an open position. The concepts are very conceptual and must be evaluated in much greater detail as ACD progresses. 


\subsection{Emplacement on Wheeled Cart Using Locomotive}

As described in Section 8.5.1.1, this in-drift emplacement concept consists of an MPC based WP permanently mounted on a steel-wheeled cart that rolls on rail laid in the invert of a 5.0 meter diameter emplacement drift.

It is assumed that the WP and its emplacement cart would be inserted into a transport cask in a hot cell located in the waste handling building on the surface before being moved away from the waste handling building. The transport cask could be designed to reduce surface dose radiation exposure to "stand-beside" limits.

Figure 8.7.2-1 portrays the steel cask concept that is envisioned. It would be outfitted with an outer set of steel wheels that facilitate loading the cask onto a transport carrier and offloading of the cask onto an emplacement platform situated at the mouth of an emplacement drift. The interior of the cask would be equipped with a device to secure the WP/cart during transport and a self-contained mechanism capable of offloading the WP/cart assembly into one end of an emplacement drift.

The transport cask would be moved to the subsurface on a specially designed, but relatively simple rail carrier. The carrier would be coupled to a locomotive and the pair would travel down the North Ramp to the waste handling main, i.e., that portion of the TBM launch main that is located on the emplacement operations side of the repository. Access into the waste handling main is gained by first entering the service main (the portion on the emplacement side) at the bottom of the North Ramp, then reversing direction and traveling north in the service main through the curve that transitions into the perimeter main, then reversing direction once again and entering the waste handling main, probably through a set of doors that control access. If necessary, that portion of the service main not used as a travelway might be equipped with an energy arrestor used to stop the transport vehicles in the unlikely event of a "runaway" on the North Ramp. This transportation route minimizes the possibility of a runaway colliding with an in-process emplacement operation, as the final approach is on an uphill grade following a reversal of direction.

An alternative means of accessing the waste handling main from the surface would be via the potential waste transport connector drift shown on Figure 8.6.3-1 that connects the North Ramp extension to the waste handling main.

An emplacement platform situated in the waste handling main would be used to facilitate offloading of the transport cask and insertion of the WP into an emplacement drift. The locomotive would back the transport cask carrier against the edge of this platform. Hydraulic outrigger jacks and a sliding carriage on the carrier would then be used to position the cask in such a manner that it could be pulled off of the carrier and onto the platform. A turntable mounted in the emplacement platform would then rotate the cask into alignment with the emplacement drift as shown on Figure 8.7.2-2.

Up to this point, all operations could be conducted without unusual concerns for worker radiation exposure, so long as the transport cask has been designed to "stand-beside" standards. The actual opening of the cask, and insertion of the WP into the emplacement 


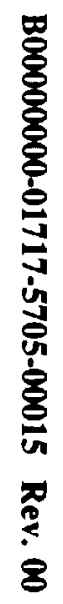

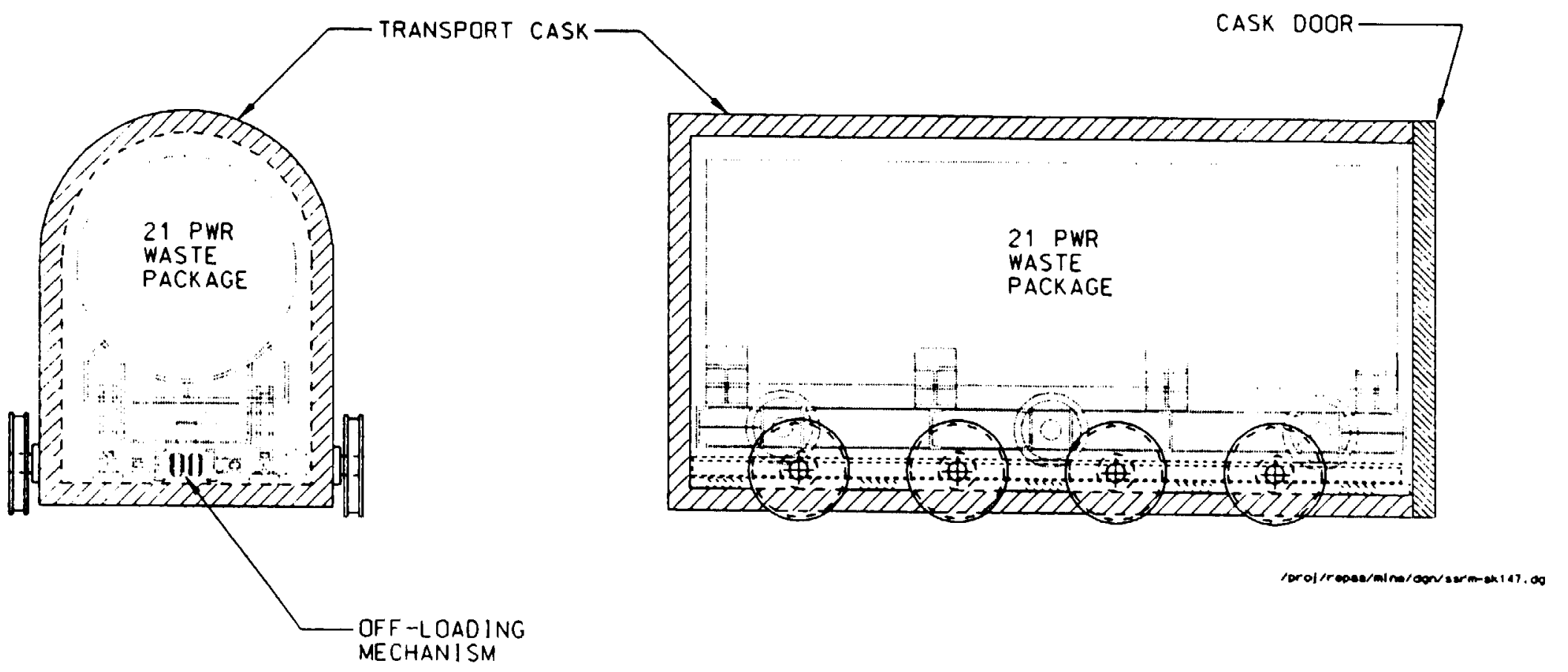

赵

Figure 8.7.2-1. Subsurface Transport Cask Concept 
$91349<1691$

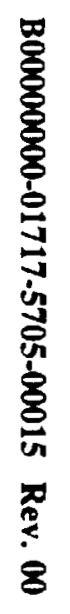

$\stackrel{\infty}{\dot{L}}$

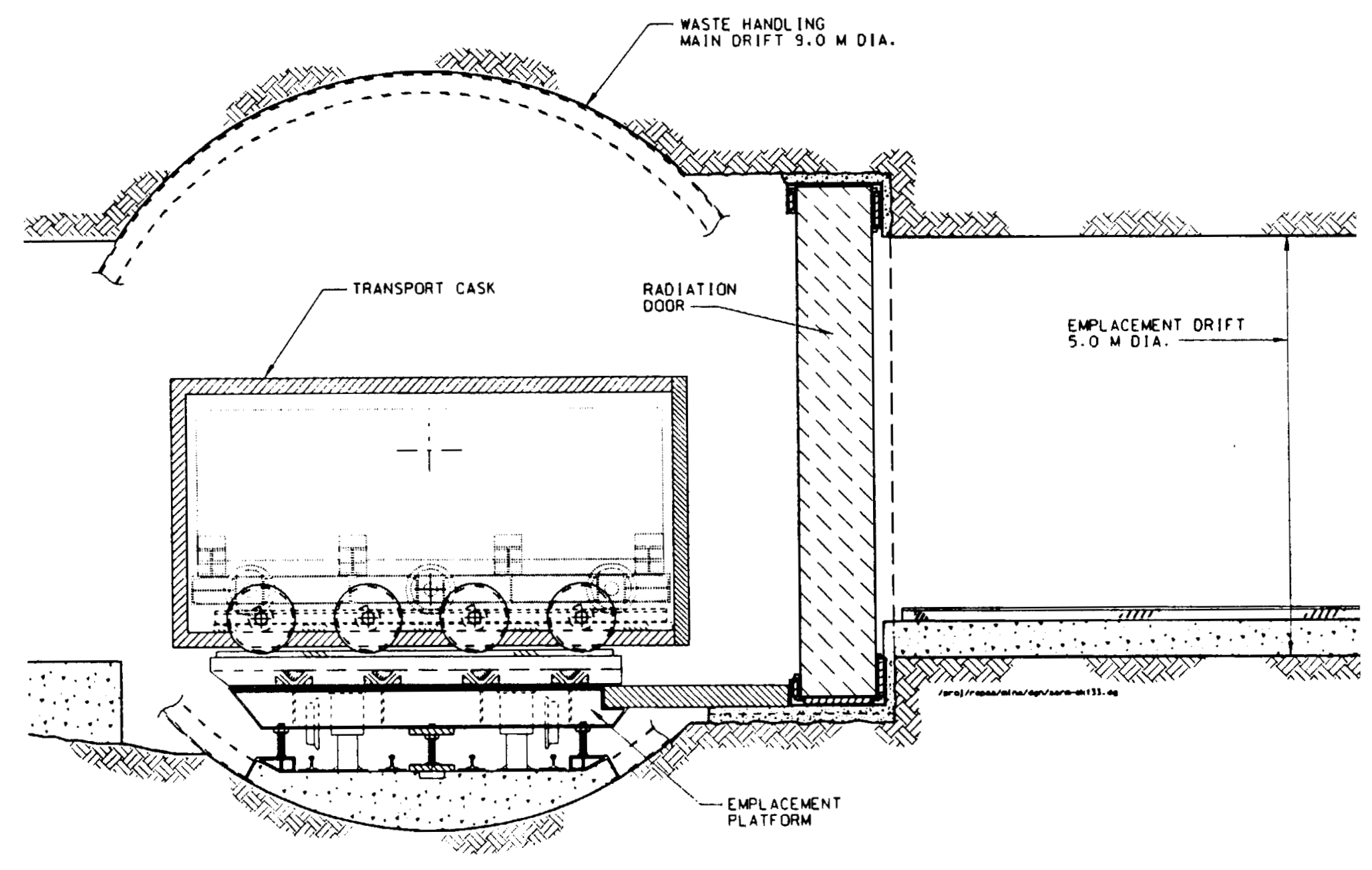

స్.

Figure 8.7.2-2. Cask Aligned with Emplacement Drift 
drift, would result in exposure risks for anyone positioned in-line with either the drift or cask openings. Therefore, workers and operators would position themselves ten to twenty meters away from the emplacement platform, probably inside of a portable, shielded enclosure (shielded for purposes of offering an additional level of protection beyond that afforded by being located out of line with the radiation sources) prior to opening either the cask or the sliding radiation door situated across the mouth of the emplacement drift. All operations involved with the actual emplacement of the WP would be conducted remotely from within the shielded enclosure.

The remotely guided, video monitored steps involved with conducting the actual emplacement operation are envisioned as follows:

A. With the transport cask centered on the emplacement platform, the radiation door on the emplacement drift would slide open. As the door assumes its full open position, it pulls a structural transition piece into place that is used to bridge the gap between the platform and the invert rail situated just inside the emplacement drift.

B. The transport cask would be moved toward the drift, on the emplacement platform, until resting its forward wheels fully on the transition piece. The door on the cask would then be opened, as it is now in an overlapping position with the end of the open drift door, and thereby afforded a substitute layer of shielding.

C. With its door open, the transport cask would be moved forward once again, pushing a short section of sliding rail on top of the transition piece forward until mated firmly with the rail in the emplacement drift and the rail inside of the cask. The cask would then be secured to prevent further movement.

D. The self-contained mechanism inside of the cask used for moving the WP into the drift would then be activated. This device would be capable of pushing the package fully into the end of the drift and would activate a "stop" or brake on the emplacement cart to hold it in position. (The mechanism would also be designed to pull packages into the cask, if necessary, for performance confirmation, retrieval, or other purposes.) After pushing the WP into the drift, the mechanism would be withdrawn into the cask. Figure 8.7.2-3 shows the WP being moved out of the transport cask, into the end of the drift.

E. With the WP "parked" just a meter or so inside of the drift, the cask would be withdrawn fully onto the emplacement platform, pulling the sliding rail on top of the transition piece back into a retracted position.

F. The radiation door on the emplacement drift would then be closed, allowing workers to resume non-remote operations. The door on the cask would be closed and the cask would be rotated on the platform into longitudinal alignment with the main drift as shown on Figure 8.7.2-4. The cask would then be loaded back onto the rail carrier. The carrier would lower itself back onto the rail and the locomotive would pull the empty cask back to the surface to pick-up another WP. 


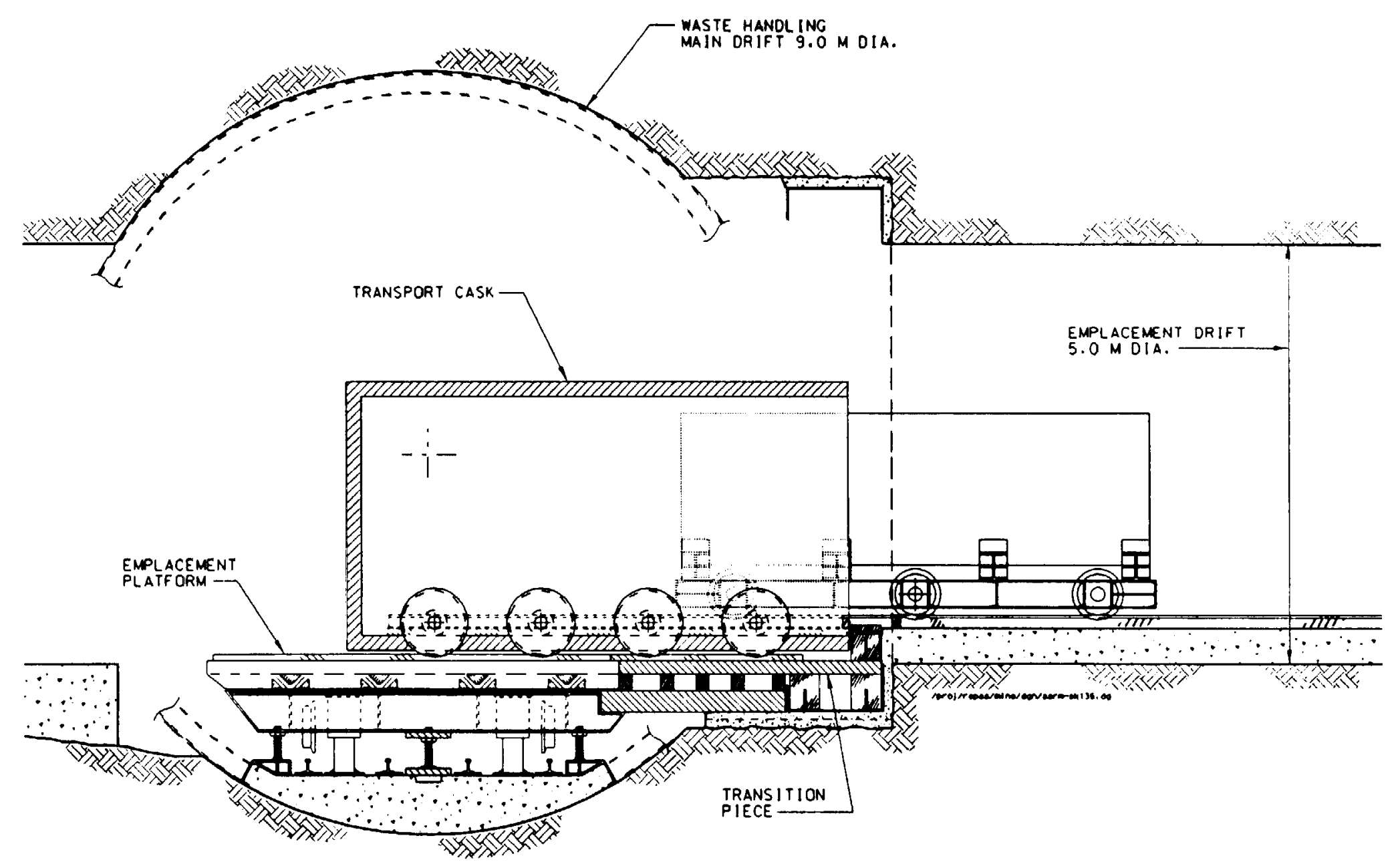

:

Figure 8.7.2-3. Waste Package Being Pushed into Emplacement Drifts 


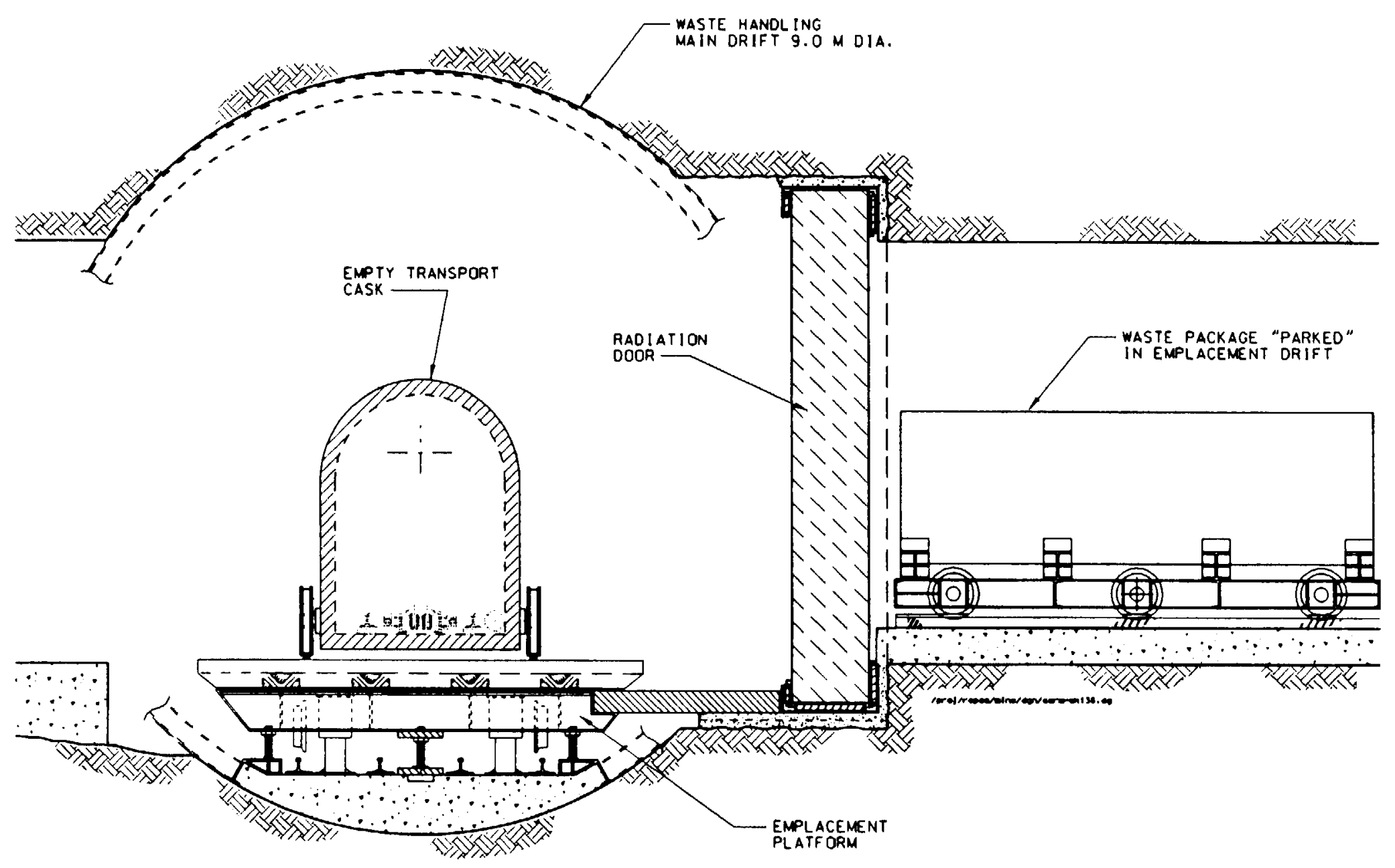

疍

Figure 8.7.2-4. Empty Cask Rotated for Return Trip to Surface 
G. A remotely operated, battery-powered locomotive used for pushing the WP to its emplacement position in the drift would then be readied for operation. (While the cask is on the turntable, this locomotive would be parked in a stand-by position on a non-rotating extension of the emplacement platform located opposite from the cask delivery area.) The locomotive would be mounted on a fixture that resembles the floor of the transport cask in order to properly fix the vertical position of the locomotive wheels relative to the rail in the emplacement drift. Using the same mechanism designed for moving the transport cask on and off of the platform, the locomotive would be positioned on the platform turntable and would be rotated into alignment with the emplacement drift. Workers would re-enter their remote enclosure and the drift door would be reopened.

H. By completing the same basic movements on the platform as described above for the transport cask, the locomotive would be directed into the drift and would couple to the WP. The emplacement cart stop mechanism would be deactivated and the locomotive would push the WP/cart to its intended emplacement location in the drift as shown on Figure 8.7.2-5. The radiation door would be closed. Upon reaching the emplacement position, the locomotive would activate the stop mechanism on the cart and would decouple from it. The locomotive would then return to the emplacement platform and the radiation door on the drift would close.

I. The emplacement crew would resume non-remote operations in the main drift to prepare for the next WP. The emplacement locomotive would be repositioned in its stand-by location on the emplacement platform.

For efficiency of operations, it is envisioned that the emplacement platform would be positioned only one time for each emplacement drift, and that emplacement of all of the packages for that drift would be completed before moving the platform to the next drift location. This concept is not mandatory but would eliminate the downtime that would result from numerous platform relocations.

Moving of the emplacement platform would be accomplished by lowering the vertical positioning jacks so that the weight of the platform is transferred onto steel wheels that roll on rail laid on the invert of the main drift. The platform would be towed to the next emplacement drift in line and would be repositioned, using survey index points established during construction of the emplacement drift as a reference base. These points would allow the platform to be located at the precise location necessary for horizontal and vertical control of the emplacement operation. Vertical positioning jacks would be used to establish the precise rail elevation necessary, then the platform would be mechanically fixed in position to relieve the hydraulic pressure in the cylinders. The transition piece mentioned above would be utilized once again, but would probably require a slight amount of height adjustment, using metal shims or similar methods, to allow the platform, cask, and locomotive to be properly mated with the rail in the emplacement drift. The portable shield enclosure and the device used to open and close the radiation door would be moved ahead prior to moving the platform. 


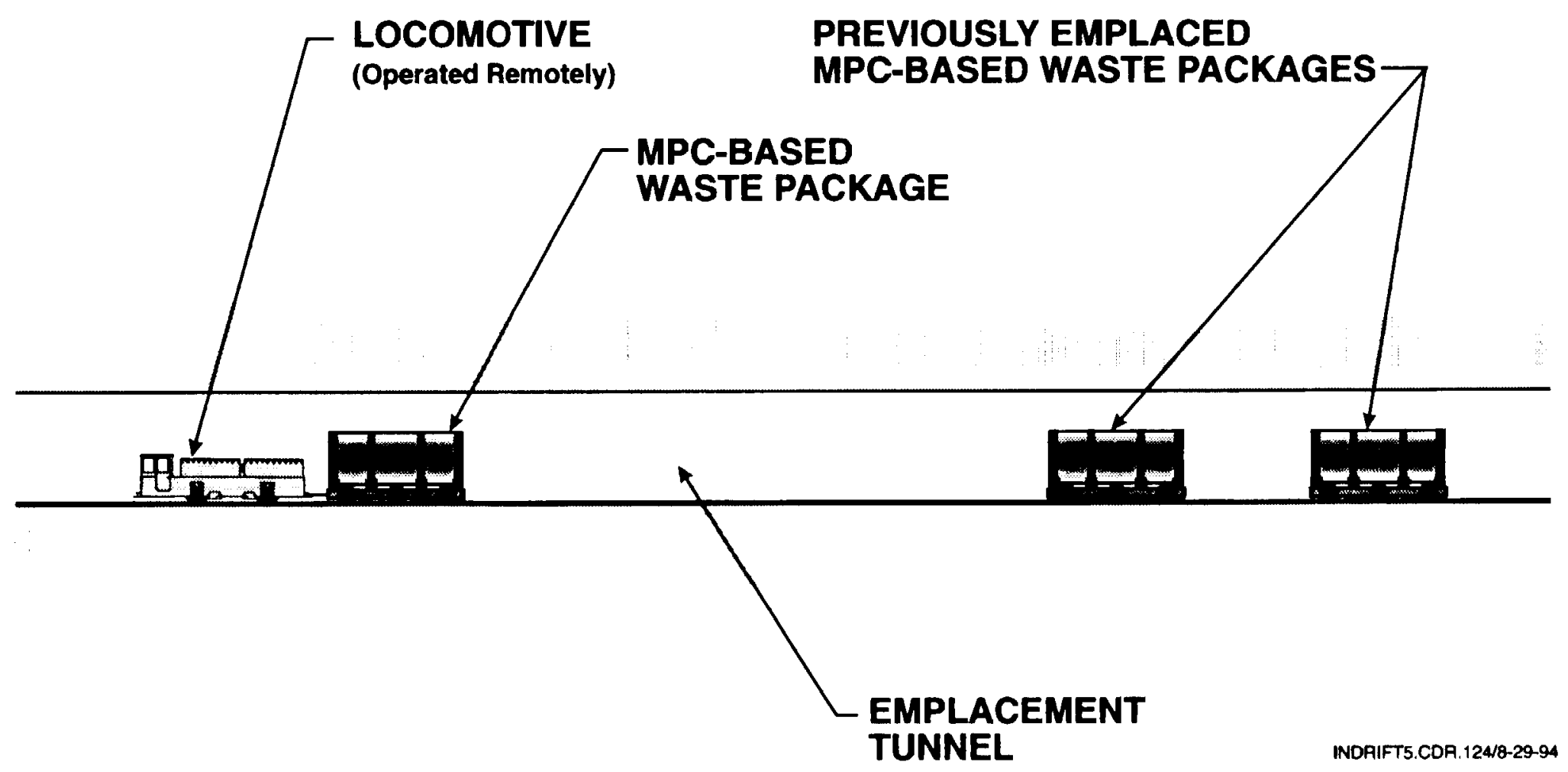


Emplacement operations under the interim layout concept would proceed sequentially, drift by drift, from the north end of the layout toward the south. If more than a single emplacement operation is needed in order to sustain the waste receipt schedule, then some of the crosscuts connecting the service and launch mains would be excavated to a larger profile during development in order to provide additional points of access from the service main for the waste transport vehicles. This adjustment to the basic concept would be necessary because the emplacement platform blocks access to that portion of the main drift that is located south of the emplacement operation. Chances are good, however, that a single emplacement system designed to operate more or less as described above could maintain a sufficient rate of emplacement. Current projections are that a total of approximately 12,000 packages will be emplaced at a peak rate of just over 500 packages per year, or approximately 2 packages per day (M\&O 1994m, Key 041). A key aspect of the concept described above that would allow the system to work with a minimum number of transport vehicles is the "divorcing" of the transport function from the actual emplacement function. This allows the cycle times for the transport and emplacement operations to overlap, and simplifies the range of functions that each piece of equipment must be capable of performing.

Future ACD efforts will investigate the practicality of performing the entire subsurface portion of the emplacement operation remotely. Remote systems are already used to perform many of the more complicated tasks described in the discussion of emplacement operations presented above. It may be that consideration of ALARA principles result in further application of remotely operated concepts, perhaps in conjunction with different emplacement/waste handling schemes.

A potential alternative might be to eliminate the emplacement platform, bringing a rail mounted WP into the service main, through the appropriate crosscut and then through the radiation door and straight into the emplacement drift without having to go through the offloading and rotation tasks associated with the platform concept as described earlier. This and many other concepts remain to be evaluated as the ACD effort progresses.

\subsection{Emplacement on Raised Pedestals Using Gantry}

This concept is similar to that described in the preceding section, except that the WPs do not require a permanent cart to facilitate the emplacement and retrieval processes. Rather, a gantry type mechanism would be used to move the WPs inside the emplacement drift and for lowering them onto pedestals in predetermined emplacement positions. The gantry/pedestal concept requires a larger drift cross-section than is required using the cart/locomotive and involves more complex remote handling movements inside the emplacement drift but it offers the ability to thermally manage the WPs by adjusting their position inside the drift during the preclosure years without removing any packages from the drift.

Gantries are commonly used in many heavy industrial applications to lift and move large, heavy objects. They are often custom designed to fit a specific application. In the underground construction industry, gantries are often used to advance, set, and support large and heavy concrete forms. Examples of two preliminary conceptual gantry designs developed to emplace and move WPs in the Center-In-Drift concept are shown in Figures 8.7.2-6 and 8.7.2-7. 


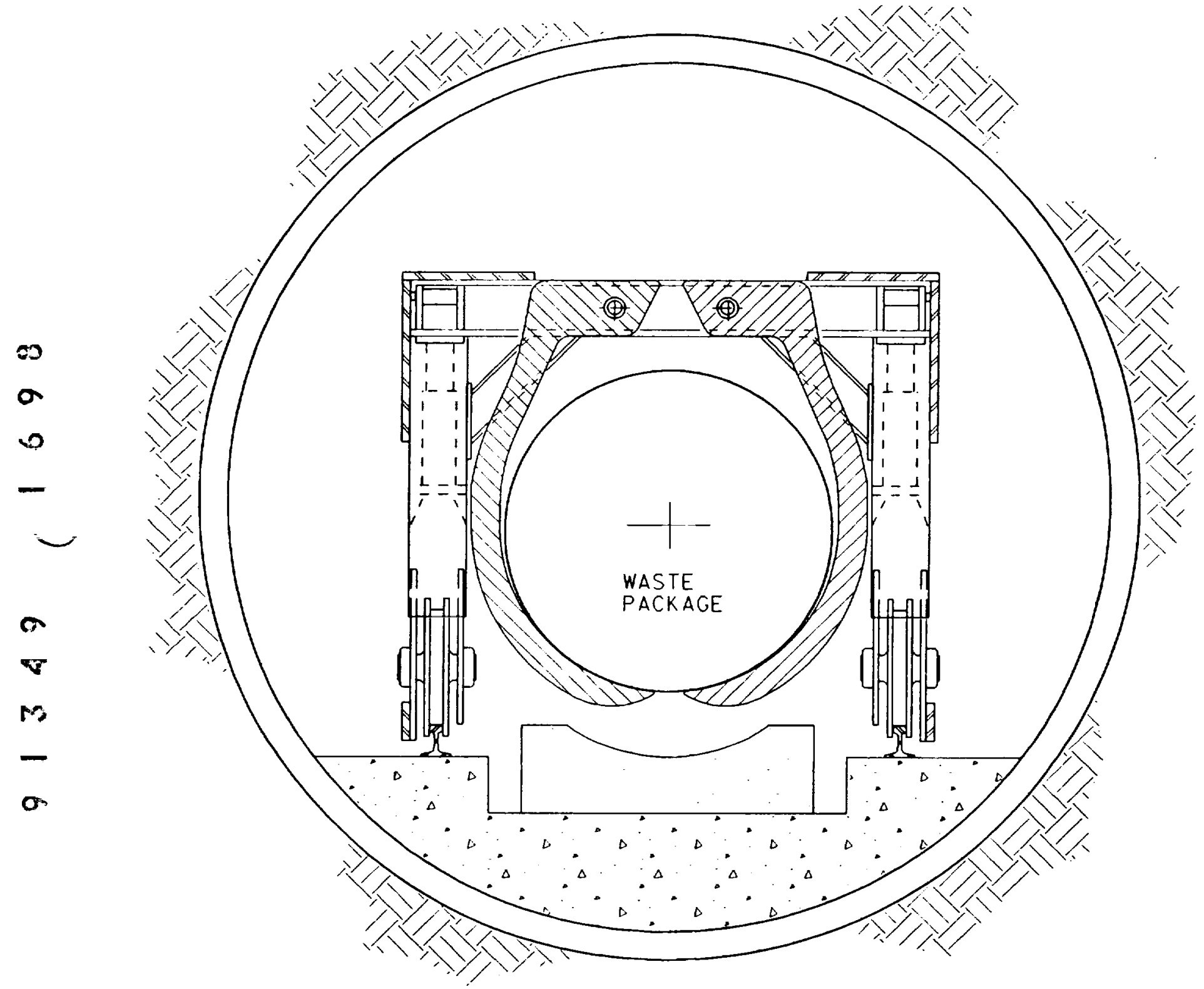

Figure 8.7.2-6. Conceptual Gantry Concept 

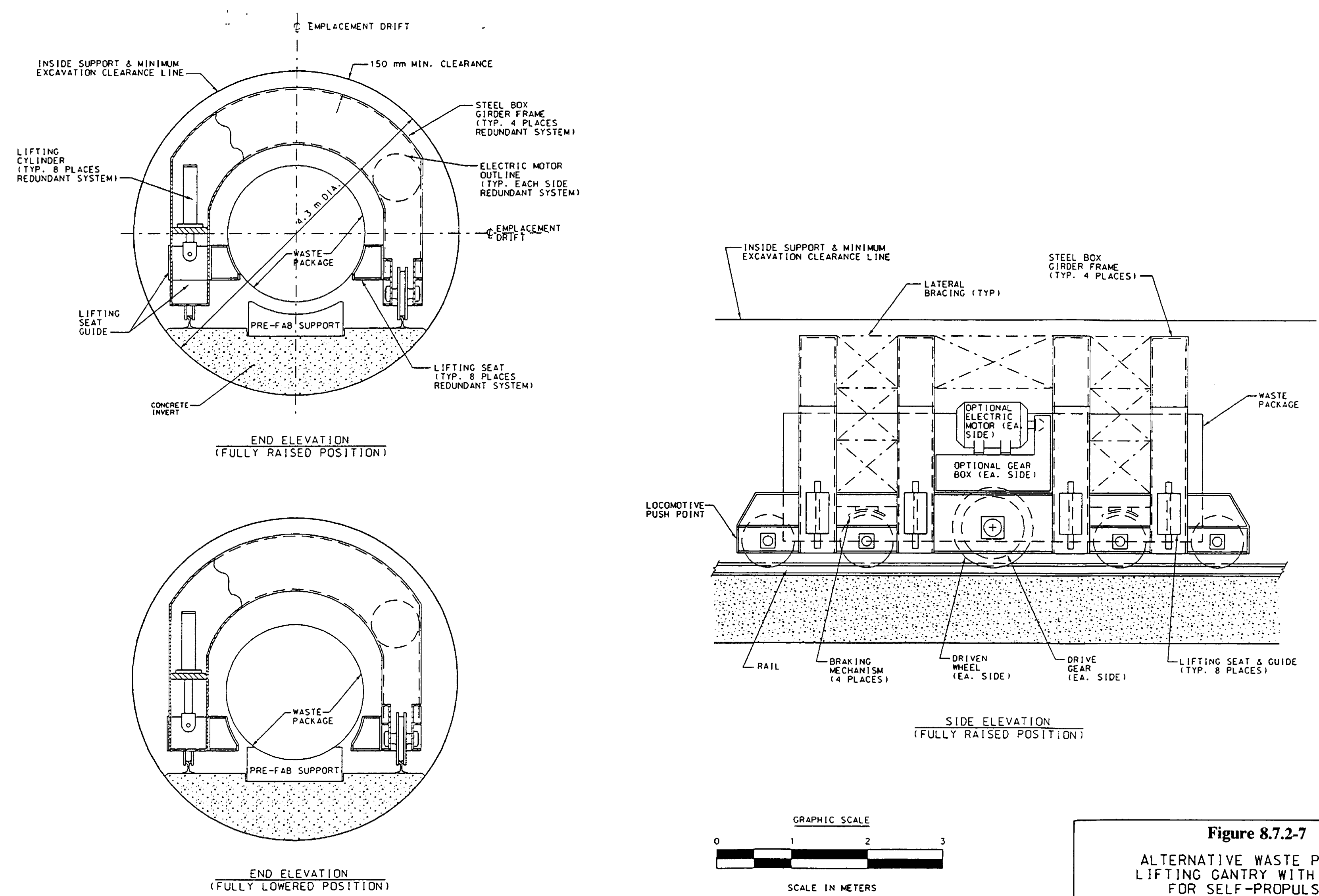

GRAPHIC SCALE

SCALE IN METERS

Figure 8.7.2-7

AL TERNATIVE WASTE PACKAGE FOR SELF -PROPULSION

R REGAN ${ }^{\text {orsicmeo }}$ D EINARSON CAD FILESSRM-SKO97. DGN 
Figure 8.7.2-7 shows a design concept for a self-propelled gantry. The gantry is designed to lift a WP off of a temporary transport cart, which would resemble an emplacement cart in the permanent emplacement cart option. This lifting operation would occur in the emplacement drift entrance, just inside of the radiation door. A WP in the horizontal position is lifted from its lower quadrant by lifting seats attached to guides mounted integrally into the frame of the gantry. Slots in the frame guide the lifting seat/guide mechanism. Although not shown in Figure 8.7.2-7, the guide mechanism would be equipped with suitable linear-bearing assemblies to prevent binding of the guide.

The mechanics of the lifting mechanism will exert large, opposing, horizontal forces into the gantry frame. The large, horseshoe-shaped, steel box girders, provide the strength and rigidity to resist such forces without significant lateral deflections which would be detrimental to the rail on which the gantry rides.

Lifting jacks are incorporated to raise and lower the guide seat mechanisms. The jacks could be hydraulic cylinders, or alternately, acme-thread screw jacks equipped with a swivel. Since the jacks must raise simultaneously with relative precision, screw threaded jacks powered by a precision drive source may be a preferred alternative. For simplicity, Figure 8.7.2-7 portrays hydraulic cylinders, but future conceptual sketches will be developed which incorporate screw jacks and their drive mechanism.

The gantry would be propelled at a low acceleration rate and slow speed, probably in the range of 0.5 to $1 \mathrm{~m} / \mathrm{s}$, by an electric motor which drives a gear box. The slow speed and acceleration will allow a reasonably sized motor to be used and would reduce the potential for accidents during the transportation operation. To provide speed variation, the electric motor could be $\mathrm{DC}$, or $\mathrm{AC}$ with variable-frequency drive. The final gear in the gear box is a drive gear which is integrally mounted to a driven wheel, as shown in Figure 8.7.2-7. The drivenwheel propels the gantry. This drive arrangement has some similarities to electrically powered locomotives. Braking mechanisms are provided, and would be designed to stop the gantry without aid of the drive system components. Drive system components could also provide dynamic braking capability.

Conceptual design features incorporated into the gantry shown in Figure 8.7.2-7 have a threefold purpose: reliability, total redundancy of critical components, and robust construction as discussed below. First, the lifting principle incorporated into the gantry concept is designed with reliability in mind by using a minimum of moving parts as well as single direction, welldefined, ranges of motion.

Total redundancy of critical components is provided as indicated in Figure 8.7.2-7. For example, four lifting points with associated lifting mechanisms are required but eight are provided. In addition, the outer four lifting mechanisms would be designed to operate from a separate control system from the inner four. Similarly, two support frames consisting of steel box girders are required but four are provided. The gantry drive system consists of duplicate electric motor, gearbox, drive gear, and driven wheel components. Again, separate control systems for each drive system would be included, and each drive system would be designed to propel the gantry on its own. Redundant support wheels are also provided. 
The gantry shown in Figure 8.7.2-7 is of robust construction where the steel box girders (constructed of heavy plate sections), associated bracing, and deep wheel support girders will provide considerable multi-axis rigidity in the gantry frame.

The gantry is also conceptually designed to recover from failure modes in several ways. Redundancy in drive system and lifting components would minimize the chance for crippling failures, but nevertheless, several features will aid in recovery. In failure of both drive systems, or their power source, recovery can be accomplished by using a conventional battery-powered locomotive as an alternate prime-mover. The locomotive would attach itself by a simple mechanism to the gantry frame in the locomotive push point position shown. The gantry could then be pushed into the drift to complete the emplacement operation or could be towed out of the drift.

Redundancy built into the lifting mechanisms would minimize the possibility for a crippling failure mode which would cause the WP to be dropped. However, if a package could not be raised for some reason, the bottom of the box girder will act as a lower stop for the lifting seat guide. The gantry could be moved out of the drift with the lifting seat guides in the fully lowered position, similar to that shown in Figure 8.7.2-7, and the WP resting on them; although, the pre-fabricated pedestals would have to be moved out of the drift to do this.

\subsubsection{Emplacement Drift Monitoring and Instrumentation}

Specific emplacement drift monitoring and instrumentation requirements have not been defined at this time regarding the frequency and nature of inspections and tests that are important. Given the hostile radiation and thermal environment that will exist adjacent to unshielded WPs emplaced in an open emplacement drift, equipment used to monitor and obtain measurements inside the drift must be robust. Remote systems will need to be developed that can easily install and remove this equipment so that maintenance and calibration can be performed. A lightweight monorail beam or similar trackway might be suspended from the crown of the emplacement drift, extending throughout, and used to support and guide a device that performs the inspection functions. Alternatively, gantry emplacement concepts might use another lightweight gantry that carries the monitoring and instrumentation equipment throughout the emplacement drift. These and other concepts, in addition to the functional requirements for this subsystem, remain to be examined as ACD progresses.

\subsubsection{Transportation of Personnel and Supplies}

Although this particular aspect has not received much attention at this point in repository $A C D$, requirements for transportation of personnel and supplies to support emplacement operations should be less than the total number of trips necessary relative to development operations.

As mentioned in Section 8.7.2.1, a key element to be considered for the emplacement side will be the careful coordination of waste transportation activities with personnel and supplies transport through the North Ramp and on into the emplacement area.

This and other considerations will be more fully evaluated as ACD progresses. 


\subsection{SUBSURFACE VENTILATION}

The basic function of the repository subsurface ventilation system for the potential repository is to control air movement (quantity, quality, and direction of airflow) to meet the needs of repository underground activities including:

- Initial repository construction or development

- Simultaneous development and waste emplacement

- Emplacement after completion of construction

- Postemplacement (caretaker) repository operations.

This section is intended to provide a preliminary discussion of air distribution concepts, potential airflow requirements, and some typical results from modeling of the ventilation system. It focuses primarily on the ventilation concepts for development and emplacement. Discussions of preliminary considerations for emergency and escape are also provided. Considerations of retrieval ventilation during the postemplacement (or caretaker) period are addressed later in Section 8.12.5.

General airflow distribution strategies for a ventilation system are governed by factors including safety, cost, flexibility, and development sequence. A primary concern is safety. The repository design requirement stipulated by 10 CFR 60.133(3)(g) dictates that the underground facility ventilation system shall separate the ventilation of excavation and waste emplacement areas. Although specific definition of the separate system is not given in the CFR, the main purpose of the requirement is to limit potential radiation exposure. To meet this requirement, proper arrangement of the primary air intake and exhaust for development and emplacement areas requires consideration. The Repository Underground Ventilation Concepts (M\&O 1993j) analyzed several alternatives regarding separate ventilation. It indicated that planning two entirely independent ventilation systems is a favored scheme for safety concerns.

The repository ventilation is arranged to maintain two separate airflow systems. One system provides air for the development of the repository while the other provides air for the waste emplacement operations. Each system has its own primary intake and exhaust openings to the surface for the supply of fresh air and exhaust of return air. Underground openings between the two ventilation systems are sealed with bulk-heads (air stoppings) or air locks (double air doors).

The two completely independent ventilation systems basically have no operational impacts on each other. For balancing the network, fan coordination, design and construction of ventilation control devices, independent systems are simpler and more reliable than two systems with common intake or exhaust airways. The pressure difference of the ventilating air between the two systems can be designed in such a way that the unavoidable air leakage always moves from the development to the emplacement area. Each system will have continued functions during normal operations or when accident conditions occur in the other.

For example, if areal or major reversals of airflow were necessary for one system due to a fire emergency, the other system can remain unchanged and operations are not affected. 
More importantly, personnel under such emergency conditions have an extra choice to escape by entering the other system through the strategically placed air locks. A disadvantage of this scheme is that simultaneous development and emplacement are possible only after construction of four major access openings to the surface are completed. However, with the interim layout, two of the openings (ramps) would be completed as a part of the ESF.

Figures 8.8-1 and 8.8-2 show (diagrammatically) the general method that is envisioned for air flow distribution for the development and emplacement areas, respectively, using the interim repository layout concept. The configuration of the ventilation network for other layout concepts would vary according to the specific layout that might be used and the development and emplacement operational scenarios that might be employed. The ventilation system would be designed so that all air leakage between the two systems is from the development area to the emplacement area. This pressure differential is created by using a primary forcing, or positive pressure main fan(s) in the development intake (South Ramp) and using exhausting, or negative pressure main fan(s) installed at the collar of the emplacement exhaust shaft. With this type of arrangement, the pressure differential forcing air leakage from the development area to the emplacement area always exists, even if the ventilation pressure supplied by one of the systems is interrupted. Since the development and emplacement areas are ventilated separately, discussions of the two independent systems are made separately in the following two sections.

\subsubsection{Development System Quantities and Distribution Concepts}

The development side ventilation system will support initial construction and continuous development after waste emplacement begins.

Initial construction covers the excavation prior to waste emplacement. Due to potential scheduling constraints, it would not be desirable to construct the entire repository before waste emplacement begins. To facilitate simultaneous construction and emplacement and maintain separate ventilation circuits, the initial development of the repository is needed to provide excavated underground area and sufficient major openings to the surface. This initial excavation can proceed in much the same manner as the development of a comparably sized mine, and can be supported by a single ventilation system. The ventilation considerations for this stage will be governed by conventional underground ventilation requirements, such as items stated in 30 CFR 57, 29 CFR 1926 and CAC Title 8. [RDRD 3.7.5.B.7]

[RDRD 3.7.5.C]

Simultaneous development and waste emplacement operations will occur when minimum required initial excavation is completed. As shown on Figure 8.8-1, the development operation is in advance of the emplacement operation from north to south. Although heat released from WPs will affect ventilation of the emplacement area, it will have little effect on the development system. This is because the air flows of the two ventilation systems are independent and conduction is the only means for heat exchange between the two systems; when there is insufficient time for conductive heat to reach the advancing development areas, the rock temperatures in development airways will not be affected. 


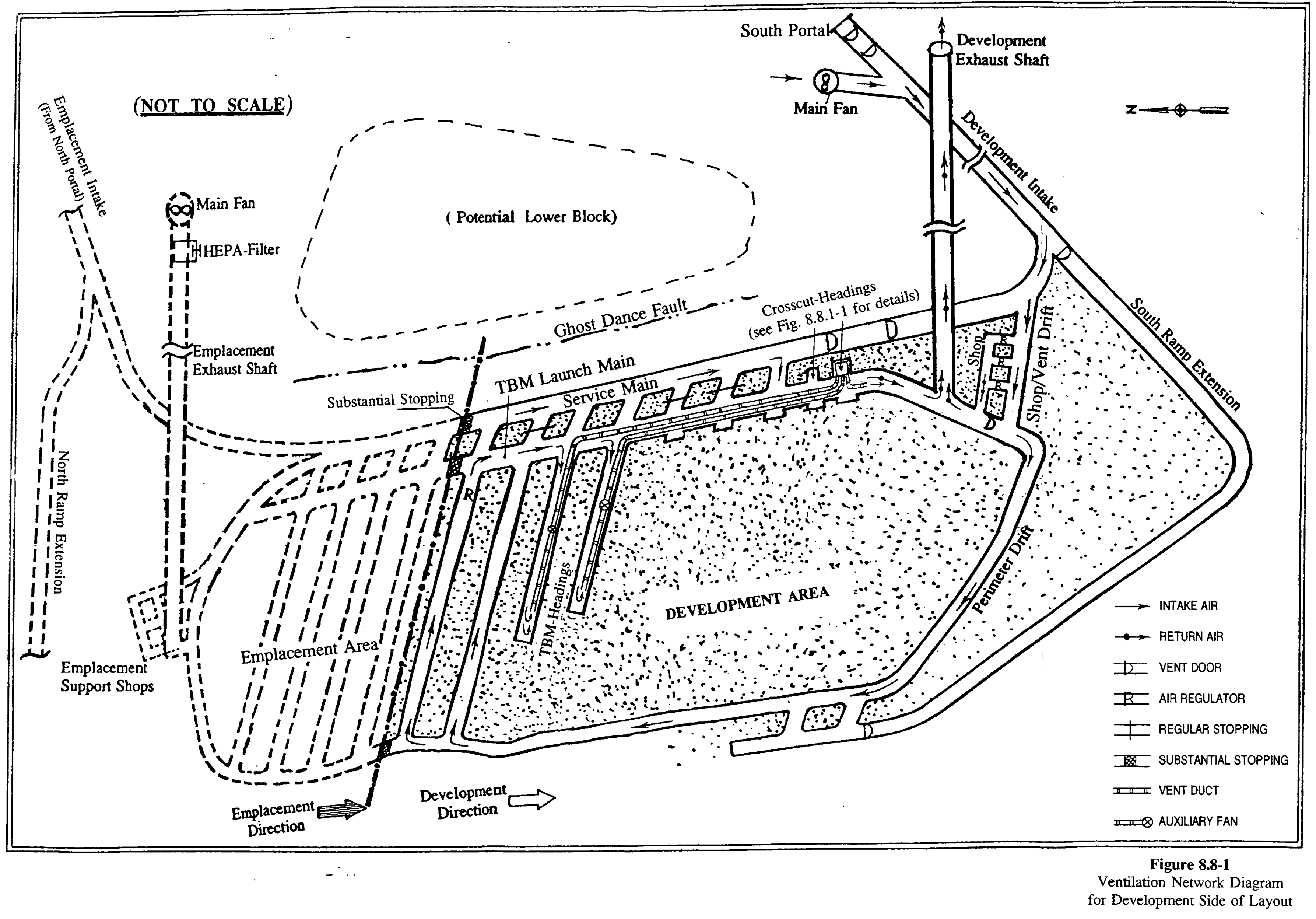




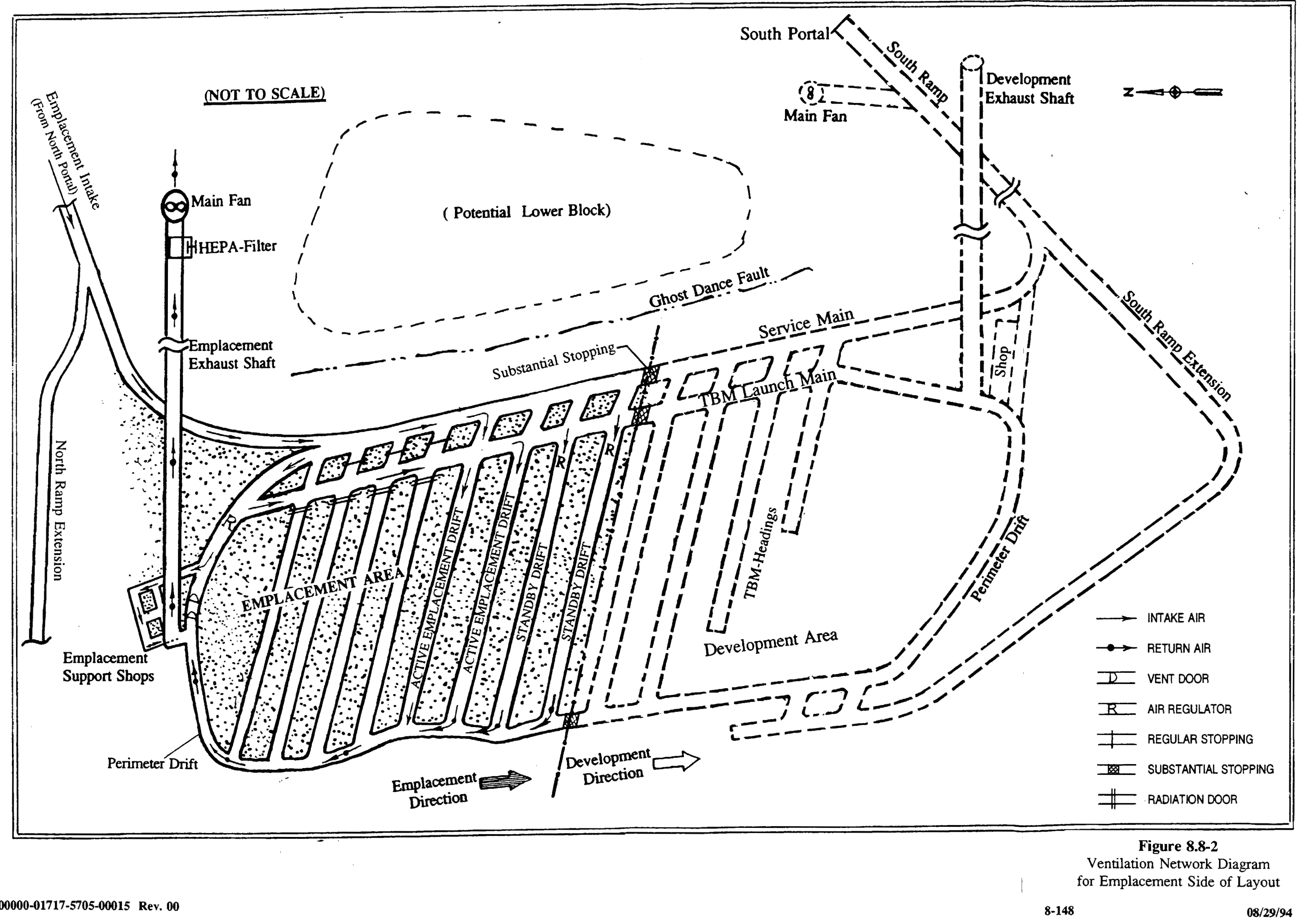


The ventilation network diagram for the development side (Figure 8.8-1) illustrates the concepts of the development ventilation system and air flow arrangements. In addition to the two main ramps constructed during site characterization, two vertical shafts would be constructed, one north and one south, in order to establish the two independent ventilation systems necessary for simultaneous development and emplacement operations. The bottoms of these shafts would be connected to the perimeter main at the north and south ends of the repository. After completion of construction for the shafts and main drifts, development of the emplacement drifts would begin, advancing from north to south, followed by emplacement.

The intake air for development side operations would be brought through the South Ramp, followed by a short ventilation supply drift, the west side perimeter main, and into two or more excavated emplacement drifts (awaiting turnover to emplacement operations) that deliver the fresh air to the launch and service main drifts. Fresh air for active emplacement drift headings being excavated by the TBMs is drawn into the ends of these drifts from the service and/or launch mains by auxiliary fans and ventilation duct that extend to the TBM cutterhead and that operate in an exhausting, or locally negative pressure mode. Dusty air from the TBM cutting zone is routed through the TBM dust scrubbers and directly into the ventilation duct that extends beyond the crosscut headings located in downstream airflow, thereby allowing personnel in both developing emplacement drifts and crosscut areas to always work in fresh intake air. Return air in the launch main exits via the south perimeter drift section, and is exhausted to the surface through an exhaust shaft. As shown in Figure 8.8.1-1, crosscut development headings would also be ventilated using auxiliary fans and duct that operate in a suction mode. The air supply for developing crosscuts is supplied from the upstream launch main where the flow contains no potential dusty air exhausted from the TBM operations; the return air from the crosscut faces would exhaust through portable dust scrubbers into the launch main, then into the perimeter main which is connected to the exhaust shaft.

Figure 8.8.1-1 also illustrates that the used air from the TBM headings (scrubbed by a built-in dust collector) is directed into ventilation ducts, then through a portable dust scrubber for further dust reduction, before discharging into the main return air stream. At the muck car dump and conveyor feeder station, potential dusty air produced during dumping and conveyor loading operations can be drawn through an exhaust hood installed over the conveyor transfer point (Figure 8.7.1-7). Dust would be collected through a portable scrubber before the used air enters the launch main. A relatively small quantity of air would be split from main intake air in the ventilation drift near the shop area to ventilate potential development support shops that might be needed in the subsurface; the used air from the shops would be directed into the nearby perimeter main and then the exhaust shaft.

The required airflow quantities for underground development areas are estimated and summarized in Table 8.8.1-1. The air flow rates are generally determined by the need to supply fresh air for personnel and special TBM operations, and to control air temperature, dust and potential emission from diesel equipment in the repository. 


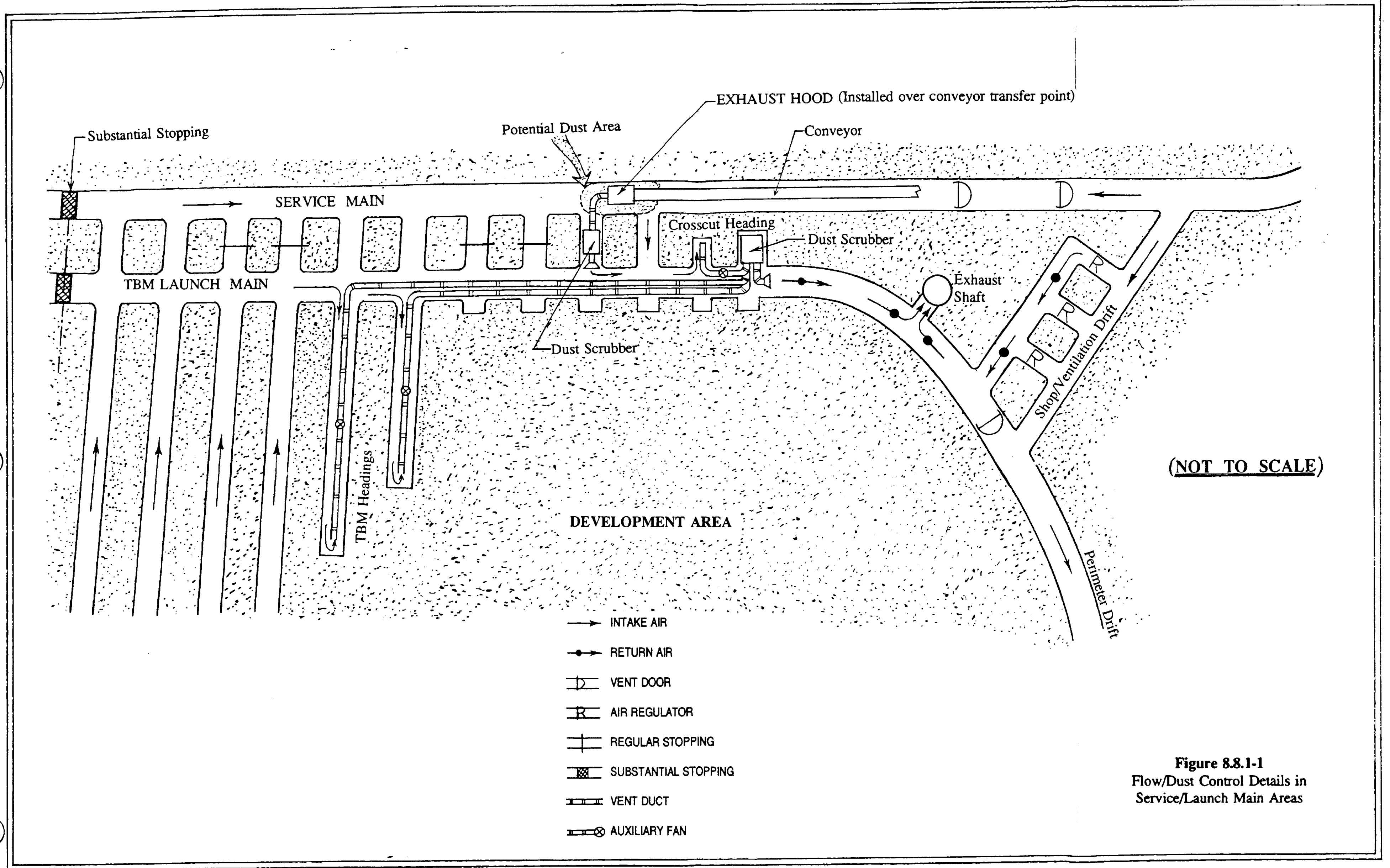


Table 8.8.1-1. Estimated Air Quantity for Development Operations

\begin{tabular}{||l|r|r|}
\hline \multicolumn{1}{|c|}{ Development Area } & \multicolumn{1}{|c|}{$\begin{array}{c}\text { Required } \\
\text { Air Quantity } \\
\left(\mathrm{m}^{3} / \mathrm{s}\right)\end{array}$} & $\begin{array}{c}\text { Design } \\
\text { Air Quantity* } \\
\left(\mathrm{m}^{3} / \mathrm{s}\right)\end{array}$ \\
\hline \hline $\begin{array}{l}\text { Emplacement Drift } \\
\text { (TBM Heading \#1) }\end{array}$ & 27.12 & 33.90 \\
\hline $\begin{array}{l}\text { Emplacement Drift } \\
\text { (TBM Heading \#2) }\end{array}$ & 27.12 & 33.90 \\
\hline $\begin{array}{l}\text { Emplacement Drift } \\
\text { (Postexcavation Construction, } \\
\text { 8 Drifts) }\end{array}$ & 48.72 & 60.90 \\
\hline Crosscut (Roadheader) & & 31.10 \\
\hline Crosscut (Drill and Blast) & 24.88 & 25.30 \\
\hline Shop Maintenance & 20.24 & 32.45 \\
\hline \hline
\end{tabular}

* Includes 20 percent of total for leakage/uncertainty allowance.

Figure 8.8.1-2 illustrates the general ventilation air flow quantity distribution on the development side. The results are obtained from the Subsurface Ventilation Concepts Report for Repository ACD-FY 1994 (M\&O 1994q), which was prepared using the interim layout concept described in Section 8.6.4.

For the typical ranges of air quantity requirements and the general concepts of air flow distribution presented herein for the interim layout concept, the ventilation equipment and devices are expected to be similar to those used in conventional underground mining facilities, including main and auxiliary fans, bulkheads (or stoppings), air regulators, air doors, air locks, ventilation duct or tubing, air quality monitoring devices and dust collectors. More in-depth evaluation of these facilities will be addressed in future repository ACD ventilation studies.

\subsubsection{Emplacement System Quantities and Distribution Concepts}

Figure 8.8-2 is a conceptual illustration of the ventilation system for the emplacement area. Ventilation intake air for the emplacement side of operations is supplied via the north (waste) ramp, then directed to the active emplacement drifts and standby drifts through either the service main, or through the emplacement operations end of the TBM launch main. Return air is directed into the west side perimeter drift, and then exhausted through the emplacement exhaust shaft. If an accident were to result in the release of radionuclides, the return air would be routed through a bank of HEPA filters before being discharged to the atmosphere. 


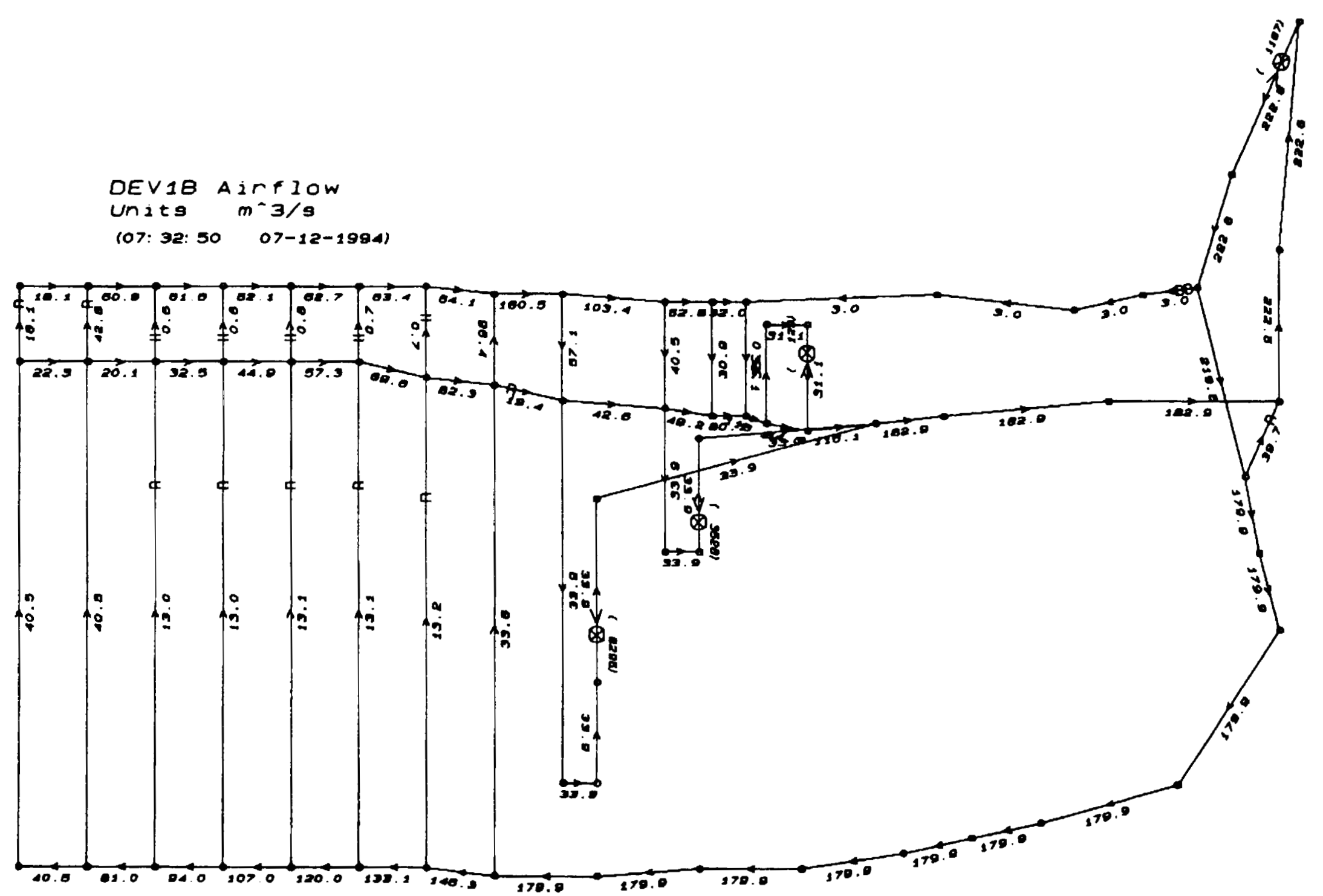

웅

Figure 8.8.1-2. General Air Flow Quantity Distribution on Development Side of Layout 
During emplacement of WPs, heat released from waste will increase temperatures of air flowing in the emplacement drifts and the surrounding rock. The impact of heat load on the ventilation air flow must be evaluated, in addition to the considerations of ventilation for general underground operations. Based on an assumption in the CDA, the design air flow must be capable of maintaining an acceptable air temperature less than $50^{\circ} \mathrm{C}$ in the operating drifts (M\&O 1994m, DCSS-019).

The required airflow quantities for underground development areas are estimated and summarized in Table 8.8.2-1. The results are obtained from the Subsurface Ventilation Concepts Report for Repository ACD-FY 1994 (M\&O, 1994q), which was prepared using the interim layout concept described in Section 8.6.4. The air flow rates are generally determined through analysis of the conduction, convection and radiation heat transfer processes in the drift during waste emplacement operations, and the need to supply fresh air for general emplacement related activities in the repository. Figure 8.8.2-1 illustrates the general ventilation air flow quantity distribution on the emplacement side. These typical ranges of air quantity requirements and the general arrangement of air flow distribution indicate that the temperature of the operating emplacement drifts can be controlled within an acceptable level with adequate air flow in the same order of magnitude as that for development drifts; thus, commonly accepted underground ventilation principles may be used in design of ventilation for the repository emplacement operations.

Table 8.8.2-1. Estimated Air Quantity for Emplacement Operations

\begin{tabular}{||l|r|r||}
\hline & \multicolumn{1}{|c|}{$\begin{array}{c}\text { Required } \\
\text { Air Quantity } \\
\left(\mathrm{m}^{3} / \mathrm{s}\right)\end{array}$} & $\begin{array}{c}\text { Design } \\
\text { Air Quantity* } \\
\left(\mathrm{m}^{3} / \mathrm{s}\right)\end{array}$ \\
\hline \hline Emplacement Area & 30.81 & 38.51 \\
\hline Emplacement Drift \#2 & 30.81 & 38.51 \\
\hline Supporting Shops & 25.96 & 32.45 \\
\hline Standby Drift \#1 & 6.09 & 7.61 \\
\hline Standby Drift \#2 & 6.09 & 7.61 \\
\hline \hline & Total & 124.69 \\
\hline
\end{tabular}

* Includes 20 percent of total for leakage/uncertainty allowance

\subsubsection{Emergency and Escape Considerations}

Each emergency situation is unique. Systematic analysis of accident scenarios is an extremely complex subject and generally involves a number of research topics including: development of accident scenario, event tree frequency and dose consequence analyses, and planning for emergency responses. Comprehensive study and modeling of the accident scenarios require efforts beyond the scope and effort for this stage of the design study. 


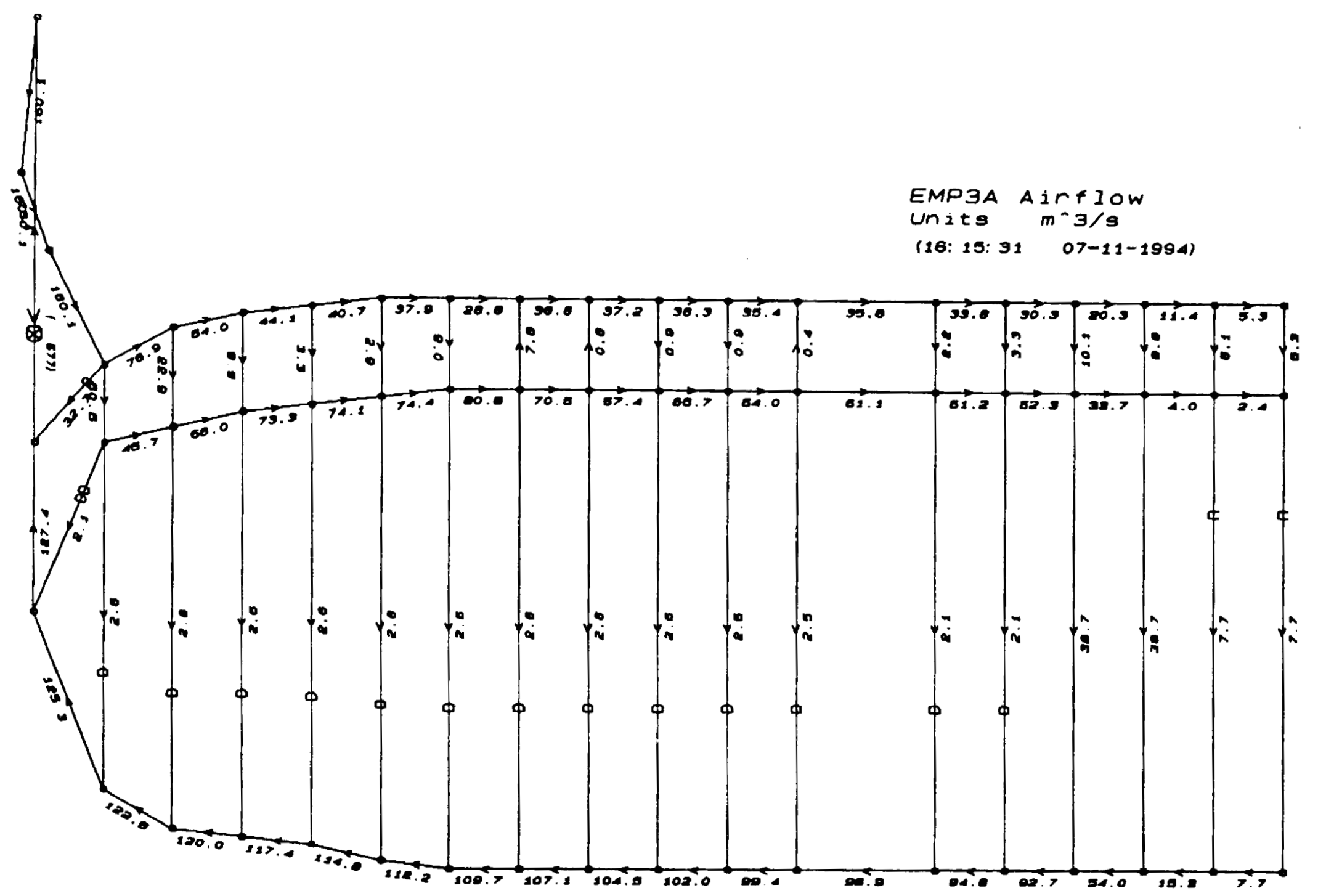

Figure 8.8.2-1. General Air Flow Quantity Distribution on Emplacement Side of Layout 
This section is intended to provide a preliminary discussion of some generic considerations regarding potential escape routes for underground personnel during some accident scenarios. The following discussions are based on the underground ventilation schemes presented in the previous two sections.

Potential contaminants, either accidently released radioactive materials in the form of gas or suspended particulates, or products of combustion generated by accidental underground fires, will follow the prevailing winds and be carried to the downstream areas from the original source location. Although fires can themselves alter ventilation air flow conditions, during the initial stage of a fire, and while the underground areas are being evacuated, the air will generally continue to flow in the original direction. Consequently, potential escape routes can be planned according to the air flow schemes and potential locations of contamination sources. Some examples of the preliminary considerations that may allow personnel in underground areas to travel in uncontaminated air streams and to reach the surface areas are presented as follows. It is worth noting that the following examples are used generically for the purpose of illustrating that underground personnel can escape from anywhere in the underground facility regardless of the accident location. The actual schedules for emergency responses will depend on detailed accident analysis.

Fire in developing emplacement drift:

- Personnel in TBM headings: $\Rightarrow$ excavated crosscuts $\Rightarrow$ service main $\Rightarrow$ South Ramp $\Rightarrow$ surface. Alternatively, from the TBM headings $\Rightarrow$ launch main $\Rightarrow$ excavated emplacement drift $\Rightarrow$ perimeter main $\Rightarrow$ shop/vent drift $\Rightarrow$ South Ramp $\Rightarrow$ surface.

- Personnel in crosscut headings: $\Rightarrow$ launch main $\Rightarrow$ existing crosscut $\Rightarrow$ service main $\Rightarrow$ South Ramp $\Rightarrow$ surface.

- Personnel in excavated emplacement drifts: $\Rightarrow$ existing crosscut $\Rightarrow$ service main $\Rightarrow$ South Ramp $\Rightarrow$ surface. Alternatively, $\Rightarrow$ perimeter main (west side) $\Rightarrow$ shop/vent drift $\Rightarrow$ South Ramp $\Rightarrow$ surface.

- Personnel in development shop area: $\Rightarrow$ vent drift $\Rightarrow$ South Ramp $\Rightarrow$ surface.

Fire in South Ramp (main intake air stream):

- Personnel in TBM and crosscut headings: $\Rightarrow$ launch main $\Rightarrow$ stopping (at north end of development area in launch main) $\Rightarrow$ buffer zone or refuge station in emplacement area (as discussed in Section 8.7.2.1).

- Personnel in excavated emplacement drifts: $\Rightarrow$ launch main $\Rightarrow$ stopping (at north end of development area in launch main) $\Rightarrow$ buffer zone or refuge station in emplacement area.

Alternatively, from excavated emplacement drifts $\Rightarrow$ perimeter main $\Rightarrow$ stopping (at north end of development side in perimeter main) $\Rightarrow$ buffer zone or refuge station in emplacement area. 
- Personnel in west section of perimeter main of development area or in development shop area: $\Rightarrow$ perimeter main $\Rightarrow$ stopping (at north end of development side in perimeter main) $\Rightarrow$ buffer zone or refuge station in emplacement area.

Fire in developing crosscuts: (similar routes to those for fire in developing emplacement drift).

Fire in the development shop area: (similar routes to those for fire in developing emplacement drift except that the alternatives involving the use of the shop/vent drift will not be available).

Contaminant release in active emplacement drift or standby drift:

- Personnel in active emplacement drift or standby drift: $\Rightarrow$ nearby crosscut $\Rightarrow$ service main $\Rightarrow$ North Ramp $\Rightarrow$ surface.

- Personnel in emplacement shop area: $\Rightarrow$ perimeter main $\Rightarrow$ North Ramp $\Rightarrow$ surface. Alternatively, from shop area $\Rightarrow$ perimeter main $\Rightarrow$ stopping (at south end of emplacement side in waste handling main) $\Rightarrow$ buffer zone or refuge station in development side.

Contaminant release in North Ramp:

- Personnel in active emplacement drift or standby drift: $\Rightarrow$ perimeter main (west side) $\Rightarrow$ stopping (at south end of emplacement side in perimeter main) $\Rightarrow$ buffer zone or refuge station in development side.

- Personnel in emplacement shop area: $\Rightarrow$ emplacement exhaust shaft $\Rightarrow$ surface. Or, from shop $\Rightarrow$ perimeter main (west side) $\Rightarrow$ stopping (at south end of emplacement side in perimeter main) $\Rightarrow$ buffer zone or refuge station in development side.

Contaminant release in waste handling main:

- Personnel in active emplacement drift or standby drift: $\Rightarrow$ perimeter main (west side) $\Rightarrow$ stopping (at south end of emplacement side in perimeter main) $\Rightarrow$ buffer zone or refuge station in development side. Alternatively, from emplacement drift $\Rightarrow$ nearby crosscut $\Rightarrow$ service main $\Rightarrow$ North Ramp $\Rightarrow$ surface.

- Personnel in emplacement shop area: $\Rightarrow$ perimeter main $\Rightarrow$ North Ramp $\Rightarrow$ surface. 


\subsection{SUBSURFACE DRAINAGE}

The interim layout is designed to drain any water seeping into the main drift openings toward a sump located at the emplacement exhaust shaft. Figure 8.9-1 provides approximate elevations at key points in and around the layout block. Figure 8.9-2 portrays the resulting general drainage pattern. As noted in Section 8.6.4.6, the emplacement drifts in the interim layout are flat-lying, and the design would be adjusted later to facilitate drainage out of these drifts if the concept undergoes further refinement. The emplacement drifts would then drain into one of the main drifts, and on toward the emplacement exhaust shaft as described above.

The bulkheads or air stoppings described in Section 8.8 , which physically separate the development and emplacement sides of the repository, present a problem for drainage in that they block the flowpath in the main drifts. Water encountered on the development side of the repository would flow toward these stoppings. There it would be collected in a sump at each stopping location and either pumped through the stopping to the emplacement side, or to the surface through discharge pipelines hung in the service and perimeter mains. Any leakage through the stoppings would be from the development to the emplacement side, similar to ventilation air leakage at these locations. 


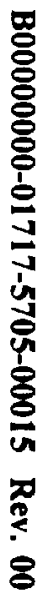

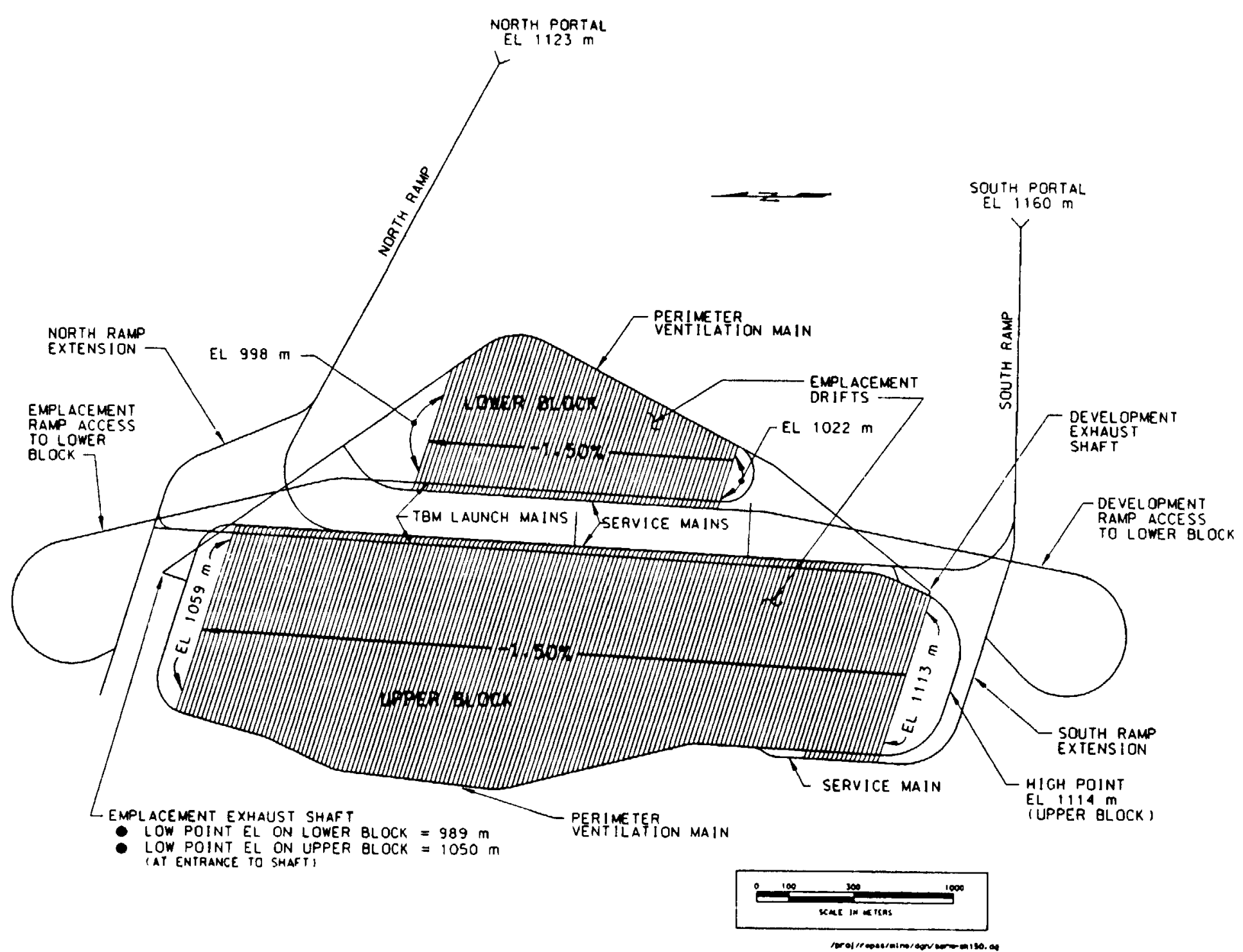

Figure 8.9-1. Elevation and Grade Data-Interim Layout 


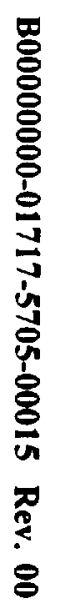

$\frac{\infty}{6}$

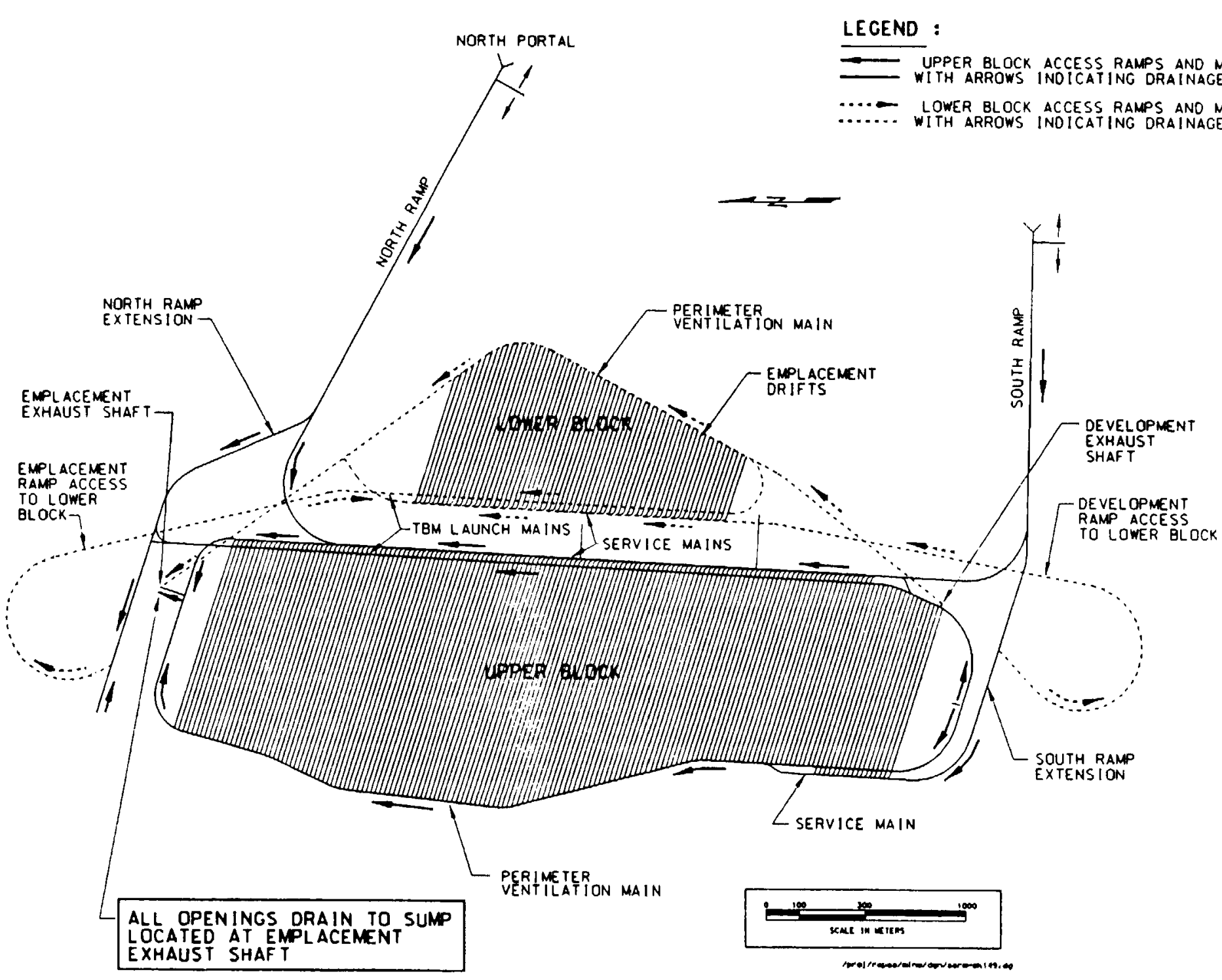

Figure 8.9-2. Subsurface Drainage Pattern-Interim Layout 


\subsection{SUBSURFACE SUPPORT SERVICES AND UTILITIES}

As ACD progresses, new concepts for excavation and transport equipment, repository layout, and available access corridors to the subsurface will have a significant influence in the configuration and location of subsurface facilities and utilities. This section provides a preliminary assessment of several of the more significant changes that have taken place during repository ACD which will affect subsurface support facilities. The general utility corridors into the repository using the latest ACD repository layout concepts are also identified.

\subsubsection{DEVELOPMENT SIDE SUPPORT FACILITIES}

Development side support facilities will generally be comprised of the warehousing and maintenance facilities needed to support development side construction operations. Major issues to be addressed in this area include the extent of facilities that should be placed underground versus on the surface.

In the SCP-CD, the majority of equipment requiring regular maintenance consisted of diesel powered, rubber-tired mining equipment. In production mines, it is often most economical to perform the majority of maintenance work on large fleets of this type of equipment in underground shops, rather than incurring the delays and costs to transport such equipment to surface shops. This was the philosophy adopted in the SCP-CD repository design.

Significant changes in subsurface excavation and equipment concepts have occurred as $\mathrm{ACD}$ progresses. TBMs will perform the majority of excavation work (M\&O, 1994m, DCSS-005). Rubber-tired, diesel-powered equipment used in previous repository conceptual designs has been replaced by rail equipment to the extent practical (M\&O, 1994m, Key 010, 030 ). Electricity as the prime mover of rail equipment by trolley and/or battery is now a potentially preferred option due to the unanswered question of the effects of diesel exhaust components on waste isolation. Access corridors to the subsurface which are available for equipment transportation during maintenance have also changed, as discussed in the next paragraph. A reevaluation of the types of maintenance activities required for current ACD equipment concepts, as well as the economics of the location of needed maintenance facilities-surface versus underground-is necessary.

In the interim design, use of the South Ramp as a rail transport corridor, as discussed in Section 8.7.1.3, will potentially allow much faster and more efficient transportation of supplies to the subsurface areas than in previous repository conceptual designs, such as the SCP-CD. The limited number of active working places and continuous nature of TBM advance, which requires a steady stream of supplies, must be considered as a factor in addressing the logistics of supplies transport and distribution. In the SCP-CD, supplies transport was accomplished through a personnel and materials shaft and by rubber-tired equipment, making underground warehousing facilities potentially more critical than current repository concepts. Excavation operations were also cyclical in nature, using drill-and-blast methods with many working places available. The assumptions on subsurface warehousing made in the SCP-CD may no longer be valid, and require reevaluation.

These aspects will be further addressed as ACD progresses. 


\subsubsection{Emplacement Side Support Facilities}

An examination of the required emplacement side support facilities has not been performed at this stage of ACD. These aspects will be further addressed as ACD progresses.

\subsubsection{Subsurface Utilities}

This subsection provides a preliminary summary of the major types of subsurface utilities that will be required to support subsurface repository development and emplacement operations; although quantity and size estimates have not been performed to date. The major utility corridors to the repository block and within the block are also described.

The South Ramp will serve as the primary utility corridor for both the repository development and emplacement side subsurface utilities, in addition to its transport and muck handling route functions. Figure 8.6.4-4 (Section 8.6.4.7) shows the relative positions of permanently installed utilities in the ramp.

Permanent electrical utilities to be installed in the ramp include high voltage electrical cables serving as the primary subsurface feed, low voltage electrical cables for power to trolley, ramp lighting, conveyor booster drives, ramp utility outlets, and communications and monitoring cables. Piping to be installed in the ramp includes a primary subsurface dewatering line, a compressed air line, and separate pipes for fire water, chilled water, potable water, and service water.

The development exhaust shaft will also carry some utilities to the repository block; however, the shaft will function as a corridor only for those utilities necessary as a repository backup source, those necessary to operate the shaft, and for those best located in an exhaust airway. Figure 8.6.4-6 (Section 8.6.4.9) shows the general cross section of the shaft with the planned permanently installed utilities which include a high voltage electrical cable serving as a subsurface redundant or loop feeder, low voltage electrical cable for shaft and shaft station power, and communications and monitoring cables.

Utilities in the North Ramp will be minimized because it will serve as the waste transportation route. The ramp will carry only low voltage electrical power cable(s) for ramp lighting and trolley power, and monitoring and signaling cables, as shown in Figure 8.6.4-1 (Section 8.6.4.1).

Utilities in the emplacement side exhaust shaft will also be minimized. Since the shaft functions as an exhaust airway for the emplacement side, it will be a potential radiation hazard area under certain accident or abnormal scenarios involving radionuclide release in the emplacement area. Activities in the shaft will therefore be kept to a minimum involving only periodic shaft inspection. Permanent utilities installed in the shaft will include only a cable to allow communications between the surface and the shaft station.

The service main will carry the above described utilities once on the repository block, and preliminary locations for them are included on the service main cross section in Figure 8.7.1-7 (Section 8.7.1.2). 
Piping utilities that would be required to support development operations include the dewatering, compressed air, service water, and as an option, the potable water lines. To support emplacement side operations and maintenance functions, installed piping could potentially include subsurface dewatering, compressed air, fire water, service water, potable water, and chilled water. Chilled water may be necessary to support local cooling operations not reasonably provided by the repository ventilation system for specific operating or maintenance functions.

Separate electrical utilities would be required to support development operations and emplacement operations. Power supply and instrumentation cables needed only for development operations would be removed prior to turnover of the construction area to the emplacement side. 


\subsection{LOWER THERMAL LIMITS AND EXPANSION CONSIDERATIONS}

The Mission Plan (DOE, 1985) targets the first nuclear waste repository for a storage capacity of 70,000 MTU. This goal is carried forward in the CDA (M\&O, 1994m, Key 003, 005).

The total subsurface area required for emplacement of waste depends, to a large extent, on the thermal loading that is determined to be desirable. Other factors that could increase the total areal requirement include the possible presence of undetected, non-suitable geologic conditions in some locations. Definition of a thermal loading appropriate for Yucca Mountain is the subject of numerous, ongoing studies at this time. For purposes of this report and consistent with the CDA (M\&O, 1994m, Key 019), two scenarios are considered:

A. A high thermal loading scenario that will produce "above-boiling" conditions in the repository; taken to be in the range of 80 to $100 \mathrm{MTU} / \mathrm{acre}$, which is equivalent to 91 to $114 \mathrm{~kW} /$ acre based on average 22.5 year old, $42.2 \mathrm{GWd} / \mathrm{MTU}$ burnup fuel at the time of emplacement (M\&O, 1994m, Key 004).

B. A low thermal loading scenario that will produce mostly "below-boiling" conditions (except for areas within a few meters of the WPs) in the repository; taken to be in the range of 25 to $35 \mathrm{MTU} / \mathrm{acre}$, or 28 to $40 \mathrm{~kW} / \mathrm{acre}$ at the time of emplacement for average fuel.

Figure 8.11-1 presents the net area available for emplacement of waste in the interim layout. Ignoring the possibility that geologic conditions might preclude waste emplacement in certain zones, the darkened portions of the layout represent the area over which the waste could be emplaced on a regular pattern. Based on the darkened areas shown on the figure, and assuming geologic conditions are favorable throughout the entire area, the layout could accommodate the total, 70,000 MTU waste inventory at a mass loading of approximately 82 MTU/acre or higher using just the upper block. Using both the upper and lower blocks, a mass loading of approximately $66 \mathrm{MTU} / \mathrm{acre}$ or higher could be accommodated for the full, $70,000 \mathrm{MTU}$ inventory. Alternatively, because $66 \mathrm{MTU} / \mathrm{acre}$ does not fit either of the thermal loading cases considered in the CDA, a repository containing both the upper and lower blocks could accommodate the 70,000 MTU waste inventory at a mass loading of 80 MTU per acre with an approximate 20 percent contingency area available for unforeseen geologic conditions that are deemed unsuitable for waste disposal.

The unshaded portion of the layout between the main drifts and the shading is a 35 meter wide thermal barrier, or standoff zone. Requirements for this feature were discussed in Section 8.3.3; it acts to prevent heat buildup in the main access drifts.

The interim layout uses essentially all portions of the primary area that could be logically developed using the operational schemes described in earlier sections of the report. As mentioned in Section 8.3.2, the primary area cannot accommodate the full, 70,000 MTU inventory if the lower, 25- to 35-MTU/acre thermal loading case were adopted. Based on the darkened areas shown on Figure 8.11-1, only 26,400 MTU could be emplaced at a mass loading of $25 \mathrm{MTU} / \mathrm{acre}$, or $37,000 \mathrm{MTU}$ at a mass loading of $35 \mathrm{MTU} / \mathrm{acre}$. 


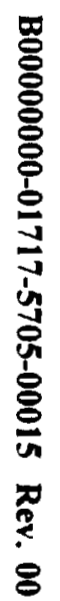

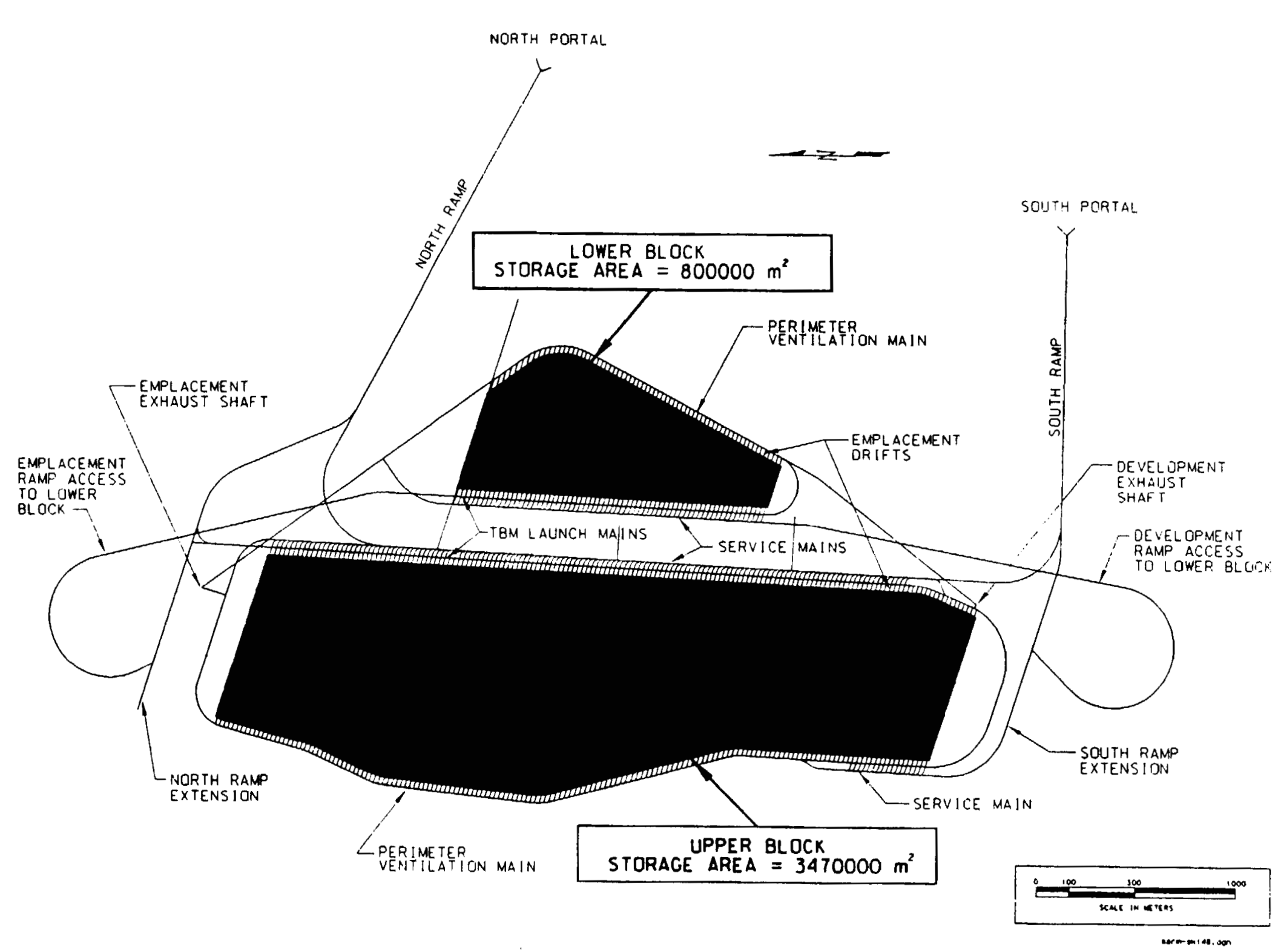

Figure 8.11-1. Net Area Available for Emplacement-Interim Layout 
Expansion outside of Area 1 has been given brief consideration in early repository work (SNL, 1984c) as well as in the SCP (DOE, 1988, pp. 8-14 to 8-17). Six potentially useable areas have been previously identified (refer to Figure 8.3.2-3 in Section 8.3.2). It should be noted that the numbering of the potentially useable areas does not reflect any significance in their ranking (SNL, 1984c, p. 10).

In the issues hierarchy of the SCP, Design Activity 1.11.3.2 - "Useable Area and Flexibility Evaluation" (DOE, 1988, p. 8.3.2.2-48) specifies parameters necessary to satisfy SCP Information Need 1.11.3. Information Need 1.11.3 consists of design concepts for orientation, geometry, layout, and depth of the underground facility that contribute to waste containment and isolation including flexibility to accommodate site-specific conditions. Work relative to this issue has been performed in support of thermal loading system studies, and is incorporated in a $1994 \mathrm{M} \& O$ report (M\&O, 1994c). In this report, design objectives similar to the interim layout were applied to develop preliminary layouts outside of Area 1 but within the TSw2 rock unit. The layouts contained in that 1994 report partially fulfill Design Activity 1.11.3.2 within limitations of currently available geologic data outside of Area 1 . The layouts also demonstrate the feasibility of expansion, using current design concepts, should contingency areas need to be developed to accommodate site specific conditions.

A current assumption in the CDA is that the repository horizon will be located within the TSw2 rock unit in the primary area (M\&O, 1994m, Key 022). This project assumption currently precludes more comprehensive subsurface design activities outside of the primary area, which makes up the majority of Area 1. 


\subsection{RETRIEVAL CONSIDERATIONS}

The Nuclear Waste Policy Act (NWPA) as amended, states that any repository shall be designed and constructed to permit retrieval of any spent nuclear fuel placed in the geologic repository, during an appropriate period of operation of the facility, for any reason pertaining to the public health and safety, or the environment, or for any purpose of recovery of the economically valuable contents of the spent fuel.

Under current assumptions in the CDA (M\&O, 1994m, Key 017), retrieval of emplaced waste will be performed for only the following reasons:

- Failure in the site or WP or some other system, causing a possible risk to public health.

- DOE would have determined that recovery of valuable resources from the spent fuel is necessary.

In addition, a fundamental program requirement listed in $10 \mathrm{CFR} 60.111$ (b) is that the repository design shall include provisions for retrieving the waste from its emplacement location throughout the operational and caretaker periods. Under current statutes, the period required for retrievability is $\mathbf{5 0}$ years after waste emplacement operations are initiated, unless a different time period is approved or specified by the NRC. In keeping with the last statement, the desirability or viability of extended retrieval periods is being given consideration in the OCRWM program, and a key assumption in the CDA upon which repository conceptual design is being based is that the repository will be designed for a retrievability period of up to 100 years after initiation of emplacement (M\&O, 1994m, Key 016).

Performance confirmation activities during the caretaker period may require a small number of WPs (compared to the total emplaced inventory) to be removed. Performance confirmation will provide the NRC with the basis for a decision to allow closure and decommissioning of the MGDS. To confirm performance of the WPs emplaced in the disposal environment, tests may be performed by instrumentation and sampling.

Removal of emplaced WPs from their disposal location for purposes of performance confirmation is not considered to be retrieval under the regulatory definitions of retrieval as applied to the Yucca Mountain MGDS. The planned performance confirmation activities and their influence on repository design are not well defined at the current stage of ACD. In order to aid in performance confirmation, an option in future repository designs may be to include specific performance test areas where WPs can be emplaced or examined as part of the confirmation processes if these areas are determined to provide representative data.

While retrievability is a requirement for MGDS design and licensing, the degree to which retrieval should influence the design of the subsurface openings in the repository is largely a function of how easy a task retrieval should be. A second aspect of retrieval is the ability or desirability to maintain openings in a state of readiness for retrieval while waste is emplaced in them. 
An illustration of the retrieval issues that must be considered in the design of the repository, and particularly in the selection of an emplacement concept, can be made. For example, emplacement drifts can be designed to be large enough to allow WPs to be accessed individually, without disturbing other packages. Such is the case in the Off-Center-In-Drift emplacement concept described in Section 8.5.1.1, where selective retrieval capability is provided. That capability, however, does not enhance the basic retrieval requirement. It only addresses the question of retrieval of WPs for performance confirmation or recovery of spent nuclear fuel as a resource. Also, with such a concept, clearance around the WPs may allow the option to conduct minor maintenance and repair functions in the drift if such an option is determined to be feasible from a personnel radiological safety viewpoint.

On the other hand, much smaller emplacement openings that require the sequential removal of all of the packages in the drift can also be considered, such as the ISDOR concept described in Section 8.5.1.1. With the small-drift concept, the basic retrieval requirement is also met; although, selective retrieval capability for performance confirmation or recovery of spent nuclear fuel as a resource can be achieved only by removing the WPs ahead of the required package. With a small-drift concept, clearance around the WPs would not allow the option to conduct maintenance and repair functions in the drift while WPs are emplaced.

The use of small diameter emplacement drifts in the interim layout subscribes to a philosophy that, while it maintains the full requirement to retrieve in a straightforward manner, it does not lend itself to make the task to remove a WP(s) for performance confirmation (if necessary) any easier than absolutely necessary. The rationale for this approach is that designing the repository toward optimized retrieval or WP removal functions, particularly when such retrieval/removal would only constitute a small number of the total inventory, is not appropriate.

Small drift emplacement also subscribes to the philosophy that the maintenance or repair of emplacement drifts (as determined in the future to be necessary) is better accomplished by temporarily moving the WPs out of them. The rationale for this is the complexity required to conduct maintenance and repair operations by remote means, and the reliability that would be needed for such an operation. Removing WPs from a drift before conditions deteriorate to a point where the operation no longer becomes practical allows maintenance and repair functions to be conducted with the care, reliability, and probability for success warranted for such an operation.

Such a philosophy also points to the desirability of identifying cost effective, robust support systems, to minimize the probability of the need for a major opening or ground support repair over reasonably long time frames such as a 100 year period of retrievability (M\&O, 1994m, Key 016).

A general operational approach to subsurface retrieval is presented in the flowchart of Figure 8.12-1 and summarized in the following two subsections. The retrieval process begins with the following two steps shown in that figure. 

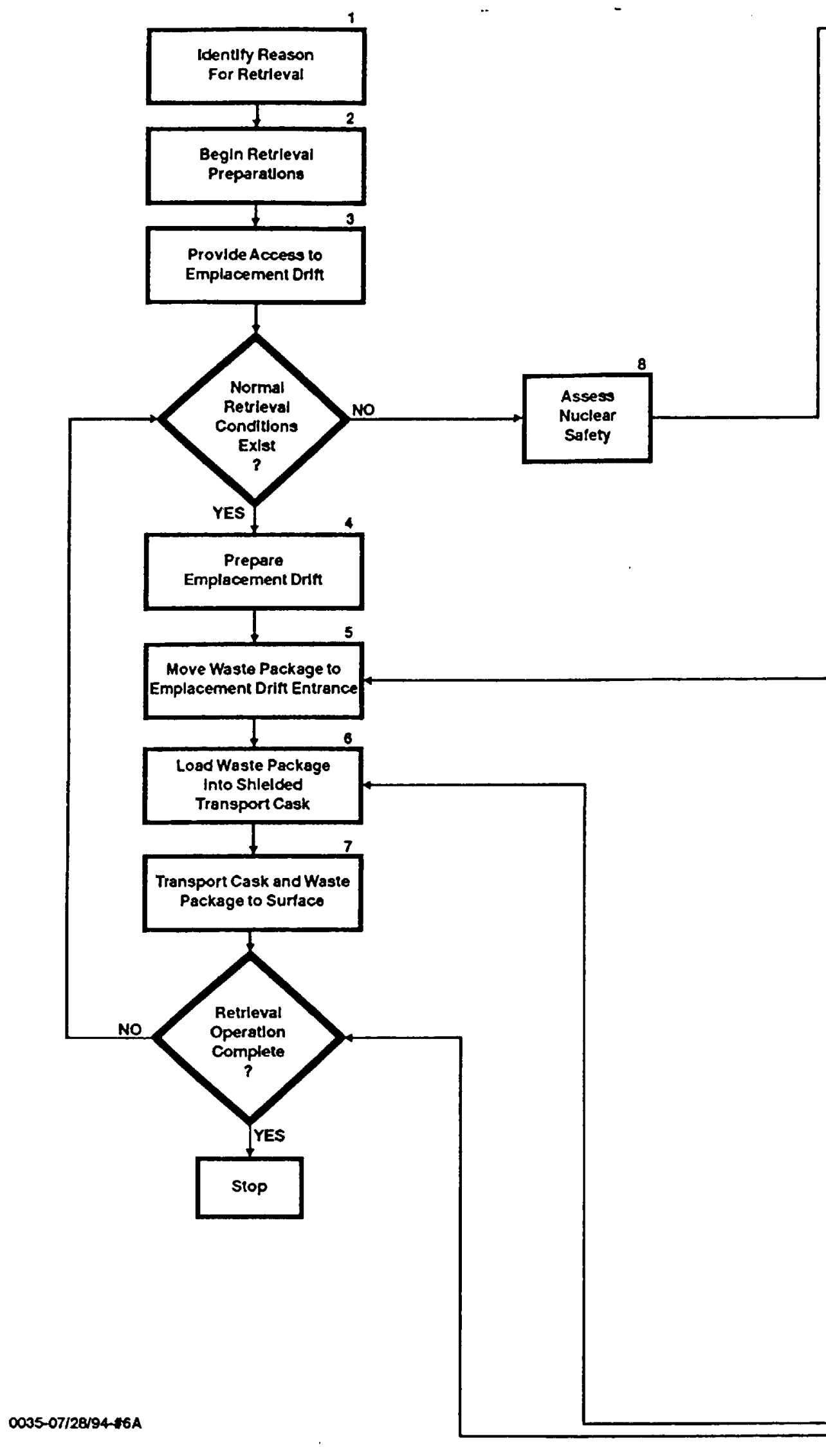

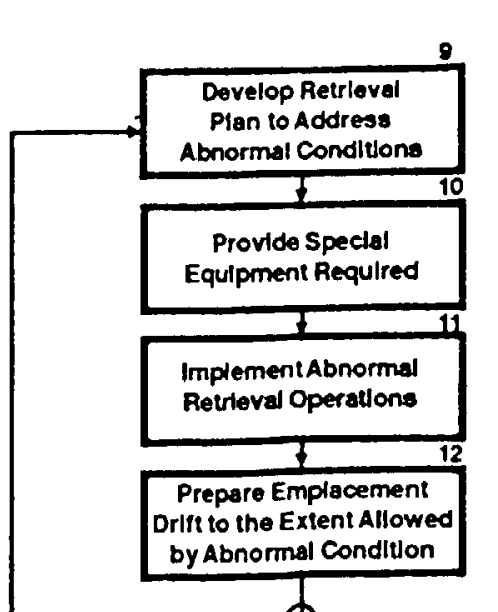
byabing condilion
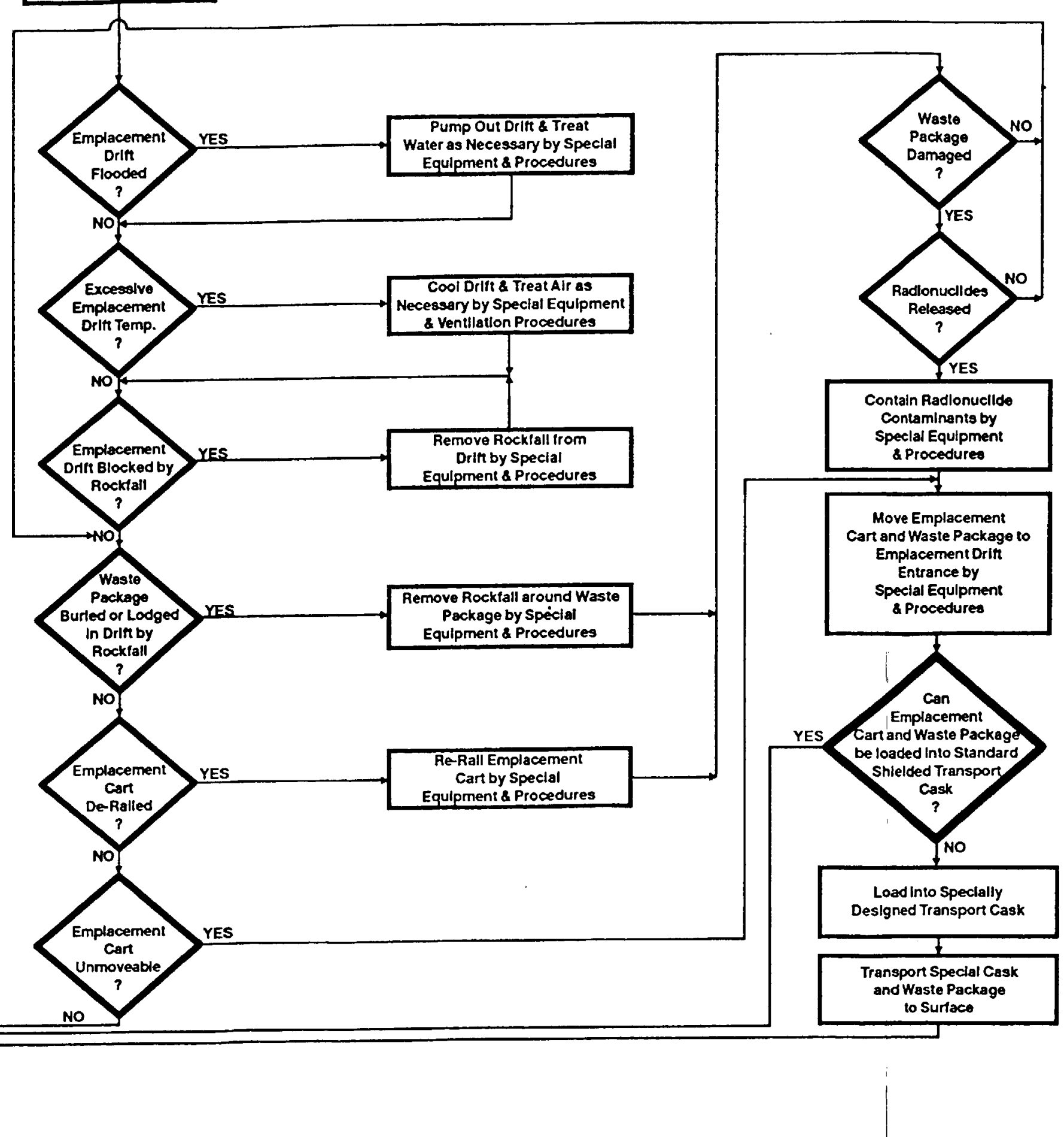

8-168
Figure 8.12-1

Preliminary Retrieval Operations Flow Chart

$08 / 29 / 94$ 


\subsubsection{Pre-Retrieval Considerations}

- Step 1- Identify Reason for Retrieval

This step determines which of the two basic reasons that retrieval is necessary: (1) failure in the site, or the WP is causing a possible risk to public health, or (2) it has been determined by the DOE that recovery of valuable resources is necessary from some or all of the emplaced waste. The decision to retrieve represents an extraordinary event involving much effort with the possibility for incurring great cost.

- Step 2 - Begin Retrieval Preparations

In the event that a decision to retrieve all or part of the emplaced waste is made, preparations for retrieval operations begin. Because of a 100-year period of retrievability (M\&O, 1994m, Key 016), and because of the long time frames required, both for emplacement and retrieval, new retrieval equipment may be needed (see Section 8.12.4) and will be procured during this period. During retrieval operations, retrieval equipment may also require periodic replacement. Surface and subsurface support facilities will be brought to full operational capability. Facility modifications and additions (if any), incorporated into the original design of the repository but not constructed at that time, will be constructed to support the retrieval operations.

- Step 3 - Provide Access to Emplacement Drifts

The first step in the sequence of subsurface retrieval operations will be to provide access to the emplacement drifts for the purposes of making an assessment of the conditions that will be encountered during retrieval. Retrieval conditions must be characterized because they may include, but may not be limited to, rock temperatures in the drifts, condition of the openings, radiation environment, and air quality. Because of the 100-year period of retrievability, and depending upon what time during that period retrieval is required, subsurface access drift and facility maintenance may be needed, which could include installation of supplemental ground support, and repair or replacement of portions of utilities and ventilation system components. However, to accommodate access for performance confirmation monitoring during the caretaker period, routine maintenance would be performed in major openings (access and primary ventilation drifts) during the period of retrievability, making such repairs at the time of retrieval relatively minor.

As shown in Figure 8.12-1, a basic assessment of retrieval operations areas would define whether abnormal conditions exist and would identify portions of the emplacement drifts that would allow normal retrieval methods and those that exhibit abnormal conditions.

An "abnormal" condition is defined as when the retrieval process must be performed with non-standard equipment or procedures. The existence of an abnormal condition may not necessarily mean that retrieval is impossible or particularly hazardous; in general, it means that modified equipment or procedures may be used. As defined by 
the SCP-CDR (SNL, 1987a), for a single-purpose canister type WP: "abnormal conditions may be precipitated by one or a combination of events such as tectonics, variability in rock characteristics, human error, aging and corrosion of equipment and facilities, and radiolysis."

It should be noted that current assumptions in the CDA for an MPC-based WP state that WP containment barriers will provide sufficient shielding for protection of materials from radiation-enhanced corrosion (M\&O, 1994m, Key 031).

\subsubsection{Normal Retrieval Operations}

For those areas where normal conditions are assessed, normal retrieval can be summarized, using the interim layout and the in-small-drift-on-rail (ISDOR) emplacement concept for purposes of example, according to the following operational steps which are shown in the flowchart of Figure 8.12-1:

\section{- Step 4 - Prepare Emplacement Drift}

One of the major aspects of emplacement drift preparation for retrieval is drift cooling. Ventilation is perhaps the most effective method to provide acceptable climate conditions for support of the retrieval activities in the emplacement drifts. Forced-air cooling of the previously unventilated emplacement drift with large quantities of ambient air will be used just prior to the time that reentry is necessary (Section 8.12.5). With the interim layout, the normal base of operations for retrieval is in the waste handling main drift and all actual WP personnel interfaces are conducted from this remote location. Since this main will function as the primary ventilation intake airway, temperatures there should remain cool throughout all phases of repository retrieval operations. Other preparation aspects could include repair or replacement of permanently installed fixtures in the drift needed for the retrieval operation that have deteriorated beyond a usable condition. Such fixtures could include rail and retrieval equipment control and power conductors; however, a detailed study of such deterioration has not been performed to-date during ACD.

- Step 5 - Retrieve WP from Emplacement Drift

During this step, the WPs and emplacement carts are moved by remote handling methods, one at a time and in the reverse order of emplacement, to the emplacement drift entrance.

- Step 6 - Load WP into Shielded Transport Cask

Once a WP has been moved to the entrance of the emplacement drift, the emplacement drift shielding door is opened and the WP is loaded into a shielded transport cask in the waste handling main. 
- Step 7 - Transport Cask and WP to Waste Handling Building Vault

The final retrieval step for normal (and abnormal) retrieval operations is transportation of the shielded cask and package from the underground, via the North Ramp, to the surface waste handling vault. As shown in Figure 8.12-1, in the case of abnormal operations, the condition of the WP (damaged or intact) as well as the type of shielded transport cask required (if the WP or carrier has been significantly damaged), may represent a special condition requiring special equipment and procedures.

After completion of the above steps for normal retrieval of a WP, an opportunity is available to reassess the conditions within an emplacement drift under active retrieval. This is because retrieval of part of the WPs from any one emplacement drift may be possible under normal conditions while an abnormal condition may be present which might affect retrieval for one or more of the remaining WPs in the drift.

If normal conditions are still deemed to exist, then retrieval can proceed under the normal conditions described under steps 4 through 7 . The drift cooling step may be greatly reduced or eliminated if retrieval operations are relatively continuous.

If an abnormal condition is found to be present in the emplacement drift, there are several options which can be considered. One is to continue the normal retrieval process in other locations of the repository while addressing the abnormal condition encountered. An abnormal operations plan could then be implemented while normal retrieval continues in other areas. The interim layout offers sufficient flexibility to operate under such a plan.

A second option, which may only be practical if the abnormal condition represents a serious condition throughout the repository, would be to suspend all normal retrieval operations until the abnormal condition is mitigated.

\subsubsection{Abnormal Retrieval Conditions and Operations}

For those areas where abnormal conditions are assessed, abnormal retrieval can be summarized, using the interim layout and the ISDOR emplacement concept for purposes of example, according to the following operational steps which are shown in the flowchart of Figure 8.12-1:

- $\quad$ Step 8 - Assess Nuclear Safety

Once access to the emplacement drifts has been achieved and abnormal conditions are found, as assessment of the nuclear safety aspects of abnormal retrieval is necessary. This assessment must determine to the extent possible by the abnormal condition(s) whether radionuclide release(s) will be a factor in abnormal retrieval operations. A radionuclide release would indicate that there is a problem with one or more containment barriers provided by the WPs. It should be noted that a determination of this as a credible event has not been made to date, but this aspect is included in this preliminary operations concept to address the need for such work. Such a release would cause elevated radiation levels within the emplacement drift beyond those 
expected from intact emplaced WPs and would also indicate a need to contain the radionuclides and other contaminated items as a part of the retrieval operation.

- Step 9 - Develop Abnormal Retrieval Plan to Address Conditions

Most retrieval operations functions that must be performed under abnormal conditions are fundamentally the same as normal operations, with the exception that an "abnormal" condition is defined as when the retrieval process must be performed with non-standard equipment or procedures. The existence of an abnormal condition may not necessarily mean that retrieval is impossible or particularly hazardous; rather, it means that modified equipment or procedures may be used. If an abnormal condition exists within the subsurface repository environment, predeveloped or specially prepared plans, depending upon the abnormal condition(s) present, may be used to address the abnormal condition(s). In the event of a radionuclide release associated with an abnormal condition, retrieval plans must also address the containment and disposal of radionuclides and other contaminated material in addition to retrieval of the WPs themselves. In some cases, such as contaminated water in a flooded drift for example, treatment of the contaminated material (i.e., the water) by special equipment and procedures would be necessary and must be included in the development of a retrieval plan.

- Step 10 - Provide Special Equipment Required

The necessary special equipment required to implement the abnormal operating plan(s) will be procured, as required. It should be noted that during the course of retrieval operations, one or more combinations of abnormal conditions may be encountered, which may require differing special operating plans, equipment, or procedures to be used. Both special equipment and procedures will be tested during this period, all applicable to the condition(s) present.

- Step 11 - Implement Abnormal Retrieval Operations

Both prior to and during the course of abnormal retrieval operations, abnormal conditions may be precipitated by processes and events such as tectonics, variability in rock characteristics, human error, or aging and corrosion of equipment and facilities. Abnormal retrieval operating plan(s) to provide access to the WPs, and remove them from the emplacement drifts will be implemented as appropriate to the conditions present.

- Step 12 - Prepare Emplacement Drift to the Extent Allowed by Abnormal Condition

As discussed in Step 4, one major aspect of emplacement drift preparation is cooling. Forced-air cooling of the previously unventilated emplacement drift with large quantities of ambient air will be used just prior to the time that reentry is necessary (see Section 8.12.5). However, an abnormal condition within the emplacement drift may prevent the drift from being fully cooled by normal, flow-through ventilation as a cooling procedure. This step in the abnormal retrieval operation would allow for cooling of the emplacement drift to the maximum extent practical using normal 
procedures. Special procedures and equipment may be used to achieve a fully cool opening. Other preparation aspects could include repair or replacement of permanently installed fixtures in the drift needed for the retrieval operation that have deteriorated beyond a usable condition. Potential fixtures are as described in Step 4.

Several abnormal conditions, precipitated by the processes and events described earlier, are presented to provide an example of a preliminary approach to abnormal retrieval using the ISDOR emplacement concept and the interim layout. The abnormal conditions include the following:

- Flooding of the emplacement drift - Potentially caused by blockage of drains at the emplacement drift entrance if allowed to go unmaintained over a long period.

Flooding of the drift may also prevent normal drift cooling procedures to be used.

- Excessive drift temperature - Potentially caused by a drift fully or partially blocked by rockfall preventing or impeding normal flow-through ventilation cooling.

- Emplacement drift blocked by rockfall - Potentially caused by deterioration of ground support components in the opening in-between WPs.

- WP buried or lodged in the drift by rockfall - Potentially caused by deterioration of ground support components in the opening over a WP.

- Emplacement cart derailed - Potentially caused by a seismic event, deterioration or deformation of the supporting rail, or by a large rockfall in the drift onto or against the WP. Also potential for this occurrence during normal retrieval operations when the WP is being transported to the emplacement drift entrance.

- Emplacement cart unmovable - Potentially caused by rusted emplacement cart wheel bearings or wheels rusted to the rails.

The above conditions have been identified by engineering judgment, and have not yet been established by statistical analysis techniques as credible events. They are presented at this time only for clarity of the logic discussed in this Section.

Figure 8.12-1 provides a preliminary example of the logic that would be followed to address the above conditions. As can be seen from the flowchart, each condition may require a special plan of operations, procedures, and different operating functions from special equipment. These items require further investigation during ACD. Each abnormal occurrence may or may not involve a release of radionuclides as a result of the abnormal condition. As can be seen from Figure 8.12-1, a radionuclide release would affect the plans, procedures, and equipment necessary to accomplish retrieval.

It should also be noted that one, or possibly a combination of the above mentioned abnormal conditions may be present in a single emplacement drift. The logic flow in Figure 8.12-1 presents the order of priority that would likely be followed as each WP is removed from the emplacement drift in a repository configured similar to the interim layout. Also, at any time 
during the retrieval operation, retrieval equipment failure could result in a normal retrieval operation changing to an abnormal operation.

\subsubsection{Retrieval Equipment Considerations}

Mobile emplacement equipment used for normal retrieval in the ISDOR concept consists of four primary items: (1) an electric trolley powered locomotive used in main drifts and ramps; (2) a movable rail turntable used in the waste handling main; (3) a shielded rail transport cask used in main drifts and ramps; and (4) a battery powered, remotely operated, locomotive used in the emplacement drifts.

Other mobile support equipment needed during the retrieval period include rail transporters (M\&O, 1994m, Key 010, Key 030) for personnel, and minor supplies and equipment used for routine maintenance.

The availability of original mobile emplacement equipment for normal retrieval operations will, to a great degree, be dependent upon the duration of the emplacement period and the condition of the equipment after that period. Maintenance of emplacement equipment during the emplacement period will consist of normal routine maintenance, and scheduled equipment rebuilds or replacement as total-life-cycle-cost economics dictate.

Retrieval of all the WPs is required in a reasonable schedule mandated by 10 CFR 60 "about the same time as that devoted to construction of the GROA and the emplacement of wastes" (10 CFR 60.111(b)(3)). Under past estimates made for the SCP-CDR conceptual design, the construction and emplacement period could last for a period up to 34 years. While no overall repository construction and emplacement schedules have been developed for the interim layout using small drift emplacement, retrieval should be easily achieved in a time frame similar to the SCP-CDR, although it may require several suites of equipment.

It is unusual to find mobile equipment operating in an underground environment for a period longer than 10 to 20 years, even if such equipment has been operated under good maintenance practices. The reasons for this are normal deterioration, equipment obsolescence, or unfavorable economics when considering further existing equipment maintenance compared to replacement. The conclusion that can therefore be drawn from the above emplacement time frame is that there would be a high probability of a need for new mobile equipment at the start of retrieval operations. This statement should hold true regardless of at what time during the 100 year period of retrievability the start of retrieval operations would begin.

For a retrievability period of up to the statutory 50 year length after first emplacement, it is reasonable to assume that mobile equipment used for normal retrieval operations will be of the same or similar design as that used when emplacement operations were completed (or suspended, as applicable). The rationale for this statement is that the end of such a retrievability period may only be approximately 16 years (the 50 years minus the 34 years to construct and emplace). It is also possible that replacement equipment procured during the emplacement period may have been upgraded, making the equipment technology used at last emplacement reasonably current at the time of retrieval. 
For a retrievability period beyond the statutory 50-year period and up to 100 years in length, available material handling equipment and methods at that time will have likely advanced significantly beyond current technology. Therefore, for retrievability periods beyond 50 years and up to the current assumption of 100 years in the CDA (M\&O, 1994m, Key 016), it is reasonable to assume that technology of the time will be examined for use in retrieval operations. The rationale for this statement is that the cost and safety implications for using out-dated, although by then well-proven technology, must be compared with the cost and safety improvements that could be available using state-of-the-art equipment available at that time.

Certain stationary plant equipment including surface and subsurface ventilation fans, dewatering pumps, and permanent utilities associated with subsurface operations will be necessary to support both performance monitoring activities and retrieval operations. Fans and pumps will be required to operate to some degree throughout the emplacement and caretaker periods, and consequently, will be rebuilt and replaced at somewhat regular intervals. Utilities in main access drifts and other access openings into the repository will require periodic routine maintenance and selected replacement when deteriorated or damaged beyond a condition of reasonable and economic repair.

\subsubsection{Retrieval Ventilation Considerations}

The CDA states that the repository will be designed for a retrievability period of up to 100 years after initiation of emplacement (M\&O, 1994m, Key 016). To satisfy this objective, the repository underground ventilation system must be designed so that acceptable climate conditions can be provided to support the retrieval activities. The CDA specifies that the air temperature in emplacement drifts during retrieval shall not exceed $50^{\circ} \mathrm{C}(\mathrm{M} \& \mathrm{O}, 1994 \mathrm{~m}$, DCSS-019). Ventilation is perhaps the most effective temperature control method. Two primary concepts of ventilation for retrieval are being considered:

Continuous Ventilation: continuously ventilating all of the emplacement drifts, beginning at the time of emplacement and continuing throughout the pre-closure period (ventilation fixtures could be incorporated into the radiation doors to facilitate ventilation while maintaining shielding);

Ventilation as Needed: after completion of waste emplacement, keep the emplacement drifts unventilated; when drift accesses are needed for required operations (such as waste retrieval or performance confirmation), cool the previously unventilated drifts with large quantities of ambient air just prior to reentry. This ventilation mode is also frequently referred to as rapid cooling, forced-air cooling, or blast cooling.

The Subsurface Ventilation Concepts Report for Repository ACD-FY 1994 (M\&O, 1994q) analyzed the feasibility of both types of cooling by ventilation, and performed preliminary calculations for temperature in emplacement drifts of the interim layout concepts. The following discussions of ventilation for retrieval of emplaced waste are based primarily on that study and use an air temperature of $50^{\circ} \mathrm{C}$ (M\&O, 1994m, DCSS-019) as representative of acceptable working conditions during the potential retrieval process. 
The drift temperature under continuous ventilation is a complex function of ventilation air flow rate, time of ventilation, drift configuration, rock properties, heat load, emplacement mode, and so on. This long term transient state heat transfer process involves conduction, convection, and radiation. Preliminary investigations have indicated that it is feasible to maintain the accessibility of an emplacement drift for an extended period by providing ventilation continuously. Continuous ventilation removes heat from the repository from the beginning of the heat transfer processes, thus a relatively low drift temperature is expected in comparison to that in an unventilated drift. However, this approach requires an extremely large total air quantity because all of the emplacement drifts are ventilated simultaneously. Calculated examples for the interim layout show that to maintain the temperature of ventilating air in an emplacement drift below $50^{\circ} \mathrm{C}$, using intake air at a temperature of $30^{\circ} \mathrm{C}$, the air flow rates required are up to $30.81 \mathrm{~m}^{3} / \mathrm{s}$ for a $1235 \mathrm{~m}$ long drift. This illustrates that ventilation air flowing in what could be considered a normal range would be capable of continuously removing the desired amount of heat from a single emplacement drift without exceeding the $50^{\circ} \mathrm{C}$ temperature. However, simultaneously ventilating all emplacement drifts requires a very large total air quantity (i.e., up to $4800 \mathrm{~m}^{3} / \mathrm{s}$ for the upper block in the interim layout); consequently, excessive costs for ventilation related construction and operation could be expected and additional shafts might be needed. Further study of alternate ventilation cooling concepts is recommended before seriously considering continuous ventilation as a viable option.

When a drift emplaced with waste is unventilated for an extended period such as 100 years, the heat transfer from the waste to the surrounding rock, mainly through conductive and radiative processes, will cause a large scale increase in rock and drift wall temperatures. This is because the drift has been sealed from ventilation and almost all of the energy released from the waste is transferred to its surroundings. Cooling an emplacement drift under these circumstances within a reasonable period of time requires a relatively large quantity of air for a single drift when compared to the continuous ventilation case, due to increased temperatures of the drift wall and surrounding rock mass. However, the total air quantity required is substantially reduced because the number of drifts undergoing cooling at a given time would be reduced. The maximum initial rock temperature at the beginning of cooling depends on factors including thermal loading, emplacement mode, rock properties and drift configuration. For a given initial rock temperature, the quantity of ventilation air becomes the predominant factor in temperature control. Transient state calculations and analysis (M\&O, 1994q) show that it is possible to regain access to an emplacement drift that has been closed for an extended period by ventilating the drift with large quantities of ambient air.

Figure 8.12.5-1 provides an example of the temperature distributions along an emplacement drift and their variation as a function of the time of cooling. A typical air quantity of 150 $\mathrm{m}^{3} / \mathrm{s}$ was selected to illustrate a complete emplacement drift cooling process to a temperature of $50^{\circ} \mathrm{C}$. As shown on the figure, the air temperature steadily increases while passing through the drift, due to the high initial rock temperature. The highest air temperature always occurs at the airway exit. Based on the parameters stated on the plot, to reduce the air temperature to $50^{\circ} \mathrm{C}$ for reentry, it takes about a day for the first 400 meters of the drift, and three days for the first 600 meters. After about a week of ventilation, the first 900 meters of the drift would become accessible. For an emplacement drift $1300 \mathrm{~m}$ long, the maximum air 


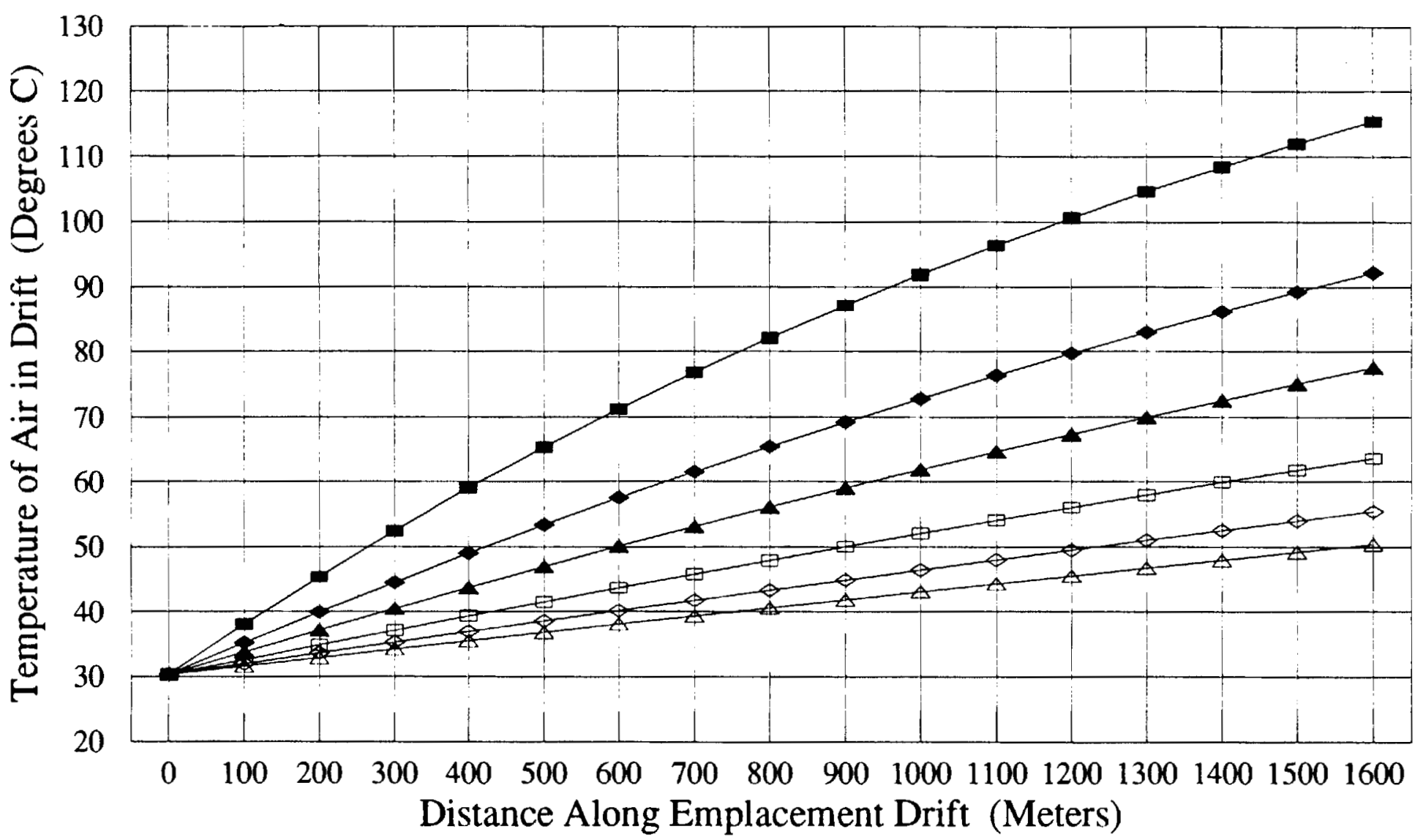

$\leftarrow 1$ day $\rightarrow 3$ days $\_1$ week $\multimap 3$ weeks $\multimap 8$ weeks $\triangle 20$ weeks

* Calculated for: 1) In-drift emplacement. 2) Airflow rate 100 cubic meter per sec. 3) Drift diam. 5.0 m.

4) Intake air ternperature $30.3 \mathrm{C}$. and 5) Initial rock temperature of $170 \mathrm{C}$ at beginning of ventilation.
[File:"FIG118.794" - h.yang]

Figure 8.12.5-1. Temperature of Ventilating Air Along an Emplacement Drift During the Cooling Period 
temperature (occurring at drift exit) can be reduced to below $50^{\circ} \mathrm{C}$ in less than three weeks of rapid cooling. To reduce the maximum temperature of a longer drift $(1600 \mathrm{~m})$ to $50^{\circ} \mathrm{C}$, six weeks of cooling time will be necessary.

The highest temperature profile in the initial stage of cooling indicates that the highest heat load on the air flow occurs at the beginning of the cooling. During the period of ventilation, the heat load on the air flow is reduced at a decreasing rate. This type of behavior reveals the importance of the initial air quantity at the beginning of drift cooling. It would be advantageous to provide very high air flow quantities initially for rapid and effective cooling. After the heat transfer rate is reduced, a lower air quantity could be used to maintain the desirable drift temperature. This suggests the possibility of using a staged approach for concurrently cooling additional drifts in order to reduce the total air quantity requirement

Figure 8.12.5-2 presents the calculated temperatures of air exiting emplacement drifts during cooling, based on various air quantities and cooling times. For a $1235 \mathrm{~m}$ long drift and other parameters shown on the figure, the temperature profiles demonstrate that an air flow of 150 $\mathrm{m}^{3} / \mathrm{s}$ can reduce the temperature of air exiting the drift to below $50^{\circ} \mathrm{C}$ after two and a half weeks of cooling by ventilation. Cooling with an air flow rate $100 \mathrm{~m}^{3} / \mathrm{s}$ can also provide the allowable temperature level along the entire drift length within a little longer but still acceptable period of time (about 8 weeks). If a very high air quantity of $200 \mathrm{~m}^{3} / \mathrm{s}$ is used, access to the entire drift is possible within the first week of ventilation. For air flows equal to or lower than $60 \mathrm{~m}^{3} / \mathrm{s}$, it is impossible to reduce the air temperature at drift exit to $50^{\circ} \mathrm{C}$ within 26 weeks. 


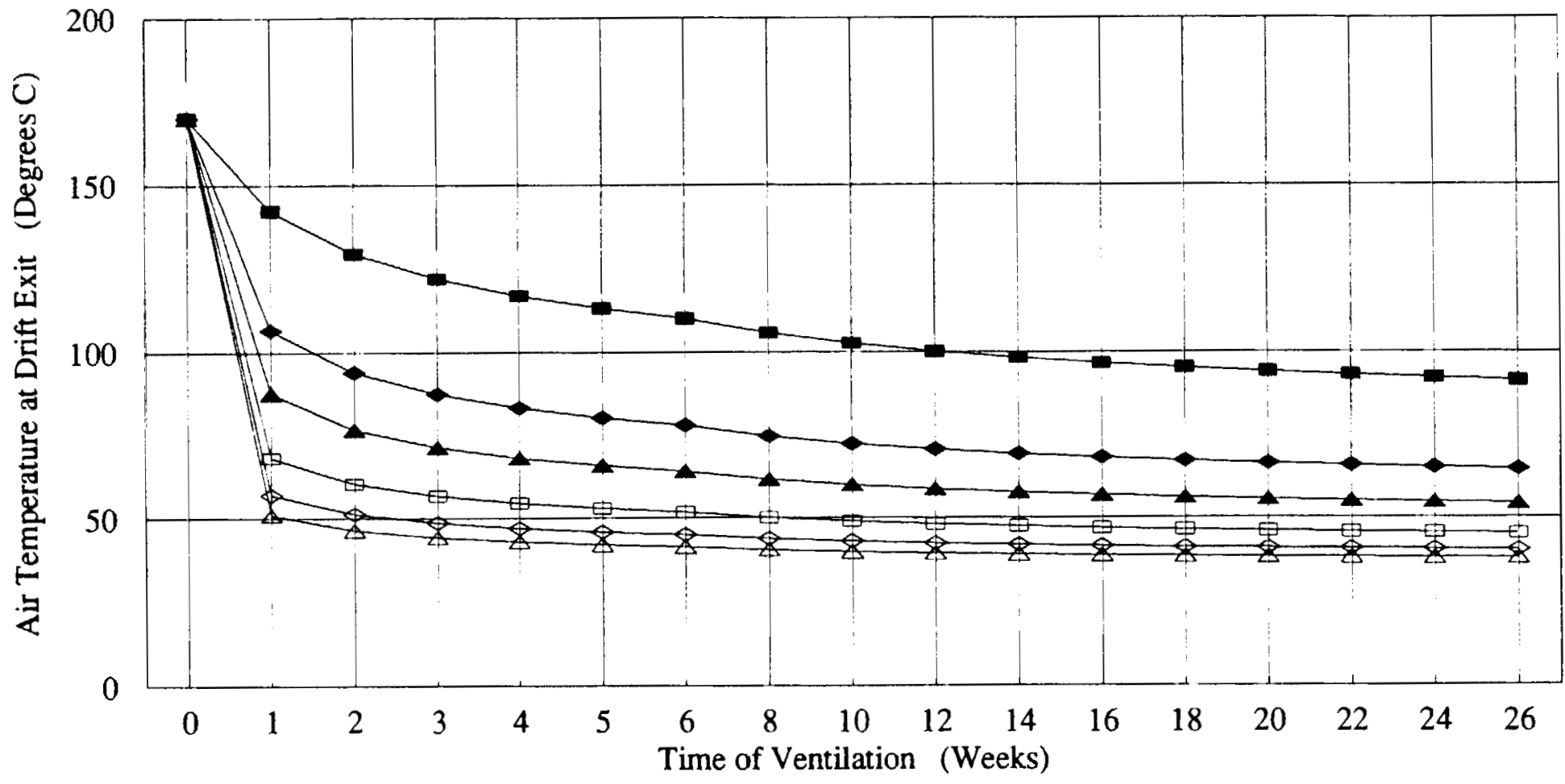

$$
\begin{aligned}
& \rightarrow \text { Air Flow } Q=20\left(m^{\wedge} 3 / \mathrm{s}\right) \longrightarrow Q=40\left(m^{\wedge} 3 / s\right) \quad \longrightarrow Q=60\left(m^{\wedge} 3 / s\right) \\
& \curvearrowleft \mathrm{Q}=100\left(\mathrm{~m}^{\wedge} 3 / \mathrm{s}\right) \quad \sim \mathrm{Q}=150\left(\mathrm{~m}^{\wedge} 3 / \mathrm{s}\right) \quad \triangle \mathrm{Q}=200\left(\mathrm{~m}^{\wedge} 3 / \mathrm{s}\right)
\end{aligned}
$$

* Calculated for: 1) In-drift emplacement. 2) Emplacement drift length 1235 m. 3) Drift diam. 5 m.

4) Intake air temperature $30.3 \mathrm{C}$, and 5) Initial rock temperature of $170 \mathrm{C}$ at beginning of ventilation. 


\section{CLOSURE AND DECOMMISSIONING}

\subsection{SUBSURFACE CONSIDERATIONS}

Closure and decommissioning of subsurface related facilities will occur after the period of retrievability, currently established as 100 years after first emplacement (M\&O 1994m, Key 016). In general, subsurface activities related to repository closure will involve sealing of the ends of emplacement drifts; the removal, to an extent practical or safe, of utilities, structures and equipment from the subsurface environment; backfilling of major subsurface access drifts on the repository block; and backfilling and placement of seals in all shafts and ramps. In addition, the placement of backfill in the emplacement drifts is an option that will be available at closure and is discussed in greater detail in Section 9.1.1.

Activities planned at decommissioning relate primarily to the decontamination and dismantling of surface facilities and the surrounding site. Of the surface structures and facilities, several will be related to subsurface operations including the shaft collars and ramp portals, and associated facilities such as mechanical ventilation plants, air ducts, and hoisting facilities.

ACD activities related to a majority of the above areas were not included in the FY 1994 scope of work; consequently, these topics will be addressed in greater detail as ACD progresses. Backfill placement in the emplacement drifts was included in the scope of work and is summarized in Section 9.1.1.

\subsubsection{Backfilling and Sealing of Emplacement Drifts}

Backfill in the emplacement drifts could be placed for four major reasons: (1) to prevent deleterious rock movement in the strata between the surface and the repository horizon which may cause surface subsidence; (2) to provide a pre-determined environment around waste packages to enhance the long-term performance of the waste package exterior; (3) to protect, or cushion, the waste package from damage caused by rock falling onto the waste package; and (4) to retard the transport of radionuclides to the accessible environment.

The choice of whether to backfill the emplacement drifts at closure is an option that will be available to repository operations management (DOE). However, placement of backfill in the emplacement drifts is neither required nor prohibited by regulation, and the current Yucca Mountain Project position is that no backfill will be used in emplacement drifts (M\&O, 1994m, Key 046). The rationale for this position is that since no performance requirement is currently allocated to backfill, the waste package will be designed to withstand expected rockfall during the substantially complete containment period, and it will be difficult and expensive to emplace backfill. 
As with all controlled assumptions, the validity of the assumption not to backfill an emplacement drift must be substantiated during ACD. As a part of this process, backfill concepts and operations were examined on a preliminary basis in FY 1994. The interim layout formed the basis for the examination of concepts.

Investigations of emplacement drift seals were not included in the FY 1994 scope of work.

\subsubsection{Backfill Materials and Selection Considerations}

Potential materials available for use as a backfill for a horizontal, in-drift emplacement configuration include dry materials, concrete, and hydraulic slumies. However, preliminary conclusions presented by the Waste Package Development group (M\&O, 1994r) regarding backfill are that the most promising backfill strategies are to use no backfill or to use crushed tuff, possibly with an additive for controlling water chemistry. Any additives must be chosen to avoid harmful effects of microbial growth which might enhance waste package corrosion rates. This section of the report therefore provides its remaining focus on some of the preliminary aspects of dry crushed tuff backfill placement. General materials and operations considerations related to other backfill materials can be found in a 1994 M\&O report (1994b).

Recent studies (Conca et al., 1993; M\&O, 1994r) have examined the use of a coarse material (gravel) placed near the waste package, with a sloping layer of fine material (sand) placed on top of the coarse material. Because of capillary forces, water that drips onto the fine particles will be held in the small pores and will not penetrate into the larger gaps in the coarse layer as long as unsaturated flow conditions exist. Sloping the fine layer down at the sides will direct water to the sides of the drift. To achieve an effective diversion requires a sharp interface to be present between the two layers. It also requires no dips or low spots in the interface. The benefits of a two-layer backfill, however, have sometimes been overstated in the technical literature with the fine layer described as if it were impermeable (M\&O, 1994r). To successfully construct a sharp interface between the coarse and fine material layers in a potentially harsh environment (temperatures and radiation) by remote control or automation is a significant consideration.

Table 9.1.1-1 shows an example of the material size distribution for such a gravel and sand backfill and is included for reference with respect to discussions in Section 9.1.1.3 on backfill placement operations and quality. 
Table 9.1.1-1. Example Size Distribution for Gravel/Sand Dry Backfill Barrier System

\begin{tabular}{||c|c|c|c||}
\hline \multicolumn{2}{|c|}{ Gravel } & \multicolumn{2}{c||}{ Sand } \\
\hline \hline Sieve Size & $\begin{array}{c}\text { Weight \% } \\
\text { Passing } \\
\text { Sieve }\end{array}$ & Sieve Size & $\begin{array}{c}\text { Weight \% } \\
\text { Passing } \\
\text { Sieve }\end{array}$ \\
\hline \hline 25 & 100 & 2.5 & $90-100$ \\
\hline 19 & 75 & 0.25 & $0-5$ \\
\hline 13 & 40 & & \\
\hline 9.5 & 10 & & \\
\hline 3 & 5 & & \\
\hline \hline
\end{tabular}

After Conca et al., (1993)

\subsubsection{Dry Backfill Placement Considerations}

At Yucca Mountain, conventional underground backfilling techniques must address a set of physical placement and quality considerations which could be quite different than typically seen in the underground mining or construction industry. Backfill placement methods at Yucca Mountain must address difficult problems such as placing material in long drifts, potentially remotely, and under potentially high temperatures and radiation levels (although greatly reduced from levels at the time of emplacement). As a further complicating factor, if backfill in the emplacement drifts were needed to enhance the performance of the engineered barrier system, such as providing a water infiltration barrier, placement of a backfill with predictable and consistent emplaced properties, such as gradation and compaction, will be a key consideration.

In general, dry backfill can be placed using mechanical or pneumatic methods. The method or combination of methods is determined by the performance requirements of the backfill material, by the physical characteristics of the drift (clearances, temperature, and radiation) and by the physical limitations of the equipment and backfilling operation. For reasons discussed below, this report briefly discusses mechanical backfilling but focuses the majority of attention on placement by pneumatic backfilling systems.

\section{Mechanically Placed Dry Backfill}

Mechanically placed fill can involve techniques ranging from simple dumping by conveyor or other similar types of spreading equipment with poor compaction and support characteristics of the fill. Placement of fill can also involve the use of specialized mobile machinery to provide excellent compaction of a fill. The above assumes a sufficient operating environment and operating clearances are available, which will generally not be available in the emplacement drifts. 
The use of a conveyor to place a dry backfill followed by vibro-compaction is a method that may be feasible. Vibro-compaction is the rearrangement of particles into a denser configuration by the use of powerful depth vibrators. Depth vibrators are long, cylindrical, probe-like devices that are penetrated into a backfill medium and cause the backfill material densification process to occur. A small scale application of vibro-compaction is commonly used to compact dry ballast placed under ties used with railroad tracks.

This method would only be suited to an application requiring partial drift backfilling, or a bottom layer of backfill, because of the difficulty of placing backfill above the conveyor return belt line. Additionally, for conveyor emplaced backfill to be feasible, the drift must be cool enough and radiation levels must be low enough to permit reliable operation of susceptible mechanical conveyor components. Sufficient clearances must also be present to allow passage of the conveyor and vibro-compaction equipment. One significant drawback to this method would be if a mechanical failure or belt break were to occur somewhere in a long $(1,200 \mathrm{~m})$ emplacement drift. An idle, loaded belt would result, making recovery from such a breakdown difficult by remote means.

\section{Pneumatically Placed Dry Backfill}

Pneumatic backfill placement involves the transport and emplacement of fill material by air pressure.

Two types of pneumatic conveying systems have been developed: 1) low pressure, continuous air equipment (a dilute-phase system); and 2) high pressure, pulsating air equipment (a densephase system). With the dilute-phase system, the characteristics of the backfilling operation and in-place backfill are similar to hydraulic techniques. Dense-phase systems use intermittent blasts of material at high velocity but are less popular because of increased pipe wear resulting from high transport velocities and ricochet problems with the backfill material during deposition.

A typical dilute-phase, commercial pneumatic conveying system consists of four essential elements (Powell, 1982):

- A source of pressurized air, often supplied by a blower-compressor

- A regulated infeed to introduce the backfill material into the pressurized airstream, often achieved by the use of a rotary-airlock-feeder

- A pipeline to convey the air and material to the desired location

- A discharge piece to direct the material as it leaves the pipe, with varying degrees of control depending upon the application.

The capacity of commercially available pneumatic conveying systems commonly used to place backfill underground is from 90 to 450 tonnes/hour. 
As the throughput of the system increases, larger or alternately multiple pipelines must be used to prevent excessive system air pressure drops. In emplacement drifts, permanently installed support components for large or multiple pipes could tend to increase drift size to prevent interference with waste package emplacement equipment, such as the gantry concepts discussed in Section 8.7.2. Many kilometers of larger emplacement drifts, strictly to accommodate high backfill emplacement rates, would not be a cost effective approach. In general, it would be more prudent to size the throughput of a pneumatic system in the repository for one in which a single, reasonably sized pipe would suffice.

In repository emplacement drifts, the presence of waste packages makes the potential for remote backfilling operations and the good compaction of backfill that can traditionally be obtained by pneumatic methods in open drifts very uncertain. Multiple pipes may be required, even at reasonable emplacement rates, to achieve a particular backfill density within an emplacement drift filled with waste packages and associated supports. This aspect is discussed in Section 9.1.1.3.

The question of the insulating properties provided by a poorly compacted backfill, if such a fill were to result, and its effect on waste package performance, must also be addressed when considering the applicability of a pneumatically placed backfill at Yucca Mountain.

\subsubsection{Preliminary Concept for Placing Dry Backfill in an Emplacement Drift}

A preliminary concept of operations for pneumatic placement of a backfill configuration consisting of the coarse material and sand size distribution shown in Table 9.1.1-1 is presented as an illustrative example. The methods of producing and placing such a backfill, along with the potential placement results, are discussed. The concept presented assumes the ISDOR emplacement concept and a long $(1,200 \mathrm{~m} \pm$ ) and straight emplacement drift which is representative of the interim layout.

During the repository construction phase, a monorail support beam would be installed in each emplacement drift to facilitate future backfilling operations as shown in Figure 9.1.1-1. The beam would be designed with connections to allow careful alignment. A second function for this beam could be as a trackway for performing routine monitoring (such as with a camera) of drift conditions throughout the operational and caretaker phases of the repository.

At the time that backfill is to be placed, which could be 100 years after the first waste package emplacement, a remotely controlled camera would travel the full length of the monorail beam to inspect it for damage, corrosion, or misalignment.

If damage or misalignment is found, one option for beam repair or replacement would be to use a special piece of equipment with robotic mechanical arms that would travel over the waste packages. In this case, if the waste package is placed atop a permanent rail emplacement cart, a second set of rails would need to be permanently installed in the drift as shown in Figure 9.1.1-1. To achieve the required operating clearances at the invert for a second set of rails, the invert would need to be raised to be located nearer to the tunnel's center, or a larger tunnel would need to be excavated. In Figure 9.1.1-1, a $4.3 \mathrm{~m}$ operating clearance line is shown for illustrative purposes. As can be seen, clearances for operation of 

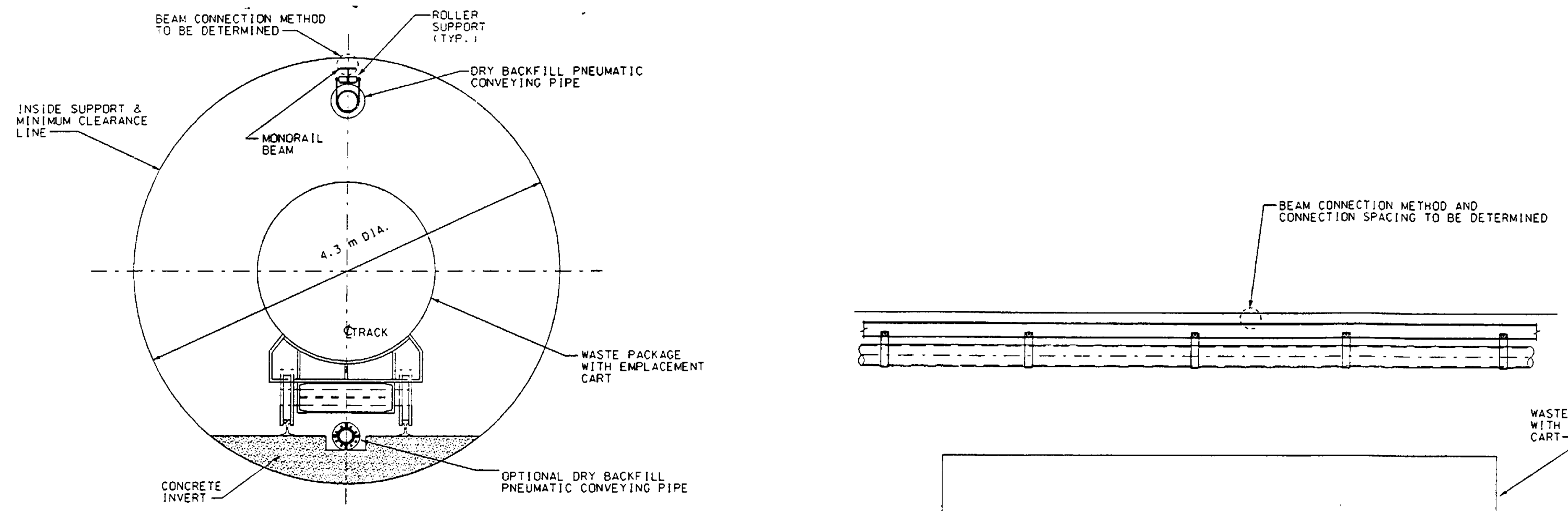

CONCEREE

PNEUMATIC CONVERTINC PIPE

MONORAIL REPAIRS REOUIRE

WASTE PACKAGE REMOVAL
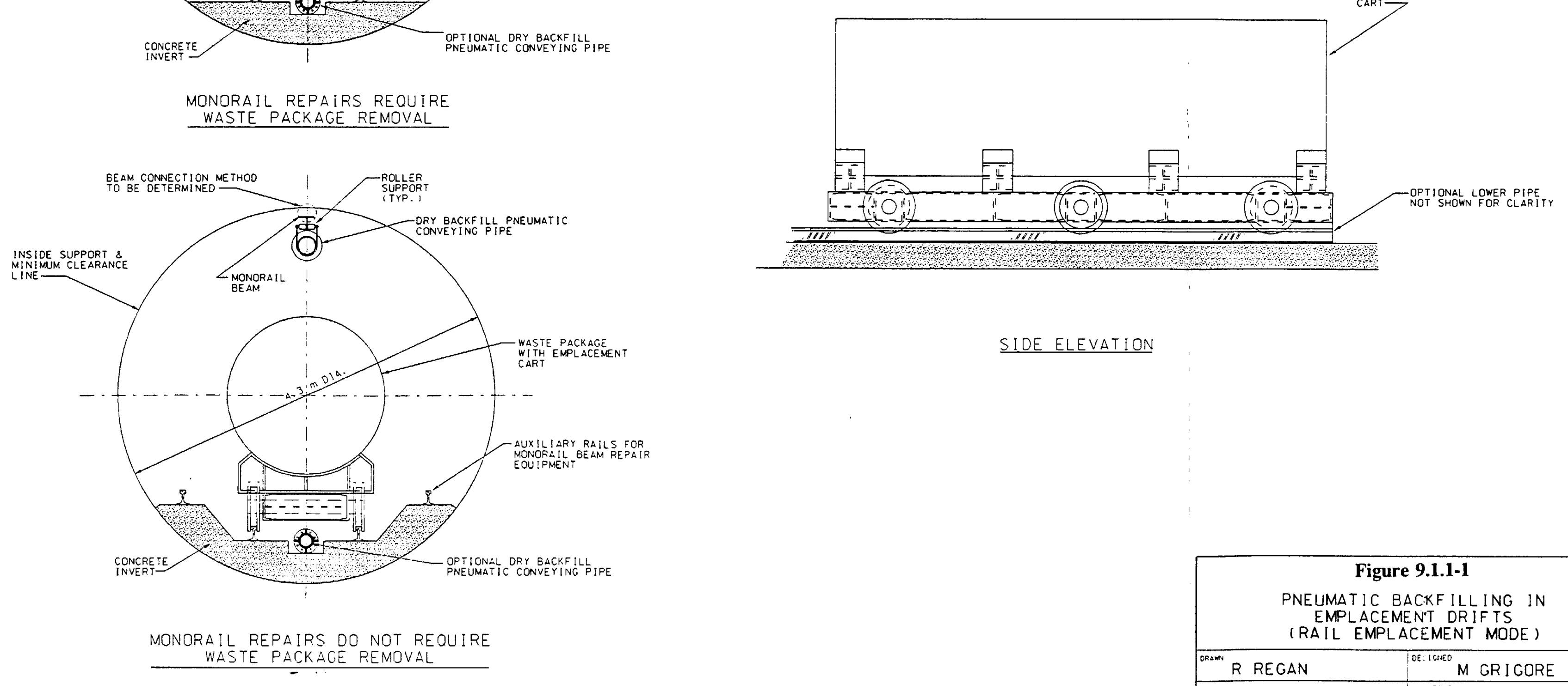

SIDE ELEVATION

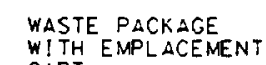

Figure 9.1.1-1

PNEUMATIC BACKF ILLING IN EMPLACEMENT DR IF TS
(RAIL EMPLACEMENT MODE) \begin{tabular}{l|l} 
DOE IOFEO M GRIGORE \\
\hline
\end{tabular} 
such a robotic device would be limited, and an operating envelope greater than $4.3 \mathrm{~m}$ may in all likelihood be required for such a device.

A second option in lieu of a robotic piece of repair equipment would be to remove all waste packages from the drift up to, and a safe distance beyond (from a radiation exposure standpoint), the damaged area. Repairs could then be accomplished using more conventional techniques, possibly with the use of temporary shielding since radiation levels within the drift would be reduced after 100 years.

In either of the above two options, drift cooling would be needed prior to inspection and repair. The second option (partial or full retrieval from a drift) may be a more realistic option for small emplacement drifts in the 4 to $5 \mathrm{~m}$ diameter range because of the limited working clearances that are available, as Figure 9.1.1-1 indicates.

After the monorail beam has been checked (and repaired if necessary), one or more pneumatic backfill pipes would be installed in the drift. As a minimum, one bolted flange pipe would be installed in the crown of the emplacement drift for a distance of $600 \mathrm{~m} \pm$ from the TBM launch main drift. An alternate method of coupling may be to use shouldered pipe joints with quick-disconnect (such as a lever) mechanical couplings which is a common method of connecting concrete slicklines. The conveying pipe would be designed to travel on the monorail beam via roller supports attached to the pipe as shown in Figure 9.1.1-1. A $200 \mathrm{~mm}$ nominal diameter pipe is shown in that figure. The conveying pipe would be assembled in $6 \mathrm{~m}$ long sections from the TBM launch main drift as shown in Figure 9.1.1-2.

A second $600 \mathrm{~m} \pm$ long conveying pipe would be installed in the drift crown by identical means from the opposite end of the emplacement area (i.e., perimeter main drift); thus, the full $1,200 \mathrm{~m} \pm$ drift length would be covered. Pipes would be run from both sides of the emplacement area because a $900 \mathrm{~m}$ total pipe length approaches the maximum economical length for pneumatic conveying systems commonly used underground (Powell, 1983).

An additional conveying pipe could also be installed in a pre-formed slot (either cast into a pre-cast invert segment or formed in a cast-in-place invert slab). Examples of a nominal $150 \mathrm{~mm}$ diameter lower pipe are shown in Figure 9.1.1-1. The lower conveying pipe is an option to aid in backfill placement in the narrow spaces under the emplacement carts. A reliable method of sliding the pipe couplings across expansion joints in the invert would be a critical consideration if a lower pipe is used. Skid bars welded to each side of the coupling would be one option to allow a coupling to slide across an expansion joint with less chance for hang-up.

The volcanic tuff excavated during repository construction will be a plentiful source for dry backfill material. A general size distribution of excavated tuff from TBM operations which would be stockpiled on the surface is shown in Table 9.1.1-2. 


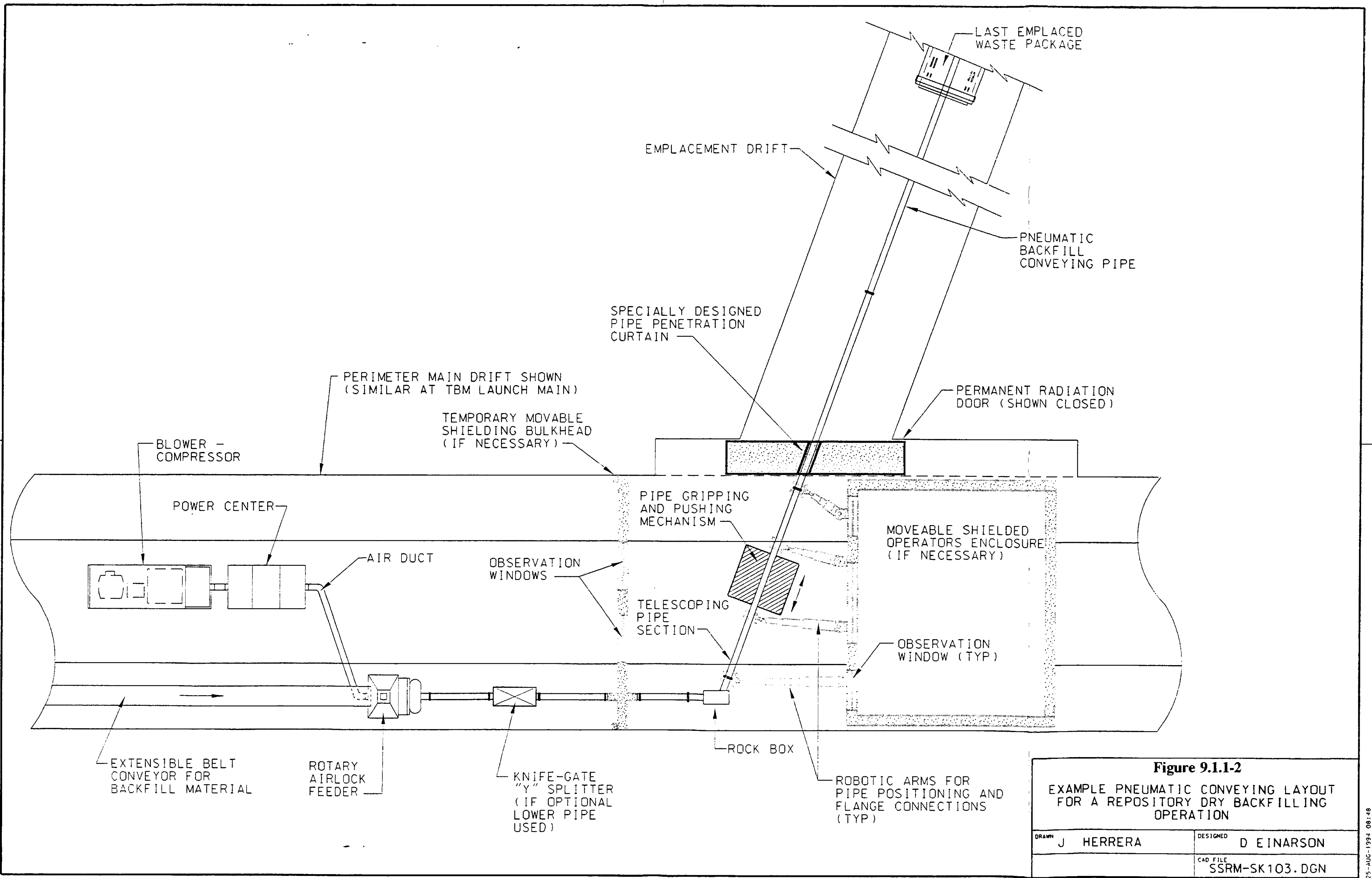


Table 9.1.1-2. Typical TBM Excavated Material Sizes

\begin{tabular}{|c|c|}
\hline Screen Size (mm) & Weight \% Passing \\
\hline \hline 305 & 100 \\
\hline 152 & 90 \\
\hline 76 & 80 \\
\hline 25 & 60 \\
\hline 6 & 30 \\
\hline
\end{tabular}

Modified from M\&O (1993d)

A typical backfill placed pneumatically underground consists of material less than $100 \mathrm{~mm}$ in size, and a material in the range of 0 to $75 \mathrm{~mm}$ produces the greatest compaction (Powell, 1983). As can be seen, a majority of the material in Table 9.1.1-2 would be below $100 \mathrm{~mm}$ and would fall in the 0 to $75 \mathrm{~mm}$ size range. If this were the only requirement for a pneumatic fill, only simple screening of the oversized material would be necessary.

If a more specific material size distribution was required, such as the coarse and fine material shown in Table 9.1.1-1, for example, additional processing steps would be needed. As shown in the distribution in Table 9.1.1-1, it is also fully compatible with placement by pneumatic methods because all particle sizes are less than $100 \mathrm{~mm}$. First, to obtain the coarse (gravel) material layer of Table 9.1.1-1, excavated tuff would be transferred from a surface stockpile and passed through a multiple-deck screening plant. The rejected material from this screening operation would be transferred to a separate stockpile for use as the fine (sand) material layer of Table 9.1.1-2.

Multiple-stage crushing and additional screening would be needed if sufficient coarse material was not obtained from the screening operation. As a minimum, primary and secondary crushing would be required, with a possible tertiary stage.

Fines from the screened reject stockpile (and/or multiple-stage crushing and screening operation, as applicable) would be used to achieve the sand shown in Table 9.1.1-1, but would require further screening and classifying to achieve the size distribution shown in that table. If sufficient fine material was not available from the above operations, additional stockpiled material would need to be fine-crushed, screened, and classified to obtain the remaining sand sizes required.

All of the screening and crushing operations described above can be combined into a single integrated operation using common modular "off-the-shelf" equipment used in the industrial minerals and hardrock mining industries. Washing or other material treatment processes could also be readily incorporated into such a plant if such items were necessary to ensure compatibility with the waste package materials or other long-term performance issues. 
Once the material has been processed, it would be transferred down a repository shaft in two slickline pipes, one for the coarse (gravel-like) material and the second for the sand. Steel bins located at the base of the slickline pipes would provide some underground surge and storage capacity. The coarse material or sand, as needed, would be carried by a combination of conventional conveyors and two extensible belt (M\&O, 1993d, pp. 5-17 to 5-20) conveyors from the shaft to the entrance of the emplacement drift to be backfilled. One extensible belt conveyor would travel to the appropriate emplacement drift via the perimeter main drift, and a second would travel to the appropriate emplacement drift via the TBM launch main drift.

The discussion below describes backfilling operations in the TBM launch main at the entrance to an emplacement drift, or in the perimeter main at the exit of an emplacement drift. If backfilling were performed many years after first emplacement, such as 100 years, the radiation emissions from the waste packages will be greatly reduced. However, detailed calculations necessary to establish what the actual radiation environment would be in these areas have not been performed to date. It, therefore, cannot be determined whether radiation levels would be significant enough to prohibit personnel from working in these areas unprotected by shielding. The following operations description example and equipment layout reflect the conservative viewpoint that radiation emissions from any penetration through a shielding door to allow clearance for items such as a backfill pipe could still be significant enough to warrant some amount of special equipment and shielding.

A minimum of two pneumatic conveying equipment setups would be required. One setup would be located at the TBM launch main drift and one at the perimeter main drift. An example of this equipment setup in the perimeter main drift is shown in Figure 9.1.1-2. The setup in the TBM launch main drift would be similar.

Penetrations are made through the closed radiation doors located at the ends of the emplacement drift, as shown in Figure 9.1.1-2. The penetrations in the radiation doors would be just wide enough for a pipe coupling or flanged joint to pass through with minimum clearance. The penetration would include a specially designed pipe penetration curtain to reduce radiation emissions through the penetration into the TBM launch or perimeter mains. However, as stated above for conservatism, some radiation emissions are still assumed to occur through this gap, and the entrance to the emplacement drift at the perimeter main (or TBM launch main) drift is thus assumed to be a radiation hazard environment. A movable shielded enclosure, equipped with several arms operated from within the enclosure is provided (again, for conservatism) to handle and couple new lengths of pipe. A temporary bulkhead in the perimeter main (or TBM launch main) drift would provide any additional level of required shielding to allow personnel to work around the pneumatic conveying equipment and feed conveyor without any further radiation safety precautions.

If a lower conveying pipe is used, a second pneumatic conveying setup at each location could also be installed to feed this pipe; or, more practically, a diversion "Y" with knife-gate valves could be connected to the two pipes, thus enabling a single set of pneumatic conveying equipment to be used. With the diversion "Y," the flow of backfill material could be alternated at will between the upper and lower pipes. An approximate position of the diversion " $\mathrm{Y}$ " is shown in Figure 9.1.1-2. 
The backfill placement operation would be performed in a retreating manner from each end of the emplacement drift. A mechanism to grip the pipe string(s) and pull the string(s) out of the emplacement drift in a controlled manner would be located in the perimeter or TBM launch main as shown in Figure 9.1.1-2. The mechanism would also be used to initially push the pipe(s) into the drift.

One potential problem with a pneumatically placed backfill could be the difficulty in achieving a uniform and predictable gradation of particles if a backfill similar to that described in Table 9.1.1-1 is used. Due to the momentum of the backfill as it leaves the pipe, the coarser, heavier particles will be projected further out of the pipe and down the drift than the finer particles. If a backfill pipe is moved in $6 \mathrm{~m}$ increments, backfill materials may tend to segregate in zones by size increment along the longitudinal length of the drift. Each complete size range zone would be roughly the length of a backfill pipe segment with the segregation again repeating the next $6 \mathrm{~m}$, and so on. This segregation may not be as pronounced in areas where a waste package is located because material striking and bouncing off the outer surface of the package may cause better mixing to occur.

A method of addressing the particle size segregation described above would be to provide a $6 \mathrm{~m}$ long telescoping section of pipe to allow the backfill pipe to be moved in and out of the drift for each length of the conveying pipe. This method could provide better mixing of different particle sizes. The telescoping section of pipe would consist of an inner pipe with an outer, larger diameter pipe sleeve. The upstream end of the sleeve pipe would be constructed with an air seal ring(s) to prevent air pressure leakage from the pipe line. The front or downstream end of the outer pipe sleeve would be constructed with a reducer to change the diameter back to the main conveying pipe size. Each end of the telescoping section would be equipped with whatever style pipe coupling or flange used for the remainder of the conveying pipe line.

To provide placement of the upper sand layer, the lower coarse material would be placed first for the entire length of the drift. The backfill conveying pipe would then be pushed back into the drift from both the TBM launch main and perimeter mains. Both pipe line lengths would then be $600 \mathrm{~m} \pm$ long. Sand would be placed on top of the coarse material layer by again retreating each pipe line out of the drift.

Several key considerations should be emphasized regarding backfill placement quality:

- Although mixing of the coarse material can be accomplished as described above, it will be difficult to predict what the in-place gradation and compaction of this material will be. The effect of the waste packages in the backfill stream will further increase prediction difficulty.

- The top of coarse material could be uneven depending on how the pipe line was moved during the backfilling operation. A possible way to "grade" the coarse material to an approximate (but likely not exact) sloping configuration described in Section 9.1.1.1 would be to move a traveling, vibrating screed down the length of the drift. The screed could be designed to travel on the backfill pipe support monorail beam. 
- Careful metering of material volume would be required to predict how the operation was proceeding and to ensure a relatively constant coarse material height down the length of the drift.

- The top layer of sand (or top of the coarse material if sand was not used) could never be placed any higher than roughly the bottom of the backfill pipe, unless a flexible, remote-controlled nozzle could be designed to aim the backfill stream at the drift roof. This flexible elbow would represent a significant wear item in the system. 


\section{COST ESTIMATING}

As of the time of this report, no definitive cost estimate has been developed for repository design. This work is scheduled to be accomplished in FY 1995 and FY 1996. 


\section{SCHEDULE AND MILESTONES}

The ACD phase precedes future design and construction efforts as depicted in Figure 11-1. This figure also illustrates the integration of design among various repository elements that include design, construction, license application, permitting, and data needs. Following is a description of key milestones as they are developed for the OCRWM Proposed Program Approach to overall project scheduling.

\subsection{KEY MILESTONES}

\subsubsection{Project Summary Milestones}

The milestones were developed under the program plan known as the Proposed Program Approach (PPA). Under this plan, the Technical Site Suitability (TSS) in late FY 1998 is expected to cover DOE's evaluation of site suitability with respect to all the qualifying and disqualifying conditions of 10 CFR 960, except for those pertaining to environmental, socio-economic and transportation. The latter conditions will be addressed through the NEPA process.

The Draft EIS (DEIS) in late FY 1998 will be prepared in accordance with the requirements of NEPA (as modified by the NWPA) and implementing regulations. It is expected to address environmental impacts associated with repository construction, operations, postclosure, and transportation.

The Final EIS (FEIS) in late FY 2000 will address comments received from the public on the DEIS and include any relevant additional information that has become available since the time the DEIS was issued. The FEIS will accompany the recommendation to the President, if the site is suitable.

The Site Recommendation Report (SRR) in late FY 2000 will be submitted to the President if the site is found suitable. It will be prepared in accordance with the content requirements of Section 114 of the NWPA.

The License Application (LA) will be submitted to the NRC in mid to late FY 2001, if both the President and Congress approve the site recommendation. The LA will be prepared in accordance with the content requirements of 10 CFR 60.21 and the NRC's Format and Content Regulatory Guide. The LA will be used as the basis for NRC issuance of the Construction Authorization.

It is expected that the NRC will issue the Construction Authorization (CA) in late FY 2004, after it has reviewed the LA and conducted the required hearings. This will be the point in the licensing process when the NRC makes its "reasonable assurance" finding in accordance with 10 CFR 60, which will be based on the information DOE provides in the LA and any subsequent supplements. Upon receipt of the CA, construction of the repository may begin. 
The updated. LA would be submitted to the NRC in late FY 2008, after sufficient construction (both surface and subsurface) has been completed to support initial operations. This updated LA will be the basis for NRC issuance of the license to receive and possess waste.

NRC issuance of the license to receive and possess waste is expected in late FY 2010, after it has reviewed the updated LA and conducted any required hearings. At this point, DOE may start accepting waste at the repository.

\subsection{SITE SUITABILITY}

\subsubsection{Site Suitability Process}

The higher level findings (HLFs) required for site suitability by 10 CFR 960 are expected to be conducted in a step-wise manner. Generally, the process would entail the preparation of a technical report that combines different qualifying and disqualifying conditions that are similar in topical area; this report would be peer reviewed. DOE would then make the regulatory assessment needed for the higher level finding. Indicated below are the key milestones related to the HLFs.

HLFs in FY 1995 will address the topic of surface processes and will include erosion, surface characteristics, and preclosure hydrology.

HLFs in FY 1996 will address the topics of preclosure rock characteristics and preclosure radiological safety. The latter topic, radiological safety, also includes site ownership and control, population density, off-site installations, and meteorology.

HLFs in FY 1997 will address the topics of tectonics and reasonably available technology. The former topic includes the postclosure tectonics disqualifying condition and the preclosure tectonics qualifying and disqualifying conditions.

HLFs in FY 1998 will address the topics of pre-waste-emplacement groundwater travel time, the postclosure system guideline, and all the remaining postclosure qualifying conditions geohydrology, geochemistry, rock characteristics, climate, and tectonics. Also, a report on Technical Site Suitability will be issued consolidating these HLFs and all previous ones into a single document.

In late FY 2000, the SRR will be issued to the President combining the results of the TSS and the NEPA process, in addition to the other items called for in Section 114 of the NWPA. 


\subsection{NEPA}

\subsubsection{Repository}

In mid-FY 1995, a Notice of Intent will be issued in the Federal Register to announce DOE's intent to prepare an EIS for the repository and initiate the public scoping process required by NEPA.

In late FY 1998, DOE will issue a DEIS for public comment (see "Key Milestones" above).

In late FY 2000 DOE will issue an FEIS (see "Key Milestones" above). No sooner than 30 days later, DOE will issue a Record of Decision (ROD), as required by NEPA, which will document DOE's decision to proceed with this major Federal action.

In late FY 2008, it is expected that DOE would prepare an EIS Supplement to address additional information regarding potential environmental impacts that have become available since the issuance of the original FEIS. This supplement would accompany DOE's updated LA to be submitted to the NRC for receipt of the license to receive and possess waste.

\subsubsection{Nevada Rail Spur}

This NEPA process applies only to the construction of the Nevada rail spur. The timing of this process is such that the spur would be available for use by the time DOE obtains the license to receive and possess waste (projected year 2010).

In late FY 2002, a Notice of Intent will be issued in the Federal Register to announce DOE's intent to prepare an EIS for the rail spur construction and initiate the public scoping process required by NEPA.

In late FY 2004, DOE will issue a DEIS for public comment. The DEIS will be prepared in accordance with the requirements of NEPA (as modified by the NWPA), and implementing regulations. It is expected to address environmental impacts associated with construction of the rail spur within Nevada.

In late FY 2005 DOE will issue an FEIS. The FEIS will address comments received from the public on the DEIS and include any relevant additional information that has become available since the time the DEIS was issued. No sooner than 30 days later, DOE will issue a Record of Decision (ROD), as required by NEPA, which will document DOE's decision to proceed with this major Federal action. 


\subsection{LICENSING}

\subsubsection{Issue Resolution}

Pre-licensing issue resolution and interaction activities will continue to be conducted until the LA is submitted to the NRC in FY 2001. The issues being actively addressed at this time include: extreme erosion, origin of calcite-silica deposits, seismic hazards, volcanism, substantially complete containment, boundary of the engineered barrier system, pre-wasteemplacement groundwater travel time, and burnup credit. As other issues are identified, they will be addressed and documentation prepared to support resolution with the NRC.

After the LA is submitted in FY 2001, the DOE and NRC enter into a formal process for resolving issues and interacting. This includes the NRC review of the LA, NRC issuance of a Safety Evaluation Report, and the hearings that are conducted in accordance with 10 CFR 2. After the CA is issued by NRC and DOE begins construction, NRC will continue to interact with $\mathrm{DOE}$ in a formal manner as the regulator.

\subsubsection{LA Annotated Outline}

Revision 4 (early FY 1995): The scope of the MGDS License Application Annotated Outline (LA AO) Revision 4 includes the following:

- Complete Chapter 3 [assuming section 3.1 is completed by incorporating the updated Site Description (funded out of WBS 1.2.3].

- Update Chapter 6 to incorporate the results of TSPA 1993.

- Resolve NRC comments on LA AO Revisions 2 and 3.

- Track acquisition of information needed in licensing by developing and implementing regulatory databases and coordinating with PACS.

- Produce Site Characterization Program Feedback Report from Revision 4 information needs and input into annual planning and long range planning process.

Revision 5 (early FY 1996): Fully implement the LA AO process to initiate the repository program licensing approach outlined in the Regulatory Compliance Plan. The process involves the following:

- Integrate multi-disciplinary technical expertise into a unified repository licensing approach by writing skeleton text using NRC guidance. Reference all existing information and specifically identify the need for missing information. 
- Import applicable sections of the SCP into the appropriate LA AO sections and document the linkage for inclusion in the transition matrix in RCP Appendix A.

- Specifically identify the missing information needed to support the unified licensing strategy and define data/designs/analyses needed from the site characterization, design, and performance assessment programs.

- Link LA AO information needs to the Project plans that are currently in place to acquire such information. In this manner, the LA AO process either verifies the site characterization program or initiates a request to change it.

- Produce Site Characterization Program Feedback Report from LA AO information needs and input into annual and long range planning process. In effect, produce specifications for data, designs, and analyses deliverables from Site Characterization activities.

Revision 6 (early FY 1997): Evaluate information from site characterization for use in licensing and incorporate/update LA AO sections, as appropriate. A request to initiate changes to the project plans may be necessary as a result of LA AO development. Similarly, a request may be initiated to defer or eliminate studies that are no longer needed in support of licensing. The dynamic feedback provided by this phase of the process focuses site characterization activities on the acquisition of information needed to support the unified licensing approach embodied in the LA AO.

Revision 7 (early FY 1998): Evaluate information from site characterization for use in licensing and incorporate/update LA AO sections, as appropriate. A request to initiate changes to the project plans may be necessary as a result of LA AO development. Similarly, a request may be initiated to defer or eliminate studies that are no longer needed in support of licensing. The dynamic feedback provided by this phase of the process focuses site characterization activities on the acquisition of information needed to support the unified licensing approach embodied in the LA AO.

Revision 8 (early FY 1999): Evaluate information from site characterization for use in licensing and incorporate/update LA AO sections, as appropriate. A request to initiate changes to the project plans may be necessary as a result of LA AO development. Similarly, a request may be initiated to defer or eliminate studies that are no longer needed in support of licensing. The dynamic feedback provided by this phase of the process focuses site characterization activities on the acquisition of information needed to support the unified licensing approach embodied in the LA AO.

Revision 9 (early FY 2000): Finalize LA AO for use in DOE's request for preliminary comments from the NRC related to the extent to which at-depth site characterization analysis and the waste form proposal seem to be sufficient for inclusion in any LA. These comments must be included in the Site Recommendation Report (SRR) pursuant to NWPA Section 
114(a)(1). After Revision 9 is issued, the LA AO will be converted into a draft license application by incorporating information that satisfies all remaining information needs and initiating formal license application review.

LA (mid-FY 2001): Incorporate Congressional Resolution of Site Approval into the LA and forward to the Secretary of Energy. The Secretary of Energy submits the Mined Geologic Disposal System (MGDS) LA to the NRC. This must occur no later than 90 days after Congress passes a joint resolution of siting approval, as required in NWPA 114 (b). The LA must contain the general information and the Safety Analysis Report (SAR) specified in 10 CFR 60.21. The LA must also be accompanied by the EIS.

CA, Updated LA, and License: See above under "Key Milestones."

\subsection{PERFORMANCE ASSESSMENT}

\subsubsection{Total System PA}

Each PA iteration should include total system and applicable sub-system analyses. Each PA iteration should include ample sensitivity/uncertainty analyses to indicate the significance of assumptions. Each PA iteration is assumed to take a full year of analyses. The analysis portion is assumed to be preceded by a six month planning phase. The analysis portion is assumed to be followed by a period to prepare the summary document describing the major findings and remaining uncertainties. Following the summary document, an additional three months are allowed for external and internal review. Thus, the time between full TSPA iterations is about two years.

The next PA iteration, TSPA-1995 (in late FY 1995), is to be a dry run for the TSPA that is to feed the TSS. The reason a dry run is needed is that TSPA-1991 and -1993 were "conservative" analyses that assumed bounds on data that led to the system not meeting certain performance measures in current applicable and non-applicable regulations. A trial TSPA that represents site data ranges less conservatively is needed relatively soon, to allow at least a year for specific additional data gathering and code enhancement activities to be conducted prior to TSPA-1997. TSPA-1995 is somewhere between the "Conservative" and "Bounded" classifications, in that it attempts to insert more realism, but data sparsity demands that conservative estimates still be used in key data distribution assumptions.

TSPA-1997 (in late FY 1997) and related PA calculations will directly feed the TSS by supporting HLFs on the postclosure system performance guideline [10 CFR 960.4-1(a)] and the qualifying conditions requiring assessment of postclosure performance (i.e., Geohydrology, Geochemistry, Rock Characteristics, Climate, and Tectonics). This is a "Bounded" calculation in that there are sufficient data and information to come closer to a realistic and defensible calculation than in previous TSPAs. 
TSPA-1999 (in late FY 1999) and related PA calculations will directly feed the FEIS and SRR. This is also a "Bounded" calculation, and an improvement over the previous iteration in terms of the data and information allowing a realistic and defensible calculation.

TSPA-2001 (in early FY 2001) and related PA calculations will directly feed the LA for the CA. However, this PA iteration will be somewhat abbreviated and only the key issues identified following the TSPA-1999 iteration will be addressed; hence its labeling as TSPA Revisions. The label "Subfinal" may be applied to this iteration, since the LA contains calculations that must satisfy the criterion of a reasonable expectation that results will not be changed by new data from the Performance Confirmation program.

\subsubsection{Waste Package Subsystem PA}

The PA activities addressed here are those addressing the Substantially Complete Containment subsystem performance requirement of 10 CFR Part 60 . It is to be noted that future TSPA iterations are to progressively begin to address the system-level regulatory criteria more fully, including preclosure and postclosure, total system, and sub-system criteria. In this context, estimates of subsystem behavior will be part of each TSPA iteration.

Bounded (mid-FY 1997): This is to be used as part of the Waste Package Title I design documentation that is to be prepared by FY 1998. This analysis is to be "realistic and defensible" as per the "Bounding" definition. This is the limit to which available design and testing data can be interpreted by 1997.

Final (late FY 2000): This is the WP subsystem PA that is part of the documentation for the Waste Package Title II design, scheduled to be completed by 2001 . This analysis is "Final" in that it supports compliance with the Substantially Complete Containment requirement, and further testing is not expected to change the analytical conclusions. In order to make this a "Final" subsystem model, the design must be sufficiently robust to allow for the fact that certain testing activities are not as complete at 2001 as had been previously planned: (1) Waste package material testing will be less than 100 percent of what was previously planned to support the LA at 2001, and (2) Near Field Environment studies will be less than 50 percent of what was previously assumed necessary for 2001 .

\subsubsection{Groundwater Travel Time Subsystem PA}

The PA activities addressed here address the Groundwater Travel Time site subsystem performance requirement of $10 \mathrm{CFR}$ Part 60 . It is to be noted that future TSPA iterations are to progressively begin to address the system-level regulatory criteria more fully, including preclosure and postclosure, total system, and subsystem criteria. In this context, estimates of subsystem behavior will be part of each TSPA iteration.

Bounded (mid-FY 1997): This is to serve as an in-depth treatment of this issue, and is intended to be a "realistic and defensible" estimate of this performance measure as defined in 
10 CFR Part 960. This in-depth treatment is to a large extent dependent on progress in the site-scale models being provided by the Site Investigations function, which, since they are to be at the "Bounded" state of development, largely dictate the limit to which the technical status of the GWTT calculation can be interpreted by 1997.

Subfinal (late FY 2000): This GWTT subsystem PA is to support the SRR and the LA. At this point in time, the site-scale models will have advanced beyond the "Bounded" state of development. The logic for expecting the GWTT calculation to be at the "Subfinal" state here lies in the expectation that the changes in the site-scale models resulting from new information will not cause substantive changes to the conceptual understanding of water flow in the unsaturated environment of Yucca Mountain, and that the database supporting the radionuclide transport part of the GWTT calculations addressing 10 CFR Part 960 will also be relatively mature at this point in time.

Final (late FY 2007): This GWTT subsystem PA is to support the 2008 Updated LA. At this point in time the supporting site-scale models are largely in the "Subfinal" state of development. Continued confirmatory testing is to result in the finalization of those models, which will be important to updating TSPAs, but no further changes in estimates are expected from further developments in data and information.

\subsubsection{Engineered Barrier System (EBS) Subsystem PA}

The PA activities addressed here address the Controlled Release Rate subsystem performance requirement of $10 \mathrm{CFR}$ Part 60 . It is to be noted that future TSPA iterations are to progressively begin to address the system-level regulatory criteria more fully, including preclosure and postclosure, total system, and sub-system criteria. In this context, estimates of subsystem behavior will be part of each TSPA iteration.

Conservative (mid-FY 1997): This EBS subsystem PA is to be used as part of the evolving repository design. This analysis is to be based on an Areal Power Density that is not yet final, and a repository design that is in the initial stages of Title I. At this point in time, significant design decisions are not yet final, and available design and testing data are less mature for determining releases from failed containers than they will be for supporting estimates of the time of failure for those containers.

Bounded (late FY 2000): This EBS subsystem PA is to be part of the repository Title I design documentation scheduled to be completed by late FY 2000. This analysis is "Bounded" in that it supports the finding that performance estimates for the Controlled Release Rate criterion are "realistic and defensible" based on the results of design and testing. The "Bounded" classification in this instance should actually be somewhere between "Conservative" and "Bounding," because testing related to the Near Field Environment at 2001 will be about 50 percent, and testing of waste form release will be about 25 percent of what was previously considered necessary to support the LA. 
Final (late FY 2007): This EBS subsystem PA will be produced in support of the 2008 Updated LA. To make this a "Final" analysis, the repository Title II design basis is available for the calculations, and testing related to the Near Field Environment and to waste form release behavior in that environment must be substantially complete. Confirmatory testing in both these areas will continue after waste begins to be emplaced, however.

\subsection{SITE INVESTIGATIONS}

\subsubsection{Three-dimensional Geologic Description}

Subfinal (early FY 1997): The major objectives of SCP Studies 8.3.1.4.2.1, 8.3.1.4.2.2, and 8.3.1.4.2.3 will have been achieved, leading to an essentially complete geologic framework model for the site. The geologic framework model will include the definition and description of all appropriate stratigraphic units within the Tertiary volcanic section at the site and the location and description of the major structural features at the site. Additional site information would be used to refine the model but would not be expected to require substantive changes to the model. This Subfinal degree of completeness is needed as a basis for site hydrologic and performance-assessment modeling to support the technical site suitability evaluation and the license application.

Final (early FY 2000): This includes all activities under SCP Studies 8.3.1.4.2.1, 8.3.1.4.2.2, and 8.3.1.4.2.3 with respect to available site data and information. No additional activities would be planned specifically to support further development of the site geologic framework model. Additional site data would be used to refine the model but would not be expected to require major changes to the model. A final status is needed because of the fundamental importance of the geologic framework for siting and evaluating the performance of the geologic repository.

Updated (late FY 2007): Additional site geologic data that would become available would be ancillary to other studies and would be incorporated into the site geologic framework model. These data would be expected to permit refinement of model details or, perhaps, to permit extension of the lateral and vertical domain of the model but would not be expected to lead to substantive changes within the existing model domain.

\subsubsection{Climate Description}

Conservative (early FY 1997): Based on evaluations of modern climatic conditions and conditions occurring during the Quaternary Period, as inferred from paleoclimate and paleoenvironmental studies, the timing, duration, and magnitude of possible extreme future climatic change would be estimated. The magnitude of climatic change would be estimated quantitatively as the effective moisture (precipitation minus evapotranspiration), which is the quantity most relevant to possible climatic induced changes in the site and regional hydrologic systems. 10 CFR 960 specifically requires that consideration of climatic conditions in the Quaternary be the basis for evaluating future climatic change. 
Bounded (early FY 2000): Sufficient data from the paleoclimate program and preliminary future-climate modeling studies would be needed to set realistic bounds on the timing, duration, and magnitude of expected future climatic change. In addition, bounding relations for translating effective moisture into net infiltration and recharge need to be developed to support site and regional hydrologic modeling and performance-assessment modeling.

Subfinal (late FY 2007): The major objectives of the paleoclimate and future-climate programs as described in the SCP need to be achieved in order that performance assessment can adequately address the expected effects of future climatic change on waste containment and isolation. Additional data and climate-modeling would permit refinements of model details, but would not be expected to lead to substantive changes in the evaluation of possible consequences of expected future climatic change.

\subsubsection{Postclosure Tectonics Description}

Bounded (early FY 1997): Based on data from volcanism and faulting studies in the region and near the site, limits on the likelihood of occurrence of igneous activity or faulting that could disrupt the postclosure repository would be estimated. Because these likelihoods are expected to be small for the site, bounding values based on partial information will suffice for the technical site-suitability evaluation.

Bounded (early FY 2000): Additional site and regional data will permit updating and refinement of the limiting likelihoods used for the technical site-suitability evaluation and would be sufficient to support the license application.

Subfinal (late FY 2007): The major objectives of the SCP tectonics program need to be achieved at this point to support detailed performance-assessment evaluations of the consequences for waste containment and isolation due to possible future tectonic processes at the site.

\subsubsection{Unsaturated/Saturated Geochemistry Description}

Bounded (early FY 1997): Realistic limits on the mineralogic composition, water chemistry, and geochemical retardation properties of the site are needed at or between key horizons (such as, most importantly, the Calico Hills non-welded hydrogeologic unit between the potential repository and the water table) and for selected representative radionuclides to support the technical site-suitability evaluation.

Bounded (early FY 2000): Additional data will be needed to refine and extend the limits to additional units and radionuclides other than those used for the technical site-suitability evaluation in order to support a demonstration of substantially complete containment and subsequent performance-assessment evaluations. 
Subfinal (late FY 2007): The major objectives of the SCP geochemistry program will need to be achieved in order to support realistic performance-assessment evaluations for the repository system. Additional data would enlarge the geochemical database but would not be expected to change major results and conclusions.

\subsubsection{Unsaturated Zone (UZ) Hydrologic Description}

Bounded (early FY 1997): Bounding limits on expected ground-water fluxes in the unsaturated zone are needed to support performance assessment. Based on geohydrologic and geochemical evidence (e.g., fracture mineralogy and chlorine-36 data), bounds on the presence of present and past active preferential flow pathways in the unsaturated zone need to be established. Bounds on the occurrence and factors controlling the occurrence of perched water also need to be established. Finally, limiting conditions on sustained non-equilibrium flow in fractures and faults and rates of imbibition into the adjacent rock matrix need to be established. Sufficient data are needed to support ground-water travel-time evaluations in the context of the disqualifying condition in 10 CFR 960 for the site-suitability evaluation.

Bounded (early FY 2000): Improved bounds on expected ground-water flux at the repository horizon will be needed to support a demonstration of substantially complete containment.

Subfinal (late FY 2007): The major objectives of the unsaturated-zone geohydrology program will need to be achieved in order to provide percolation-flux fields needed to support performance-assessment evaluations.

\subsubsection{Saturated Zone Hydrologic Description}

Bounded (early FY 1997): Bounds on ground-water flow velocities, mixing depth, and existence of preferential flow pathways in the saturated zone need to be estimated and will be adequate for performance-assessment evaluations to support the technical site-suitability evaluation.

Bounded (early FY 2000): The limits established for the technical site-suitability evaluation will be refined for input to performance-assessment models to support the application for construction authorization.

Subfinal (late FY 2007): The major objectives of the saturated-zone geohydrology program will need to be achieved in order to provide ground-water flow-field data to support performance-assessment modeling.

\subsubsection{Thermal Effects Description}

Bounded (early FY 1997): Bounding estimates of the maximum magnitude and spatial extent of repository induced temperature change will suffice for evaluating technical site suitability and supporting EIS preparation. 
Subfinal (early FY 2000): Reasonably accurate and complete knowledge of expected repository-induced thermal effects, especially the early near-field thermal environment, will be needed to demonstrate substantially complete containment.

Final (late FY 2007): Essentially complete and final knowledge of the repository-induced thermal regime will be needed to support performance-assessment evaluations.

\subsection{ESF CONSTRUCTION}

\subsubsection{ESF 7.8 Kilometer Loop}

Complete Accesses to Ghost Dance Fault (late FY 1996): Complete TBM excavation at the Topopah Spring level to approximately Station $52+00 \mathrm{~m}$, including Ghost Dance Fault penetrations necessary to identify the potential existence of water, the North Ramp extension with a $5.5 \mathrm{~m}$ diameter TBM, and thermal test area penetrations at the North Ramp extension.

Complete $7800 \mathrm{~m}$ Loop (mid-FY 1997): Complete TBM excavation at the Topopah Spring level to the South Portal. Completion of this milestone may be delayed if excavation to the Calico Hills level is required based on information gathered from the Ghost Dance Fault penetrations.

\subsubsection{Calico Hills}

Evaluate Options Calico Hills (CH) Access (Slant Drilling/Excavation) (late FY 1995): Evaluate options and select method for access to the Calico Hills level based on the potential discovery of water at the Ghost Dance Fault penetrations at the Topopah Spring level. Develop the design(s) necessary to implement the selected Calico Hills access.

Implement CH Decision (late FY 1996): Implement the selected design and excavation option for the Calico Hills access assuming that information from the Ghost Dance Fault penetrations at the Topopah Spring level requires investigation at the Calico Hills level.

\subsection{REPOSITORY/WASTE PACKAGE}

\subsubsection{Repository}

Complete Advanced Conceptual Design (ACD) (end of FY 1996): The goal of the ACD phase is to develop the repository design to a conceptual level of detail that will confirm the technical feasibility of the proposed operations, satisfy statutory requirements, allow the preparation of reliable total system life cycle costs and performance schedules, and identify environmental safety features. The ACD will provide the basis for the DEIS. Major design products include basic facility and component drawings that show significant features and general arrangements, an energy conservation report, project design criteria that include health, safety, safeguards and security requirements, and identification of design uncertainties 
and contingencies. The final ACD Report is required to support the DOE Key Decision 1 (KD1) milestone.

Complete Title I Design (late FY 2000): Title I Design is also referred to as Preliminary Design. The goal of the Title I Design phase is to utilize the Advanced Conceptual Design to firmly establish (freeze) the repository concept of operations and major design features, further refine the repository costs and performance schedules, complete evaluations of key design alternatives, and provide additional design input to the FEIS. Major Title I Design products include preliminary drawings that expand on the conceptual level of detail and reflect the finalized concept of operations and the recommendations from the evaluations of alternatives. Outline specifications for equipment procurement and construction are prepared. The preliminary drawings and outline specifications are used to develop more accurate cost estimates and performance schedules. Preliminary estimates of construction labor, equipment and material quantities, and long-lead procurement items are developed. Design features that assure compliance with health, safety and environmental regulations are further developed and analyzed. A Preliminary Safety Analysis Report (required by DOE Orders) is also prepared during the Title I Design phase. The Title I Design Report is required to support the DOE Key Decision 2 (KD2) milestone and submittal of the NRC License Application for a repository.

Complete Title II Design (late FY 2004): Title II Design is also referred to as Definitive Design. The goal of the Title II Design phase is to utilize the Title I Design to develop detailed construction drawings, equipment lists, detailed procurement and construction specifications, detailed construction cost estimates, and firm construction and start-up schedules. Major Title II Design products include various construction packages that contain approved for construction (AFC) drawings, detailed procurement and performance specifications, firm construction schedules, testing and operational start-up plans, equipment procurement plans, and detailed estimates of construction labor, equipment and material quantities. A Final Safety Analysis Report (required by DOE Orders) is also prepared during Title II Design phase. The Title II Design Report is require to support the DOE Key Decision 3 (KD3) milestone.

Complete Construction (Title III Design) (late FY 2010): After the CA is received from NRC, repository construction will commence. Title III Design assures through ongoing inspection activities that the construction is proceeding in accordance with the approved drawings, specifications and plans. Inspection services include verification of vendor drawings and equipment, construction workmanship, materials and equipment. Approved changes to the Title II Design packages will require preparation of as-built drawings and revisions to specifications. Completion of Title III Design (construction) is required to support the DOE Key Decision 4 (KD4) milestone. This milestone is complete when sufficient construction (both surface and subsurface) has been done to support initial repository operations. 


\subsubsection{Waste Package}

Complete Advanced Conceptual Design (ACD) (late FY 1995): The goal of the ACD phase is to develop the Waste Package/Engineered Barrier System (WP/EBS) design to a conceptual level of detail that will confirm the technical feasibility of the proposed operations, satisfy statutory requirements, allow the preparation of reliable total system life cycle costs and performance schedules, and identify environmental safety features. Major design products include WP/EBS design concepts, MPC, Uncanistered, and Defense High Level Waste (DHLW), waste package handling, closure processes, NDE/SI processes, component drawings, assembly drawings, preliminary specifications, and general arrangements, project design criteria, and identification of design uncertainties and contingencies. The final ACD Report is required to support the DOE Key Decision 1 milestone. The ACD will provide the basis for the DEIS.

Complete Title I Design (late FY 1997): Title I Design is also referred to as Preliminary Design. The goal of the Title I Design phase is to utilize the Advanced Conceptual Design to firmly define the leading WP/EBS concepts and the concept of operations and major design features, further refine the associated WP/EBS costs and performance schedules, complete evaluations of key design alternatives, and provide additional design input to the FEIS. Major Title I Design products include preliminary drawings that expand on the conceptual level of detail and reflect the finalized concept of operations and the recommendations from the evaluations of alternatives. Outline material, component, and assembly specifications for procurement and fabrication are prepared. The preliminary drawings and outline specifications are used to develop more accurate cost estimates and performance schedules. Preliminary estimates of fabrication labor, equipment and material quantities, and long-lead procurement items are developed. Design features that assure compliance with long term containment of the waste are further evaluated and analyzed, including probabilistic evaluation of the WP/EBS system. A Preliminary Safety Analysis Report (required by DOE Orders) is supported during the Title I Design phase. The Title I Design Report is required to support the DOE Key Decision 2 milestone.

Complete Title II Design (late FY 2000): Title II Design is also referred to as Definitive Design. The goal of the Title II Design phase is to utilize the Title I Design to develop detailed WP/EBS design and fabrication drawings, equipment lists, detailed procurement and material and component/assembly engineering and fabrication specifications, detailed fabrication and assembly cost estimates, and fabrication and construction and start-up schedules. Major Title II Design products include various design and fabrication packages that contain approved for construction (AFC) drawings, detailed procurement and long term performance specifications, firm fabrication and construction schedules, testing and handling, closure, NDE/ISI, WP filler operational start-up plans, equipment procurement plans, and detailed estimates of construction labor, equipment and material quantities. A Final Safety Analysis Report (required by DOE Orders) is also prepared during the Title II Design phase. The Title II Design Report is require to support the DOE Key Decision 3 (KD3) milestone and will form the basis for the LA. 
Complete Prototype (Title III Design) (late FY 2004): This phase will focus on NRC licensing issues raised during the review of the LA, WP processing through the surface and subsurface facilities, performance confirmation test planning/testing, and material, component specification, and drawing package (Waste Package Parts List). Inspection services include verification of vendor drawings and equipment, fabrication and construction workmanship, materials and equipment. Approved changes to the Title II Design packages will require preparation of as-built drawings and revisions to specifications. Completion of Title III Design (Prototype) is required to support the DOE Key Decision 4 (KD4) milestone.

Complete Fabrication (late FY 2010): By this period in time, fabrication of the waste packages needed to support initial waste emplacement is completed.

\subsection{RAIL SPUR}

\subsubsection{Rail Spur}

Route Analysis/Conceptual Design (late FY 2000): An evaluation of the Nevada rail spurs pre-conceptual studies and one completed conceptual study to date will be performed and routes will be selected for conceptual design. Conceptual design may be performed on more than one route. The design package will include a conceptual level cost estimate for performing further design, construction, and operation of the rail spur. This information will be used for the repository DEIS.

Title I Design (mid-FY 2004): A Title I design will be performed on the Nevada rail spur route selected. At the end of the Title I design, the design will be essentially "frozen" with no major changes expected in later stages of design. A design package including report, drawings, cost estimate, and outline specifications will be prepared for the rail spur facilities to meet DOE Order 4700.1 and other requirements.

Title II Design (late FY 2007): Title II design will be performed on a single route base on the design developed during Title I. Detailed construction and procurement drawings and specifications will be developed. A detailed cost estimate for Title III engineering, construction, and operations will also be produced at the end of Title II.

Rail Spur Construction (late FY 2010): Construction of the Nevada rail spur will be done in time to support accepting waste in the repository by 2010 . 


\section{UNCERTAINTIES, ISSUES, AND RECOMMENDATIONS}

With the current dearth of underground data, the levels of uncertainty are high for a number of parameters that may be important to waste isolation. If these uncertainties could be reduced, the understanding of waste isolation/waste emplacement would be improved. Sensitivity analyses are needed to fully identify parameters important to waste isolation. Based on this, it will be necessary to ensure that test programs can provide the necessary data to reduce uncertainties. Some studies have been done, including the FY 1993 Thermal Loading Study (M\&O 1994u), which have identified some of these uncertainties. A synopsis of the parameters or issues identified where uncertainty currently exists is provided below for those parameters influenced by thermal loading. The issues are divided into five areas: Waste Stream, Waste Package, Geochemistry, Hydrothermal, and Cost.

\subsection{WASTE STREAM}

In the area of uncertainties about waste and waste characteristics, the issue that must be addressed is the effect fuel variability has on thermal loading. The variability could produce local hot or cold spots which could influence pre- and postclosure performance. This issue will be evaluated in the FY 1994 Thermal Loading Study.

\subsection{WASTE PACKAGE}

Certain issues must be considered in establishing the performance of Waste Packages (WPs). Specifically, the corrosion of the WP materials under conditions in the potential repository over long time periods is not well known, and estimates differing by an order of magnitude are currently used. Thus, it will be necessary to establish corrosion initiation time and rates as a function of temperature, humidity, and time (for corrosion rates).

There is considerable uncertainty as to what performance allocation can or should be given for the fuel cladding. It is possible that no postclosure performance can be obtained from the cladding. In any case, it will be necessary to ensure that the cladding has sufficient mechanical integrity for retrieval operations. This is particularly important given the use of large WPs to accommodate large multi-purpose canisters (MPCs). The time/temperature dependence of fuel cladding performance needs to be investigated.

\subsection{GEOCHEMISTRY}

The effect of geochemical changes, due to thermal and liquid saturation changes, on radionuclide and bulk hydraulic conductivity is not well understood. To obtain a better understanding of these processes, it is suggested that certain additional information is needed. Data on energetics of zeolite dehydration and transformation (recrystallization) are of specific interest. There is significant variation in the stratigraphy with respect to concentrations of the zeolite-bearing moderately and nonwelded tuffs, clays, and volcanic glasses. Thus, information is required on the effects of existing lateral stratigraphic variations, in particularthe differences between sections where $\mathrm{CHn}$ is thickest (west) and thinnest (east). 
Finally, mineralogic alteration on rock properties in terms of how or to what degree heterogeneities might be introduced needs to be understood.

A significant uncertainty in the geochemistry area is the changing water chemistry occurring as a result of the thermal environment; also, the impact of changes in water chemistry on the Engineered Barrier System (EBS) (particularly WP corrosion), fuel alteration, and radionuclide dissolution. This information is needed for understanding the implications of above-boiling conditions.

Another significant uncertainty at this time is how much actual usable area exists at the repository horizon. Determination of this issue must wait until additional drilling is completed and the ESF is actually excavated. Even this may provide only a partial answer on a relatively small area, but the results should be possible to correlate with borehole information.

\subsection{HYDROTHERMAL}

Better information is required on the host rock matrix properties and fracture densities in the potential repository. Bulk permeability, both gas and liquid, is uncertain and variations in this parameter can significantly influence the transport of both heat and fluid. The uncertainty in this parameter must be reduced as well as a determination of the degree of heterogeneity that exists in the potential repository. As a part of this, the fracture-matrix interaction in the unsaturated zone must be better known. This information will not only affect the postclosure performance but also will impact the WP and drift-scale hydrothermal regimes.

Numerical simulations have predicted formation of dry-out for sufficiently high heat loads. However, these predictions are an average over a fairly extensive area and assume local thermodynamic equilibrium between rock and fracture matrices (Pruess and Wang, 1987, and Pruess and Tsang, 1993). It has not been established whether thermodynamic equilibrium in fact holds on a drift or WP scale. The potential repository host rock is known to be heterogeneous to some degree. As such, one may expect differential drying and condensation effects that could minimize fluid flow near some packages while enhancing it near others. This needs to be investigated further.

An important example of these uncertainties is the bulk permeability. Prediction of water movement has been shown, in Section 5 and Appendix F, of the Thermal Loading Study (M\&O 1994u) to be sensitive to bulk permeabilties. A value of 280 milliDarcys is representative of rock that has three 100 micron fractures per meter. However, recent analysis (SNL 1993c, 1993d) has shown that the linear fracture frequency needs to be corrected by the angle the fracture makes with the borehole. When this is done, the fracture density in the Topopah Spring Unit is estimated at about 15 fractures per meter. Although this is significantly higher than the figures used in the thermal loading study, no fracture size information was available in the report to estimate bulk permeability. The report documented limited checking of the calculation with the conclusion that they appeared valid, but it warnedthat the derived correction factor may overestimate the number of vertical fractures. Clearly this uncertainty as to actual bulk permeability must be resolved in order to accurately predict fluid movement in the mountain. 
Another significant uncertainty is the percolation flux that exists in the mountain. The TSPA study (M\&O, 1993k) showed that under some conditions, an increased percolation flux will produce a significant increase in the release of radionuclides to the accessible environment. An example of this is shown in Figure 12.1 in which the normalized total release of Tc99 to the accessible environment is plotted as a function of liquid flux in terms of a parameter QFLUX for a $10 \mathrm{~cm}$ thick WP emplaced at $57 \mathrm{~kW} / \mathrm{acre}$.

Thermo-mechanical calculations are needed to determine the response of the host rock under the various thermal loading conditions. These analyses are planned but have not yet been done.

The thermal performance of the host rock and the thermal effect on water movement are not well established. Heated block tests are planned underground to assist in determining this information, which is particularly critical to establish the amount of water moved, whether heat pipes occur, and whether convective processes are important.

All of these tests are needed to reduce the uncertainties and develop an improved hydrologic data base. The improved data base is needed to provide sufficient information to validate or verify the equilibrium continuum models being considered at this time for the predictions of thermo-hydrologic behavior.

\section{$12.5 \operatorname{COST}$}

A number of uncertainties currently exist in the cost basis, and only some major uncertainties will be specified here. Specifically, it needs to be determined to what extent the size and cost of the site characterization program (ESF, drilling, etc.) change as a function of thermal loading. If a low thermal load strategy is chosen, there needs to be an evaluation of which expansion areas are usable and whether or not there are significant costs incurred to access these expansion areas. Critical information needed for high thermal loads is the cost of the emplacement vehicles, particularly if fully automated vehicles are required, and the cost of shielding. Finally, the costs of monitoring have not been investigated and these costs may vary with thermal load. 


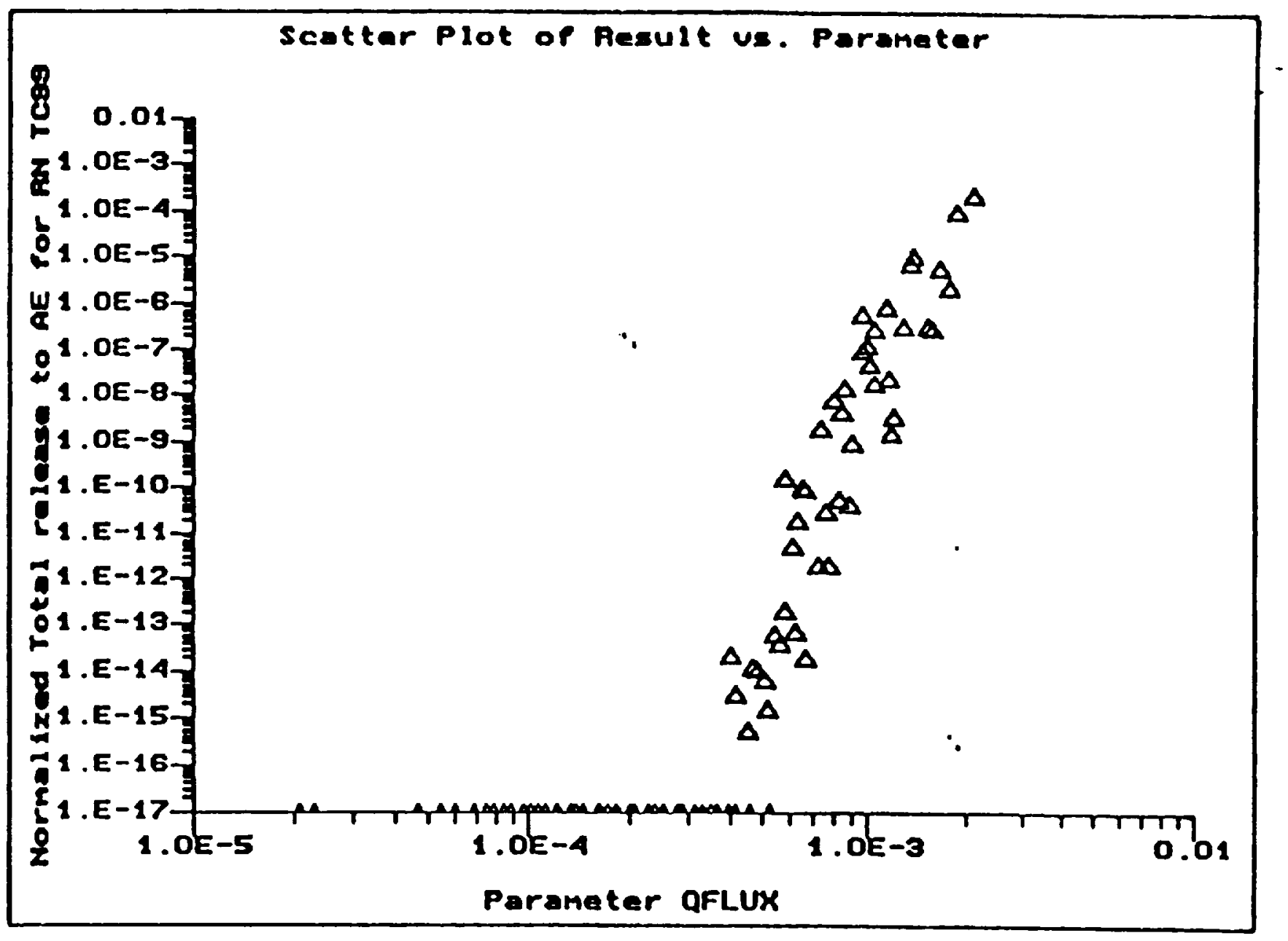

Figure 12-1. Normalized Total Release of Tc99 as a Function of Percolation Flux 


\section{REFERENCES}

\subsection{DOCUMENT REFERENCES}

ASM 1993. Handbook, Volume 6: Welding, Brazing, and Soldering, December 1993 (successor to Metals Handbook, Vol. 6, Ninth Edition, 1983), American Society of Metals.

BWNP 1988. Closure Development for High-Level Nuclear Waste Containers for the Tuff Repository, Phase I Final Report, UCRL-15964, B\&W Nuclear Power Division, September 1988.

BWNP 1990. Fabrication Development for High-Level Nuclear Waste Containers for the Tuff Repository, Phase I Final Report, UCRL-15965, B\&W Nuclear Power Division, September 1990.

BWFC 1991. Final Design Package, BR-100 100 Ton Rail/Barge Spent Fuel Shipping Cask, B\&W Fuel Company, November 1991.

BWNT 1991. ORIGEN2, Users Manual for BWNT Version, NPD-TM-18, Nuclear Technologies, March 1991.

BWNT1993a. ANISNBW: A One-Dimensional Discrete Ordinates Transport Code, B\&W Nuclear Technologies' Version of ANISN-W, NPGD-TM-491, July 1993.

BWNT 1993b. GIP, Group-Organized Cross Section Input Program User's Manual, NPGD-TM-456, B\&W Nuclear Technologies, August 1993.

Barton, N., R. Lien, and J. Lunde 1974. "Engineering Classification of Rock Masses for the Design of Tunnel Support," Rock Mechanics, Vol. 6, Springer Verlag, 1974.

Benedict, M., T. H. Pigford, and W. Levi 1981. Nuclear Chemical Engineering, Second Edition, McGraw-Hill, Inc., 1981.

Berggren, G. 1980. Helium Retention: Summary of Reports and Memoranda, K1/480/12, SKBF KBS Teknisk Rapport, February 1980.

Bieniawski, Z. T. 1973. "Engineering Classification of Jointed Rock Masses,"

Transactions, South African Institution of Civil Engineers, Vol. 15, 1973.

Bieniawski, Z. T. 1984. Rock Mechanics Design in Mining and Tunneling, A. A. Balkema, 1984. 
BNL 1990. Pescatore, C., M. G. Cowgill, and T. M. Sullivan. Zircaloy Cladding Performance Under Spent Fuel Disposal Conditions, BNL 52235, Brookhaven National Laboratory, April 1990.

Brady, B. H. G. and E. T. Brown 1985. Rock Mechanics for Underground Mining, George Allen \& Unwin, 1985.

Burrows, J., ed. 1982. Environmental Engineering in South African Mines, The Mine Ventilation Society of South Africa (with Additional Editorial Committee Members R. Hemp, W. Holding, R. M. Stroh), 1982.

Carpenter Technology Corporation 1993. Carpenter Neutrosorb Plus and Neutrosorb Borated Stainless Steels, Cartech, 1993.

Childs, K. W. and C. B. Bryan 1986. Heating Analysis of International Thermal Benchmark Problem Sets 1 and 2, ORNL/CSD/TM-239, Martin Marietta Energy Systems Inc., October 1986.

Chilton, A. B., J. K. Shultis, and R. E. Faw 1984. Principles of Radiation Shielding, Prentice-Hall, Inc., 1984.

Chin, B. A., N. H. Madsen, and M. A. Khan. Application of Zircaloy Deformation and Fracture Maps to Predicting Dry Spent Fuel Storage Conditions, Dept. of Mechanical Engineering, Auburn University.

Conca, J. L., M. J. Apted, and P. F. Salter 1993. "Engineered Barrier System Alternative Concept: Use of a Gravel Backfill as a Hydraulic and Diffusion Barrier," Technical Paper Presented at Workshop on Yucca Mountain Engineered Barriers Concept, Denver, CO., sponsored by Washington State University and INTERA Sciences, Inc., 1993.

Cook, I. and R. S. Peckover 1982. "Effective Thermal Conductivity of Debris Beds," Proceedings of the Fifth Post Accident Heat Removal Information Exchange Meeting, July 1982.

CRC Press 1980. Weast, R. C., ed., CRC Handbook of Chemistry and Physics, 61st ed., 1980.

CRWMS M\&O (Civilian Radioactive Waste Management System Management and Operating Contractor), see $\mathrm{M} \& \mathrm{O}$ references. 
DOE 1981. MATPRO - Version 11 (Revision 2), A Handbook of Materials Properties for Use in the Analysis of Light Water Reactor Fuel Rod Behavior, NUREG/CR-0497 TREE-1280, Rev. 2, EG\&G Idaho National Engineering Laboratory, U.S. Department of Energy, August 1981.

DOE 1985. Mission Plan for the Civilian Radioactive Waste Management Program, Overview and Current Program Plans, DOE/RW-0005, three volumes, U.S. Department of Energy, 1985.

DOE 1986. Environmental Assessment, Yucca Mountain Site, Nevada Research and Development Area, Nevada, DOE/RW-0073, Vol. 2, Office of Civilian Radioactive Waste Management, U.S. Department of Energy, May 1986.

DOE 1988. Site Characterization Plan, Yucca Mountain Site, DOE/RW-0199, Office of Civilian Radioactive Waste Management, U.S. Department of Energy, December 1988.

DOE 1993. Waste Acceptance System Requirement Document, Rev. 0, DOE/RW-351P, Office of Civilian Radioactive Waste Management, U.S. Department of Energy, January 1993.

DOE 1994. Radiological Control Manual, U.S. Department of Energy, April 1994.

Duderstadt, J. J. and L. J. Hamilton 1976. Nuclear Reactor Analysis, John Wiley and Sons, Inc., 1976.

Edwards, K. S. Fundamentals of Mechanical Component Design.

EG\&G 1991. Yucca Mountain Topography from 1:6000 Scale Orthophoto Mission, maps at contour intervals of 10 and 20 feet, EG\&G Energy Measurements, Inc., 1991.

EG\&G 1994. Position Information for Existing Boreholes, GENISES data base, EG\&G Energy Measurements, Inc., April 1994.

Eichhorn, F. and J. Borowka 1990. "Process-Oriented Welding Head Guidance System for Gas-Shielded Metal-Arc Narrow-Gap Welding," Welding and Cutting Journal, November 1990.

Einziger, R. E. and R. Kohli 1984. "Low-Temperature Rupture Behavior of ZircaloyClad Pressurized Water Reactor Spent Fuel Rods Under Dry Storage Conditions," Nuclear Technology, vol. 67, 1984. 
EPRI 1980. Control Rod Materials and Burnable Poisons: An Evaluation of the State of the Art and Needs for Technology Development, EPRI NP-1974, Electric Power Research Institute (EPRI), July 1980.

EPRI 1986. Einziger, R. E. "Oxidation of Spent Fuel at Between 250 and $360^{\circ} \mathrm{C}$," EPRI NP-4524, April 1986.

Ervin, E.M., R.R. Luckey, and D.J. Burkhardt 1993. "Summary of Revised Potentiometric-Surface Map for Yucca Mountain and Vicinity, Nevada," Proceedings of the Fourth Annual International Conference on High Level Radioactive Waste Management, 1993.

Friant, J. E., E. Ronnkvist, and L. Ozdemir 1993. Alcove Excavation for the Yucca Mountain Experimental Study Facility, Earth Mechanics Institute, Colorado School of Mines, October 1993.

Gaber, D. I. and R. R. Kimsey 1976. Neutron Cross Sections, Volume II, Curves, Third Edition, Brookhaven National Laboratory, January 1976.

Gaber, D. I. and S. F. Mughabghab 1973. Neutron Cross Sections, Volume I, Resonance Parameters, Third Edition, Brookhaven National Laboratory, June 1973.

Garde, A. M., H. M. Chung, and T. F. Kaisner 1978. "Micrograin Superplasticity in Zircaloy at $850^{\circ} \mathrm{C}, "$ Acta Metallurgica, Vol. 26, 1978.

General Electric 1972. Chart of the Nuclides, Eleventh Edition, General Electric Nuclear Energy Division, 1972.

Incropera, F. P. and D. P. DeWitt 1985. Introduction to Heat Transfer, John Wiley \& Sons Inc., 1985.

Klemens, T. L. and C. Hodson 1991. "Alternative to Blasting Breaks New Ground," Highway and Heavy Construction, September 1991.

Kogelmann, W. J. 1992. "North American NATM Techniques," World Tunnelling and Subsurface Excavation, Vol. 5, No. 5, 1992.

Lamarsh, J. R. 1983. Introduction to Nuclear Engineering, Second Edition, AddisonWesley Publishing Company, Inc., 1983.

LANL 1984. Vaniman, D., D. Bish, D. Broxton, F. Byers, G. Heiken, B. Carlos, E. Semarge, F. Caporuscio, and R. Gooley. Variations in Authigenic Mineralogy and Sorptive Zeolite Abundance at Yucca Mountain, Nevada, Based on Studies of Drill Cores USW GU-3 and G-3, LA-9707-MS, Los Alamos National Laboratory, 1984. 
LANL 1986. Broxton, D. E., R. G. Warren, R. C. Hagan, and G. Luedemann. Chemistry of Diagenetically Altered Tuffs at a Potential Nuclear Waste Repository, Yucca Mountain, Nye County, Nevada, LA-10802-MS, Los Alamos National Laboratory, 1986.

LANL 1989. Bish, D. L. and S. J. Chipera. Revised Minerologic Summary of Yucca Mountain Nevada, LA-11197-MS, and UC-721, Los Alamos National Laboratory, 1989.

LANL 1991. McCright, R.D. and H. Weiss. "Corrosion Behavior of Carbon Steels Under Tuff Repository Conditions," Proceedings Materials Research Society, Los Alamos National Laboratory, November 1984 (also see LLNL Report UCRL 90875, October 1984).

Lederer, M. C., J. M. Hollander, and I. Perlman 1967. Table of Isotopes, Sixth Edition, John Wiley and Sons, Inc., 1967.

Lindeburg, M. R., PE. Mechanical Engineering Reference Manual, 8th Edition, Appendix F.

LLNL 1991a. Johnson, G. L. Thermal Performance of a Buried Nuclear Waste Storage Container Storing a Hybrid Mix of PWR and BWR Spent Fuel Rods, UCID-21414 Rev. 1, Lawrence Livermore National Laboratory, November 1991.

LLNL 1991b. MCNP User's Manual, MCNP 4.2 HP 9000 Version, CSCI:B00000000-01717-1200-30006 Rev. 0, Los Alamos National Laboratory, April 1991.

LLNL 1993. Blair, S. C. Geomechanics, Preliminary Near-Field Environment Volume II: Scientific Overview of Near-Field Environment and Phenomena, Lawrence Livermore National Laboratory, April 1993.

LLNL 1994a. Buscheck, T. A. and J. J. Nitao. The Impact of Repository Heat on Hydrological Behavior at Yucca Mountain, UCRL-JC-115798, Lawrence Livermore National Laboratory, January 1994.

LLNL 1994b. Buscheck, T. A., J. J. Nitao, and S. F. Saterlie. Evaluation of ThermoHydrological Performance in Support of the Thermal Loading Systems Study, UCRL-JC-115352, Lawrence Livermore National Laboratory, February 1994.

LLNL 1994c. Clarke, W. L. Yucca Mountain Project Status Report-March 1994 SCP: N/A, LLYMP9404142, Lawrence Livermore National Laboratory, April 22, 1994. 
M\&O 1992. Doering, T. W. B\&W Fuel Company. Telephone conversation with Sandrik Specialty Metals, CRWMS M\&O September 23, 1992.

M\&O 1993a. Repository Shafts and Ramps Facility Concepts, DI\# B00000000-017175705-00002 Rev. 00, CRWMS M\&O, September 1993.

M\&O 1993b. Repository Subsurface Layout Options and ESF Interface, DI\# B0000000001717-5705-00009 Rev. 00, CRWMS M\&O, December 1993.

M\&O 1993c. Alternatives for Waste Package Emplacement, Retrieval, and Backfill Emplacement, DI\# B00000000-01717-5705-00006 Rev. 00, CRWMS M\&O, September 1993.

M\&O 1993d. Repository Materials Handling System Evaluation Report, DI\# B0000000001717-5705-00001, Rev. 00, CRWMS M\&O, September 1993.

M\&O 1993e. Description and Rationale for Enhancement to the Baseline ESF Configuration, DI\# B00000000-01717-0200-00089 Rev. 00, CRWMS M\&O, October 1993.

M\&O 1993f. Multi-Purpose Canister (MPC) Implementation Program Conceptual Design Phase Report, Volume I-MPC Conceptual Design Summary Report, Table 5-1, DI\# A20000000-00811-5705-00001 Rev. 00, CRWMS M\&O, September 1993.

M\&O 1993g. Multi-Purpose Canister (MPC) Implementation Program Conceptual Design Phase Report, Volume II A - MPC Conceptual Design Report, DI\# A20000000-00811-5705-00002 Final Draft, CRWMS M\&O, September 1993.

M\&O 1993h. Quality Administrative Procedure QAP-19-1, DI\# A00000000-017175001-00038 Rev. 03, CRWMS M\&O, October 1993.

M\&O 1993i. Mined Geological Disposal System Requirements Document, DI\# B00000000-00811-1708-00002 Rev. 01, CRWMS M\&O, February 1993.

M\&O 1993j. Repository Underground Ventilation System Concepts, DI\# B0000000001717-5705-00003 Rev. 00, CRWMS M\&O, September 1993.

M\&O 1993k. Andrews, R. W., T. F. Dale, and J. A. McNeish. Total System Performance Assessment - 1993: An Evaluation of the Potential Yucca Mountain Repository, DI\# B00000000-01717-2200-00099 Rev. 00, CRWMS M\&O, December 1993. 
M\&O 1993I. Waste Package Engineering Development Task Plan, DI\# B0000000001717-4600-00020 Rev. 00, CRWMS M\&O, September 1993.

M\&O 1993m. Thompson, A. O. Effect of Tuff Conductivity Variance on Waste Package Peak Fuel Temperatures, Interoffice Correspondence LV.WP.AOT.11/93.268, CRWMS M\&O, December 1993.

M\&O 1993n. Benton, H. A. Revision of Interoffice Correspondence and White Paper, LV.WP.HAB.12/93.278, CRWMS M\&O, December 9, 1993.

M\&O 1993o. Doering, T. W. Waste Package Design Interface Assumptions, Interoffice Correspondence LV.WP.TWD.1/94-029, CRWMS M\&O, January 29, 1993.

M\&O 1993p. Reserved.

M\&O 1993q. Multi-Purpose Canister (MPC) Implementation Program Conceptual Design Phase Report: Volume 5 - MPC Supporting Studies and Reports, DI\# A20000000-00811-5705-00008 Rev. 00 Final Draft, CRWMS M\&O, September 1993.

M\&O 1993r. Houseworth, James E. Waste Isolation Evaluation, Drilling of USW UZ-14 Through the Perched Water Zone, M\&O Technical Evaluation, DI\# BAAA0000001717-2200-00092 Rev. 00, CRWMS M\&O, November 1993.

M\&O 1993s. Memory, R. D. "Statement of Position on Rod Consolidation," Letter LV.SI.RDM.9/93-276, CRWMS M\&O, September 1993.

M\&O 1993t. Saterlie, S. F. "Waste Stream Analysis for the FY 1993 Systems Studies," Letter LV.SI.SFS.04/93-223, CRWMS M\&O, April 8, 1993.

M\&O 1993u. Vaka, G. A. Robins Engineers \& Constructors, Inc., Telephone communication with D. S. Einarson of CRWMS M\&O (Submitted to Las Vegas Local Records Center with Records Package 93-3104), June 2, 1993.

M\&O 1993v. Waste Package Design Status Report Fiscal Year 1993, DI\# B00000000-01717-5705-00007 Rev. 00, CRWMS M\&O, September 1993.

M\&O 1993w. Bahney, R. H. "Temperatures of Drift-Emplaced Waste Packages," Interoffice Correspondence LV.WP.RHB.06/93-108, CRWMS M\&O, 1993.

M\&O 1994a. ESF/Repository Interface -- Integrated Layout Description, DI\# BC00000000-01717-0200-00003 Rev. 00, CRWMS M\&O, 1994. 
M\&O 1994b. Repository Emplacement and Backfill Concepts and Operations Report, DI\# BC000000-01717-5705-00001 (In Process), CRWMS M\&O, July 1994.

M\&O 1994c. Generic Subsurface Layouts for Various Repository Thermal Loadings, DI\# BC0000000-01717-5705-00002 (In Process), CRWMS M\&O, July 1994.

M\&O 1994d. Wallin, W. E. "Response to Design Input Data Request dated March 23, 1994," Interoffice Correspondence, LV.WP.WEW.4/94.086, CRWMS M\&O, April 12, 1994.

M\&O 1994e. Topical Report on the Use of Burnup Credit for PWR SNF in Storage and Transportation Canisters/Cask Systems (In Process), CRWMS M\&O, September 1994.

M\&O 1994f. Initial Review/Analysis of Thermal and Neutronics Characteristics of Potential MPC/WP Filler Materials, DI\# BBA000000-01717-5705-00001 Rev. 00, CRWMS M\&O, May 1994.

M\&O 1994g. Tsai, F. C. and A. Smith. Preclosure Radiological Safety Assessment for the ESF, DI\# BAB000000-01717-2200-00006, CRWMS M\&O, April 1994.

M\&O 1994h. Elayer, R. W. Intended Use Report for Lynx Software System Ver. 1.0, Revision I (SCP:N/A), Letter LV.SB.RWE.6/94-075, CRWMS M\&O, June 1994.

M\&O 1994i. Gottlieb, P. Waste Package Design Basis Fuel Analysis, DI\# BBA000000-01717-0200-00012, Rev. 00 CRWMS M\&O, March 1994.

M\&O 1994j. Bonabian, S. TS North Ramp Stability Analysis, M\&O Package 2C Design Analysis, BABEAB000-01717-0200-00004 Rev. 00, CRWMS M\&O, June 1994.

M\&O 1994k. Reeves, M., N. A. Baker, and J. O. Duguid. Review and Selection of Unsaturated Flow Models, DI\# B00000000-01425-2200-00001 Rev. 00, CRWMS M\&O, 1994.

M\&O 19941. Roy, A. Materials Analysis for a Multi-Barrier Waste Package Design Concept, DI\# BBA000000-01717-0200-00001 Rev. 00, CRWMS M\&O, June 1994.

M\&O 1994m. Controlled Design Assumption Document, DI\# B00000000-01717-460000032 Rev. 00, CRWMS M\&O, June 1994.

M\&O 1994n. King, J. Data Transmittal: Summary Waste Package Heat Output Data for MPC Scenarios, Letter VA.SA.JK.06/94.066, CRWMS M\&O, June 17, 1994. 
M\&O 1994o. Segrest, A. M. Submittal of ESF/GROA Interface Drawings, DI\# BC0000000-01717-2100-89100 through 89105 Rev. 00 (SCP: N/A), Letter LV.SB.KKB.2/94-024, CRWMS M\&O, February 25, 1994.

M\&O 1994p. North Ramp Layout Calculation, DI\# BABEAD000-01717-0200-00003 Rev. 00, CRWMS M\&O, July 1, 1994.

M\&O 1994q. Subsurface Ventilation Concepts Report for Repository ACD - 1994, DI\# BC0000000-01717-5705-0004 (Draft), CRWMS M\&O, August 1994.

M\&O 1994r. "Compilation and Review of Backfill Literature," DI\# BBB000000-017175705-00001 Rev. 00, CRWMS M\&O, July 29, 1994.

M\&O 1994s. "Definition of Repository Block Limits," DI\# BC0000000-01717-020000003 Rev. 00, CRWMS M\&O, August 1994.

M\&O 1994t. Pye, J. H. TS North Ramp Ground Support Scoping Analysis, DI\# BABEA0000-01717-0200-00008 Rev. 01, CRWMS M\&O, 1994.

M\&O 1994u. Saterlie, S. F. and B. H. Thomson. FY93 Thermal Loading Systems Study Final Report, DI\# B00000000-01717-5705-00013 Rev. 00, CRWMS M\&O, January 1994.

M\&O 1994v. Seismic Design Inputs for the Exploratory Studies Facility at Yucca Mountain, DI\# BAB000000-01717-5705-00001 Rev. 01, CRWMS M\&O, 1994.

Marks, L. S. and T. Baumeister 1958. Marks' Mechanical Engineers' Handbook, Sixth Edition, McGraw-Hill, 1958.

McCright, R. D. and H. Weiss 1984. "Corrosion Behavior of Carbon Steels Under Tuff Repository Environmental Conditions," Proceedings Materials Research Society, Vol. 44, p. 287 (also LLNL Report UCRL-90875, October 1984).

Metals Handbook, Eighth Edition, Volume 6, Welding and Brazing, 1971.

Micke, R. P., J. D. Watson, and C. Young III 1994. "A Rock Excavation System Based on Penetrating Cone Fracture Technology," Proceedings of North American Tunneling '94 Conference and Exhibition, June 6, 1994.

Murray, G. T., H. Kuzuuv, and V. Klint, 1965. "Diffusion and Precipitation of Helium in Zirconium," Journal of Nuclear Materials, vol. 15, 1965.

NAC 1993. Safety Analysis Report for the NAC Storable Transport Cask, Rev. 2, 71-9235, Nuclear Assurance Corporation, July 1993. 
Nero, A.V̀., Jr. 1979. A Guidebook to Nuclear Reactors, University of California, 1979.

NRC 1985. "Safety Evaluation Report Related to the Topical Safety Analysis Report for CASTOR V/21 Dry Spent Fuel Storage Cask," U.S. Nuclear Regulatory Commission, September 1985.

NRC 1989. NRC Staff Site Characterization of the Department of Energy's Site Characterization Plan, Yucca Mountain Site, Nevada, NUREG-1347, Division of High-Level Waste Management, Office of Nuclear Material Safety and Safeguards, U.S. Nuclear Regulatory Commission, August 1989.

NRC 1993. Staff Technical Position on Consideration of Fault Displacement Hazards in Geologic Repository Design, NUREG-1ZZZ, public comment draft, U.S. Nuclear Regulatory Commission, March 1993.

Nucleon Lectern Associates 1984. Health Physics and Radiological Health Handbook, 1984.

NWTRB 1990. Nuclear Waste Technical Review Board, First Report To The U.S. Congress and The U.S. Secretary of Energy, Nuclear Waste Technical Review Board, March 1990.

ORNL 1978. Allen, E. J. Criticality Analysis of Aggregations of Actinides from Commercial Nuclear Waste in Geological Storage, ORNL/TM-6458, Oak Ridge National Laboratory, August 1978.

ORNL 1980. BUGLE-80, Coupled 47 Neutron, 20 Gamma-Ray, $P_{3}$, Cross-Section Library for LWR Shielding Calculations by the ANS 6.1.2 Working Group on Multigroup Cross Sections, Oak Ridge National Laboratory, August 1980.

ORNL 1993a. SCALE, Modular Code System for Performing Standardized Computer Analyses for Licensing Evaluation, Version 4.2, Oak Ridge National Laboratory, October 1993.

ORNL 1993b. Characteristics Data Base (CDB), Oak Ridge National Laboratory, 1993.

ORNL 1993c. DORT, Two-Dimensional Discrete Ordinated Transport Code, Oak Ridge National Laboratory, April 1993.

ORNL 1993d. SCALE-PC 1993. Modular Code System for Performing Criticality Safety Analyses for Licensing Evaluation, Version 4.1, Oak Ridge National Laboratory, June 1993. 
PBQ\&D 1989. Grieves, M. Alternative TBM Layout for the Repository, DCTR 88-PB04, Parsons, Brinkerhoff, Quade \& Douglas, Inc., 1989.

Peck, J. H., U. S. Clanton, C. R. Rautman, R.W. Spengler, and D. Vaniman 1991. Core Evaluation to Determine Contacts Between Thermal-Mechanical Units TSwl and TSw2, Letter to D.C. Dobson and J.R. Dyer, May 1991.

Pednekar, S. P. 1987. Corrosion of Carbon Steel in Aqueous Environments Below Boiling - A Literature Review," Final Report, Battelle, February 24, 1987.

PNL 1983a. "Control of Degradation of Spent LWR Fuel During Dry Storage in an Inert Atmosphere," PNL-6364, October 1987.

PNL 1983b. Johnson, A. B. and E. R. Gilbert. Mechanical Basis for Storage of Zircaloy-Clad Spent Fuel in Inert Gases, PNL-4835, Pacific Northwest Laboratory, 1983.

PNL 1983c. Guenther, R. J. "Results of Simulated Abnormal Heating Events for FullLength Nuclear Fuel Rods," PNL-4555, January 1983.

PNL 1986. Chin, B. A., M. A. Khan, and J. C. L. Tarn 1986. Deformation and Fracture Map Methodology for Predicting Cladding Behavior During Dry Storage, PNL5998, Pacific Northwest Laboratory, September 1986.

PNL 1987a. Cunningham, M. E., E. P. Simonen, R. T. Alleman, I. S. Levy, R. F. Hazelton, and E. R. Gilbert. Control of Degradation of Spent LWR Fuel During Dry Storage in an Inert Atmosphere, PNL-6364, Pacific Northwest Laboratory, October 1987.

PNL 1987b. Levy, I. S., C. E. Beyer, B. A. Chin, E. R. Gilbert, E. P. Simonen, and A. B. Johnson Jr. Recommended Temperature Limits for Dry Storage of Spent Light Water Reactor Zircaloy-Clad Fuel Rods in Inert Gas, PNL-61089, Pacific Northwest Laboratory, May 1987.

Popov, E. P. 1976. Mechanics of Materials, Second Edition, Prentice-Hall, Inc., 1976.

Powell, J. E. 1982. "Pneumatic Conveying Equipment for the Mining Industry," Bulk Solids Handling, vol. 2, no. 4, December 1982.

Powell, J. E. 1983. Letter from J. E. Powell (Beric Engineering, Co.) to R. Djahahanguiri (Office of Nuclear Waste Disposal - Battelle Project) with technical report: Salt Repository Backfilling, January 14, 1983. 
Pruess, K. and Y. Tsang 1993. "Modeling of Strongly Heat-Driven Flow Processes at a Potential High-Level Nuclear Waste Repository at Yucca Mountain, Nevada," Proceedings of the Fourth International Conference on High Level Radioactive Waste Management, April 1993.

Pruess, K. and Y. Tsang 1994. "Thermal Modeling for a Potential High-Level Nuclear Waste Repository at Yucca Mountain," Report LBL-35381, Lawrence Berkeley Laboratory, 1994.

Pruess, K. and Y. Wang 1987. "Numerical Modeling of Isothermal and Nonisothermal Flow in Unsaturated Fractured Rock - A Review in Flow and Transport through Unsaturated Fractured Rock," American Geophysical Union, Geophysical Monograph 42, 1987.

Raj, R. and M. F. Ashby 1975. "Intergranular Fracture at Elevated Temperature," Acta Metallurgica, vol. 23, 1975.

Reed-Hill, R. E. 1973. Physical Metallurgy Principles, 2nd Edition, D. Van Nostrand ed., 1973.

Roark, R. J. and W. C. Young 1982. Formulas for Stress and Strain, Fifth edition, McGraw-Hill Book Company, 1982.

Roberts, G. W. 1983. Quality Assurance in Research and Development, Babcock \& Wilcox, a McDermott Company, Marcel Dekker, Inc., 1983.

Rostami, J., D. Neil, and L. Ozdemir 1993. Roadheader Application for the Yucca Mountain Experimental Study Facility, Earth Mechanics Institute, Colorado School of Mines, October 1993.

RSN 1992. Wallin, W. E. "Cooling of Hot, Dry Emplacement Holes," Raytheon Services Nevada, September 1992.

RSN 1993. Daily Operations Report, Boring UE-25 UZ16, Job Package 92-03, Raytheon Services Nevada, 1993.

RSN 1994a. Daily Operations Report, Boring USW NRG-7/7A, Job Package 93-15, Raytheon Services Nevada, 1994.

RSN 1994b. Daily Operations Report, Boring USW SD-9, Job Package 94-07, Raytheon Services Nevada, 1994.

RSN 1994c. Daily Operations Report, Boring USW SD-12, Job Package 94-04, Raytheon Services Nevada, 1994. 
Ruffner, D. J., G. L. Johnson, E. A. Platt, J. A. Blink, and T. W. Doering 1993. "Drift Emplaced Waste Package Thermal Response," Proceedings of International High Level Radioactive Waste Management Conference, April 1993.

S. Cohen and Associates, Inc. 1990. Evaluation of Spent Nuclear Fuel as Mixed Waste, June 1990.

Schwartz, M. W. and M. C. Witte 1987. Spent Fuel Cladding Integrity During Dry Storage, UCID-21181, September 1987.

Shreir, L. L., ed. 1976. Corrosion, Volume 1: Metal/Environment Reactions, NewnesButterworths, 1976.

SNL 1981. Gartling, D. K., R. R. Eaton, and R. K. Thomas. Preliminary Thermal Analysis for a Nuclear Waste Repository in Tuff. SAND80-2813, Sandia National Laboratories, April 1981.

SNL 1982. Sundberg, W. and R. R. Eaton. 3-D Thermal Analysis for a Conceptual HLW Repository in Welded Tuff, SAND81-0215, Sandia National Laboratories, April 1982.

SNL 1984a. Jackson, J. L. Nevada Nuclear Waste Storage Investigations Preliminary Repository Concepts Report, SAND83-1877, Sandia National Laboratories, 1984.

SNL 1984b. Johnstone, J. K., R. R. Peters, and P. F. Gnirk. Unit Evaluation at Yucca Mountain, Nevada Test Site: Summary Report and Recommendation, SAND 830372, Sandia National Laboratories, 1984.

SNL 1984c. Mansure, A. J. and T. S. Ortiz. Preliminary Evaluation of the Subsurface Area Available for a Potential Nuclear Waste Repository at Yucca Mountain, SAND84-0175, Sandia National Laboratories, 1984.

SNL 1984d. Tillerson, J. R. and F. B. Nimick. Geoengineering Properties of Potential Repository Units at Yucca Mountain, Southern Nevada, SAND84-0221, Sandia National Laboratories, 1984.

SNL 1985a. Mansure, A. J. Underground Facility Area Requirements for a Radioactive Waste Repository at Yucca Mountain, SAND84-1153, Sandia National Laboratories, 1985.

SNL 1985b. Ortiz, T. S., R. L. Williams, F. B. Nimick, B. C. Whittet, and D. L. South. A Three-Dimensional Model of Reference Thermal/Mechanical and Hydrological Stratigraphy at Yucca Mountain, Southern Nevada, SAND84-1076, Sandia National Laboratories, 1985. 
SNL 1986. Klavetter, E. A. and R. R. Peters. Estimation of Hydrologic Properties of an Unsaturated Fractured Rock Mass, SAND84-2642, Sandia National Laboratories, 1986.

SNL 1987a. Nevada Nuclear Waste Storage Investigations Project, Site Characterization Plan Conceptual Design Report, SAND84-2641, Sandia National Laboratories, September 1987.

SNL 1987b. St. John, C. M. Reference Thermal and Thermal/Mechanical Analyses of Drifts for Vertical and Horizontal Emplacement of Nuclear Waste in a Repository in Tuff, SAND86-7005, Sandia National Laboratories, 1987.

SNL 1987c. Townes, G. A., W. L. Godfrey, and K. J. Anderson. Spent-Fuel Consolidation System, SAND84-7130, Sandia National Laboratories, September 1987.

SNL 1988. O'Brien, Paul D. OGR Repository-Specific Rod Consolidation Study: Effects on Costs, Schedules, and Operations at the Yucca Mountain Repository, SAND862357, Sandia National Laboratories, December 1988.

SNL 1990. Richardson, A. Preliminary Shaft Liner Design Criteria and Methodology Guide, SAND88-7060, Sandia National Laboratories, 1990.

SNL 1991a. Dennis, A. W., ed. Exploratory Studies Facility Alternatives Study: Final Report, SAND91-0025, Sandia National Laboratories, September 1991.

SNL 1991b. Hardy, M. P. and S. J. Bauer. Drift Design Methodology and Preliminary Application for the Yucca Mountain Site Characterization Project, SAND89-0837, Sandia National Laboratories, 1991.

SNL 1991c. Hertel, E. S. Jr. and E. E. Ryder 1991. Areal Power Density: A Preliminary Examination of Underground Heat Transfer in a Potential Yucca Mountain Repository and Recommendations for Thermal Design Approaches, SAND89-1989, Sandia National Laboratories, 1991.

SNL 1992a. Gertsch, R. and L. Ozdemir. Performance Predictions of Mechanical Excavators from Linear Cutter Tests on Yucca Mountain Welded Tuffs, SAND917038, Sandia National Laboratories, 1992.

SNL 1992b. Ozdemir, L., L. Gertsch, D. Neil, and J. Friant. Performance Predictions for Mechanical Excavators in Yucca Mountain Tuffs, SAND91-7035, Sandia National Laboratories, September 1992. 
SNL 1992c. Ryder, E. E. Equivalent Energy Density Concept: A Preliminary Reexamination of a Technique for Equative Thermal Loss, SAND91-1493, Sandia National Laboratories, August 1992.

SNL 1992d. Ryder, E. E. and J. Holland. Results of Two-Dimensional Near-Field Thermal Calculations in Support of an M\&O Study on Repository Thermal Loading, Draft, Sandia National Laboratories, 1992.

SNL 1992e. Ryder, E. E. Results of Two-Dimensional Near-Field Thermal Calculations in Support of an M\&O Study on Repository Thermal Loading, Draft, Sandia National Laboratories, 1992.

SNL 1993a. Data Transmittal Package for Yucca Mountain Site Characterization Project Geology and Rock Structure Log for Drillhole UE25 NRG-6, DTN: SNF29041993002.006, Sandia National Laboratories, November 1993.

SNL 1993b. Estimated Rock Mass Quality Indices Based on Core Log Data, Holes UE25 NRG-1, -2, -2A, -3, -4, -5, and USW NRG-6, DTN: SNF29041993002.011, Sandia National Laboratories, 1993.

SNL 1993c. Lin, M., M. P. Hardy, and S. J. Bauer. Fracture Analysis and Rock Quality Designation Estimation for the Yucca Mountain Site Characterization Project, SAND92-0449, Sandia National Laboratories, February 1993.

SNL 1993d. Lin, M., M. P. Hardy, and S. J. Bauer. Rock Mass Mechanical Property Estimations for the Yucca Mountain Site Characterization Project, SAND92-0450, Sandia National Laboratories, June 1993.

SNL 1993e. Ryder, E. E. Results of Two-dimensional Near-Field Thermal Calculations In Support of M\&O's Detailed Waste Package Simulations (Draft), Sandia National Laboratories, February 1993.

SNL 1994a. Data Transmittal Package for Yucca Mountain Site Characterization Project Geology and Rock Structure Log for Drillhole UE25 NRG-7/7A, DTN:

SNF29041993002.015, Sandia National Laboratories, March 1994.

SNL 1994b. Estimated Rock Mass Quality Indices Based on Core Log Data, Hole USW NRG-7, (In Process), Sandia National Laboratories, 1994.

SNL 1994c. Revisions to Geology and Rock Structure Logs for Drillholes UE25 NRG-6 and UE25 NRG-7/7A, (In Process), letter from C.E. Brechtel (Agapito \& Associates, Inc.) to Bob Elayer, June 8, 1994: Revised Estimates of Percent Lithophysal Cavities and Other Voids for Holes NRG-6 and 7/7A, Sandia National Laboratories, 1994. 
Spengler, R. W., C. A. Braun, L. G. Martin, and C. W. Weisenberg 1994. "The Sundance Fault: A Newly Recognized Shear Zone at Yucca Mountain, Nevada," Proceedings of the Fifth Annual International High-Level Radioactive Waste Management Conference, 1994.

T\&MSS 1994. North Ramp Borehole Study, geophysical logs for borings WT-2, UZ-16, NRG-4, NRG-5, and NRG-6, YMSCP, Drilling Support and Sample Management, information copy, Technical and Management Support Services, February 1994.

Taylor, R. E., H. Groot, and J. Larimore 1989. Thermal Conductivity of Aluminum-Boron Alloy, PRL 801, Properties Research Laboratory, May 1989.

UCID 1987. Swartz, M. W. and M. C. Witte. Spent Fuel Cladding Integrity During Dry Storage, UCID-21181, September, 1987.

USBR 1992. Soil and Rock Geotechnical Investigations, Field and Laboratory Studies, North Ramp Surface Facility, Exploratory Studies Facility, Yucca Mountain Project, Nevada (Boring NRG-1 Report), TM 3610-92-35, U.S. Bureau of Reclamation, November 1992.

USGS 1981. Spengler, R. W., F. M. Byers Jr., and J. F. Warner. Stratigraphy and Structure of Volcanic Rocks in Drill Hole USW-GI, Yucca Mountain, Nye County, Nevada, USGS-OFR-81-1349, U.S. Geologic Survey, 1981.

USGS 1983. Maldonado, F. and S. L. Keother. Stratigraphy, Structure, and Some Petrographic Features of Tertiary Volcanic Rocks at the USW G-2 Drill Hole, Yucca Mountain, Nye County, Nevada, USGS-OFR-83-732, U.S. Geologic Survey, 1983.

USGS 1984a. Scott, R. B. and M. Castellanos. Stratigraphic and Structural Relations of Volcanic Rocks in Drill Holes USW GU-3 and USW G-3, Yucca Mountain, Nye County, Nevada, USGS-OFR-84-491, U.S. Geologic Survey, 1984.

USGS 1984b. Spengler, R. W. and M. P. Chornac. Stratigraphic and Structural Characteristics of Volcanic Rocks in Core Hole USW G-4, Yucca Mountain, Nye County, Nevada, with a section on geophysical logs by D.C. Muller and J. Kibler, USGS-OFR-84-789, 1984.

USGS 1984c. Scott, R. B. and J. Bonk. Preliminary Geologic Map of Yucca Mountain, Nye County, Nevada, With Geologic Sections, USGS-OFR-84-494, U.S. Geologic Survey, 1984. 
USGS 1992. Fridrich, C. J., W. W. Dudley, Jr., and J. S. Stuckless. "Hydrogeologic Analysis of the Saturated-Zone Ground-Water System Under Yucca Mountain, Nevada," Journal of Hydrology, U.S. Geologic Survey, 1992.

USGS 1993a. Geslin, J. and T. Moyer. Graphical Lithologic Log of Borehole USW NRG-6, USGS/SAIC, DTN: GS931008314211.045, Ver. 1.1, U.S. Geologic Survey, November 1993.

USGS 1993b. Geslin, J. and T. Moyer. Graphical Lithologic Log of Borehole USW $N R G-7 \Pi A$, USGS/SAIC, DTN: GS940408314211.020, Ver. 1.1, U.S. Geologic Survey, November 1993.

USGS 1994a. Early Submittal of 3-D Site Lithostratigraphic Model, letter from L. Hayes to S. Jones, with attachment: Lynx Lithostratigraphic Model, Ver. YMP.RI.O, May 1994.

USGS 1994b. Spengler, R. Status of the Revised Nomenclature of the Paintbrush Group at Yucca Mountain, Memorandum from R. Spengler to M. Tynan, with attachment: Revised Stratigraphic Nomenclature and Macroscopic Identification of Lithostratigraphic Units of the Paintbrush Group Exposed at Yucca Mountain, Nevada, by D. C. Buesh, R. W. Spengler, T. C. Moyer, and J. K. Geslin, (In Process) USGS Open-File Report, U.S. Geological Survey, February 10, 1994.

Weast, R. C., ed. CRC Handbook of Chemistry and Physics, 1980, 61st ed., CRC Press, 1980.

Westinghouse 1982. Conceptual Waste Package Designs for Disposal of Nuclear Waste in Tuff, Westinghouse Electric Corporation, AESD-TME-3138, September 1982.

Westinghouse 1993. DWPF Waste Form Compliance Plan, WSRC-IM-91-116-0 Rev 2, Westinghouse Savannah River Company, June 1993.

White, M. D. and M. K. Altenhofen 1989. "A Sensitivity Study of Near-Field Thermal and Hydrological Conditions in Tuff," Proceedings of FOCUS '89, Nuclear Waste Isolation in the Unsaturated Zone, September 1989.

Whittaker, B. N. 1990. "Recent Advances in Mechanical Excavation," World Tunnelling and Subsurface Excavation, Vol. 3, No. 6, 1990.

Wilder, D. G. 1993. Preliminary Near-Field Environment Report, Volume II: Scientific Overview of Near-Field Environment and Phenomena, April 1993.

Wooton, R. O. and H. M. Epstein 1963. Heat Transfer from a Parallel-Rod Fuel Assembly in a Shipping Container, Battelle Memorial Institute, August 1963. 
YMP 1991a. Documentation of the Evaluation of Findings of the ESFAS Used to Develop a Reference Design Concept, YMP/91-28, Yucca Mountain Site Characterization Project, 1991.

YMP 1991b. Waste Package Design (Basis for Site Characterization Plan, Chapter 8) YMP/CM-0010 Rev. 00, Yucca Mountain Site Characterization Project, Chapter 8, April 1991.

YMP 1993a. Engineered Barrier Design Requirements Document, YMP/CM-0024

Rev. 0, Yucca Mountain Site Characterization Project, 1993.

YMP 1993b. Repository Design Requirements Document, YMP/CM-0023 Rev. 0, July 1993.

YMP 1993c. Reserved.

YMP 1993d. Reserved.

YMP 1993e. Reserved.

YMP 1993f. Waste Package Implementation Plan, YMP/92-11, Rev. 0, ICN 1, Yucca Mountain Site Characterization Project, September 1993.

YMP 1993g. Title I Design Summary Report for the Exploratory Studies Facility, YMP/92-40, Yucca Mountain Site Characterization Project, 1993.

YMP 1994a. Reference Information Base, YMP/93-02, Rev. 3, Yucca Mountain Site Characterization Project, March 1994.

YMP 1994b. "ESF Package 1A Starter Tunnel General Arrangement and Plan (Sht. 2)" Drawing No. YMP-025-1-MING-MG121 Rev. 3, Yucca Mountain Site Characterization Project, February 16, 1994. 


\subsection{STANDARDS AND REGULATIONS}

10 CFR 20. "Standards For Protection Against Radiation," Title 10, Code of Federal Regulations, Part 20.

10 CFR 60. "Disposal Of High-Level Radioactive Wastes in Geologic Repositories," Title 10, Code of Federal Regulations, Part 60, January 1, 1992, Edition.

10 CFR 71. "Packaging and Transportation of Radioactive Material," Title 10, Code of Federal Regulations, Part 71.

10 CFR 72. "Licensing Requirements for the Independent Storage of Spent Nuclear Fuel and HighLevel Radioactive Waste," Title 10, Code of Federal Regulations, Part 72.

10 CFR 960. "General Guidelines for the Recommendation of Sites for Nuclear Waste Repositories," Title 10, Code of Federal Regulations, Part 960.

29 CFR 1926. "Safety and Health Regulations for Construction," Title 29, Code of Federal Regulations, Part 1926.

30 CFR 57. "Safety and Health Standards Underground Metal and Nonmetal Mines," Title 30, Code of Federal Regulations, Part 57.

40 CFR 191. "Environmental Radiation Protection Standards For Management and Disposal of Spent Nuclear Fuel, High-Level and Transuranic Radioactive Waste," Title 40, Code of Federal Regulations, Part 191.

ANSI/ANS Standards: $8.1,8.3,8.5,8.6,8.7,8.9,8.10,8.12,8.13,8.15,8.17,8.20,57.2,57.3$, and 57.7. American National Standards Institute/American Nuclear Society.

ASME 1986. 1986 ASME Boiler and Pressure Vessel Code, Section III, Division 1-Appendices, American Society of Mechanical Engineers, July 1986.

CAC Title 8. "Industrial Relations," Chapter 4, "Division of Industrial Safety," Subchapter 20, "Tunnel Safety Orders," California Administrative Code.

SAE Specifications J444, "Specifications for Shot and Grit Screenings, Shot Tolerances," Society of Automotive Engineers. 
$a$

$\infty$

$n$

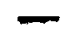

$\sim$

a

$\nabla$

$M$

on

\section{APPENDIX A \\ ACRONYMS}




\section{ACRONYM LIST}

\begin{tabular}{|c|c|}
\hline AASHTO & American Association of State Highway and Transportation Officials \\
\hline $\mathrm{ACD}$ & Advanced Conceptual Design \\
\hline ACGIH & American Conference of Government Industrial Hygienists \\
\hline $\mathrm{ACI}$ & American Concrete Institute \\
\hline ALARA & As Low As Reasonably Achievable \\
\hline AML & Areal Mass Loading \\
\hline ANS & American Nuclear Society \\
\hline ANSI & American National Standards Institute \\
\hline $\mathrm{AO}$ & Annotated Outline \\
\hline APD & Areal Power Density \\
\hline ASME & American Society of Mechanical Engineers \\
\hline ASTM & American Society for Testing and Materials \\
\hline ATL & Areal Thermal Loading \\
\hline AWS & American Welding Society \\
\hline BLM & U.S. Bureau of Land Management \\
\hline $\mathrm{BNL}$ & Brookhaven National Laboratory \\
\hline BWR & Boiling Water Reactor \\
\hline $\mathrm{C}$ & Celsius \\
\hline $\mathrm{CA}$ & Construction Authorization \\
\hline $\mathrm{CAC}$ & Configuration Audit Checklist \\
\hline $\mathrm{CCB}$ & Change Control Board \\
\hline CDA & Controlled Design Assumptions \\
\hline $\mathrm{CDB}$ & Characteristics Data Base \\
\hline CDR & Conceptual Design Report \\
\hline CFR & Code of Federal Regulations \\
\hline $\mathrm{CH}$ & Calico Hills \\
\hline $\mathrm{CHn}$ & Calico Hills Non-welded \\
\hline $\mathrm{CI}$ & Configuration Item \\
\hline CMAA & Crane Manufacturer's Association of America \\
\hline
\end{tabular}


CMF - Cask Maintenance Facility

COBRA-SFS Name of a Computer Program

COYOTE Name of a Computer Program

CRA Control Rod Assemblies

CRWMS Civilian Radioactive Waste Management System

CSM Colorado School of Mines

CTS Construction and Tunneling Services, Inc.

CWA Clean Water Act of 1977

DCCG Diffusion Controlled Gravity Growth

DEIS Draft Environmental Impact Statement

DHLW Defense High-Level Waste

DOE U.S. Department of Energy

DRD Design Requirements Document

DU Depleted Uranium

EBDRD Engineered Barrier Design Requirements Document

EB Engineered Barrier

EBW Electron Beam Welding

EED Equivalent Energy Density

EG\&G EG\&G, Inc.

EIA Energy Information Agency

EIS Environmental Impact Statement

EPA U.S. Environmental Protection Agency

ESF Exploratory Studies Facility

ESFAS Exploratory Studies Facility Alternatives Study

FEIS Final Environmental Impact Statement

FEM Finite Element Method

FIDAP Fluid Dynamics Analysis Program (Computer Program)

FPCD Final Procurement and Construction Design

FY Fiscal Year

GENISES Geographic Nodal Information Study and Evaluation System (Computer Program)

GMAW Gas Metal Arc Welding 


\begin{tabular}{ll} 
GROA & Geologic Repository Operations Area \\
GWd/MTU & Gigawatt-Day per Metric Ton of Uranium \\
GWTT & Ground Water Travel Time \\
HEPA & High-Efficiency Particulate Air (filter) \\
HEATING & Name of a Computer Program \\
HFS & Human Factors Society \\
HLF & High Level Finding \\
HLW & High Level Waste \\
HLWC & High Level Waste Canisters \\
HLWG & High Level Waste Glass \\
HVAC & Heating, Ventilation, and Air Conditioning \\
IAEA & International Atomic Energy Agency \\
IC & Integrated Circuits \\
I-DEAS & Integrated Design Engineering Analysis Software (Computer Program) \\
ISDOP & In-Small-Drift-On-Pedestal \\
IES & Institute of Environmental Scientists \\
IFF & Initial Fuel First \\
ISDOR & In-Small-Drift-On-Rail \\
ISR & Initial Summary Report \\
KBS & Kärnbränslesäkerhet \\
kW & Kilowatt \\
LA & License Application \\
LAD & License Application Design \\
LANL & $\quad$ Los Alamos National Laboratory \\
LBL & Lawrence Berkeley Laboratory \\
LLNL & Lawrence Livermore National Laboratory \\
LSA & Logistics Support Analysis \\
LWR & Light Water Reactor \\
MATPRO & Name of a Computer Program \\
MCNP & Monte Carlo Neutron and Photon Transport Core \\
MGDS & Mined Geologic Disposal System \\
\hline
\end{tabular}


MIC

Microbiologically Influenced Corrosion

MMB

Metallic Multibarrier

$\mathrm{M} \& \mathrm{O}$

Management and Operating Contractor

$\mathrm{MPa}$

Megapascals

MPC

Multi-Purpose Canister

MRS

Monitored Retrievable Storage

MSHA

Mine Safety and Health Administration

MTA

Main Test Area

MTIHM

Metric Ton of Initial Heavy Metal

MTL

Main Test Level

MTU

Metric Tons of Uranium

MWD

Megawatt Days

NAC

Nuclear Assurance Corporation

NDE

Non-Destructive Examination

NEPA

National Environmental Policy Act of 1969

NFPA

National Fire Protection Association

NGW

Narrow Gap Welding

NPDES

National Pollutant Discharge Elimination System

NRC

U.S. Nuclear Regulatory Commission

NTS

Nevada Test Site

NWPA

Nuclear Waste Policy Act of 1982

NWTRB

Nuclear Waste Technical Review Board

OCRWM

Office of Civilian Radioactive Waste Management

OFF

Oldest Fuel First

OGR

Office of Geologic Repositories

ORNL RSIC Oak Ridge National Laboratory Radiation Shielding Information Center OSHA

Occupational Safety and Health Administration

OSTS

$$
\text { Office of Storage and Transportation Systems }
$$

PA

Performance Assessment

PACS

Planning and Control System (Computer Program)

PATRAN

Name of a Computer Program 


\begin{tabular}{ll} 
PCF & Penetrating Cone Fracture \\
PNL & Pacific Northwest Laboratory \\
POC & Products of Combustion \\
PPA & Proposed Program Approach \\
PTn & Paintbrush Tuff Non-welded \\
PWR & Pressurized Water Reactor \\
Q & Quality Factor \\
QA & Quality Assurance \\
QAP & Quality Administrative Procedure \\
QARD & Quality Assurance Requirements and Description \\
RADDB & Radiological Database \\
RCP & Regulatory Compliance Plan \\
RCRA & Resource Conservation and Recovery Act of 1976 \\
RD & Requirements Document \\
RDRD & Repository Design Requirements Document \\
REECo & Reynolds Electrical and Engineering Company, Inc. \\
RIB & Reference Information Base \\
RIP & Repository Integration Plan \\
RSIC & Radiation Shielding Information Center \\
RMC & Rock Mass Category \\
RMR & Rock Mass Rating \\
RN & Radionuclides \\
ROD & Record of Decision \\
RQD & Rock Quality Designation \\
RSN & Raytheon Services Nevada \\
SAE & Society of Automotive Engineers \\
SCC & Substantially Complete Containment \\
SCP-CD & Site Characterization Plan Conceptual Design \\
SCP-CDR & Site Characterization Plan Conceptual Design Report \\
SDRC & Structural Dynamics Research Corporation \\
SFAs & Spent Fuel Assemblies \\
\hline
\end{tabular}




\begin{tabular}{ll} 
SIP & Scientific Investigation Plan \\
SMACNA & Sheet Metal and Air Conditioning Contractors National Association \\
SNF & Spent Nuclear Fuel \\
SNL & Sandia National Laboratories \\
SRR & Site Recommendation Report (DOE/HO 3-1) \\
TCLP & Toxicity Characteristic Leaching Procedure \\
TBD & To Be Determined \\
TBM & Tunnel Boring Machine \\
TBR & To Be Resolved \\
TBV & To Be Verified \\
TDPP & Technical Document Preparation Plan \\
T/M & Thermal/Mechanical \\
T\&MSS & Technical and Management Support Services \\
TOPAZ & Name of a Computer Program \\
TP & Test Plan \\
TRD & Technical Requirements Document \\
TS & Topopah Spring \\
TSL & Topopah Spring Level \\
TSLCC & Total System Life Cycle Cost \\
TSPA & Total System Performance Assessment \\
TSS & Technical Site Suitability \\
TSw & Topopah Spring welded \\
UCF & Uncanistered Fuel \\
UCRL & University of California Research Laboratory \\
UCS & Uniaxial or Unconfined Compressive Strength \\
UE & Underground, Exploratory (Drill Hole Designation) \\
UNS & Unified Numbering System for Metals and Alloys \\
USBR & U.S. Bureau of Reclamation \\
USGS & U.S. Geological Survey \\
USW & Underground, Southern Nevada, Waste (Drill Hole Designation) \\
UZ & Unsaturated Zone \\
\hline
\end{tabular}


V-TOUGH - Vectorized Transport of Unsaturated Groundwater and Heat (Computer Program)

WA Waste Acceptance

WF Weighting Factors

WHB Waste Handling Building

WP/EBS Waste Package/Engineered Barrier System

WP Waste Package

WPD Waste Package Development

YFF Youngest Fuel First

YFF10 Youngest Fuel First 10 Years or Older

YMIM Yucca Mountain Integrating Model

YMP Yucca Mountain Site Characterization Project

YMSCO Yucca Mountain Site Characterization Office 


\section{APPENDIX B \\ WASTE PACKAGE CONCEPTUAL DESIGNS}

a

$\mathbf{8}$

$m$

$\sigma$ 


\section{WASTE PACKAGE CONCEPTUAL DESIGNS}

Design layouts for six specific designs, representing three waste package design concepts, are included in this appendix, located in a separate bound figure set. The large $21 \mathrm{PWR} / 40 \mathrm{BWR}$ MPC disposal container is shown on Figures B.1-1 through B.1-4. The intermediate 12

PWR/24 BWR MPC disposal container is shown on Figures B.1-5 through B.1-8. The 21 PWR waste package with interlocking basket is shown on Figures B.2-1 through B.2-15. The 12 PWR waste package with interlocking basket is shown on Figures B.2-16 through B.2-30. The 12 PWR waste package with tube type basket is shown on Figures B.3-1 through B.3-11. The 24 BWR waste package with tube type basket is shown on Figures B.3-12 through B.321. 
0

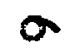

$N$

$-$

APPENDIX C

SPECIFICATION LIST 


\section{SPECIFICATION LIST}

Information for this appendix has not been developed to date. This work will be performed before completion of ACD in FY 1996. 


\section{APPENDIX D \\ EQUIPMENT LIST}

$\sigma$
$\sigma$
-
$\sigma$

B00000000-01717-5705-00015 Rev 00

$08 / 29 / 94$ 


\section{EQUIPMENT LIST}

Information for this appendix has not been developed to date. This work will be performed before completion of ACD in FY 1996.

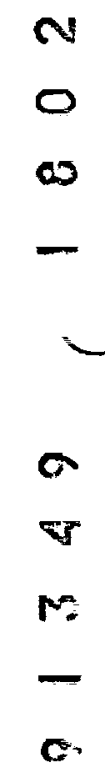


$m$

0

$\infty$

$-$

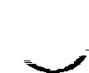

$\sigma$

$\mathbf{Y}$

$m$

0

\section{APPENDIX E}

\section{WHB OPERATIONS FLOW CHARTS}




\section{APPENDIX E \\ WHB OPERATIONS FLOW CHARTS}

$a$
$\sigma$
-
$a$ 


\section{Loaded Cask Operations}

in

$\varnothing$

os

$-$

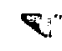

$r$

c

$E-2$ 

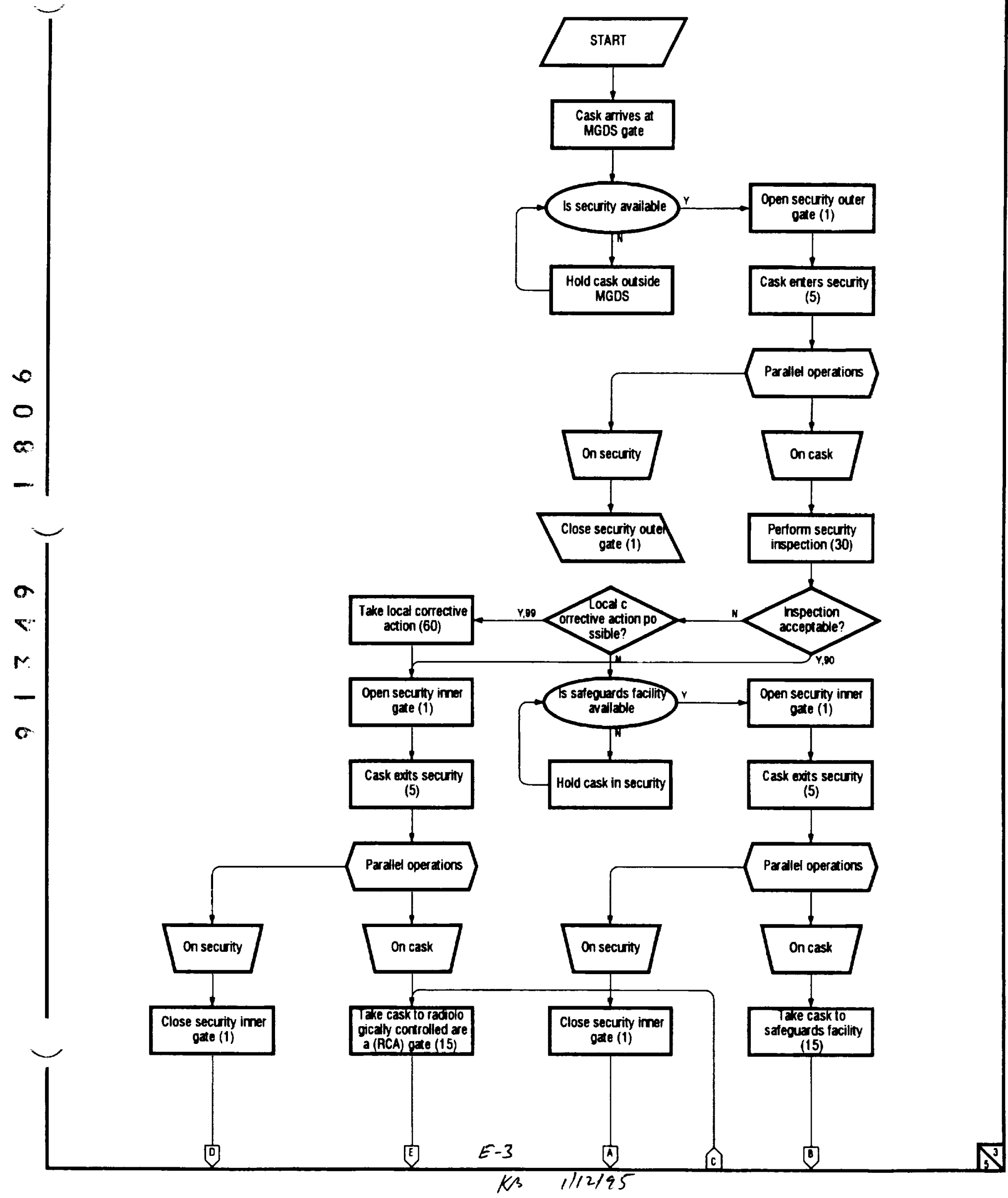

0
$\mathrm{C}$
$\mathrm{C}$ 

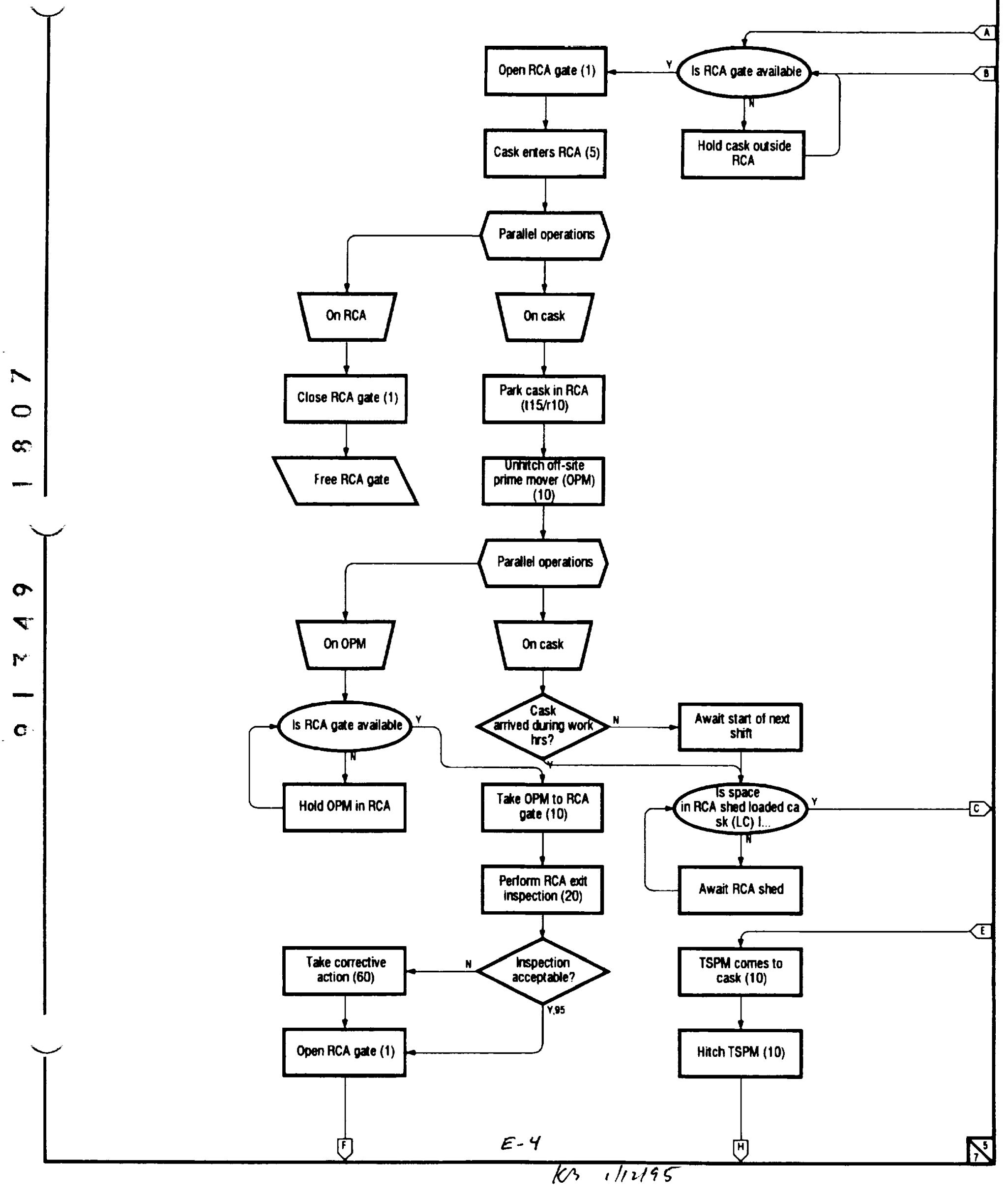


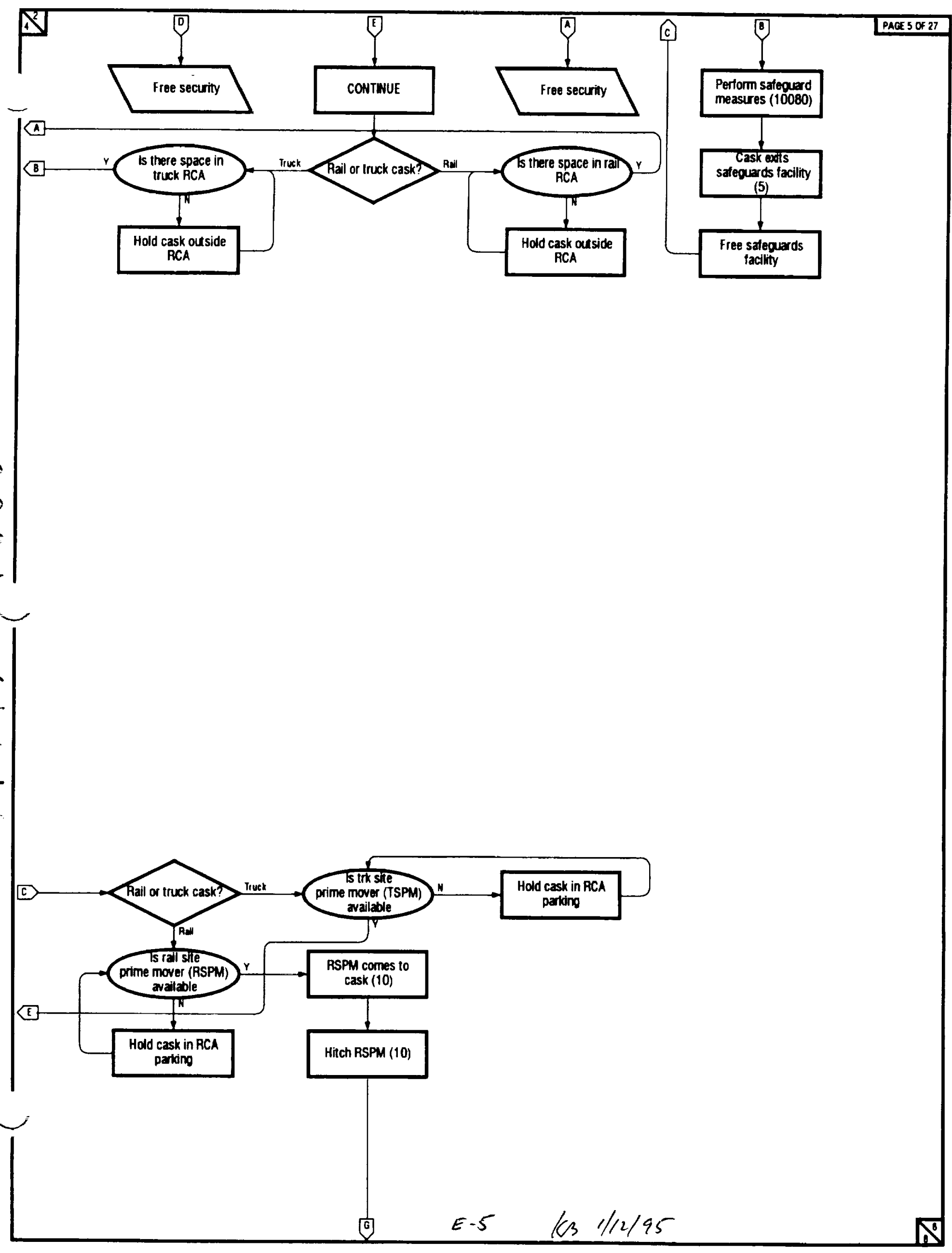




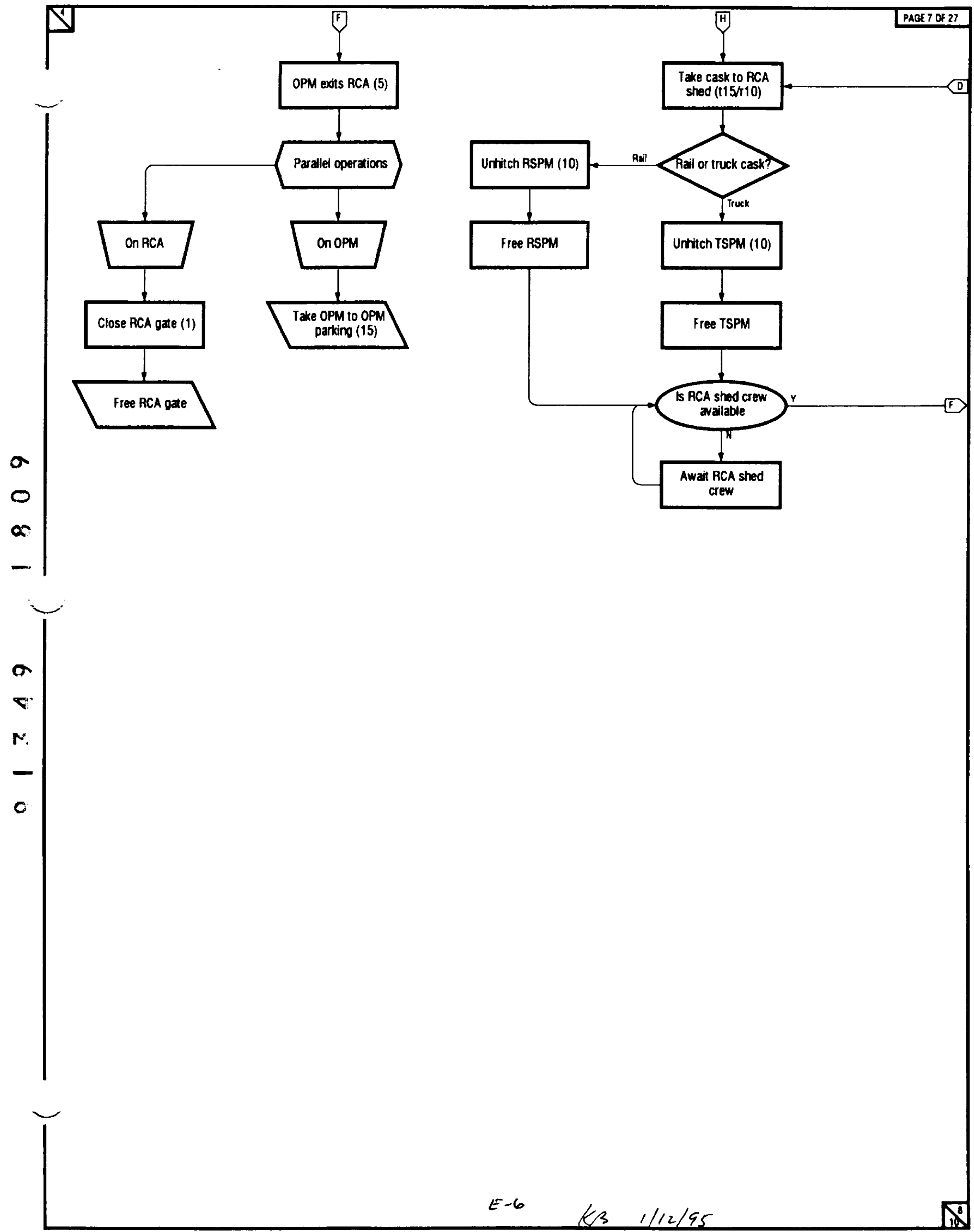




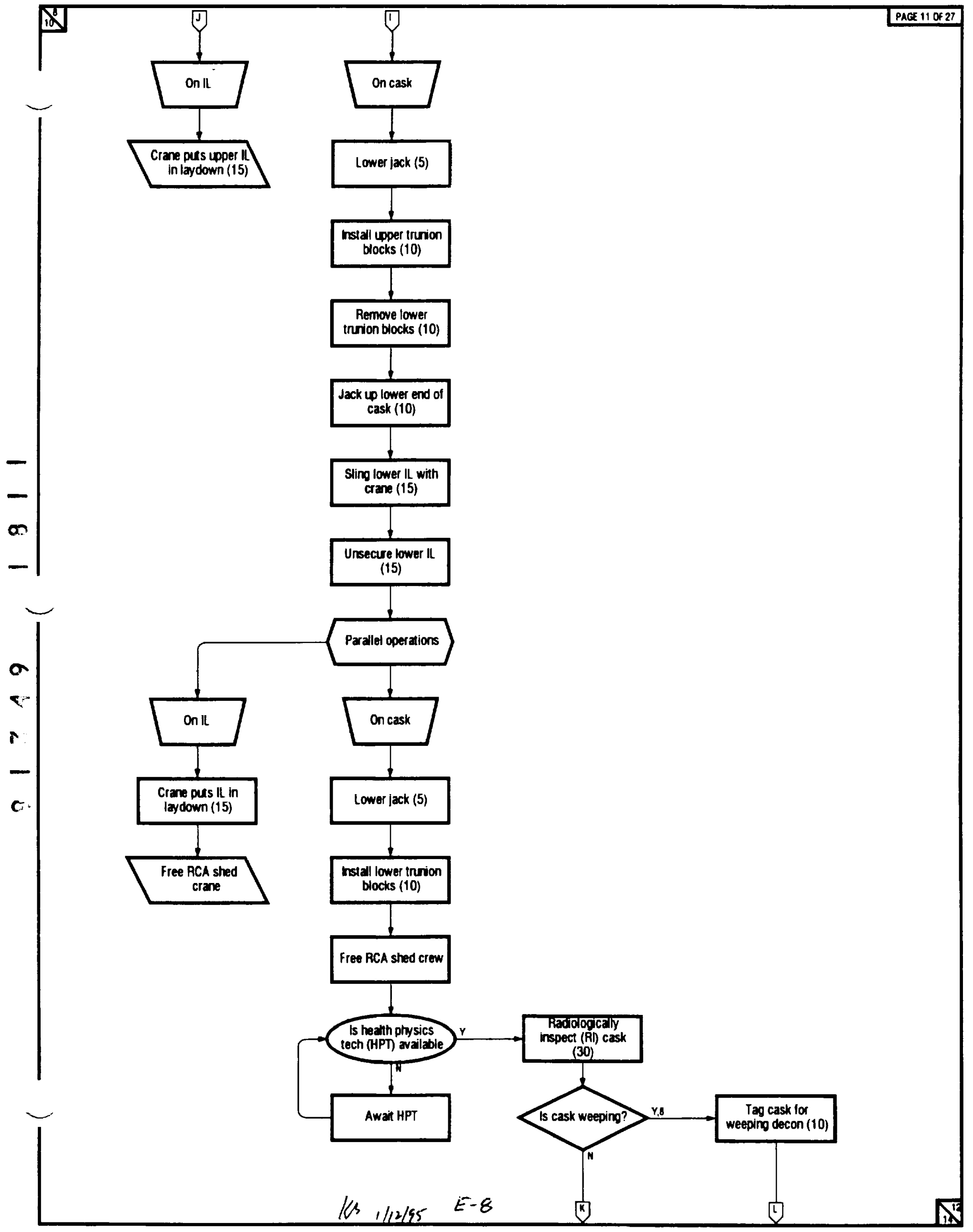




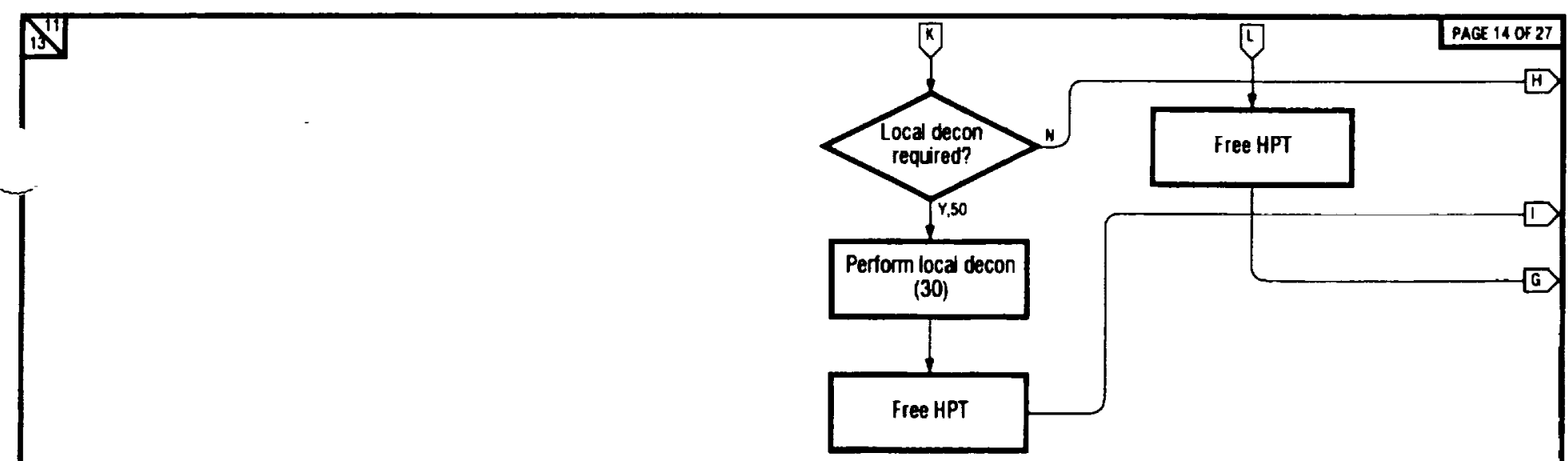

$a$
-
-
-

0 


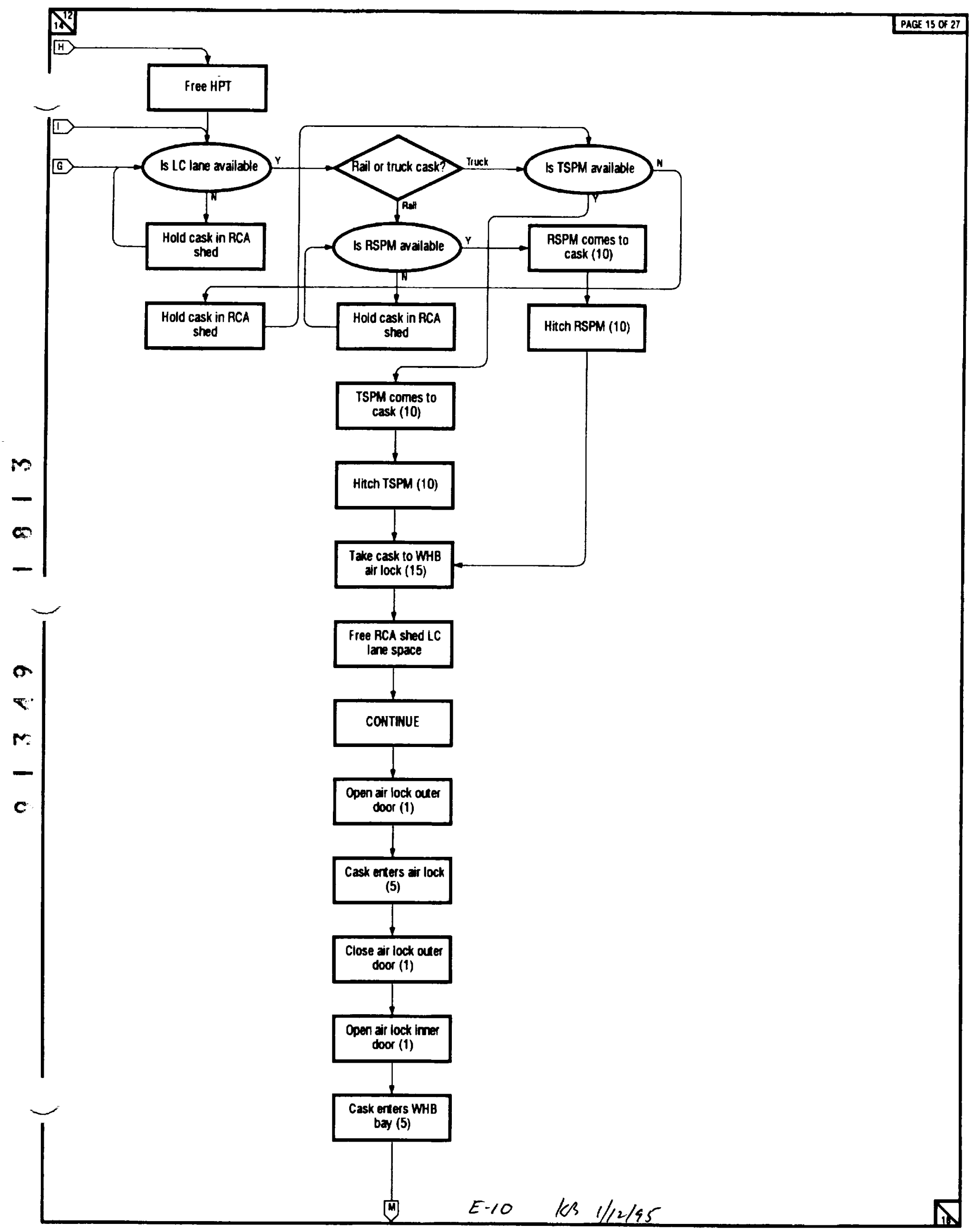


Rernove upper

irurion blocks (10)

$a$
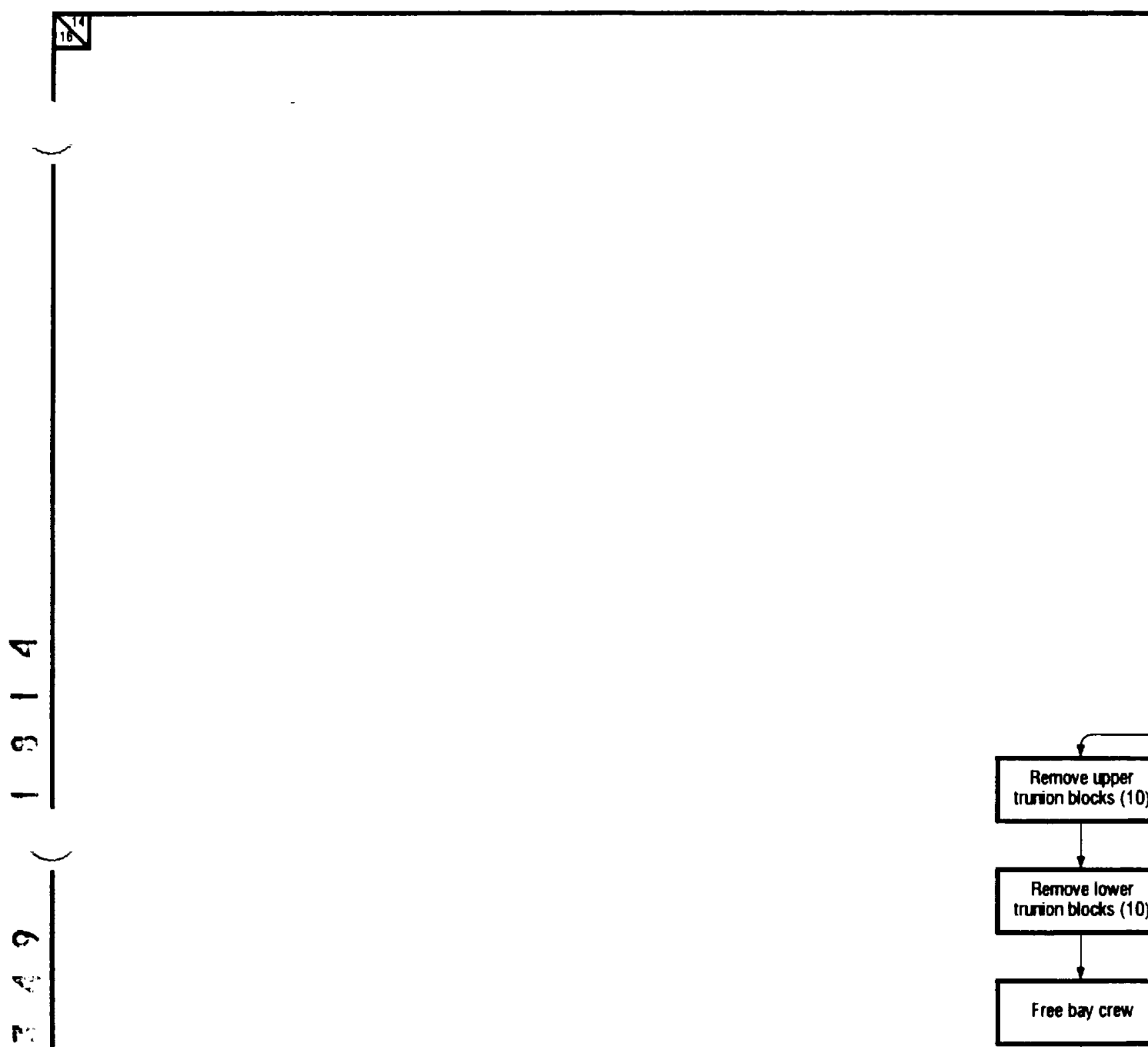

Remove lower

trurion blocks (10)

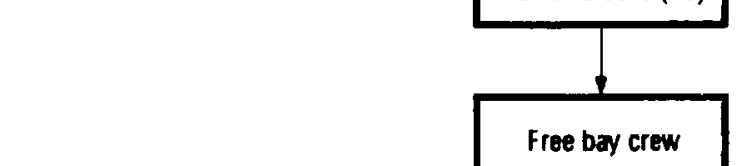

Free bay crew

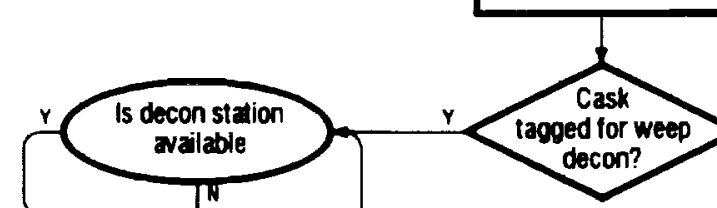

Await decon station

1

n

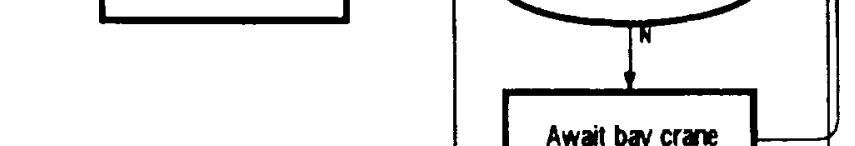

Await bay crane

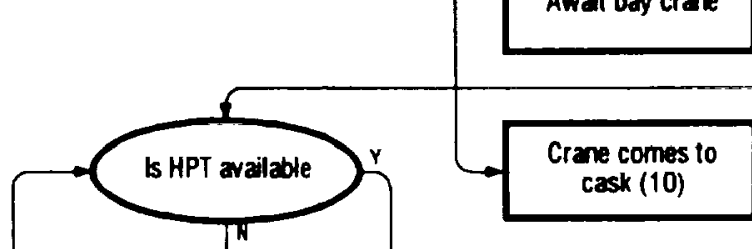

Await HPT

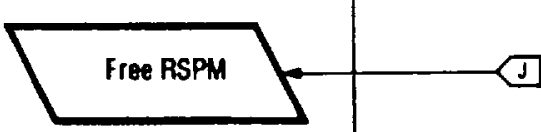

KB E-11 


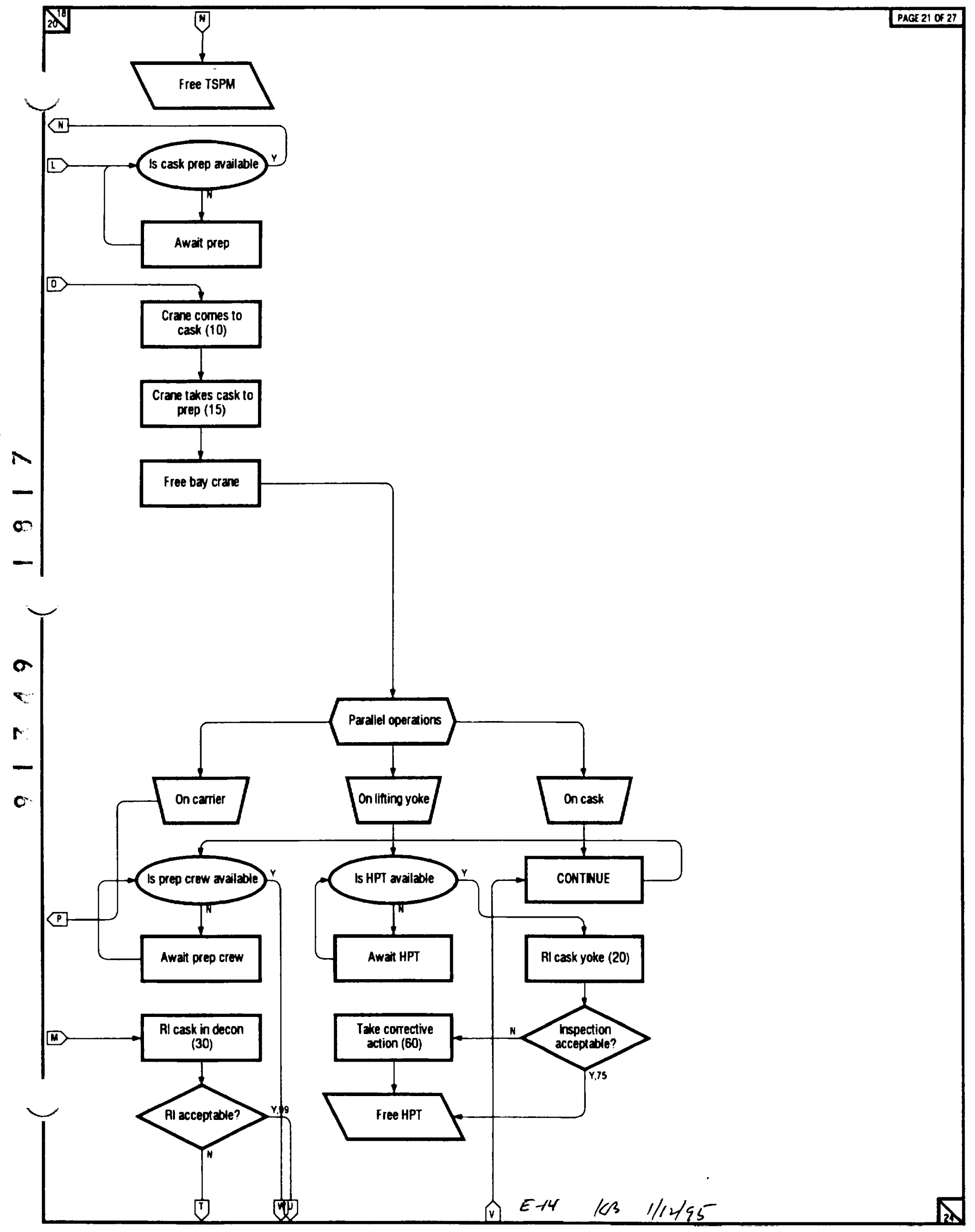




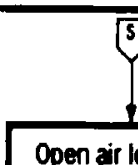

Close air lock imer door (1)

Carrier erters air lock (5)

door (1)

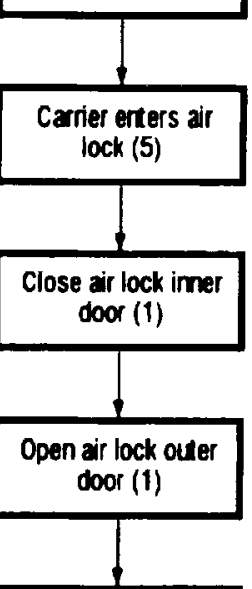

Carrier exits air lock

(5)

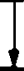

Close air lock outer door (1)

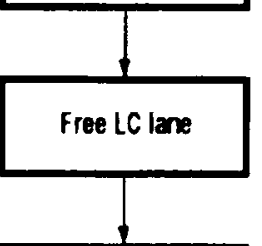

Take cartier to RCA parking (15)

a

$\nabla$

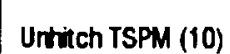

Rail of truck carier? Untritch RSPM (10)

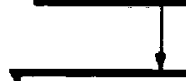

Free RSPM 


\section{Cell Operations}

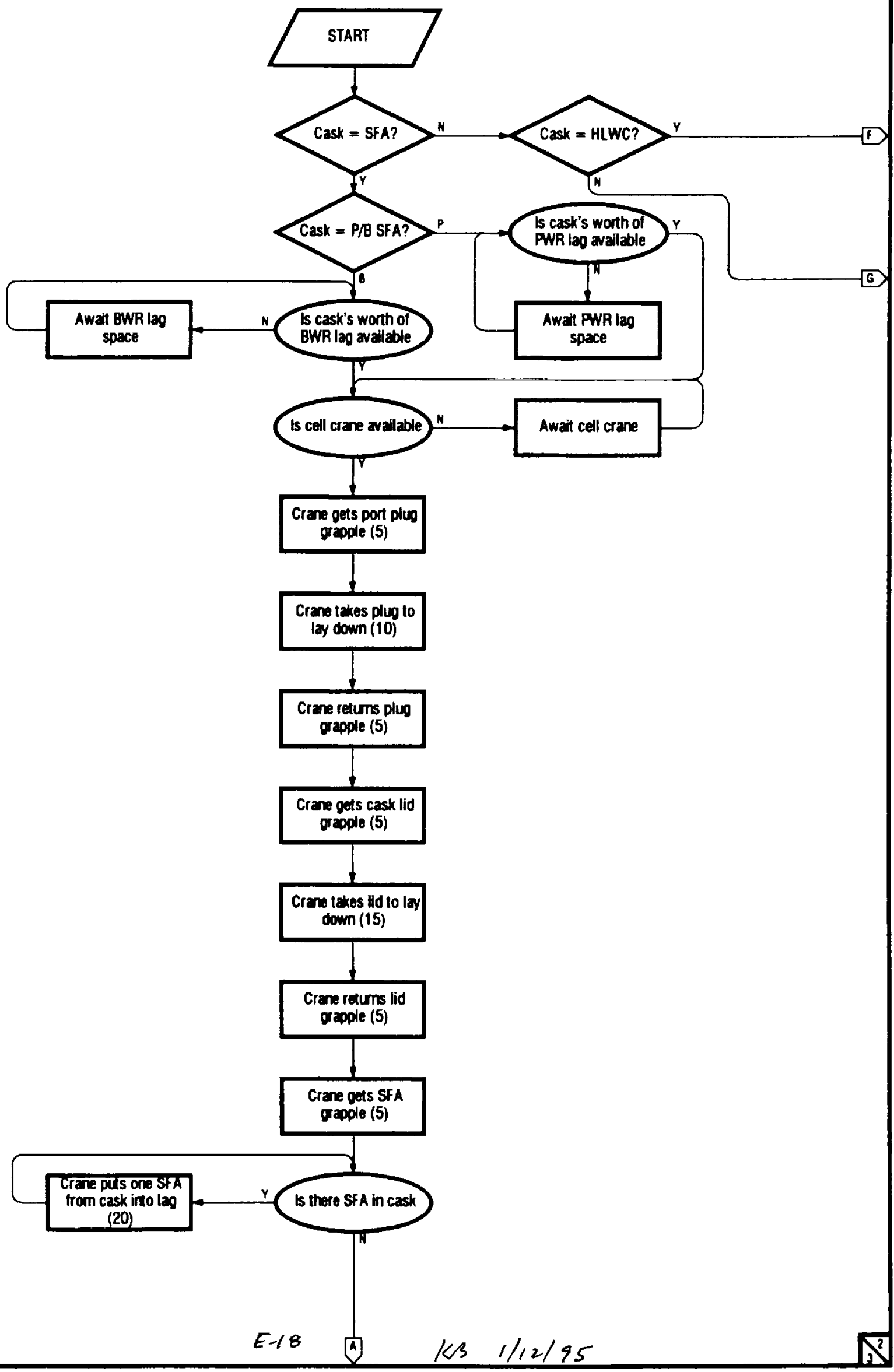


1

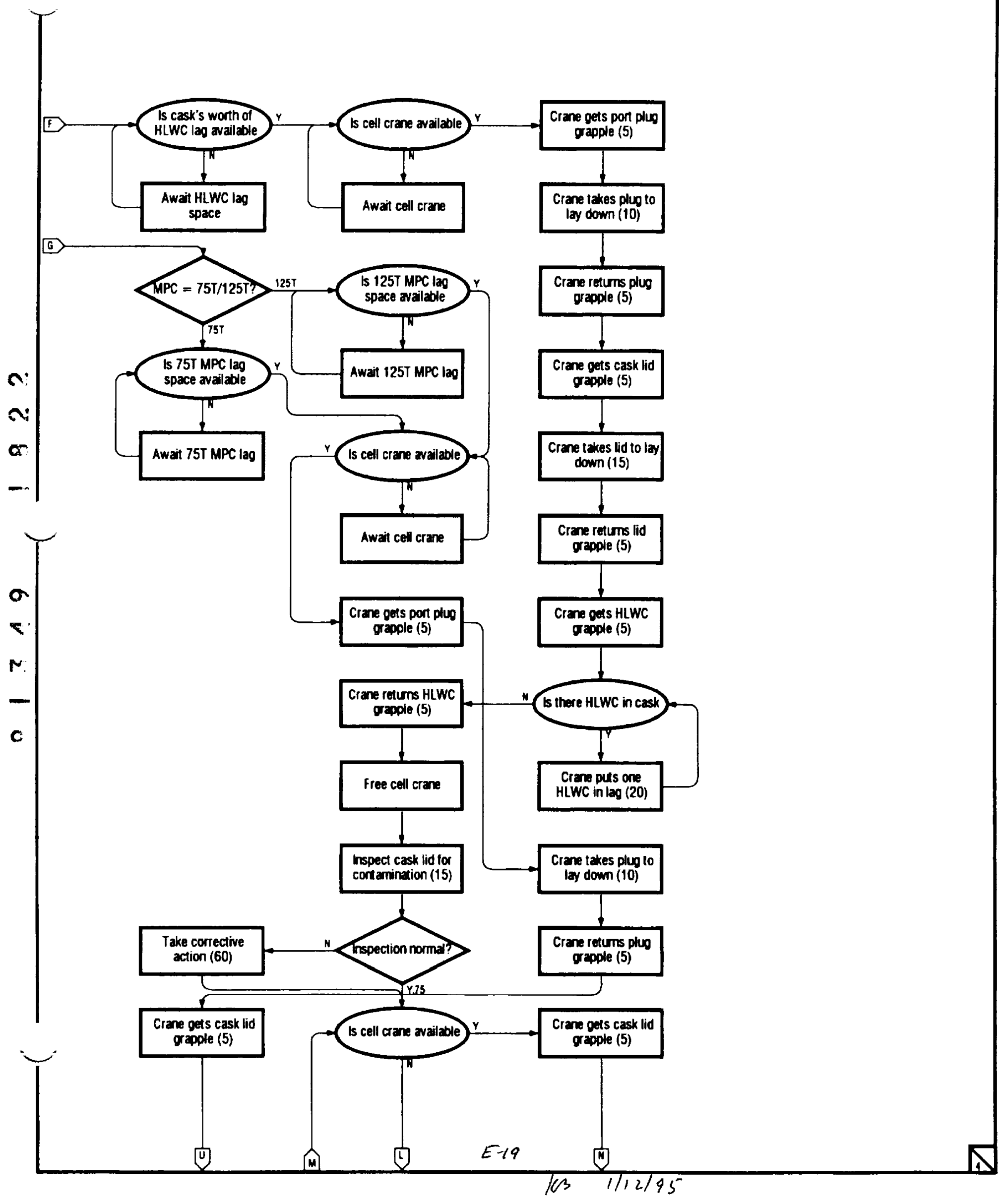




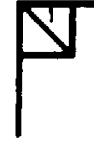

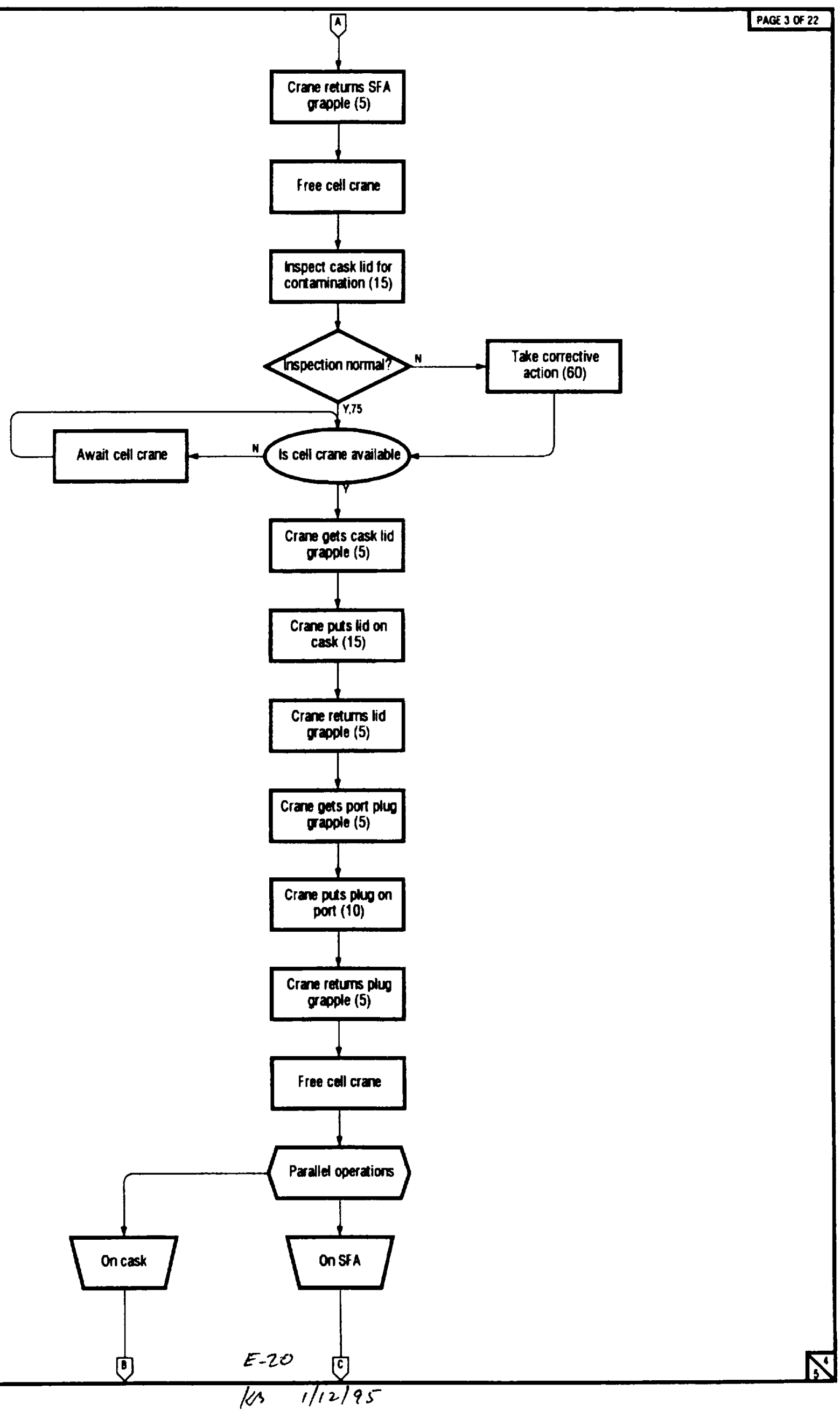




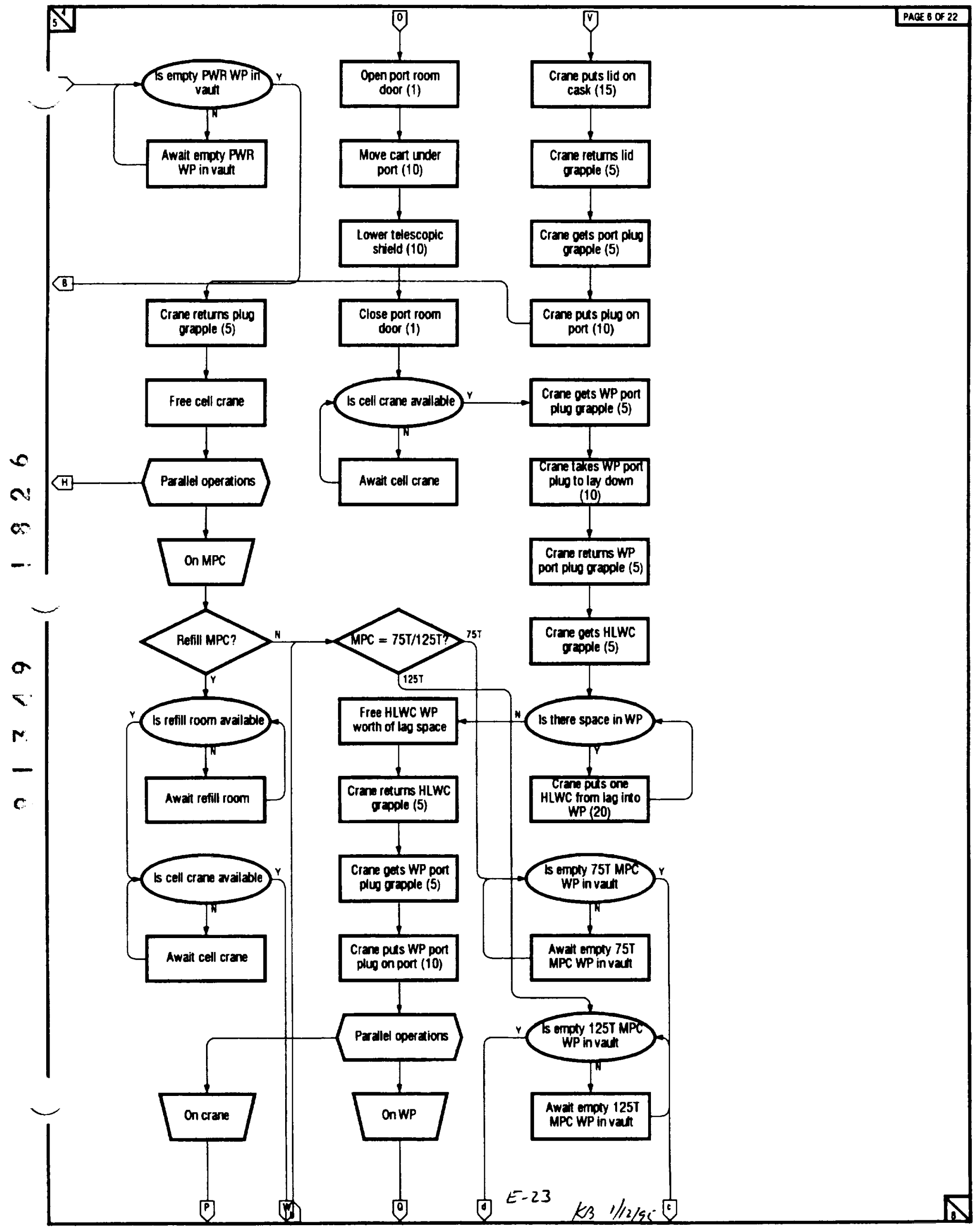




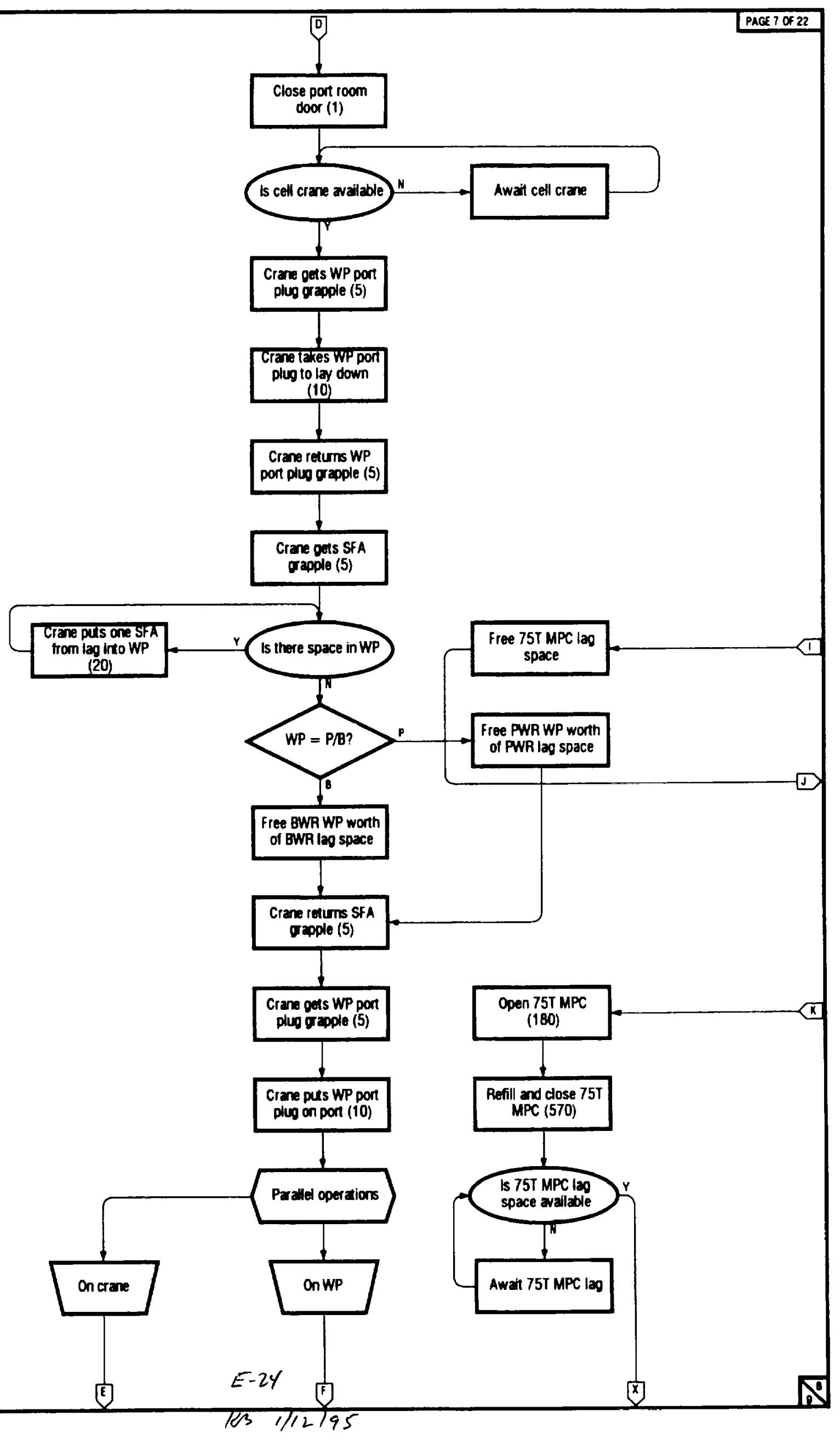




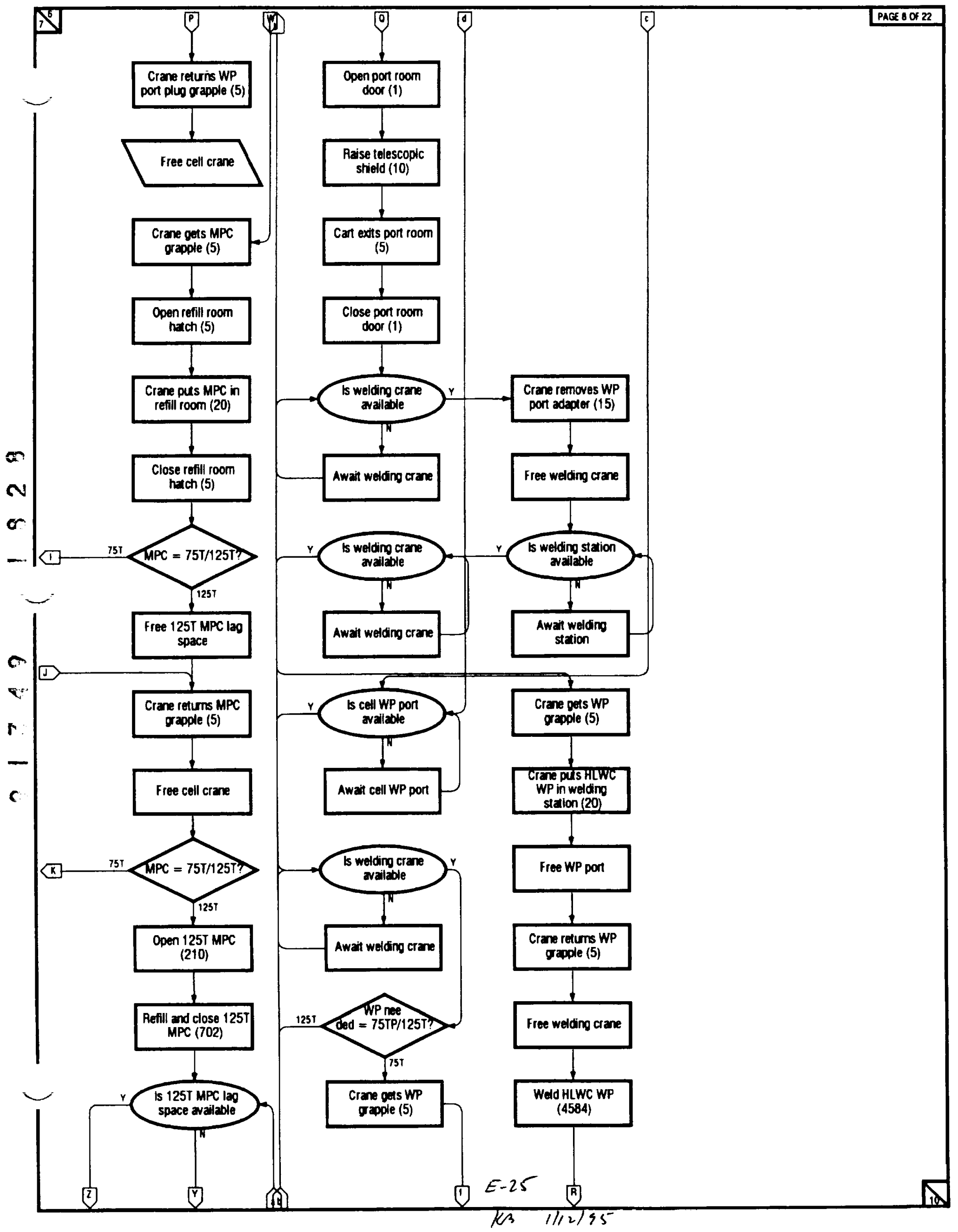




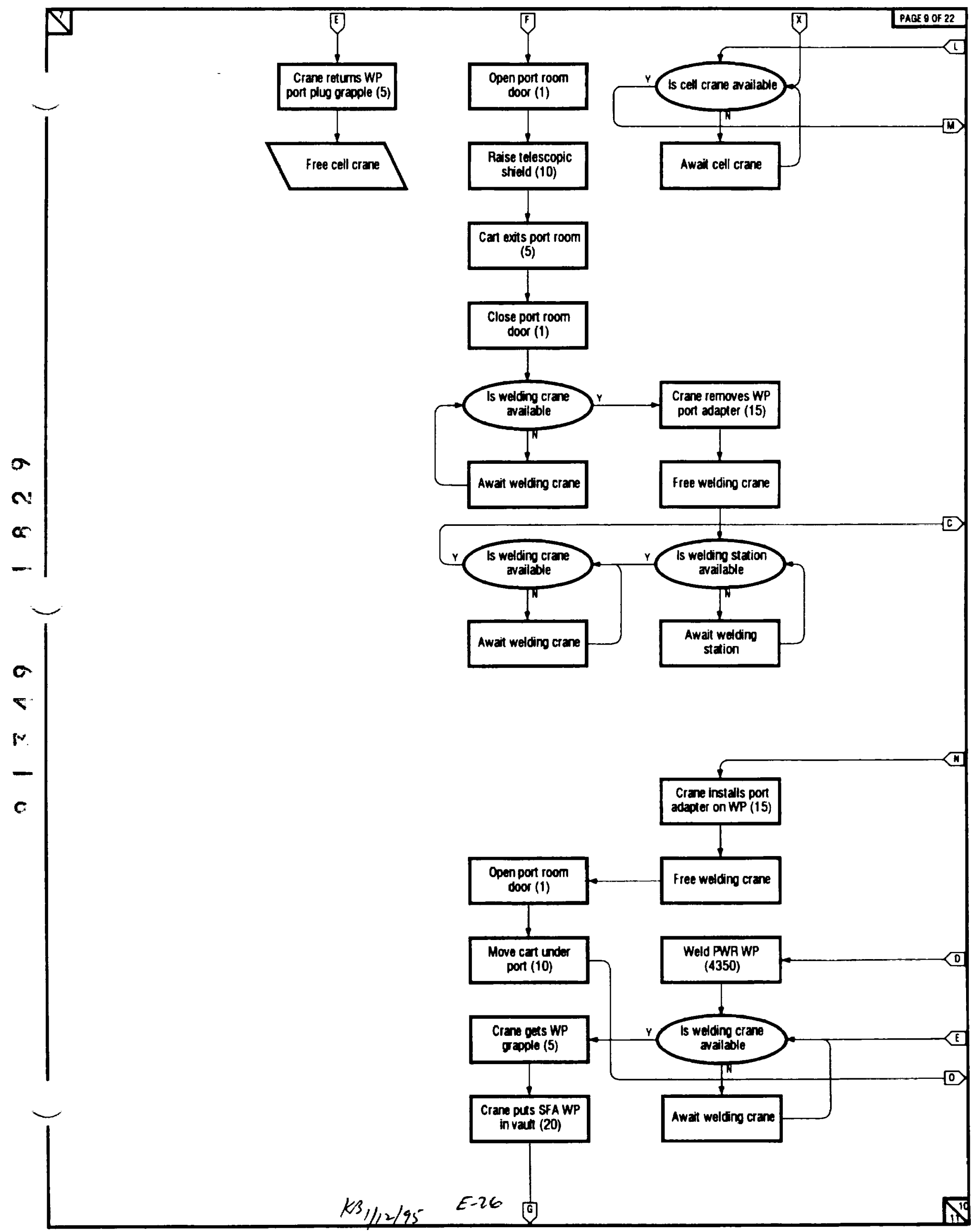



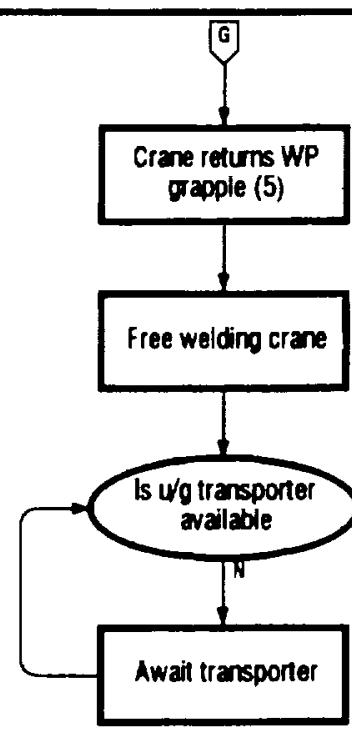

Open vast outer door (5)

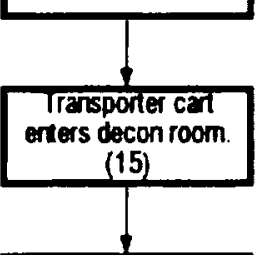

Close vaut outer door (5)

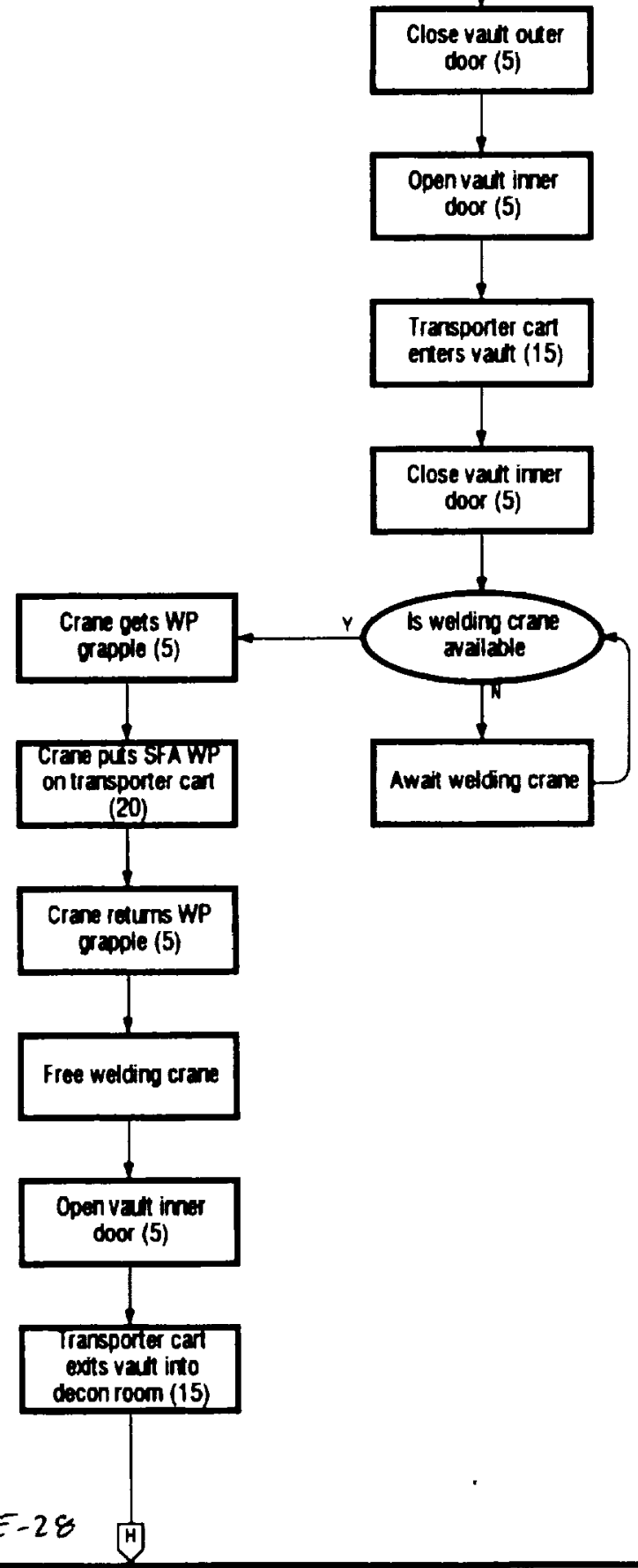




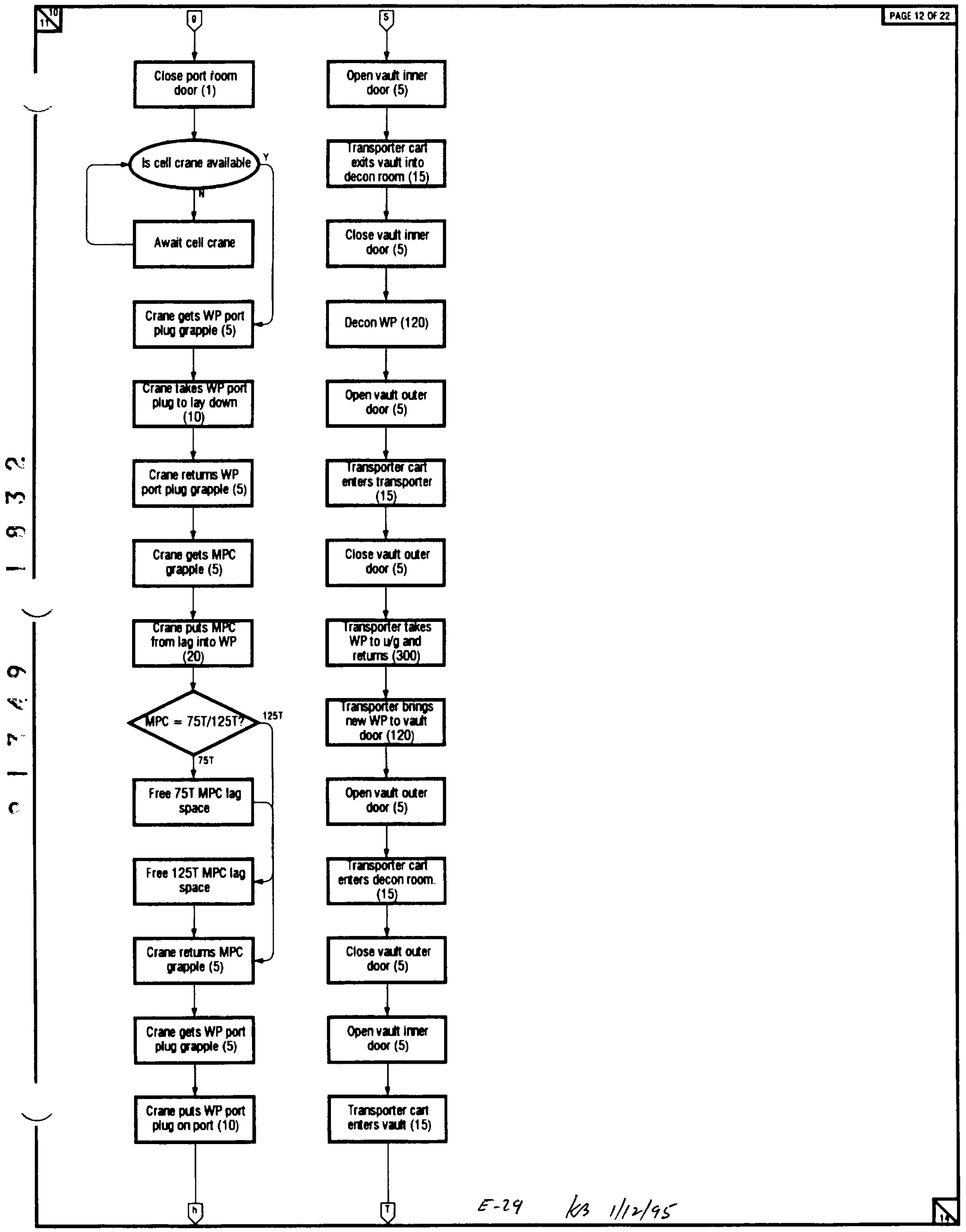




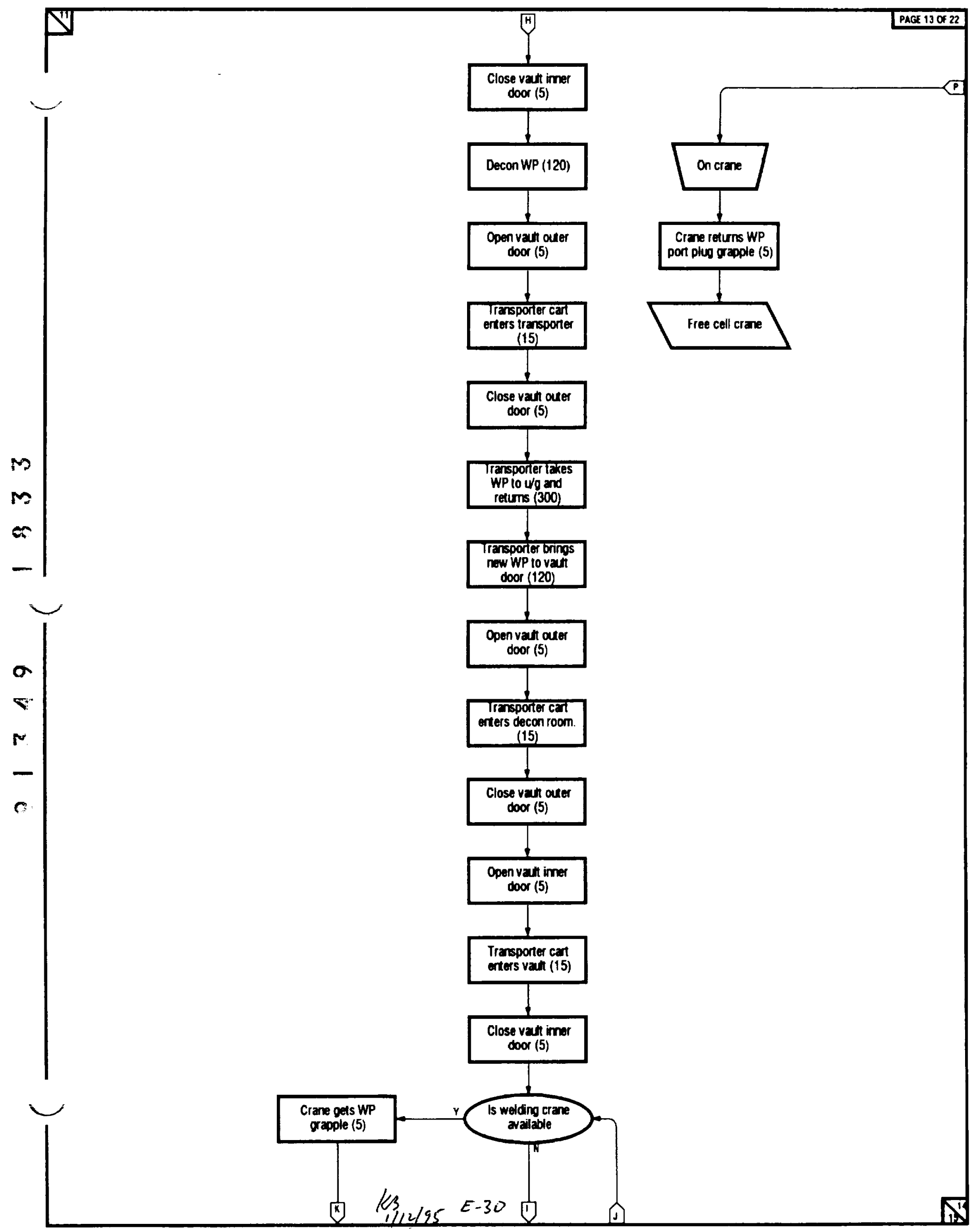




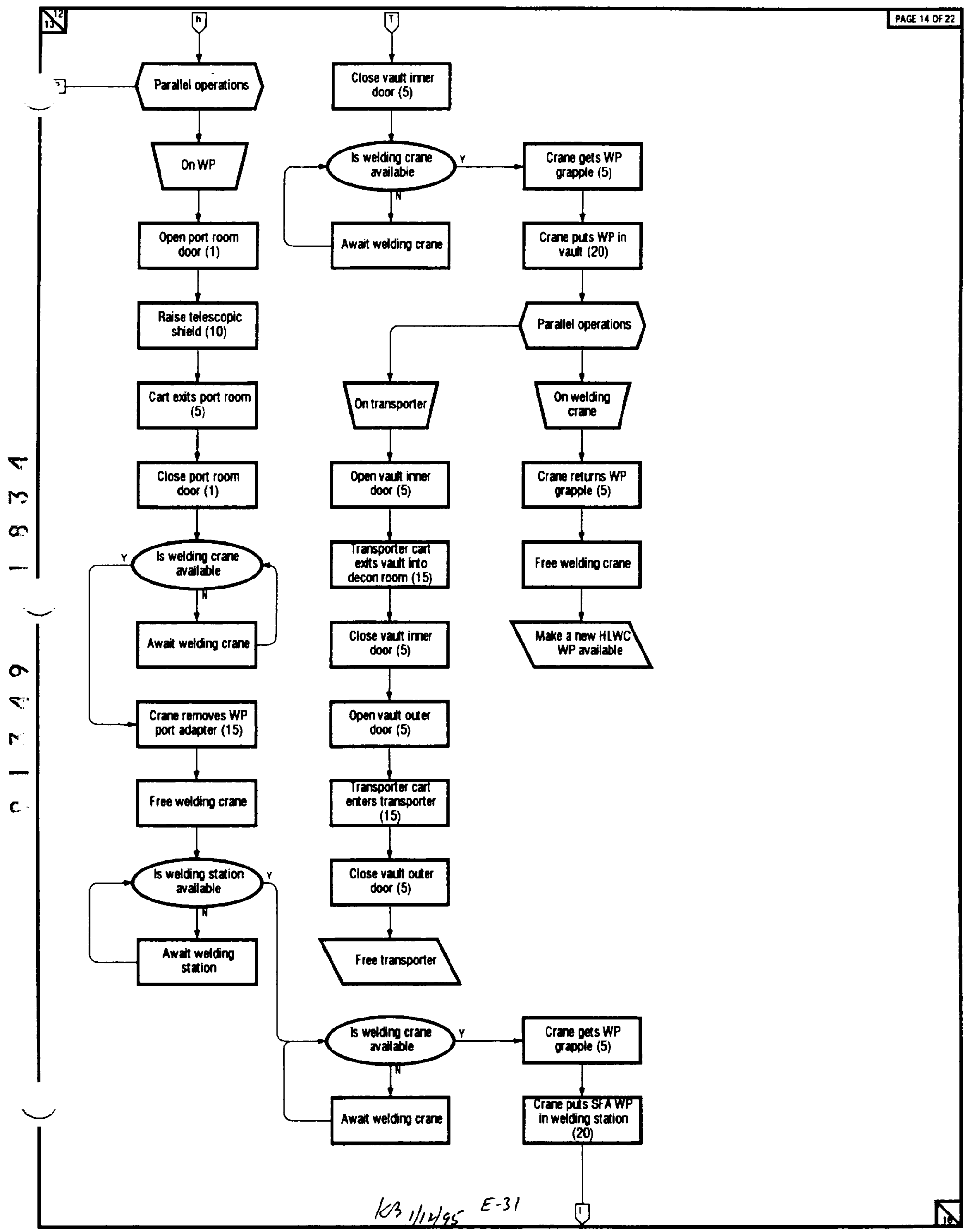




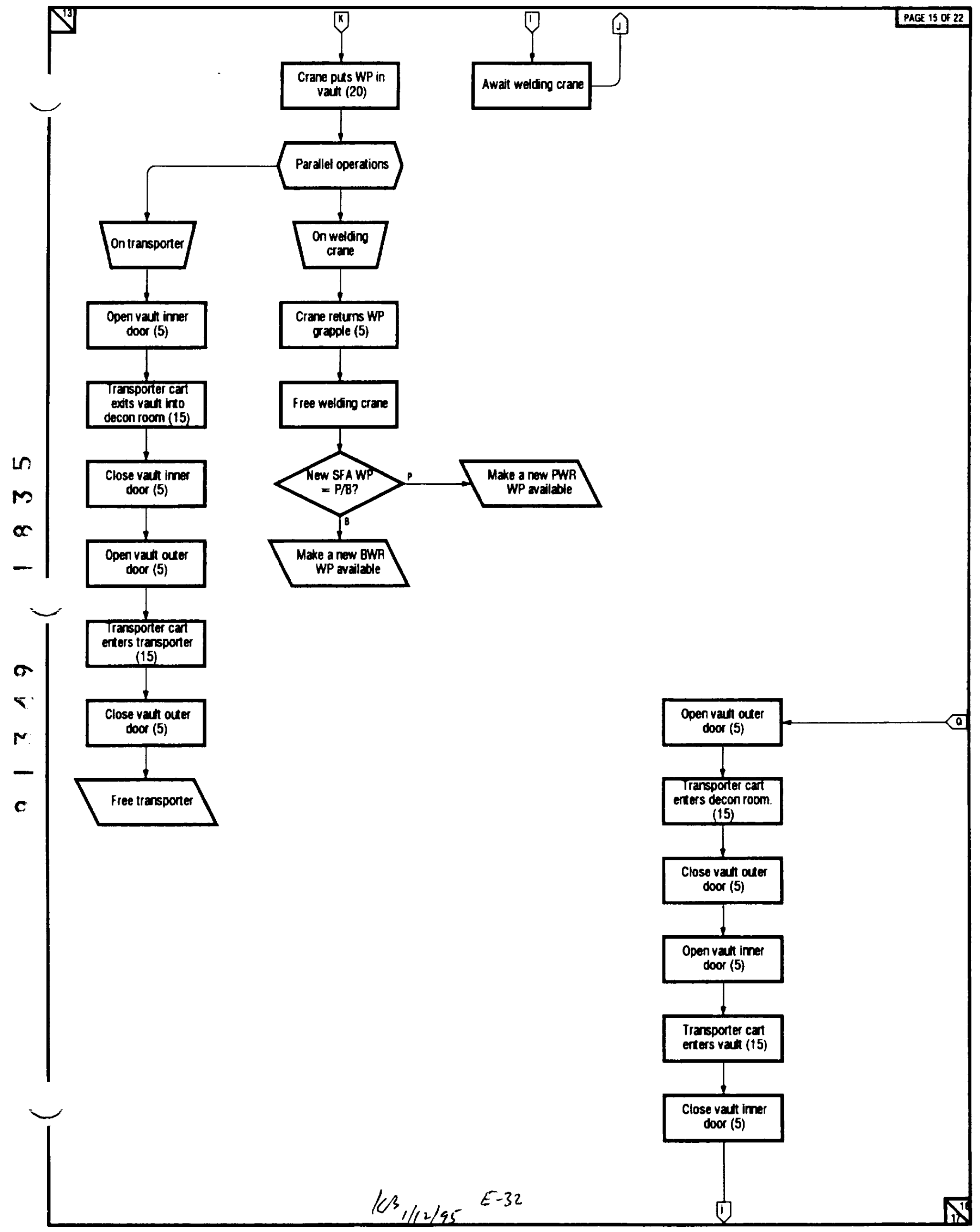




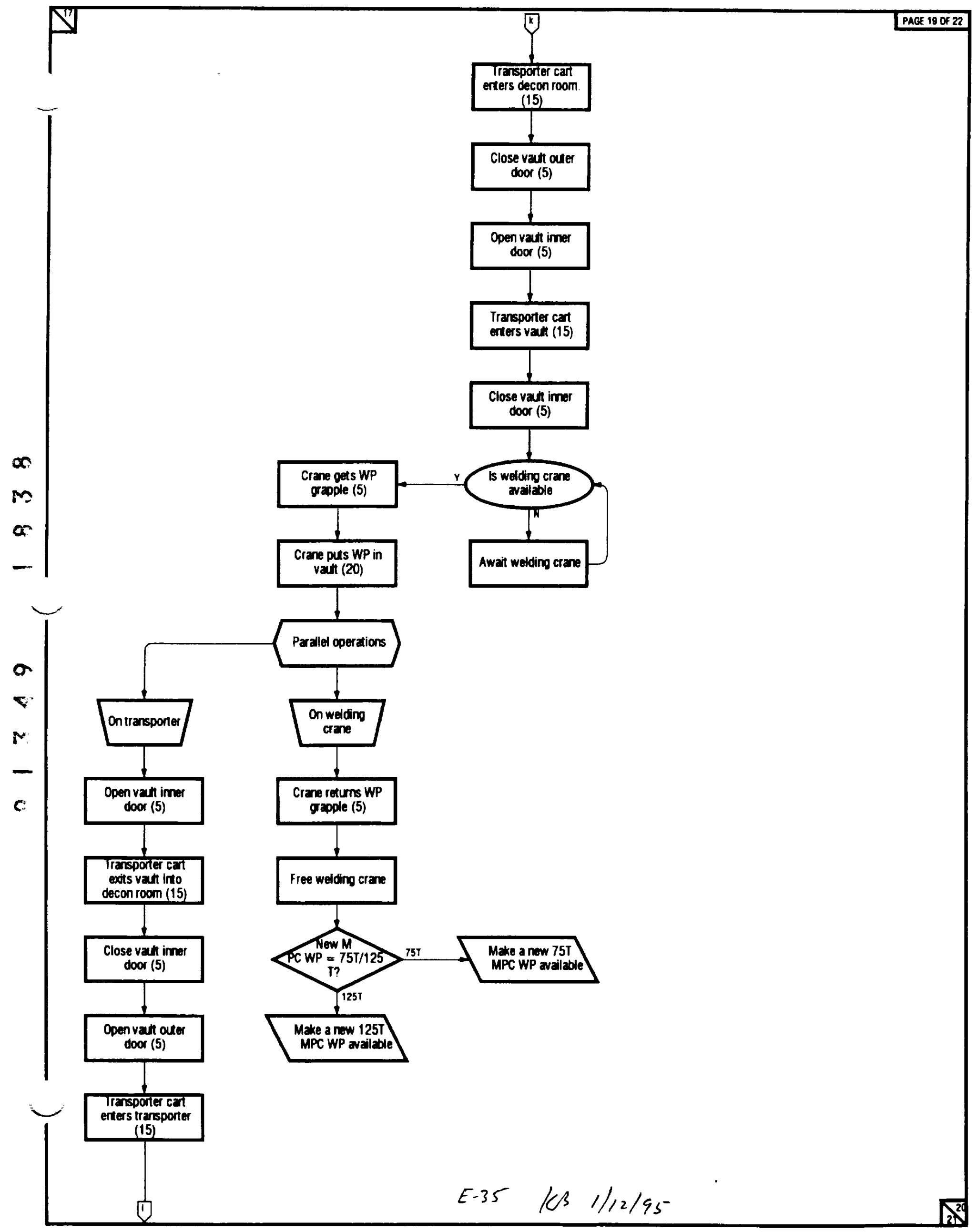




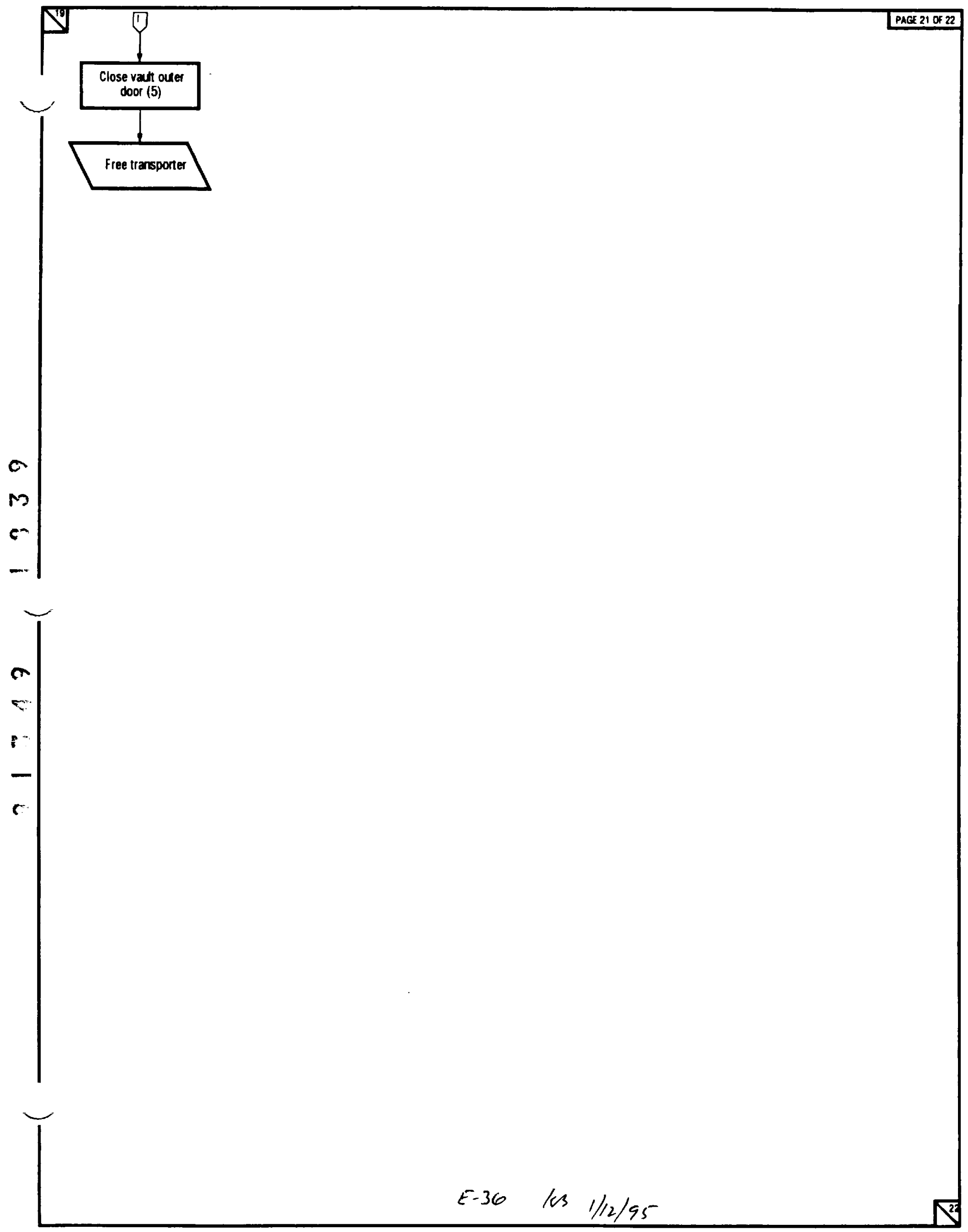




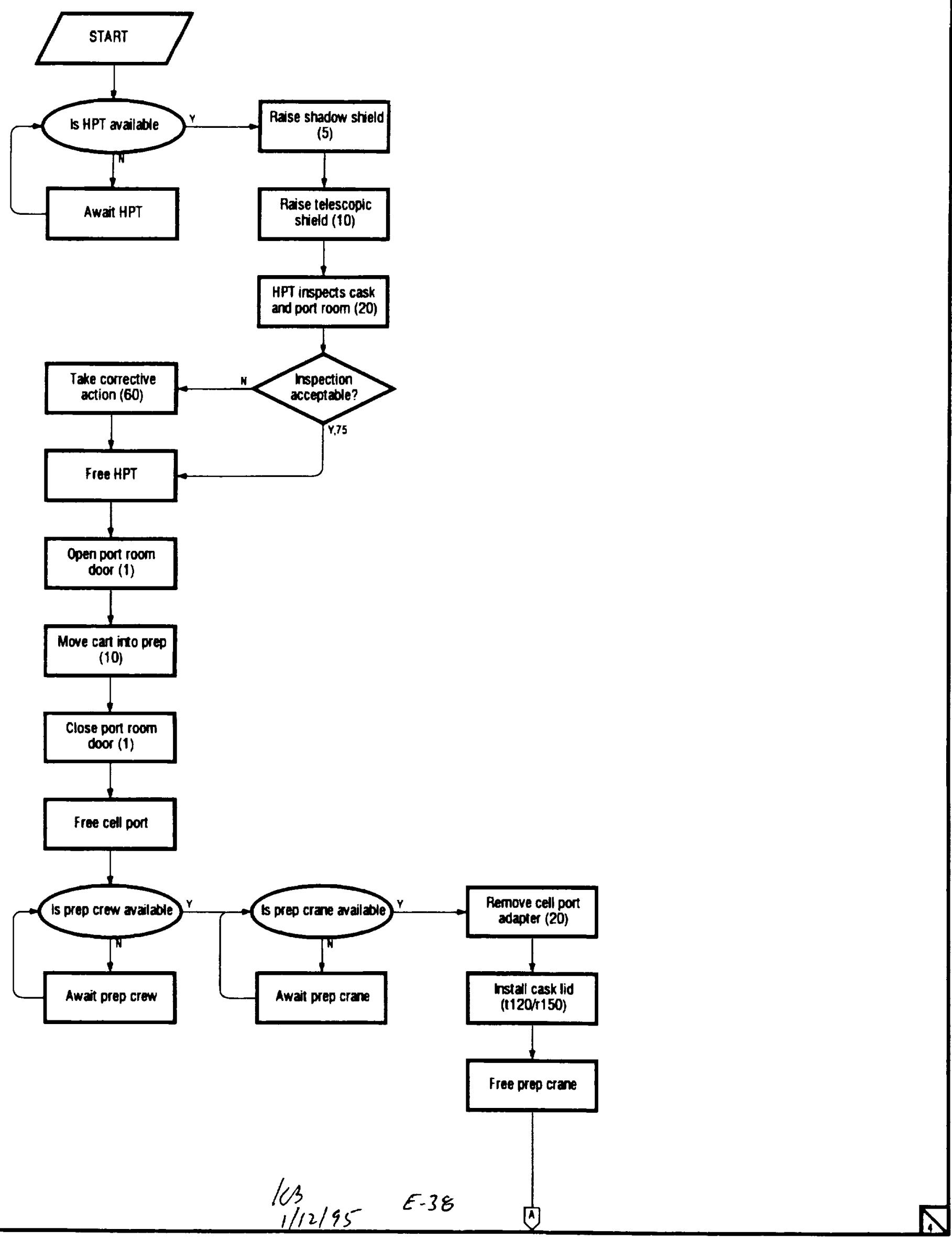




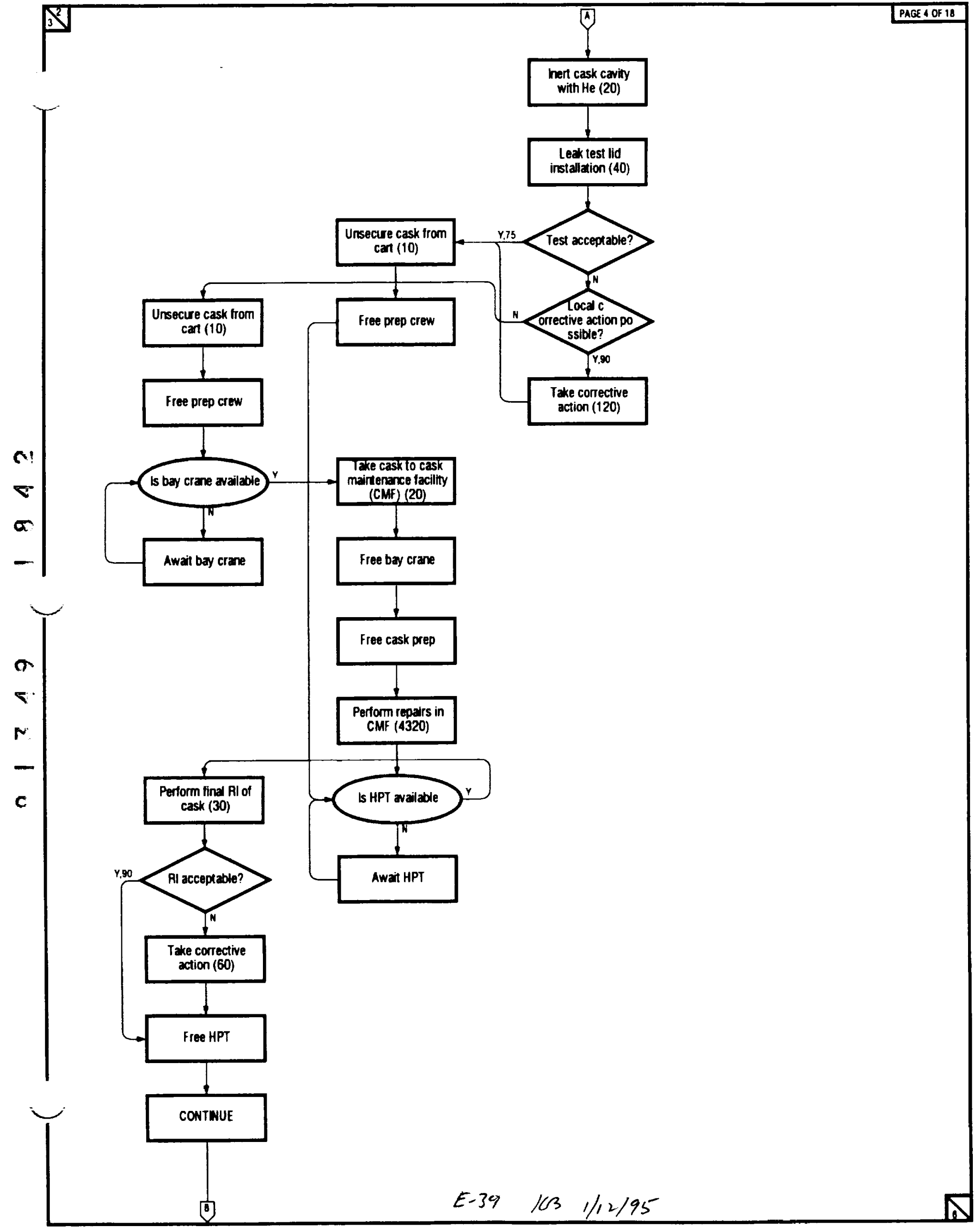




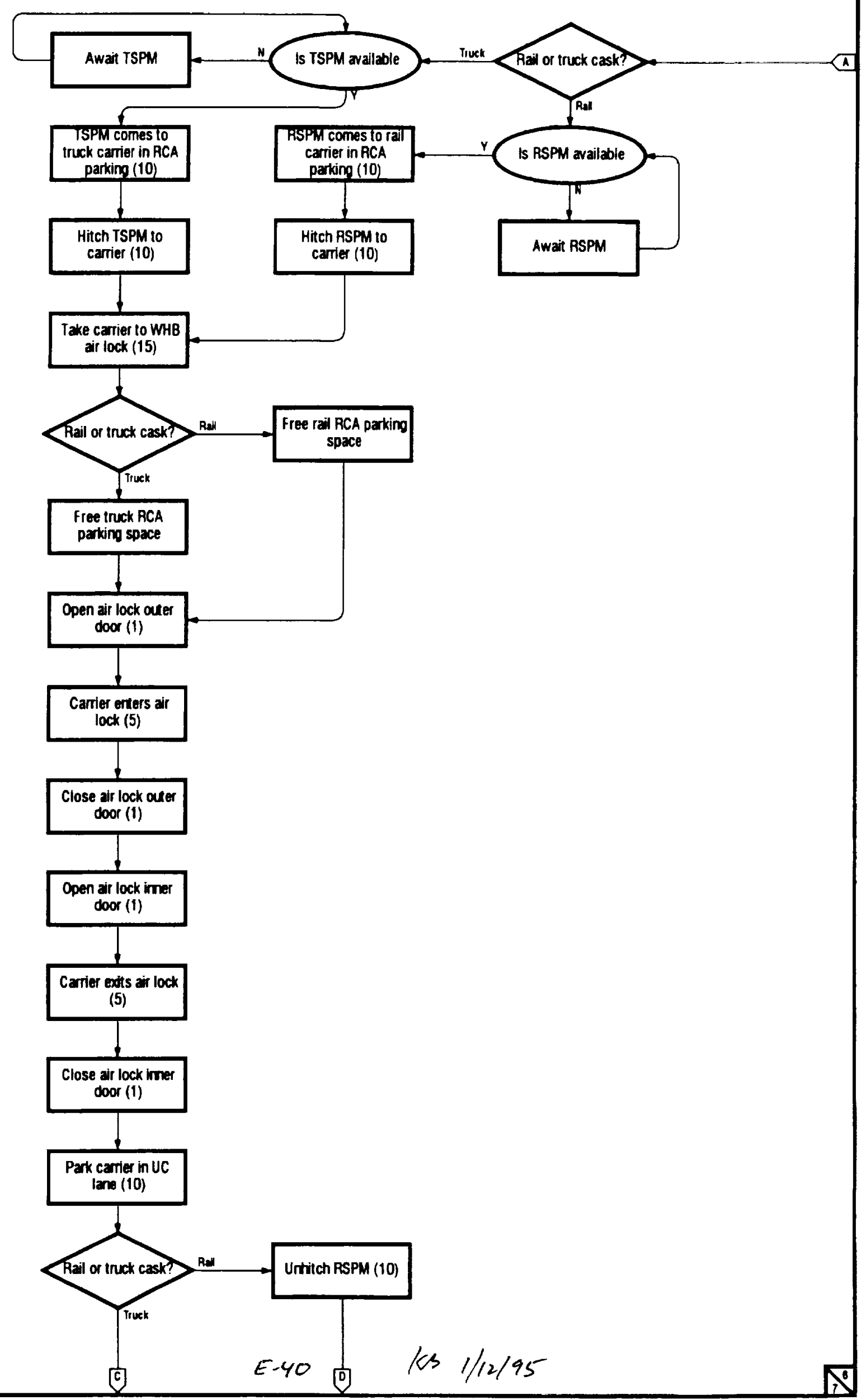




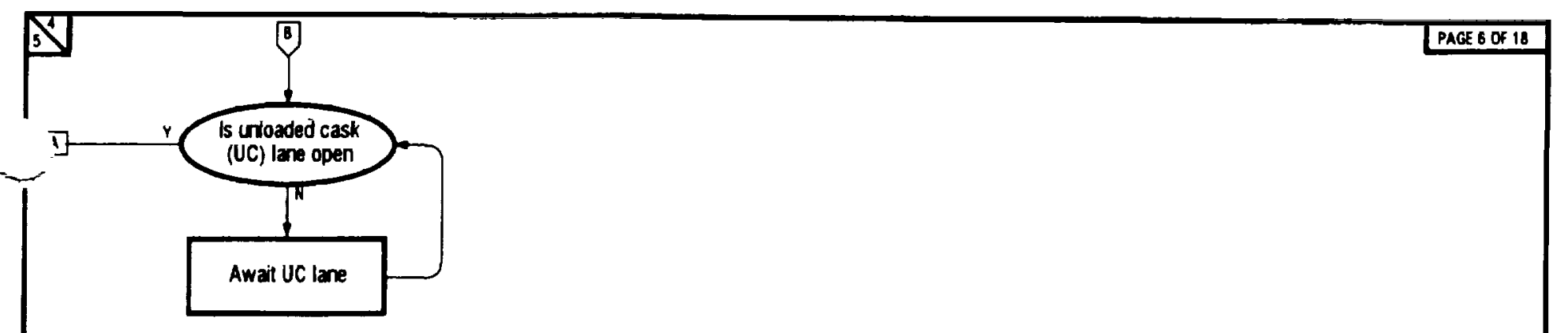

$F$
+
-

C 


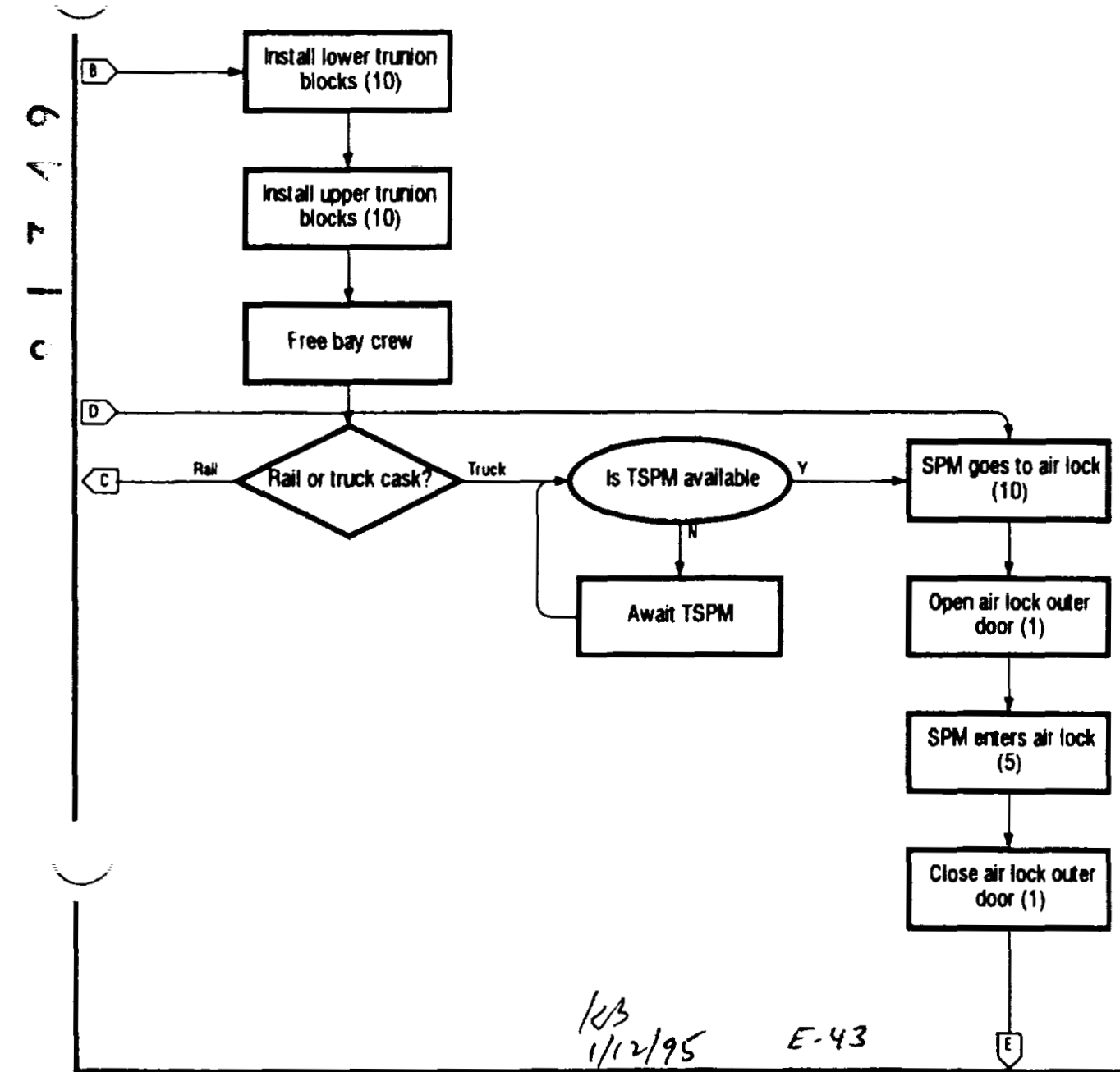




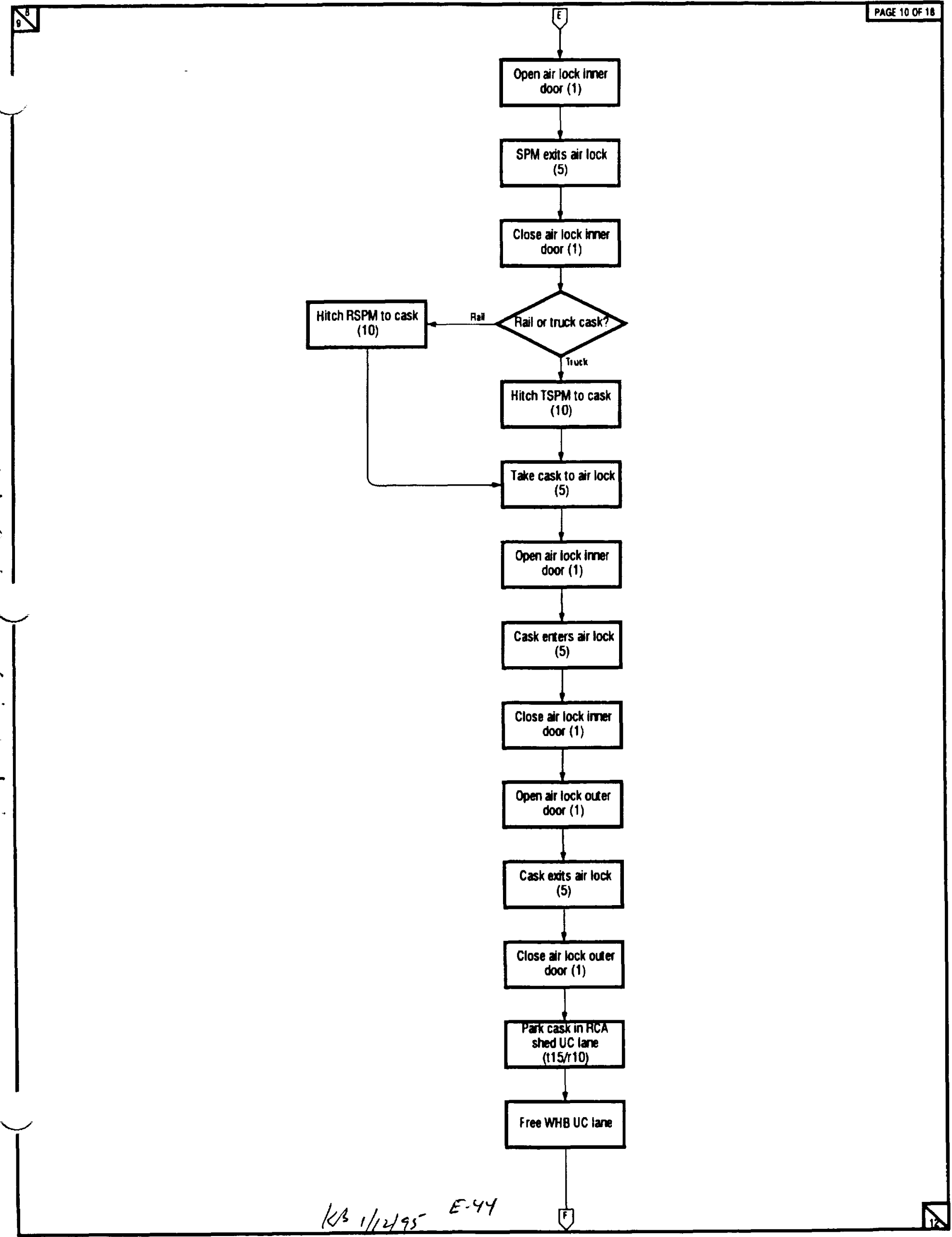




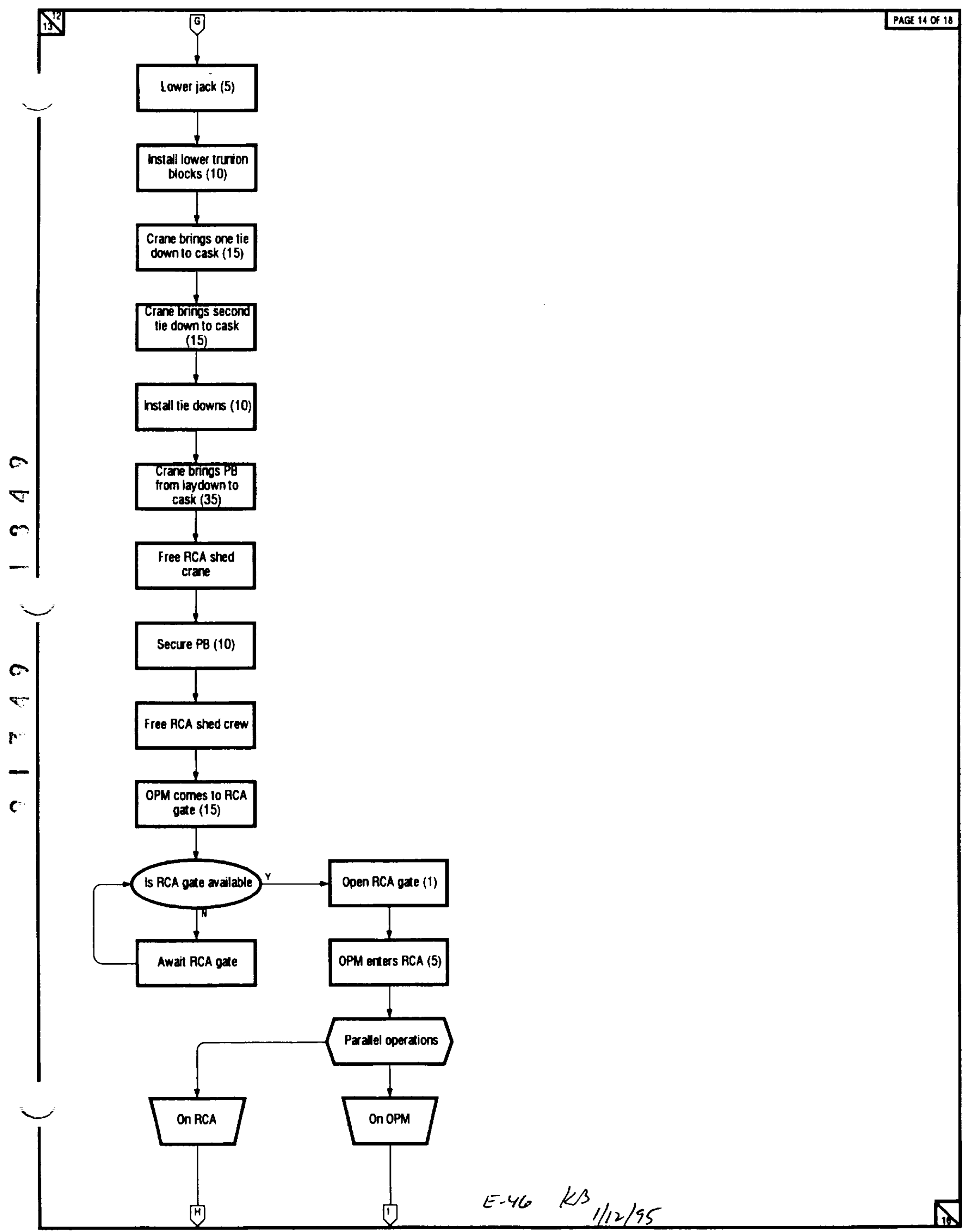




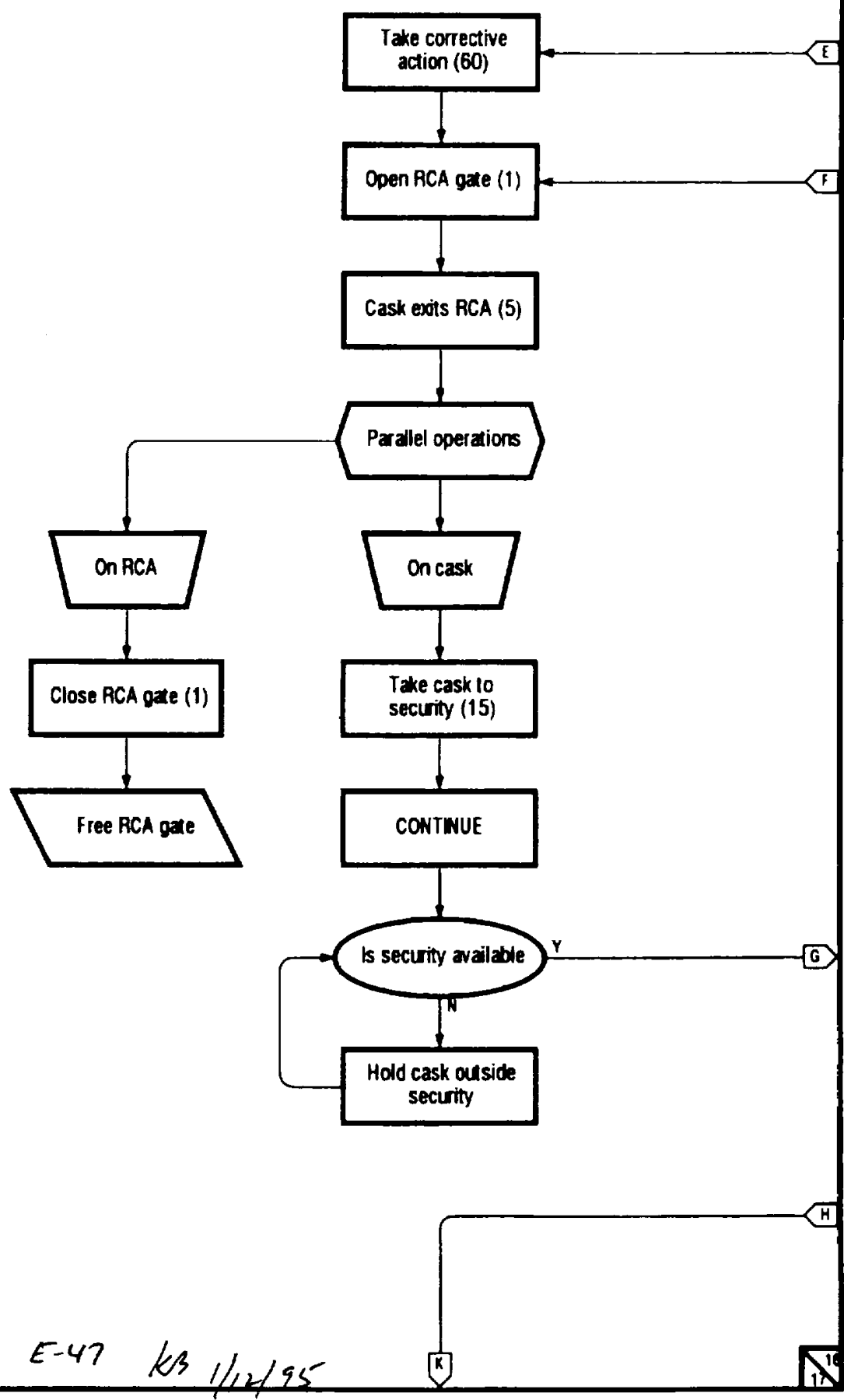




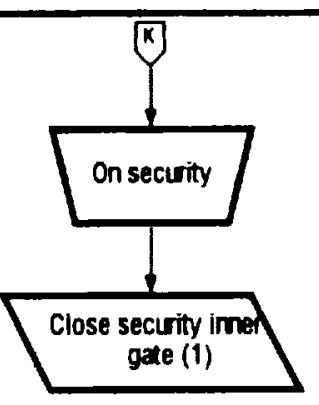

N

in

$\infty$

$-1$

$a$
$r$
+ 
